\title{
Formulating A Conceptual Framework To Understand Native American Perceptions of Place and Identity: A Temporal Examination Of The Spatio-Social Effects Of Uneven Development Through Accumulation By Dispossession
}

Denyse Wyskup

West Virginia University

Follow this and additional works at: https://researchrepository.wvu.edu/etd

\section{Recommended Citation}

Wyskup, Denyse, "Formulating A Conceptual Framework To Understand Native American Perceptions of Place and Identity: A Temporal Examination Of The Spatio-Social Effects Of Uneven Development Through Accumulation By Dispossession" (2011). Graduate Theses, Dissertations, and Problem Reports. 4817. https://researchrepository.wvu.edu/etd/4817

This Dissertation is protected by copyright and/or related rights. It has been brought to you by the The Research Repository @ WVU with permission from the rights-holder(s). You are free to use this Dissertation in any way that is permitted by the copyright and related rights legislation that applies to your use. For other uses you must obtain permission from the rights-holder(s) directly, unless additional rights are indicated by a Creative Commons license in the record and/ or on the work itself. This Dissertation has been accepted for inclusion in WVU Graduate Theses, Dissertations, and Problem Reports collection by an authorized administrator of The Research Repository @ WVU. For more information, please contact researchrepository@mail.wvu.edu. 
Formulating A Conceptual Framework To Understand Native American Perceptions of Place and Identity: A Temporal Examination Of The Spatio-Social Effects Of Uneven Development Through Accumulation By Dispossession

\author{
Denyse Wyskup
}

Dissertation submitted to the Eberly College of Arts and Sciences at West Virginia University in partial fulfillment of the requirements for the degree of

\author{
Doctor of Philosophy \\ in \\ Geography
}

Robert Hanham, Ph.D., Chair

Tyler Boulware, Ph.D.

Trevor Harris, Ph.D.

Richard Hoch, Ph.D.

Bradley Wilson, Ph.D.

Department of Geology and Geography

\author{
Morgantown, West Virginia \\ 2011
}

Keywords: Dialectics, Dispossession, Uneven Development

(C) 2011 Denyse Wyskup 


\title{
ABSTRACT \\ Formulating A Conceptual Framework To Understand Native American Perceptions of Place and Identity: A Temporal Examination Of The Spatio-Social Effects Of Uneven Development Through Accumulation By Dispossession
}

\author{
Denyse Wyskup
}

This research dialectically conceptualizes how capitalist uneven development and subsequent occurrences has shaped, and continues to shape, Native American perceptions of place and identity. Specifically, this research focuses on accumulation by dispossession, a key component of uneven development, and the spatio-historic effects this form of dispossession has had on Native American lifeworlds. This research focuses primarily upon federal legislation in the form of treaties, acts, and court rulings as the predominant component sustaining accumulation by dispossession and, in turn, perpetuating uneven development within Native American communities. In order to more holistically conceptualize the impacts of accumulation by dispossession three Native American societies are included within this research: the Oglala-Lakota, the Eastern Tewa Pueblos, and the Tlingit of Southeastern Alaska. 


\section{Acknowledgements}

Thank you to those who alongside me sacrificed much in order to see this research and personal goal come to fruition. You know who you are! 
Table of Contents

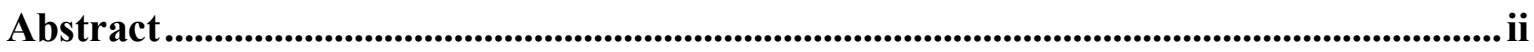

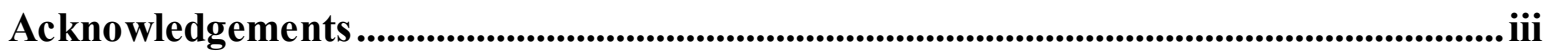

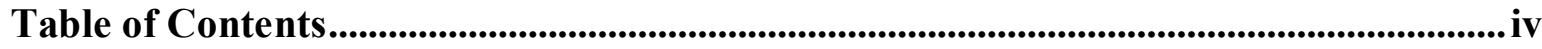

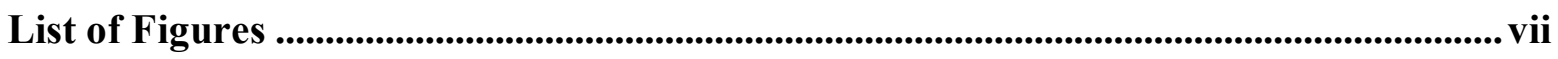

Chapter 1: Introduction ............................................................................................................... 1

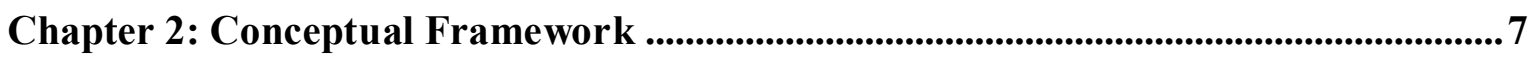

Introduction .............................................................................................. 7

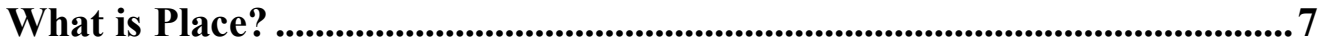

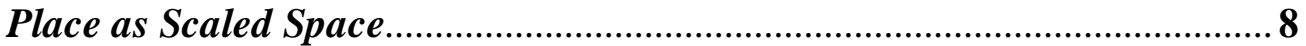

Place as a Humanist Construct ............................................................................. 10

Place as Spaces of Flows and Networks of Spatial Practice ........................... 12

Capitalism and Uneven Development ......................................................................... 14

Conditionality One ..........................................................................................14

Conditionality Two ............................................................................................15

Conditionality Three........................................................................................17 17

Conditionality Four ..................................................................................... 18

Chapter 3: Method: Conceptualizing Space and Place ..........................................................20

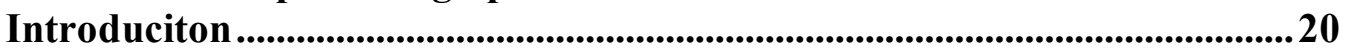

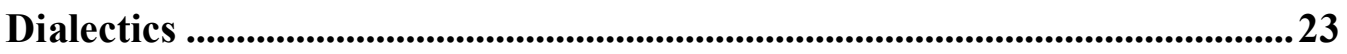

Origins and Underpinnings.....................................................................................25

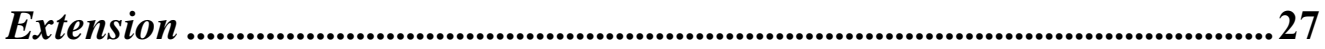

Level of Generality ...............................................................................................28

Vantage Point .................................................................................................................................. 31

The Dance .................................................................................................................. 32

Chapter 4: Conceptualizing Space and Place Utilizing Harvey's Matrix of Spatialties

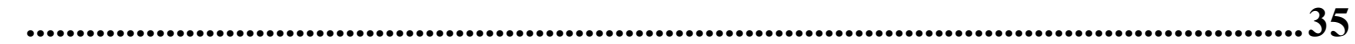

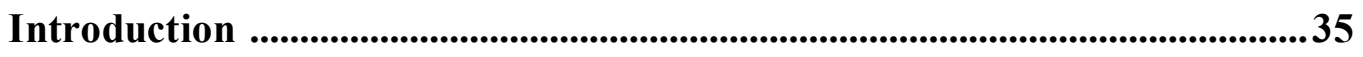

Matrix of Spatialities ............................................................................................................ 35

Testing Robustness: Harvey's Matrix of Spatialities ...........................................39

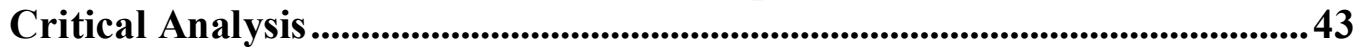

Expanding the Matrix: Spatial Practice and Perceived Space.........................48

Conclusion.....................................................................................................50

Chapter 5: Cosmology as Ideology ...........................................................................................................5 53

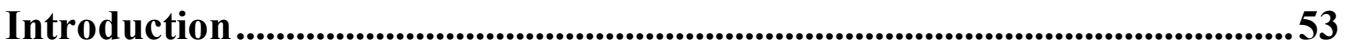

Cosmology as Cultivated History .........................................................................55

Cosmologies and Undertaking Textual Analysis ..................................................62 
Cosmologies of the Oglala-Lakota

Critical Evaluation of Source Material (Accuracy, Authorship, and

Positionality) 66

Triangulating Space, Place, and Identity

Cosmologies of the Eastern Tewa Pueblos.

Critical Evaluation of Source Material (Accuracy, Authorship, and

Positionality.... 72

Triangulating Space, Place, and Identity..... 73

Cosmologies of the Tlingit 78

Critical Evaluation of Source Material (Accuracy, Authorship, and

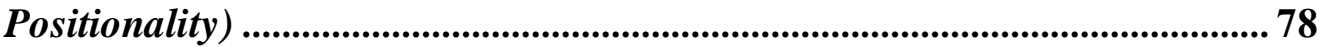

Triangulating Space, Place, and Identity ....................................................80

Conclusion...................................................................................................85

Dialectically Connecting Cosmology, Place, Identity, and Dispossession..... 85

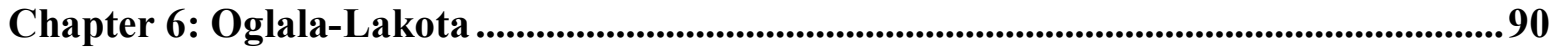

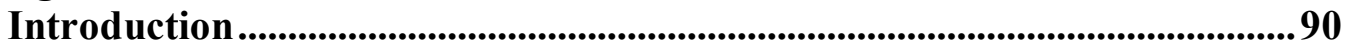

Traditional Social Organization: The Seven Fireplaces................................95

Geographic Placement and Spatial Organization ............................................99 97

Cosmologic Influence Upon Social Organization................................................. 99

The Oglala Band ..................................................................................................105

The Oyate: Socio-Political and Economic Organization and Function .......107

Conclusion......................................................................................................112

Chapter 7: Eastern Tewa Pueblos ......................................................................................................... 114

Introduction......................................................................................................................... 114

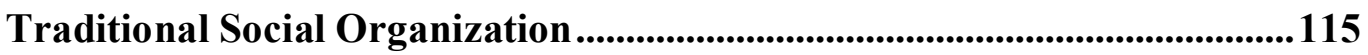

Geographic Placement \& Spatial Organization ....................................................120

Traditional Social Organization \& Cosmologic Influence................................ 128

Reformation: Spanish Colonial Influence .............................................................. 143

Spanish Conquest \& Colonization (1598-1680) .................................................. 144

Spanish Reconquest \& Colonization (1692-1820) ............................................... 148

Mexican Independence ................................................................................... 157

Conclusion............................................................................................................................... 158

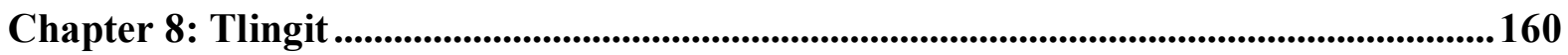

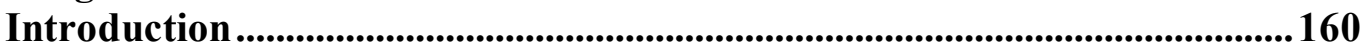

Geographic Placement \& Spatial Organization ......................................................164

'Traditional' Social Organization? .............................................................................167

Tlingit Socio-Political Organizations .........................................................170

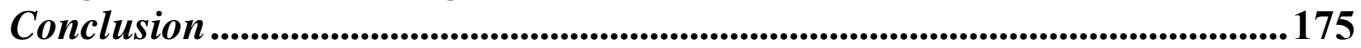

Russian Occupation and Involvement............................................................. 177

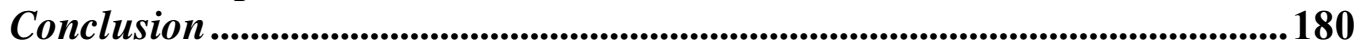

Chapter 9: Engaging Harvey's Conditionalities......................................................................... 182 
Introduction

Uneven Development and Accumulation by Dispossession: The Native American Experience.

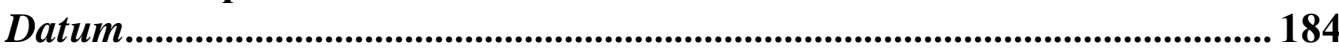

Linking Dispossession, Place, and Identity.................................................... 198

Oglala-Lakota 198

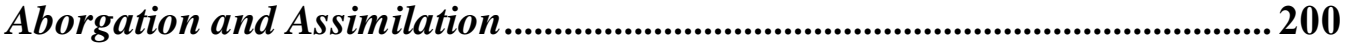

Eastern Tewa Pueblos .................................................................................. 211

Puebloans: Citizens or Wards in Trust..............................................................2213

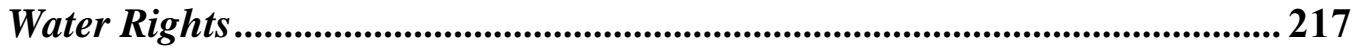

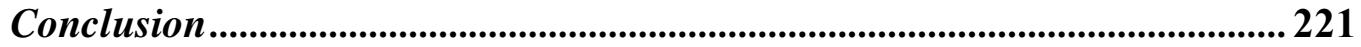

Tlingit: Alaska Native Claims Settlement Act (ANCSA) ................................223

Conclusion ............................................................................................................. 234

Conclusion: Conditionality Four \& The Cycle of Resistance and Enforcement .................................................................................................................................... 238

Chapter 10: Assessment, Reflection, \& Look Ahead .........................................................247

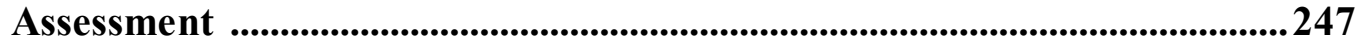

Reflection ........................................................................................................................................252

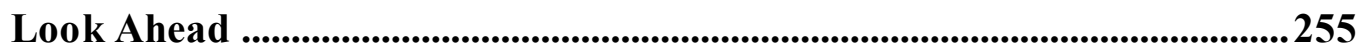

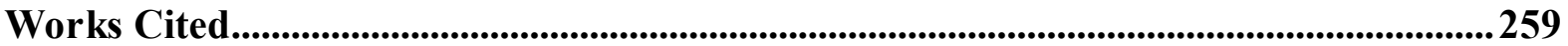

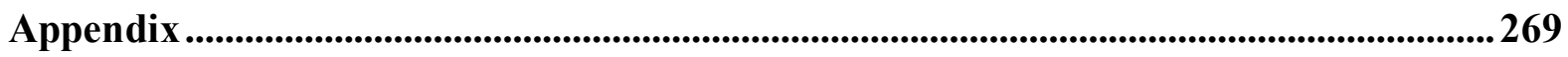




\section{List of Figures}

Figure 1: Bogg's Knowledge Use as a Bipolar Exchange

Figure 2: Ollman's Dance of the Dialectic, a source for understanding and interpolating the steps in Marx's method .33

Figure 3. Harvey's General Matrix of Spatialities .38

Figure 4. Modified Version I of Harvey's (2006) General Matrix of Spatialities............41

Figure 5. Modified Version II of Harvey's (2006) General Matrix of Spatialities .........47

Figure 6. Wind Cave National Park .......................................................................................................58

Figure 7. Detailed Map of Wind Cave National Park ....................................................59

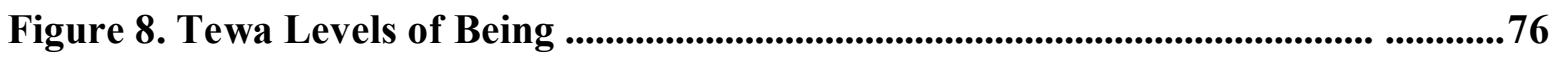

Figure 9. The traditional socio-political units of the Sioux as distinguished according to generality

Figure 10. Council of the Seven Fireplaces organized according to linguistic dialect within the Siouan language

Figure 11. The seven tribes (oyates) of the Teton who share the Lakota dialect

Figure 12. The seven original (tiyošpayes) bands of the Oglala-Lakota.

Figure 13. Eighteenth century Siouan (Lakota, Nakota, and Dakota) spatial extent within associated river basins in the contemporary boundaries of North Dakota, South Dakota, Montana, Wyoming, Colorado, and Nebraska.

Figure 14. Greater societies comprising the Oglala-Lakota social structure

Figure 15. Contemporary Location and Spatial Extent of Pueblos and Reservations within New Mexico .116

Figure 16. Spatial Extent of Pueblos located in New Mexico according to variations in linguistic stock

Figure 17. The Pueblos and the Spanish.

Figure 18. Principal reference points in the Tewa world 
Figure 19. Spatial extent of the nineteen New Mexico pueblos, including the relationship and orientation of the six Tewa pueblos to their four sacred peaks

Figure 20. Sacred and profane levels of being within the Tewa world .126

Figure 21. The flow of blessings as communicated through the Tewa cosmological hierarchy and spatial arrangement

Figure 22. The Tewa subsistence cycle.

Figure 23. The Tewa ritual calendar

Figure 24. Societies comprising the Made People in the Tewa world.

Figure 25. The annual cycle of works of the Made People

Figure 26. Societies comprising the Dry Food People Who Never Did Become in the Tewa world.

Figure 27. Hierarchical arrangement of the Spanish colonial caste system during the second era of reconquest and colonization.

Figure 28. Hierarchical illustration of the structural relations of the three groups that comprise the Tewa political system as influenced by Spanish occupation

Figure 29. Hierarchical illustration of the structural relations of the three groups that comprise the Tewa political system traditionally and as influenced by Spanish occupation

Figure 30. Map depicting Traditional Tlingit Territory.

Figure 31. Map depicting Tlingit Tribes, Clans, and Clan Houses

Figure 32. Illustration of the traditional socio-political units of the Tlingit (17501812) as classified according to generality

Figure 33. Traditional Tribal Areas of Alaska as Delineated by Corporation Boundaries

Figure 34. Socio-political and economic timeline illustrating Harvey's (2006: 75) four condiationalities. $.186-188$ 
Figure 35. Map of the Great Sioux Reservation and Surrounding Areas (18681869)

Figure 36. Restructuring of the Tlingit socio-political units 1971-Present

Figure 37. Sealaska Native Corporation boundary with inset map of all ANCSA Native Corporation Boundaries.

Figure 38. Reconfigured depiction of Harvey's general matrix of spatialites to accommodate non-Western conceptualizations and interrelations of the spatio-temporal and social as informed by the philosophy of internal relations. Modeled after Minkowski's relational quantum gravity diagram for a spherical universe 


\section{Chapter 1: Introduction}

\section{Introduction}

The goal of this research is to dialectically conceptualize how capitalist uneven development has shaped, and continues to shape, Native American perceptions of place and identity. Specifically, this research focuses on accumulation by dispossession, a key component of uneven development, and the spatio-historic effects this form of dispossession has had on Native American lifeworlds. This research focuses primarily upon federal legislation in the form of treaties and acts as the predominant component sustaining accumulation by dispossession and, in turn, perpetuating uneven development within Native American communities.

Clarification is needed at this juncture to define how the terms place, identity, lifeworld and lifeway are used in this research. Within geography the terms place and identity elicit both subjective and objective conceptualizations of human understandings

of their surrounding environment. A major objective within this research is to clarify the connection between Native American perceptions of place and identity, in relation or comparison to Western ideology. This passage from Momaday aids in clarifying the issue:

From the time the Indian first set foot upon this continent, he centered his life in the natural world. He is deeply invested in the earth, committed to it both in his consciousness and in his instinct. The sense of place is paramount. Only in reference to the earth can he persist in his identity. (Momaday, In Basso, 1996; pg. 34).

As stated by Momaday, 'The sense of place is paramount. Only in reference to the earth can he (Native Americans) persist in his identity.' While place and identity is often characterized as two similar, but mutually exclusive concepts within Western 
culture, there is little difference between these two concepts within Native American cultures. These two concepts are so closely interrelated that to be without one would negate the existence of the other. Typically, within Native American literature the concept of lifeworld is used to signify the intimate relationship that exists between place and identity. The concept of lifeway is used to address the processes that function in the development of one's lifeworld.

Within this research the terms place and identity are utilized when in reference or discussion of geographical theory. However, the terms lifeworld and lifeway are included in those sections of the dissertation specifically discussing and pertaining to the impact of uneven development and accumulation by dispossession on Native American perceptions of place and identity. The inclusion of the native concepts lifeworld and lifeway are integral components of this research because they aid in filling knowledge gaps where the native voice has often been omitted.

Dialectics, with its foundation in the philosophy of internal relations, is specifically utilized within this research to aid in filling these gaps in knowledge due to its robust and holistic approach toward seeking social interconnections from multiple vantage points. For example, an integral component within this research involves linking Native American cosmologies to perceptions of place and identity. Cosmologies ${ }^{1}$ are explored as a component to both incorporate the Native American 'missing voice' and also to aid in discerning the differences that exist between Western and Native American perceptions of place and identity and why dispossession has so detrimentally effected the

\footnotetext{
${ }^{1}$ Cosmology is the oral communication of cultural ideologies that serve to conceptually organize and classify the social and physical world typically conveyed through emergence stories and other oral narratives (Ortiz, 1969).
} 
preservation and continuance of indigenous cultures. Influenced by the research of Andrew Guillford (2000), Native American cosmologies are used to examine those connections linking the conceptual, place and identity, to the material, sacred landscapes, as communicated within Native American oral culture.

This dissertation is organized into nine additional chapters. Chapter two outlines the conceptual framework through which this research is directed. The chapter is divided into two primary sections. The first section discusses the theoretical underpinnings of the concept of place in geography. Place can be conceptualized in terms of either: (i) scaled space, (ii) social practices that generate spaces of flows and networks, or (iii) humanism that develops and evolves based upon human experiences, phenomenology. The second section of this chapter discusses Harvey's (2006) unified field theory of geographical uneven development. The four conditionalities of the theory are the following (Harvey, 2006; 75):

1) The material embedding of capital accumulation processes in the web of socio-ecological life.

2) Accumulation by dispossession

3) The law-like character of capital accumulation in space and time.

4) Political, social, and "class" struggles at a variety of geographical scales.

Chapter three presents a discussion of dialectics, the method used in this research. The chapter contains three sections. Section one discusses the bipolar method and model of social knowledge exchange and production which has typically been used in both the historic and contemporary political and judicial decision making process, as described by James Boggs (1992). This section also discusses why a more holistic and dialectic method is required when addressing multiple spatio-historic, socio-economic and socio- 
political discourses/contexts with multi-temporal and scalar connections. Section two of this chapter discusses the conceptual origins and underpinnings of the use of dialectics in geography. Section three demonstrates how the dialectical method can be used and developed within this dissertation research to include 'the missing voice' typically excluded from Western researchers who study indigenous cultures with alternative traditions such as, oral communication. This final section attempts to illustrate how dialectics can initiate the discourse needed for academics and researchers to more holistically acknowledge and include 'the missing voice' by examining forms of Native American material culture that are socio-historically pertinent to understanding the impact capitalism and uneven development has had on indigenous lifeworlds and lifeways.

Chapter four critically analyzes Harvey's Matrix of Spatialities. This chapter is composed of four major sections that examine the robustness of the matrix and determine if, conceptually, Native American perspectives of space-place are explainable within its ideological framework. Specifically, the final two sections critically analyze the matrix's ability to holistically accommodate Native American cosmological concepts of placespace, especially as these concepts relate to identity formation.

Chapter five explores the foundational spatio-temporal elements within each of the case study's cosmologies as they relate to the development of each of the societies perception of place and identity. This chapter is composed of three major sections. Section one details the theoretical underpinnings linking Native American cosmologies to place and identity construction, development, and evolution. Utilizing textual analysis, section two critically examines emergence cosmologies of the Oglala-Lakota, Eastern 
Tewa Pueblos, and Tlingit. Using the information obtained in section two, section three attempts to dialectically link cosmology to Native American perceptions of place and identity.

Chapters six through eight address the case study indigenous cultures influencing this research: the Oglala-Lakota, Eastern Tewa Pueblos, and the Tlingit of Southeast Alaska. Primarily informed through historic ethnographic research these chapters are similarly structured in order to explore four prominent variables: traditional social organization; geographic placement and spatial organization; cosmologic influence on social organization; and the socio-political and economic factors influencing social organization. Slight deviances exist within each chapter's structure to account for unique spatio-historic events resulting in modifications to these societies traditional patterns of social organization.

Chapter nine engages Harvey's conditionalities, especially conditionality three, as related to the law-like character of uneven development through accumulation by dispossession. This chapter is divided into two major sections. The first section discusses the Native American experiences in relation to uneven development and accumulation by dispossession, particularly through federal acts, treaties, and judicial case law. The second section addresses specific legislation and the impacts of rulings upon the three case study indigenous cultures. The last section explores conditionality four and the cycle of resistance and enforcement perpetuated throughout these Native American societies.

Lastly, chapter ten, the last step in the dance of the dialectic holistically examines the preconditions of the present as they may be projected toward the future. This chapter 
provides an overall assessment of how the objectives of the dissertation are met, critiques weaknesses of the study encountered during the research process, and discusses future research possibilities stemming from this analysis. 


\section{Chapter 2: Conceptual Framework}

\section{Introduction}

The objective of this chapter is to outline the prominent theoretical underpinnings of the concepts of place, uneven development and accumulation by dispossession in the discipline of geography. These theoretical constructs form the basis of the conceptual framework used to construct my argument that uneven development, through accumulation by dispossession, has significantly contributed to modifying Native American lifeworlds.

This chapter will first discuss the three dominant theoretical constructs of place that dominate the discipline of geography. This is followed by a discussion of the four conditionalities of Harvey’s unified field theory of uneven geographical development. Particular attention is devoted toward two of the four conditionalities, accumulation by dispossession and the law-like character of capital accumulation in space and time, and their spatio-historic impact on the socio-economic and socio-political development of Native American lifeworlds.

\section{What is Place?}

The concept of place in the discipline of geography elicits highly diverse and complex debates. Agnew (1987) identifies three major elements of place that mediate between the objective and subjective: 1) place as locale, the setting in which social relations are constituted; 2) place as location, the geographical area encompassing the setting for social interaction as defined by social and economic processes operating at a wider scale; 3) and sense of place, the local structure of feeling. 
Similar to Agnew (1987), Rose (1995:105) argues that a sense of place can be divided into three broad types:

1) those that argue a sense of place is natural, 2) those that argue that it is a consequence of underlying structures of power, and 3) those who see it as a way of defining the 'Other'.

These fundamental characteristics discussed by Agnew (1987), Rose (1995), and numerous other geographers are the basis for understanding the 'geographic' understanding of place in the last century. The emphases upon these varying elements constitute the 'place' debate that emerged since the early/popular 'deterministic' era.

This section focuses on three dominant conceptualizations of place prevalent in the discipline of geography, which also extend to some extent into the fields of anthropology and archaeology. These conceptualizations are best described as: (i) place being a construct of scaled space, (ii) place being a construct of social practices that generate spaces of flows and networks, and (iii) place being a humanist construct that develops and evolves based upon human experiences.

The primary objective for analyzing these perspectives is to understand and describe the diversity that exists between Western views and perceptions of place in comparison to indigenous cultures, specifically Native American. Through examining these diverse perceptions of place a more comprehensive understanding can be achieved and, in turn, make apparent the need to develop a holistic understanding of place as understood from the Native American perspective.

\section{Place as Scaled Space}

Place is typically described as a portion of geographic space. This simplistic definition of place is inadequate and is dependent on the evolving theories and concepts 
specific to particular geographic traditions. What constitutes the formation of place is a common inquiry within geography that warrants rigourous debate.

The fundamental concept of place as a form of scaled space is an empirically driven concept that flourished in the determinist era of geography which sought to label and classify areas/regions based upon specific environmental and cultural traits. Driven by Eurocentristic ideologies, as described by Blaut (1999), such as “The Age of Exploration," "Westward Expansion”, and "Manifest Destiny”, regions of the world were departmentalized/compartmentalized according to unique environmental conditions. Spurring these Western trends in exploration and classification was the ideology of global hegemonic power through territorial expansion, typically occurring through the dominant global power's (Britain, United States, Australia, etc.) ability to displace or dispossess local indigenous populations through early forms of accumulation by dispossession.

Explained by Entrikin (1991:11):

proponents of this construct wish to connect regional studies and social theory and maintain that general processes vary as a result of local circumstances. Thereby establishing the individuality of place into the difference between types of places as observable through social relations and interactions.

Merrifield (1993: 516) argues that the fundamental flaw in this theoretical construct is the failure of most researchers to establish the basic ontological nature of place itself or the manner in which they construct their specific 'object' of inquiry. Rather, Merrifield (1993: 517) advocates a reconciliation of the way in which experience is lived and acted out in place, and how this relates to, and is embedded in, political and economic practices that are operative over broader spatial scales. Merrifield (1993: 519) advocates and acknowledges the inclusion of the subjective and objective within the work of Entrikin 
and other of political and economic geographers but feels their ontological approach fails to comprehend how the locus of place is a unity containing within itself different aspects. In brief, Merrifield (1993: 519) advocates utilizing a dialectical approach that opposes the reification of fragmentation and the separation of different aspects of reality, as in the bringing together of polar opposites in a dualistic and linear manner.

Soja’s (1980 and 1999) socio-spatial dialectic functions as the impetus and medium through which the contemporary understanding and exploration of place as scaled space debate is directed. Utilizing the works of Lefebvre, especially The Production of Space, Soja reconciles the divisions between the horizontal (spatial) and vertical (social) as a dialectically interrelated process. Identifying this reconciliation as 'Third Space', this concept directs the modern debates, from researchers such as Harvey and Smith, concerned with the interconnections/relations between the social and spatial in terms of comprehending the political-economic processes of the capitalist mode of production contributing to the pervasive expansion of uneven development.

\section{Place as a Humanist Construct}

Humanist geography, in response to the positivism and empiricism projected by spatial science and regional geography, uses key concepts such as sense of place and placelessness to develop a cohesive understanding of place in a phenomenological manner that stresses individual attachment to particular places and the symbolic quality of place which link events, attitudes, and places to create a fused whole.

The concept of place in the humanist tradition is dominated by the work of Yi-Fu Tuan. Tuan (1977, 1984, and 2002) conceptualizes place as developed through experience. Through experience a sense of place is conceived and, in turn, evolves with 
the individual. Tuan (1977, 1984, and 2002) defines that the fundamental difference between space and place as perceived through senses they evoke. Specifically, place evokes a sense of security while space evokes a sense of freedom.

The literature conveyed by Tuan explores the dualisms between space and place as a product of the human condition that evolves as society/humankind develops. The uniqueness of the human condition, for Tuan, is what allows for the abstractness of space and place. Tuan (1977:12) expresses that:

....space can be variously experienced as the relative location of objects or places, as the distances and expanses that separate or link places, and-more abstractly- as the area defined by a network of places.

Tuan perceives the human condition as an evolving and abstract construct. This ideology reflects Tuan's perception of space as being the informal unperceived surrounding of life which can be transformed into place as it acquires definition and meaning. To summarize, space becomes place as it becomes for the individual an organized set of meanings.

Tuan acknowledges that senses of place are constructed through intimate sensory experiences that lead to the construction of differentiated or a hierarchical awareness of place. Coining the word 'topophilia' Tuan (1974) essentially describes the construction of place as the affective bond between people and place that will very in intensity according to individual, cultural and biological components. Tuan's perception of place construction has been employed by anthropologists, such as Keith Basso (1988 and 1996) and Andrew Guillford (2000), as a means of qualitatively understanding the spatiotemporal development of Native American perceptions of place and identity. 


\section{Place as Spaces of Flows and Networks of Spatial Practice}

Doreen Massey’s approach to exploring the diversity of place centers on discourses concerning globalization and it's affect on the nature of place. Massey explores the issues surrounding the evolving nature of place in a world that is materially changing at an accelerated pace in comparison to previous millennia where cultures/societies were more physically 'rooted' in place and spatial movement was limited.

Using the theory of time-space compression, as developed by Harvey, Massey examines how globalization has increased the porosity of borderlands and, in turn, affected the meaning of place. This theory is based on the foundation that in recent decades the spatial reach of social activities has increased tremendously due to technological advancements that decrease friction in spatial movement to create networks of spatial interactions. This 'process' based approach examines the networking of place as a product of time-space compression and convergence requires re-imaging of place to accommodate how places are changing materially.

In the last century, due to time-space compression, Massey argues that the distinctiveness of place must be re-thought to replace the previous notion of place as different, separable and bounded areas within space (Massey,1995:54). Massey’s major contribution to the theory of time-space compression was the inclusion of the concept of power-geometry as a means of understanding how the changing social organization of space has disrupted the existing forms and concepts of place.

Massey’s inclusion of power-geometry in Harvey’s concept of time-space compression was a critique of Harvey's limited discussion concerning social networks 
and his primary focus upon class relations/positions. Massey (1993: 60-63) defines the concept of power-geometry as:

The more or less systematic and usually highly uneven ways in which different individuals and groups are positioned within networks of time-space flows and connections. These variable positions derive from the intimate connections that exist between productions of power and productions of space: thus spatial modalities of power are differentially engaged such that different actors have different degrees of freedom.

Expanding on the concept of power-geometry within time-space compression, Massey further develops the idea to include a more open and situated account of the variable power-geometries of contemporary globalization that negates totalizing images and transparent spaces. Massey’s power-geometry is a complex concept that weaves within it a network of affiliations and solidarities that are central to the process of identity formation (Massey, 1998:221). Power-geometries characterize the space of maps of power and the constant making and re-making of spaces, places and identities through a complex network of social movement, power and relations, all grounded on the foundation of Lefebvre’s dialectical method.

These global networks as seen by Massey are hierarchical and assume that scales of interconnectedness occur depending on ones ability to gain access to the 'connected' network of social, political and economic structures. Differential access to these sources determines the subjective and material outcome of place construction and development. This view of place has also been gaining momentum in the sociological and anthropological literature (Anders, 1980; Guillford, 2000; Hosmer, 2003), where research is being directed toward a spatio-historical understanding of uneven development within indigenous populations as a result of accumulation by dispossession. 


\section{Capitalism and Uneven Development}

Harvey (2006) develops his unified field theory of uneven geographical development by constructing an argument around 'four radically distinct conditionalities that have different epistemological statuses' (2006: 75). For Harvey, the development of a unified field theory relies on combining these conditionalities to reveal the possibility of a general theory (2006: 75). The four conditionalities as laid out by Harvey (2006: 75) are:

1) The material embedding of capital accumulation processes in the web of socio-ecological life.

2) Accumulation by dispossession

3) The law-like character of capital accumulation in space and time.

4) Political, social, and “class” struggles at a variety of geographical scales.

It is important to point out that Harvey's approach is dialectically organized, in which the philosophy of internal relations plays a significant role in the construction of the unified field theory. With this premise in mind, it must be noted that these conditionalities are not mutually exclusive. Rather, discussion of any one conditionality often contains elements of one or more of the others.

\section{Conditionality One}

Conditionality one is predicated upon the argument that the capitalist mode of production relies on the reality that commodities must be continually produced for the purpose of generating, as designated through their use, exchange, and labor value. It is through this commodification of goods that Harvey suggests that the process of uneven development begins. The underlying basis for this argument is that capitalism has become so ingrained in humanity's daily existence that the continuous commodification of goods is necessary to sustain human life. 
Typically, this processes was strictly perceived as embedded in Western life styles, but the need for capital to find spatial 'fixes' has led to the introduction of capitalism and expanded commodification into non-western societies and cultures. In turn, this continual embeddedness of commodities into everyday life has resulted in the expanded globalization of capitalist commodities and markets, which has therefore resulted in increased uneven development as attempts to 'modernizing' non-western societies persist.

\section{Conditionality Two}

Conditionality two argues that capital accumulation is integral to preserving the capitalist mode of production and it is through this process that capitalism generates societal detachment. For instance, as the increasing scale of commodities becomes ingrained in daily life (conditionality one), divorcing the producer from the land results in the expansion of primitive accumulation (Smith, 1990).

Harvey (2003:143) states:

'The role of the capitalist as a commodity producer and exchanger is already well established, and labor power has become a commodity that trades generally at its appropriate value. 'Primitive' or 'original' accumulation now proceeds as expanded reproduction (albeit through the exploitation of living labor in production) under conditions of peace, prosperity, and equality.'

Accumulation by expanded reproduction is founded essentially upon the belief that the commodification of labor power and the suppression of alternative or indigenous forms of production and consumption has gained momentum in the neo-liberal movement (Harvey, 2006: 43).

Harvey (2004: 145), further comments on Marx’s concept of primitive accumulation, which he redefines as accumulation by dispossession, by stating that many 
of the processes outlined by Marx are still relevant and that some are gaining in importance in the neo-liberal market place. In addition to the commodificaton of labor power, dispossession involves the privatization of land and the forceful expulsion of peasant populations; the conversion of various forms of property rights (common, collective, and state) into exclusive private property rights; the suppression of rights to the commons; and the colonial, neo-colonial, and imperial processes of appropriation of assets.

The fact that expanded reproduction now preceeds primitive accumulation under conditions of peace, prosperity, and equality, reinforces the capitalist ideology of detachment. Capitalism thrives on the detachment of humans from the commodities they produce and, through privatization, the ability to conceal the actual processes of uneven development is made easier. Harvey (2003) attributes increased multi-spatial and scalar uneven development to the coalescence of both territorial and capitalist logics of power. As explained by Harvey, the state historically acted as a medium to regulate capital power, but the two logics are now becoming more concordant in their endeavors to secure profit, as evident in the increased transfer of once nationalized institutions, often through outsourcing, to privatized corporations or industries.

Harvey develops his critique of the contradictions found in the ongoing processes of capital accumulation by examining the inter- and the outer transformations that occur to produce spatio-temporal fixes (Jessop, 1999:6). For instance, the role of spatiotemporal fixes in internal transformation is linked to expanded reproduction (Jessop, 1999:6). As outlined by Jessop (1999:7): 
'Harvey stresses the general need for long- term investment in fixed, immobile capital to facilitate the mobility of other capitals and explores how such investments affect locational dynamics.'

This connects to expanded reproduction in so far as capital's growth imperative leads to market expansion and hence to the need to intensify transport and communication links within and/or beyond a given region.

\section{Conditionality Three}

Harvey constructs conditionality three as a means to combine and generate discourse surrounding two controversial topics, emerging environmental deterministic philosophies and their relationship within contemporary capitalism. This conditionality is of particular importance to this research because, as explained in detail by Harvey (2006: 91), accumulation by dispossession became a necessary condition to ensure the survival of capitalism. Therefore, in order for capitalism to survive, it relies on the assumption that external coercion from a superior capitalist power will penetrate noncapitalistic society (indigenous) to, often forcibly, embed and replace the pre-existing social system (Harvey, 2006). What conditionality three implies, in my view, is that environmental and territorial specificities generate specific forms of social organization that govern societal constructs such as labor, but still within the construct of continuous capital accumulation.

This conditionality assumes that capitalism is already firmly embedded in society, typically through accumulation by dispossession or expanded reproduction, establishing the commodification of physical, human or intellectual resources for the purpose of ensuring the capitalist mode of production is secure. In relation to this research and the impact of capitalism in Native American uneven development, Harvey (2003) attributes 
this more recent intrusion into indigenous culture as a product of neo-liberal imperialism, with state power used to impose (or resist) conditions of free trade, including the adoption of intellectual property rights.

. The intrusion of neo-liberal imperialism in the United States economy has particular significance because of the often-tumultuous relationships indigenous cultures

and state/national entities have shared. A significant threat to Native Americans from the embedded neo-liberal imperialist movement is the stagnation of their economic development within the capitalist market due to legal and federal restrictions on land-use, property rights (physical and intellectual) and resource development. In some instances, states are now becoming involved in Native American economic development due to federal legislation, such as the Native American Gaming and Regulatory Act of 1988, which allows states to tax gaming operations on federally recognized Indian lands. Contradictions such as this, in which free market capitalism became embedded within alternative social structures but, regulated and kept in check by the dominant social structures, generates class consciousness awareness that may initiate change and reform in social paradigms. These inherent contradictions within the capitalist mode of production and economy are what lead to social unrest and societal movements, conditionality four.

\section{Conditionality Four}

According to Marx, an inherent product of capitalism is social struggle that can manifest itself as social, economic or political movements at multiscalar levels (family, community, town, city, state, nation, etc...). This ideology reinforces Brenner's notion 
that geographical scale and scalar configurations are socially produced and politically contested through human social struggle rather than being pregiven or fixed.

Lefebvre acknowledged that the capitalist political-economic conception operates as a fluid network that acts as a constraint upon society and increases 'alienation', interrupting the development of social agents to achieve the 'total person'. Capitalism in this essence, essentially generates lifeworlds that are banal, trivial and repetitive. These sentiments perhaps reflect the fact that a maladjusted person is actually on the correct path to becoming a 'total person’ by modern societal standards.

For instance, socio-cultural concepts conveyed in Native American literature repeatedly reinforce the notion that Native American values do not correspond with those of Western culture. Alienation from traditional lifeways and detachment from the basic units of social organization are repeated in numerous ethnographic and biographic studies: Neither Wolf nor Dog, Iron Hawk, I Buried My Heart at Wounded Knee, etc. These types of social conflict derive from the contradictions inherent in the forcible implementation of a capitalist culture and economy into that of indigenous alternative forms, sparking the organization of the Indigenous Rights Movement and the American Indian Movement (AIM) to actively participate and initiate discourse from glocal to global scales. 


\section{Chapter 3: Method}

"Knowledge was inherent in all things. The world was a library..."

- Chief Luther Standing Bear (Oglala Sioux)

(In Nerburn, K., 1999; pg. 13)

\section{Introduction}

Cross-cultural relations between Native Americans and Western capitalism are essential components of indigenous lifeworlds and lifeways. The choice of dialectics contrasts with the bipolar model of social knowledge that permeates both the historic and contemporary political and judicial decision making process, as described by James Boggs (1992).

It is important to distinguish between these two methods of knowledge generation because the bipolar model was, and continues, to influence the ability of Native Americans to achieve sovereignty. The struggle for Native American sovereignty is important to this research because Native Americans perceptions of place and identity are intimately tied to their ability to freely control their socio-economic and political development, a prominent contemporary goal of which is the reclamation of tribal lands.

The bipolar model has been the primary method through which federal decisionmaking is achieved. The impacts made through the political and judicial decisionmaking process, utilizing legal instruments such as acts and treaties, continues to impact Native American lifeworlds and lifeways. An understanding of the bipolar process aids in determining how uneven development within, and between, tribal and reservation communities has become the status quo.

The bipolar model of social knowledge reduces the production of knowledge to a dyad of knowledge between producers and knowledge users (Figure 1). To illustrate how 
this process affected Native American lifeworlds and their socio-economic and political development one must think of the knowledge producer as the academic, committee person or federal delegation assigned to study a particular tribe or reservation and the knowledge user as the congressman, senator or president in charge of formulating or drafting Native American policy. The transmission or 'collaboration' of knowledge between the producer and user, devoid of any inclusion of the 'native voice', was a typical method through which federal acts and treaties were created and implemented.

(a) Knowledge Use as Dissemination or Transmission

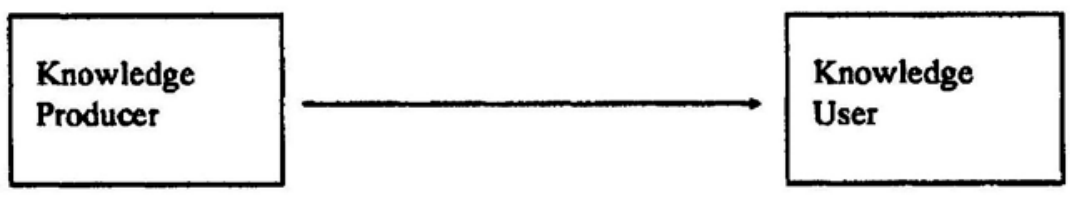

(b) Knowledge Use as Transaction or Collaboration

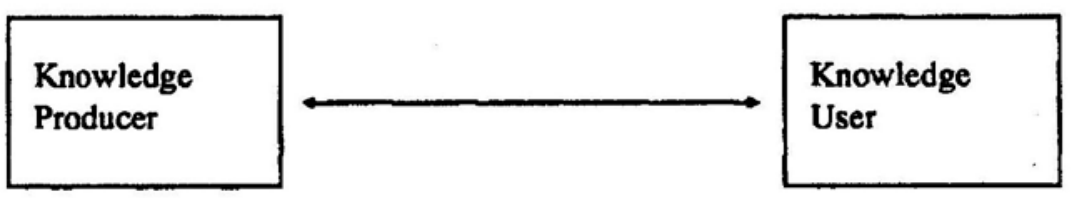

Figure 1: Bogg's Knowledge Use as a Bipolar Exchange. Source: Boggs,1992, Implicit Models of Social Knowledge Use, pg. 32.

The bipolar model was implemented as the basic system through which Native American policy typically aimed toward dispossession was developed. The bipolar process omitted the Native American vantage point and perspective, which affected the shaping of their perceptions of place and identity. Therefore, textual documents such as 
Congressional treaties, acts and judicial case law represent reductionist/assimilationist thinking that lie at the foundation of the impact Western capitalism had on the development of native lifeworlds and lifeways. An important goal of this research is to include the Native voice, achievable through the use of the dialectical method.

These discourses are integral to this research because they spatio-temporally situate the contexts within which Native American 'culturing' occurred, in turn allowing for a more complete and holistic understanding of Native American culture as viewed within contemporary discourses. I utilize the term 'culturing,' as characterized by anthropologist Kirk Dombiowski (2001), because it implies an ongoing/fluid process of cultural development. This ideology perpetuates the concept of indigenous cultures as moving beyond the stereotypical 'traditional' culture label, rather than as active participants in contemporary socio-political and economic processes.

Drawing indigenous cultures out of the tightly bounded space of the traditional reservation Indian stereotype or noble savage imagery communicated throughout modern society is a difficult task. Contemporary literatures emerging from Native American cultural studies, anthropology and ethnology aid in redefining the once passive voice of Native Americans as an active participant within modern society, but sparse attention is being directed toward Native American responses to alternative methods of sociopolitical and economic development that deviate from typical Western conceptualizations.

Geography offers the theoretical framework for the conceptual development of the Native American vantage point, omitting the passive voice, within historical and contemporary interactions and responses to Western culture. Dialectics is employed in 
this research because the theoretical foundation for this method is grounded upon the philosophy of internal relation that seeks to establish, from multiple vantage points, connections between the social relations that comprise societal organization, development and stability.

\section{Dialectics}

Dialectics is founded on a basis of fluidness and interconnectedness that allows for an intense contextual analysis that goes beyond the surfacial to reveal associations not visible through other methods. The concepts of place and identity is of concern to the discipline of geography, but it must also be noted that it is not exclusively so. The concepts of place and identity are also addressed by other disciples such as anthropology, archaeology, social science, history and ethnography. Understanding place is a multidisciplinary effort. What is important to understand within each of these ideologies centered on the concept of place is the 'object' under study. Merrifield (1993:516) addresses this dilemma of place by stating:

...this boils down to the failure of much research to establish more thoroughly the basic ontological nature of place itself. There has, for instance, been a relative neglect of the basic ground rules from which many theorists and researchers construct their understandings of place: which is to say, the manner in which they construct their specific 'object' of inquiry.

In short, he is criticizing the discipline’s inability to properly understand the methodological approach needed to adequately address the research question.

Merrifield and numerous other geographers such as Massey, Harvey and Tuan attempt to compensate for this methodological shortcoming by incorporating dialectics as a foundation to organize and construct their research question and 'object' of inquiry. Described by Ollman (1990:30), the dialectical method is best utilized: 
In order to perceive change, dialectics emphasizes process, movement, flow, relations and, more particularly contradiction.

The common thread is the concern to address the question of change, different kinds of change and different degrees of movement, interconnection and interaction.

This logic of inquiry addresses Merrifield's (1993) concern with the discipline’s neglect or inability to more thoroughly develop a basic ontological understanding of the nature of place. This method assumes that all structures and processes contain their history and have internal relations with other things. Internal relations stimulate change, in contrast to external connections which are purely associational.

Dialectics was designed as a way in which the processes of the world could be mass abstracted in order to more readily understand how these processes affect the concrete (real) world, including the geographical landscape. Although dialectics is more closely associated with the 'post' and Marxist ideologies, influences from human and cultural theorists are apparent from Tuan, Howitt, Guilliford and Basso. As argued by Shields (1999), it was Lefebvre who first urged dialectical theorists to look outside the macrosocial structures to the individual and the details of 'everyday' life.

Using the dialectical method, in addition to incorporating knowledge from other disciplines, allows us to more fully comprehend the web of relations, dynamics and fluidness of Native American perceptions of place and identity and the effect of accumulation by dispossession on indigenous lifeworlds and lifeways. A more adequate understanding of these concepts will benefit both Western and Native cultural relations and, in turn, generate a revolution in cultural relativity that benefits each ideology and sponsors communication to sustain indigenous lifeworlds. 


\section{Origins and Underpinnings of Dialectics}

The origin and popularization of dialectics as a method of analysis is typically attributed to Marx. As discussed by Ollman (2003) and Shields (1999), Marx used and developed this methodology as a means to more holistically decipher the complexity of the social, political and economic forces propagating capitalism. Ollman (2003: 4) explains Marx's method as a revelation of the unobvious that occurs by:

...focusing on the interconnections that constitute the key patterns in capitalism, the dialectic brings the capitalist system itself, as a pattern of patterns, into "sight" and makes it something real that requires its own explanation.

Dialectics, as explained by Ollman (2003) and Shields (1999), was developed as a method by Marx, and Lefebvre, to combat the inherent process of 'alienation' grounded within capitalism. Capitalism, according to Lefebvre, restricted human nature and the human ability to become a 'total person' .

Ollman (2003: 13) describes dialectics as a restructuring of the way in which humans perceive and think of 'things'. Instead of examining a 'thing' unilaterally, dialectics emphasizes 'things' not simply as something that contains its history and possible futures but rather a 'process' and 'relation' that contains its history and futures as part of what it is that ties it with other relations (Ollman, 2003: 13).

Marx develops these concepts of process and relation through the philosophy of internal relations and process of abstraction. The processes of abstraction is Marx's mental exercise method that starts from the 'real concrete' (the world as it presents itself to us) and proceeds through 'abstraction' (the intellectual activity of breaking this whole down into mental units with which we think about it) to the 'thought concrete' (the reconstituted and now understood whole present in the mind (Ollman, 2003: 60). The 
process of abstraction is paramount to understanding Marx's philosophy of internal relations because it exercises the mind to think in terms of multi-scalar, spatio-temporal networks instead of lateral progressions.

The philosophy of internal relations is constructed on the basis that all 'social things' are 'emergent' on one or another time scale, so that everything in society is internally related (Ollman, 2003: 177). The foundation of 'relations' of all social things are reinforced by the ideology that both nature and the social realm are mutually interdependent (Ollman, 2003: 177). Integral to understanding the philosophy of internal relations is the emphasis placed upon 'totality'.

Totality refers to the way the whole is present through internal relations in each of its parts (Ollman, 2003: 72). The ability to decipher the interconnectedness of relations relies upon three modes of abstraction: extension, level of generality, and vantage point. These modes of abstraction operate as a multifaceted, interconnected process that allows the researcher, as described by Ollman (2003: 74\&75), to:

...achieve a certain extension in the part abstracted both spatially and temporally. In abstracting boundaries in space, limits are set in the mutual interaction that occurs at a given point of time. While in abstracting boundaries in time, limits are set in the distinctive history and potential development of any part. The level of generality functions to bring into focus particular levels for treating not only the part but the whole system. This movement operates or enables the researcher to see the unique qualities of any part or the qualities associated with its function. The third mode of abstraction, vantage point, establishes a place within the relationship to view, think about, and piece together the other components in the relationship from multiple perspectives.

These three modes of abstraction are prescriptions for avoiding the misnomers associated with misunderstanding the goals of the dialectical method: (i) its purpose is to reify what lies between; (ii) investigating a problem can go on forever; (iii) boundaries 
established in the process are arbitrary, (iv) humans are unable to work or mark important objective distinctions found in reality; and (v) that the vocabulary associated with the process of internal relations cannot be used to refer to the world that comes into being after the process of abstraction has occurred (a 'totality' can become emergent) (Ollman, 2003: 72). The following three subsections more intimately discuss the conceptual framework informing each of the three modes of abstraction. In addition, this discussion clarifies how a more holistic understanding is conceptually relevant and achievable as prescribed through the philosophy of internal relations.

\section{Extension}

Verhältnis (relation) versus Beziehung (connection); explained by Ollman (2003) Marx uses these two terms to signify the differences that exist between relations that are parts but logically interrelated (Verhältnis) from those that are empirically separated elements Beziehung (connection). As discussed, the foundation for the philosophy of internal relations is organized around the guiding principle that there are multiple interrelated parts that together comprise an understanding of the whole. Therefore, when discussing each of three modes of abstraction it is inherent that singularly none can stand on their own. Rather, it is the interrelationships that exist between the three modes of abstraction that allows for the appropriate spatio-temporal connections to be explored within their proper contexts. Equally significant, these modes also aid in establishing the spatio-temporal and socio-historic boundaries guiding the research question and objective.

Extension is the first mode of abstraction inherent to the philosophy of internal relations. This mode operates to examine relation as a function of spatio-temporal 
relevance. Extension predicates the researcher to mentally explore the possible multilayered spatio-temporal boundaries guiding their research. In essence, the researcher is mentally establishing the spatio-temporal boundaries for each part as it relates to the understanding of the whole or the research objective. For instance, the objective of this research is to conceptualize how capitalist uneven development, specifically through accumulation by dispossession, has shaped, and continues to shape, Native American perceptions of place and identity. The spatio-temporal boundaries mentally abstracted for this research question required exploring and defining the parts related to the whole.

To address the goals identified at the start of this research the temporal boundary was established between 1871 and the present. Although this seems like a considerable time period, 1871 represents a significant change in the social-political and socioeconomic ideologies guiding the actions of the United States toward Native Americans. The establishment of the temporal boundary aided in determining the spatial extent of this research in that relationships between Native American actual physical material spaces were being visibly modified through federal intervention. These spatio-temporal boundaries gave definition, order, and context to the interrelationship of the parts to the whole.

\section{Level of Generality}

The next mode of abstraction, the level of generality, further clarifies the spatiotemporal extent of the parts to the whole by examining their interrelations as existing within a multi-scalar framework. This mental abstraction, according to Ollman (2003: 75): 
'clarifies the particular 'level' of generality for treating not only the part but the whole system to which it belongs by moving from the most specific to the most general characteristics to determine what sets it apart or makes it similar to other entities.'

Two prominent components are central to understanding the function of the level of generality as a feature within the modes of abstraction: the seven major 'levels' of generality and the 'laws of the dialectic'. The seven major 'levels' of generality function to organize the spatio-temporal boundaries around which to investigate the relationship of the 'part' to the 'whole,' as examined through multiple levels outlined by Marx. The 'laws of the dialectic,' as clarified by Ollman (2003: 97), are used to help organize, clarify, and focus upon the most common forms of change and interaction occurring at each 'level' of generality. The forms of change and interaction viewable at specific 'levels' are discussed below in further detail.

Ollman (2003: 88) clarifies that Marx’s conceptual design for utilizing the level of generality is as an investigative tool for understanding the world as it is occurs at seven major 'levels.' These seven major 'levels’ represent conceptual scales, or planes of comprehension (Ollman, 2003:88), on which Marx focuses in order to organize and investigate problems. The seven major levels, beginning from the most specific, are as follows (Ollman, 2003: 88-89):

(I) Person/situation, this level comprises all variables that distinguish individuals and situations from one another. (II) General to people, this level comprises abstracting people not as specific individuals, as in level one. Instead this level investigates how general qualities, such as profession, are abstracted to consider those that share those similar qualities as examined through multi-temporal (temporal extent in which quality exists) and spatial (city, county, state, country, and etc...) lenses. (III) Capitalism, at this level person's are brought further out of the focus utilized in level two. Here, everything that is peculiar to people, their activity, and products due to their appearance and 
functioning in capitalist society is brought to focus. The focus at this level exists to contemplate how the qualities of the 'worker' operate within the capitalist mode of production. (IV) Class society, as in the previous, this level expands its spatio-temporal boundaries to focus upon produced social boundaries as created through distinctions in the divisions of labor viewable through multiple political constructs (capitalism, feudalism, slavery, and etc...). (V) Human society, this level examines the wholeness of the human condition as it relates to shared qualities of activity and production specific to human society. (VI) Animal world, this level examines what qualities such as instinct, physical condition or life cycle we share with other species. (VII) Human materiality, this level examines the most basic qualities of human interactions with nature as material beings such as movement, weight, or physical footprint.

In accordance with the above description it can be said that within each 'level,' all qualities exist simultaneously but the seven levels of generality function as a means to organize and situate spatio-temporal qualities within contexts that become more in-focus within specific 'levels. In short, the origin of specific problems only becomes apparent when the appropriate 'level' emerges.

The 'laws of dialectics’ as described by Ollman (2003: 96), are those movements or qualities that can be found in one or another recognizable form on every level of generality, that is, in the relations between the qualities that fall in each of these levels, including that of inanimate nature. These laws are described by Ollman (2003: 94-97) as follows:

... the law of transformation is the transformation of values into prices or quantity into quality; the law of contradiction produces development through contradiction; the law of polar opposites is the process by which a radical change in the conditions surrounding two or more elements or in the condition of the person viewing them produces a striking alteration, even a complete turnabout, in their relations; the law of negation is the process by which the most recent phase in a development that has gone through at least three phases will display important similarities with what existed in the phase before last. 
These laws are not intended to predict patterns but rather to aid in organizing contexts as revealed through spatio-temporal 'levels.' Additional work is required to address if certain dialectical laws more adequately address problems found at specific 'levels' or 'multilevels.'

The third mode of abstraction, that of vantage point, establishes the level of rigour within research by first acknowledging that all the prior modes of abstraction are influenced by perspective. This mode addresses the issue of perspective and its effect upon developing the boundaries and interrelationships between the parts to the whole in the mental progressions associated with the previous modes of abstraction.

\section{Vantage Point}

The mental act of abstraction is interrelated through three mutually interrelated modes. Through the two previously discussed modes, the researcher is able to acquire an extension, level of generality, and vantage point that brings into focus the components of any particular relation and, given its then extension, from which to reconstruct the larger system to which a particular relation belongs (Ollman, 2003). The function of vantage point is to allocate perspective within the context of the mental act of abstraction.

This mode is integral to the process of abstraction and critical to developing a rigourous research methodology. Essentially, vantage point requires the researcher to mentally acknowledge and address the motivations driving their research objective. In relation to its function within the modes of abstraction, vantage point sets up a perspective that uniquely distinguishes everything that falls into it, establishing order, hierarchy, and priorities, distributing values, meaning, and degrees of relevance, and asserting a distinctive coherence between the parts (Ollman: 2003). 
Vantage point acknowledges predisposition to particular processes that influence the mental organization, classification, compartmentalization, and hierarchization of relations based upon experience; essentially this comprises those processes influencing identity formation. Marx states that it is particular vantage points that structure the process through which mental acts are developed and organized. Therefore, some vantage points are more advantageous to comprehending the relationships between the parts to the whole given their embeddedness within the network of relations. This is why differences exist in perceptual outcomes (Ollman: 2003). Especially for the researcher, being cognizant of, and recognizing, the impact particular vantage points have in influencing, directing, and structuring the research process becomes integral to maintaining an appropriate level of rigour that ensures personal, social, and cultural relativity throughout the study.

\section{The Dance}

Dialectics is a mental exercise that challenges its users to conceptually organize their thinking to search out connections as they interrelate to conceive the whole. The dance of the dialectic (Figure 2) was created by Ollman (2003 and 2008) to more easily communicate the complex mental processes comprising the conceptual foundation structuring the method: the philosophy of internal relations and the three modes of abstraction. 


\section{Dande of the Dialentio}
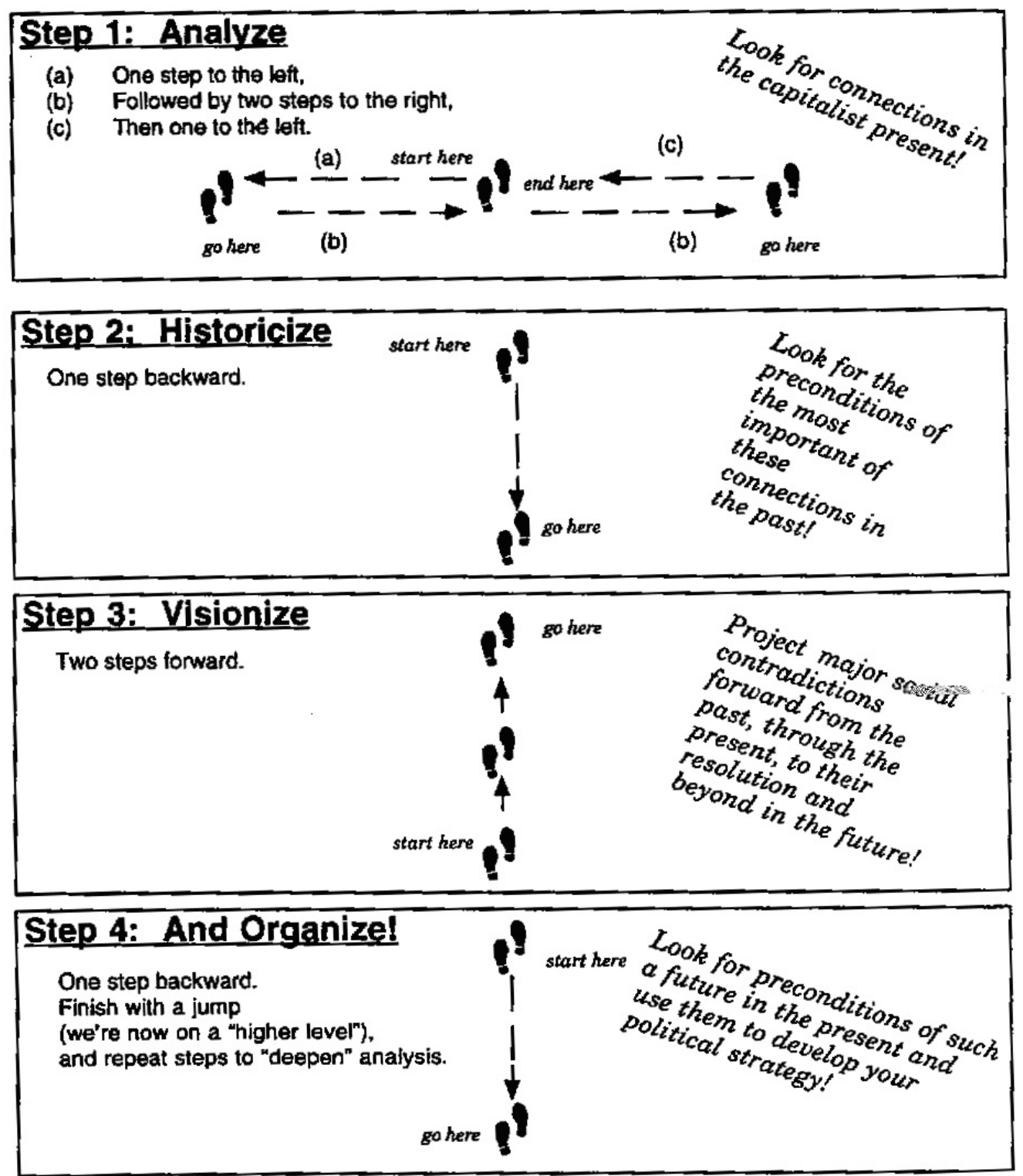

Toxt and Choreography by Bertell Oliman

Layout by Fran Moran

Figure 2: Ollman's Dance of the Dialectic, a source for understanding and interpolating the steps in Marx's method. Source: Ollman (2003) Dance of the Dialectic Steps in Marx's Method, pg. 169. 
As explored by Ollman (1990, 2003 and 2008) Shields (1999), and Merrifield (1993), the dialectical method was utilized by such theorists as Marx and Lefebvre as a means to comprehend the present socio-economic and political conditions as influenced by capitalist processes, the historic underpinnings and origins for the existence of these preconditions, and the ability to comprehend and visualize probable alterations in socioeconomic and political conditions as projected through modifications in capitalist processes. The dance of the dialectic (Figure 2), aides the researcher by taking them through the 'dance' step by step so the process of creating and building spatio-temporal interconnections, as prescribed in the philosophy of internal relations and the three modes of abstraction, becomes demystified and conceptually manageable as connections are identified, boundaries established, and perceptions (vantage points) are appropriated within their proper context. 


\section{Chapter 4: Conceptualizing Space and Place Utilizing Harvey's Matrix of Spatialties}

\section{Introduction}

Harvey’s (2006) matrix of spatialities is explored within this chapter as a conceptual tool organizing the ontological space-place dilemma informed by Merrifield (1993). Within this section Harvey’s (2006) matrix is dissected in order to derive the sources informing the geographical concepts structuring and organizing Merrifield’s (1993) space-place ideology. This critical exploration illuminates many of the conceptual challenges associated with the epistemological and ontological dichotomies that exist between Western and Native American ideologies. Dialectics is used as the conceptual tool guiding this critical examination of Harvey’s (2006) matrix of spatialities.

Utilizing Merrifield's (1993) argument permits the use of dialectics as a conceptual instrument to overcome many of the ideological barriers that, typically, separate or compartmentalize researchers' ability to achieve holistic understandings as communicated through multiple contexts, structures, social relations, and perspectives. Dialectics allows the researcher to freely examine socio-historic contexts as perceived from varying stances or perspectives. This type of research requires immense responsibility and dedication, on behalf of the researcher, to maintain and ensure rigour throughout the research process. The following section explains and critically examines the ideaological underpinnings of Harvey’s (2006) matrix of spatialities.

\section{Matrix of Spatialities}

Harvey’s (2006) matrix of spatialities effectively communicates the complexity associated with understanding how the concept of 'space', within the discipline of geography, is dialectically conceptualized and spatio-temporally organized. 
Conceptualized dialectically, this matrix represents a mental exercise exposing the dialectic interrelationships and processes at work and contributing to an understanding of how conceptualizations of space are formulated. Harvey $(2006 ; 128)$ explains the need for a dialectical conceptualization of space by stating,

'What we do as well as what we understand is integrally dependent upon the primary spatio-temporal frame in which we situate ourselves'.

Harvey's three by three matrix (Figure 3) is organized horizontally, to capture space as understood through Lefebvre's conceptualizations of human experience and vertically, to capture space as understood through Harvey’s conceptualization of perspective or vantage point. Harvey (2006) acknowledges that the linear appearance and organization of the matrix contradicts the fluidness associated with dialectics however, he does not encourage visualizing the matrix as a step-by-step progression. Rather, each box within the matrix should be viewed to consider the combinations that arise at different intersections, allowing the viewer to individuate phenomena with greater clarity and then dialectically observe how such phenomena interrelates with each element within the matrix (Harvey, 2006; 134).

Reflecting back to the aforementioned section concerning place outlining the three primary conceptualizations of place within the discipline of geography: place as scaled space, place as a humanist construct, and place as spaces of flow and networks of spatial practice. These conceptualizations relate to the current discussion of Harvey's matrix because standing alone each concept individuates and disproportionally address the ideological components, experience and perspective, informing place and identity construction. Tuan (1977: 201) recognized these deficiencies early in his research stating, 
'Experiences are slighted or ignored because the means to articulate them or point them out are lacking.' 

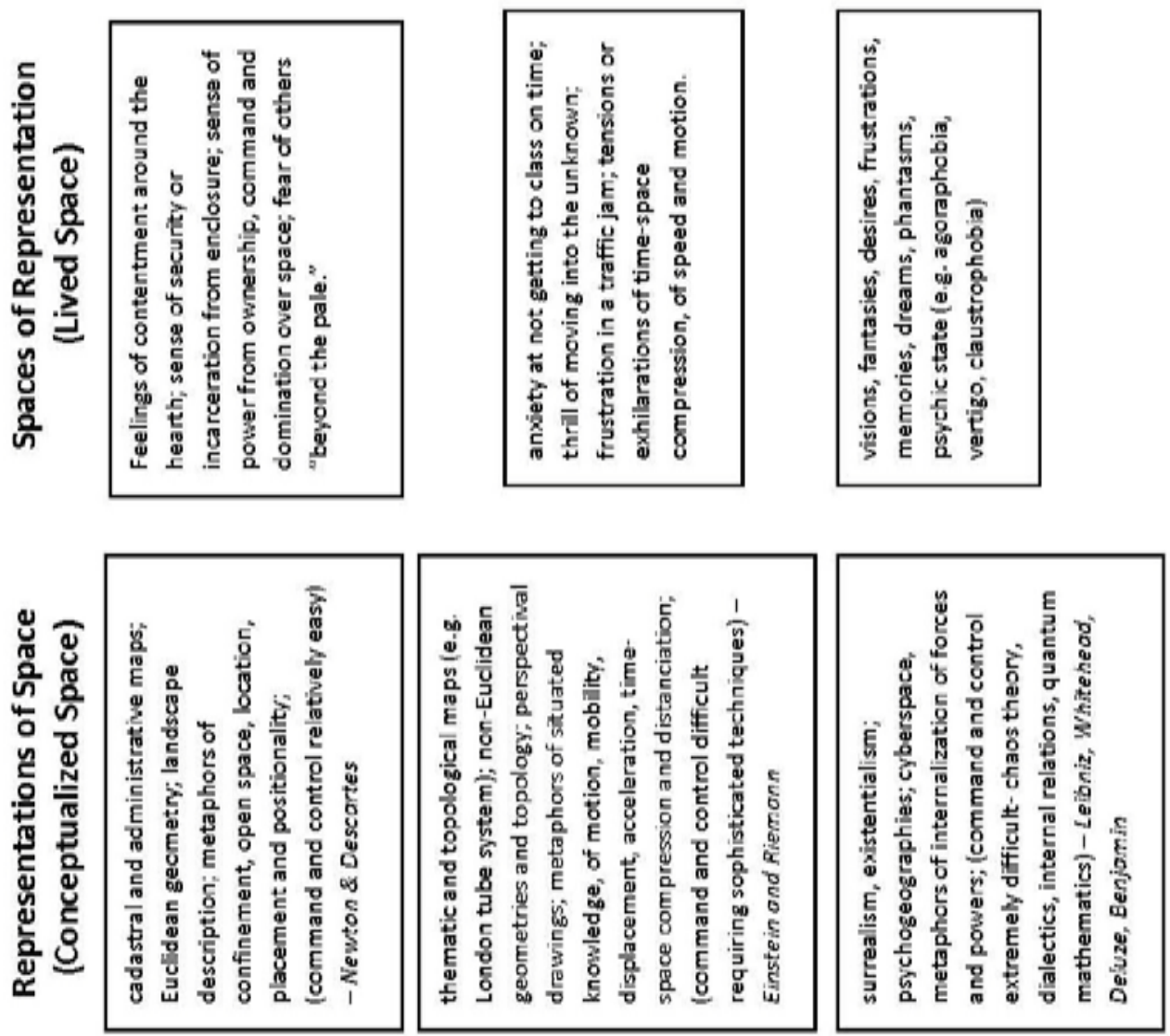

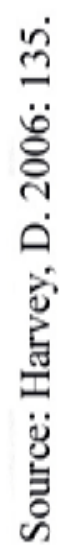
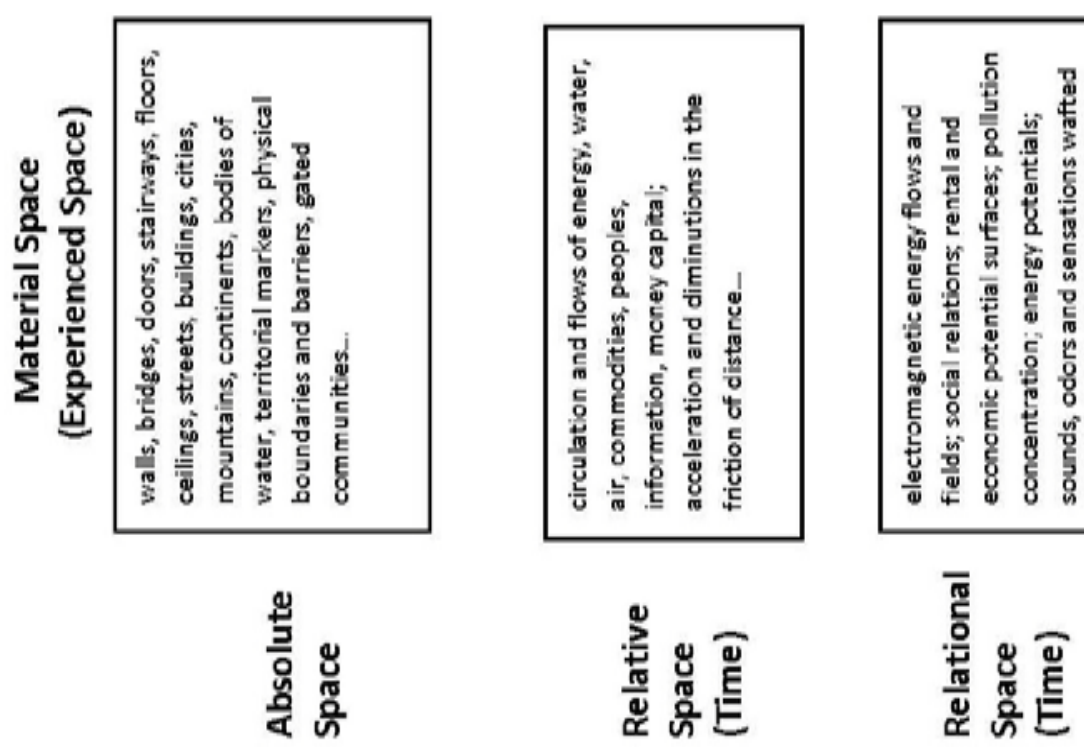

药 
This research argues that examining these three geographical concepts, as a part of Harvey’s (2006) matrix, provides a conceptual context for dialectically addressing the multiple spatio-temporal interrelations comprising place and identity formation. In short, Harvey’s matrix represents what Tuan (1977: 201) was searching for, ‘a means to articulate experience', and remove 'man’s blindness to experience.' Tuan (1977) and Merrifield's (1993) arguments boil down to an inability to conceptualize the interrelations comprising experience and place due to ontological gaps. Harvey's matrix is viewed within this research as exceptional, in that it attempts to fill gaps in ontological paradigms by examining the social through spatio-temporal modalities. Essentially, within this research, the matrix is understood to function as a means to comprehend the spatio-temporal boundaries, contexts, and perspectives that comprise the processes influencing place and identity formation and development.

The robustness of Harvey’s (2006) matrix is tested in the following section by introducing the Native American perception or vantage point in addition to cosmology. To accommodate these additional modalities and demonstrate the importance of cosmologies as a part of Native American construction of place and identity, Harvey’s matrix is amended and reworked to accommodate the Native American perspective and vantage point.

\section{Testing Robustness: Harvey’s Matrix of Spatialities}

. Modifying Harvey's (2006) matrix (Figure 4) to include the Native American perspective is an attempt to more intimately communicate Native American 'experience' as a component functioning within the geographic concepts informing this research. Research conducted by Barnhardt and Kawagley (2005), focused upon the differences 
and commonalities shared between Western and traditional indigenous ideologies, aided the conceptual organization of materials included within the modified matrix. 


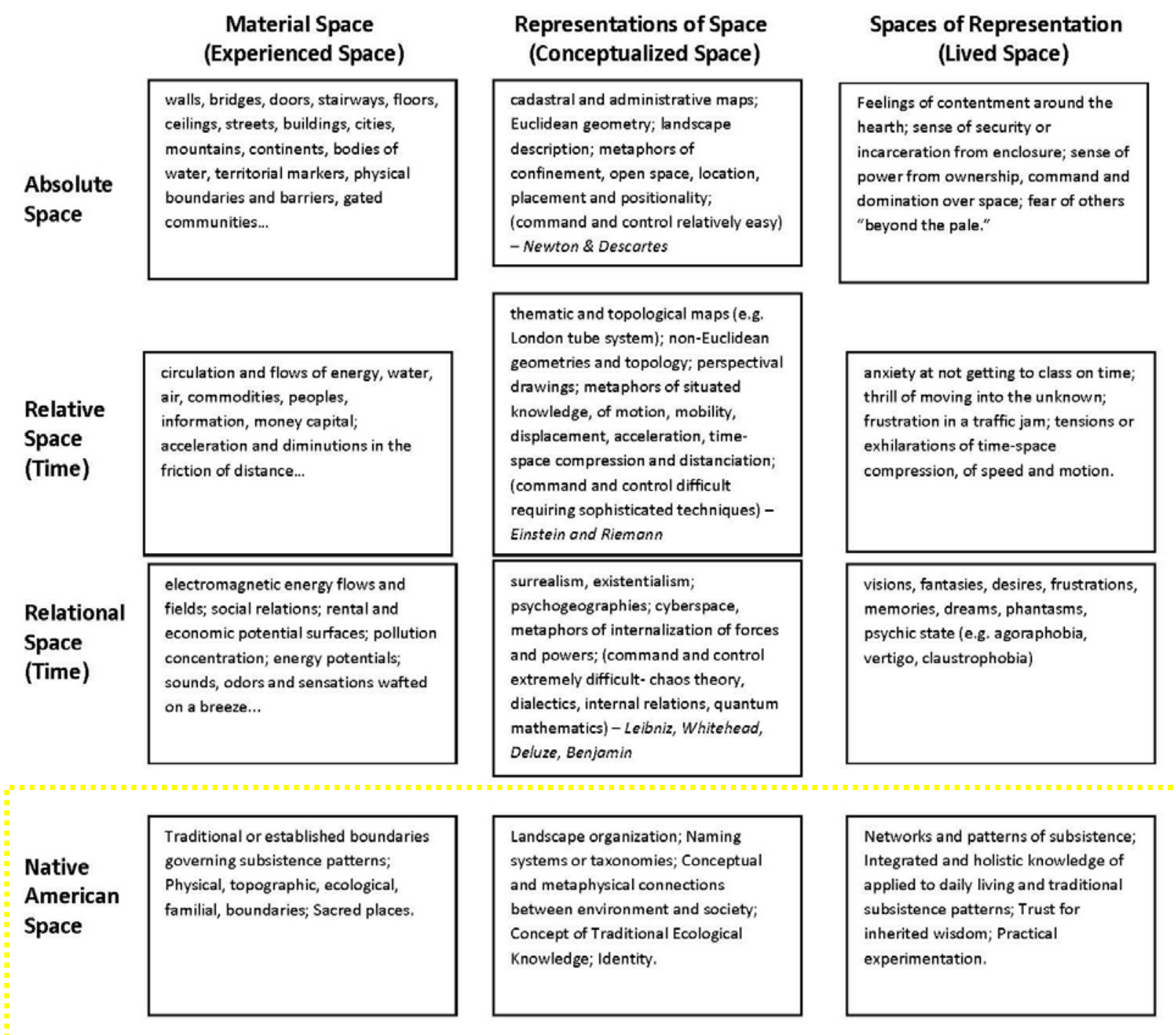

Figure 4: Modified Version I of Harvey's (2006) General Matrix of Spatialities.

I

In order to demonstrate the conceptual logic at work within Harvey’s matrix the

proceeding example walks the reader through the amended matrix (Figure 4). The intent

of this ideological stroll through the amended matrix is to conceptually demonstrate to

the reader the complexity encompassing a holistic comprehension of place and identity

construction, formation, and development as viewed from an alternative geographic

experiential perspective. 
As explained by Harvey (2006:134), the matrix is presented in a manner to inform the reader of the complex combination of scenarios that comprise multiple spatiotemporal contexts. The reader is asked to further keep in mind the geographic concept of conceptual sacred space and how it interrelates through the multiple spatio-temporal perspectives and experiences (Figures 4-5). The concept of sacred space, specifically informed through Native American cosmologies, is more intimately explored in the following chapter. However, it is integral to mention at this juncture the importance placed upon cosmologies, within this research, in comprehending the socio-historic construction, development, and organization of Native American perceptions of place and identity. Therefore, as the reader scans the amendedfour-by-three matrix he or she is asked to mentally discern the intimate connections shared among perspective and experience.

Following the direction outlined by Harvey (2006; 134), the proceeding example engages the experiential and perspective modalities in a manner that informs the varying meanings the spatial and spatio-temporal acquire as they connect and intersect within the matrix. The following example is not static; it merely represents a path of representation connecting the experiential and perspective modalities. 


\section{Critical Analysis}

Thus far, Harvey’s (2006) matrix has been explored as a holistic attempt to dialectically conceptualize the spatio-temporal as perceived from multiple perspectives and experiential modalities. The challenge of this section is to dissect Harvey’s matrix to determine its ability to truly be holistic. Utilizing the Tlingit as an example, the reader is walked through the matrix and, more importantly, both strengths and weaknesses in the matrix are highlighted and critically discussed. For instance, special attention is directed toward the matrix's ability to conceptually address the importance of sacred space and cosmology within Native American ideologies.

Envision, for instance, the Tlingit of Southeastern Alaska and their relative relationship to the absolute material space comprising their geographic location (i.e. stream, mountains, inlets, bays, and etc...). Depending upon geographic locality and the surrounding physical environment the Tlinglit conceptualized relationship to physical space (i.e. traditional ecological knowledge, geographic naming, and ect...) will vary ${ }^{2}$. The relationship between experienced and conceptualized space contributes to the development of a secure lived space (i.e. definable boundaries organized by localized knowledge of an area). Within this lived space, a relational sense of place is coalesced where Tlingit 'place’ within the surrounding physical material environment is understood as a complex socio-temporal development that varies according to perspective and the social practices that act as the glue that bind societal structure and realities.

This example of the intimate relationship that Native Americans, specifically Tlingits, share with their physical environment, in relation to, experienced,

\footnotetext{
${ }^{2}$ For a more detailed explanation of Tlingit relationships with their surrounding environment please refer to chapter eight.
} 
conceptualized, and lived spaces readily identifies multiple interrelations linking the experiential and perspective modalities that aid in conceptualizing the Tlinglit understanding, organization, and development of the spatio-temporal. Examined within the context of the matrix the surface of these connections and interrelations are readily identifiable.

However, in the process of modifying Harvey's (2006) matrix it became evident that only surficial understandings of the experiential interrelations comprising Tlingit social organization were addressed. Namely, this researcher found, the intimate connections shared between Native Americans and their physical environment was reduced to a simplistic needs based relationship. Stopping here and merely identifying common surficial relations does not address the goals outlined in this research. For instance, comprehending the effects dispossession had and has upon Native American perceptions of place and identity is not reducible to social organization based solely upon environment, hunter-gather, and cultivator relations. While this is a key component to mentally constructing the conceptual interrelations comprising Native American social organization the underlying experiential is not explainable within the current parameters of the matrix. This research purposes that cosmologies can be used as primary sources of information that communicate the role of perceived space within Native American place and identity formation.

This is not to say the matrix is flawed according to Western conceptualizations of the perceived and experiential. Rather, Harvey (2006) has made it more readily identifiable for this researcher to identify differences in the conceptual structure of social organization between Western and Native American societies. This variance is 
somewhat relieving in that capitalism's attempt to create a global monoculture, as described by early theorists such as Marx, Engel, and Lefebvre, has thus far remained thwarted.

The logical progression according to the dialectical method is to then search deeper to find the underlying connection structuring the whole. The experiential categories within Harvey’s (2006) matrix are modeled after Lefebvre’s spatial triad. However, variations do exist between the categories outlined by Harvey within the matrix and Lefebvre's original spatial triad. Namely, Harvey (2006) seems to combine Lefebvre's concept of social practice or perceived space within the category of spaces of representation. While incorporating these two concepts within one category appears to work well within Harvey’s reorganization of Lefebvre’s original spatial triad; this may represent the underlying discordance contributing to the misconceptualization of the whole within Native American societies.

For the purpose of clarity and conceptual cohesiveness, this researcher purposes that the concept of social practice/perceived space be treated as a separate experiential component (Figure 5). Merrifield (1993; 524) clarifies the logic for this decision by stating:

'Spatial practices structure daily life and a broader reality and, in so doing, ensure societal cohesion, continuity and a specific spatial competence.'

Expanding the current parameters of the matrix to include social practices/perceived spaces allows for a deeper investigation and understanding of the multiple experiential and perspective interrelations comprising the whole. Specifically, in the interest of this research, the concept of perceived sacred space becomes an underlying component informing social organization. The remainder of this section clarifies the importance of 
expanding the matrix to include spatial practices/ perceived space as a separate category, in addition to, the importance of the concept of sacred space in developing, structuring, and organizing a holistic conceptualization of Native American social organization as it pertains specifically to place and identity (Figure 5). 

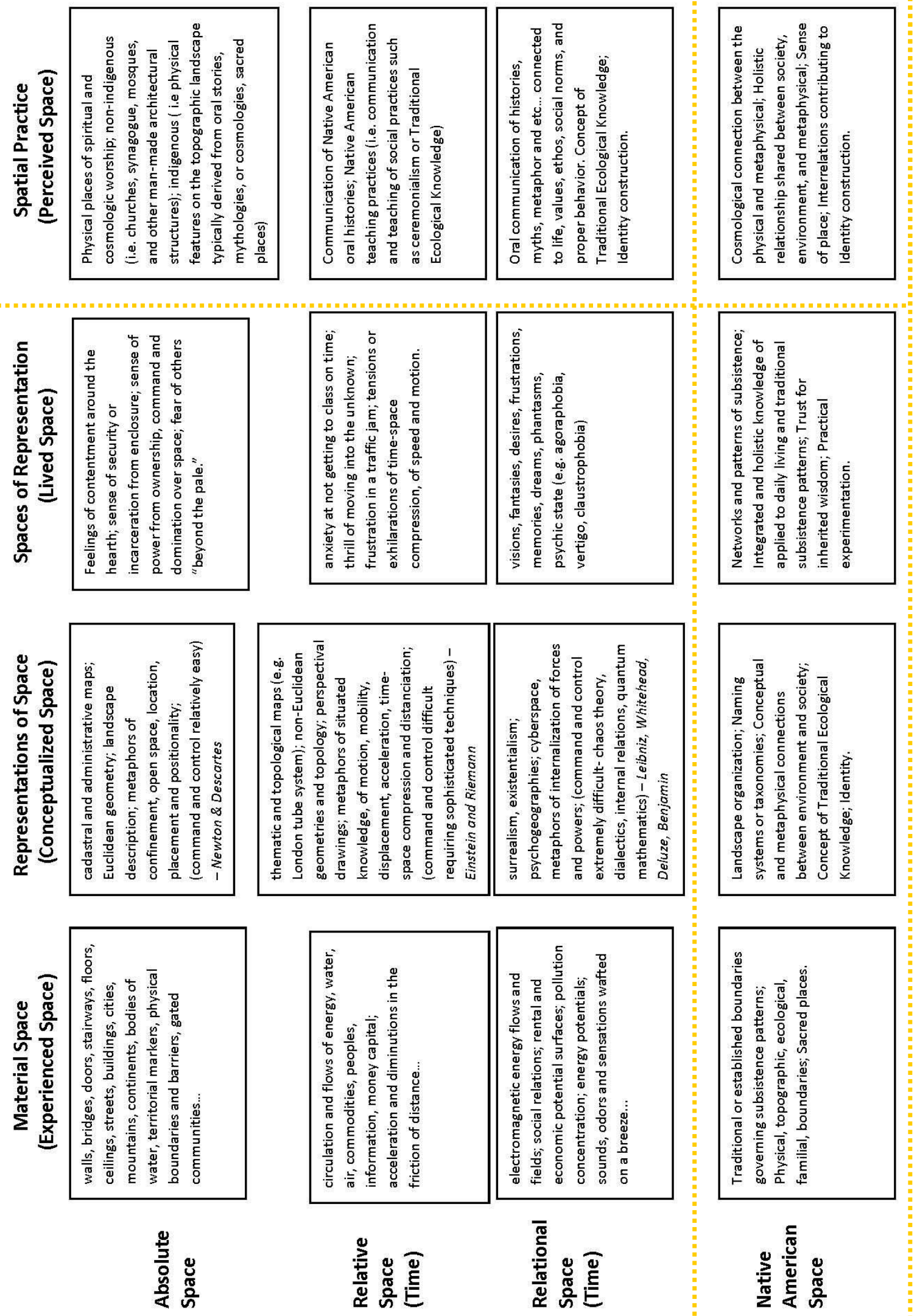


\section{Expanding the Matrix: Spatial Practice \& Perceived Space}

Spatial practice (perceived space), as understood by Lefebvre, aids in mentally constructing the intimate connections shared between the experienced, conceptualized, and lived spaces. Utilizing perceived sacred space, as a specific object of inquiry within the matrix, acknowledges the complex interrelationship between experienced, conceptualized, and lived space as it relates to the development of a place and identity. More importantly perceived space extends itself one step further to acknowledge the importance of social practice in developing Native American social cohesion and organization.

Focus is placed upon perceived space because it is recognized as a binding agent that makes more recognizable those interrelations that contribute to Native American place and identity formation and development. As stated as the start of this research, incorporating the native 'missing voice' is a primary objective. The argument suggested here implies the 'missing voice' is accounted for when native concepts that specifically acknowledge those processes that contribute to an understanding of native place and identity formation are given equal importance and consideration alongside those traditionally considered more 'academic.' This statement acknowledges the importance of incorporating primary accounts and native ideologies, when and where possible, within this research to identify and illuminate those processes and interrelationships that might otherwise remain latent within Western ideologies.

Native cosmology represents one latent ideology that typically receives little to no attention within traditional academic research regarding place and identity. Native 
cosmologies are underutilized sources of primary information that communicate the intimate interrelationships and processes organizing native social practices. As described in the Tlingit example, to comprehend the intimate relationship this society shares with its surrounding environment requires going beyond typical descriptions of relative relations between society and environment. Rather, Tlingit relations with their surrounding environment are composed of interrelations comprised of multiple spatiotemporal experiences informed though perspective.

Cosmologies are here viewed as 'lived oral-histories,' with specific spatiotemporal knowledge, to establish actual physical localities that further collaborate indigenous peoples connections to, or within, specific areas or localities. Reinforced through Andrew Gulliford's (2000) comprehensive research surrounding the spatiotemporal development of Native American perceptions of place and identity as perceivable through the complex connections shared between sacred landscapes and oral history, physical material places within this research, are viewed as cosmologically related to a indigenous society's 'lived' and evolving history. If sacred space is examined further as understood within the framework of relative space, certain temporal and perspective interconnections are apparent. For instance, sacred space becomes significant because of the personal relationships and connections established between the environment and individuals, clans, moieties ${ }^{3}$, tribes, and etc... through shared oral cosmologies.

From a relational perspective within the matrix, sacred space and cosmologies function as derivatives for defining, organizing, and establishing the ethos guiding the

\footnotetext{
${ }^{3}$ Within many indigenous societies the moiety functions as a socio-political unit within an overall hierarchical scale of generality. Moieties are often identified through cosmologic origin.
} 
spatio-temporal development of societal norms and values of indigenous cultures. This modality within the matrix is most important in that it is the first instance where questions concerning place and identity development are critically explored as communicated through multiple perspectives and geographic 'experience', a reformation of ontology. Acknowledged by Harvey (2006), the robustness of the relational perspective derives from the ability to collaborate and draw interrelations from multiple spatio-temporal contexts.

In brief, this allows for linkages in spatio-temporal perspectives based upon relational connections in the experienced, conceptualized, lived, and in the interest of this research, perceived sacred space. So, rather, than devising singular spatio-temporal connections within absolute or relative space, the relational perspective corroborates multiple connections in space and time to contrive holistic understandings of social and tribal development explainable through geographic experiential perspectives.

\section{Conclusion}

The added vertical column, social practice, completes Lefebvre's spatial triad of space as conceptualized through human experience. This column addresses the role spatial practices play in structuring daily life and a broader social reality (Merrifield, 1993: 524). Merrifield (1993: 524) characterizes this component of Lefebvre’s spatial triad as the 'glue' that ensures societal cohesion and continuity. This modality functions as a binding social agent when interpreted, according to Merrifield (1993), as the perceived spaces informing individual's perceptions that organize their daily reality. In the interest of this research, cosmology (perceived sacred space) is examined as the conceptual social binding agent informing place and identity formation within Native 
American society. In addition, the boxes within this column include both conceptual similarities and differences that exist between typical Western conceptualizations of perceived (sacred) space versus that of the Native American. Key to conceptualizing the inclusion of this additional component is to examine the role each horizontal (spatiotemporal) perspective contributes to interpreting the complex interrelations that exist as particular vantage points illuminate certain aspects of social practice as the reader moves down through the column.

Brought to attention within this section were the multiple spatio-temporal perspectives and experiences informing place and identity development. Linking the spatio-temporal importance of experienced, conceptualized, lived, and perceived space within multiple perspectives; this discussion emphasized the use of Native cosmologies in order to more holistically conceptualize Native American place and identity formation as understood through their intimate relationship with their environment. The more intimate the conceptual interrelationships between place, identity, and environment can be established, the greater the likelihood a cohesive theoretical explanation for the impact accumulation by dispossession has played a part in Native American uneven development becomes achievable.

Utilizing the research of Basso (1988 and 1996) Cajete (2000), E. Deloria (1988 and 1993), Dombrowski (2001), Dunbar-Ortiz (2007), Feld and Basso (1996) Guilliford (2000), Ortiz (1969) and Thornton (2008) the concept of sacred space, as it intimately relates to cosmology, is developed in the following chapter to clarify the relationships that exist within Harvey’s (2006) matrix. To further develop this line of conceptual thinking, the following chapter critically examines the cosmologies of each indigenous 
culture included as a case study(Oglala-Lakota, Tlingit, and Eastern Tewa Pueblos) by employing the method of textual discourse analysis. The objective of this analysis is to uncover specific concepts intertextually communicated through themes found within each indigenous culture's cosmologies. The intent in identifying these concepts is to critically examine the basic conceptual foundation in which Native American perceptions of place and identity are constructed. 


\section{Chapter Five: Cosmology as Ideology}

\section{Introduction}

'Local narratives tell us less about 'history' and more about how people construct their sense of place and cultural identity.' (Bird, 2002; pg. 519)

The cosmological component within this section explores the foundational spatiotemporal elements within each selected cosmology as they relate to the development of each indigenous culture's perception of place and identity. Essentially, this component represents the figurative starting point in which alterations in societal perceptions of place and identity can be explored based upon relational connections between fluctuations or changes in the physical material environment or, more importantly for this research, pressures from external power structures; such as through congressional acts that sponsored mechanisms of dispossession.

Cosmology is an underrepresented component within research pertaining to place and identity, and especially pertaining to Native Americans. Cosmology, as described by Ortiz (1969), is the oral communication of cultural ideologies that serve to conceptually organize and classify the social, spiritual and physical world typically conveyed through emergence stories or other oral narratives. Effectively, cosmologies communicate a people’s sense of being and place within their social, physical, and metaphysical worlds. This research purposes the most meaningful way to understand cosmology is through the creation or emergence stories associated with each indigenous culture included as a case study.

There is a relative understanding within Western normative doctrines of the ‘value' that indigenous peoples allocate to oral communication, cosmologies, and sacred 
places as a part of preserving tribal identity. For instance, the National Register of Historic Places categorizes ‘sacred places’ as ‘traditional cultural properties’ (Gulliford, 2000: 70). Analyzing the topic as dialectic or multi-relational, within the framework of Harvey's (2006) matrix, the goal of this section is to illustrate the ontological knowledge gaps/ shortcomings of the normative relative approach taken by the federal government in regard to the Native American perspective of experience. Harvey's (2006) matrix aids in identifying the socio-political and economic inequalities created when employing a normative relative ideology as a guide to creating and establishing intercultural relations.

Genres of history are devoted to the historic documentation of the political atrocities and inequalities that transgressed through the application of the dyadic ideology (Figure 1) of the federal government toward Native American indigenous cultures. The goal of this research is not to reformulate well known historic interpretations of evidenced federal-Native American relations, nor those economic, political, and environmental conditions affecting tribal organization as those made by prominent Native American historians and researchers including: Deloria (1974 and 1985), Wilkins and Lomawaima (2001), Prucha (1984 and 1994), Deloria and Wilkins (1999), and Wilkinson (2005). Rather, the scope of this research involves contextualizing these historic 'facts' as spatio-temporal sources that aid in clarifying the dialectical interrelations that link documented spatio-temporal dispossession to place and identity development within Native American societies specifically, those of the Oglala-Lakota, Tlingit, and Eastern Tewa Pueblos.

The following section describes an instance from Lakota history that demonstrates the fluidness of cosmologies and ability to be reworked, as communicated through 
historic spatio-temporal contexts. This section is incorporated here to further demonstrate the complex relational connections shared between Lefebvre's spatial modalities outlined in Harvey's (2006) matrix as expressed through historic spatio-temporal social, economic, political, and environmental changes. The Lakota are utilized as an example to intimately engage the modalities within Harvey's (2006) matrix in relation to the spatio-temporal development of this indigenous culture's cosmology.

\section{Cosmology as Cultivated History}

As aforementioned, emergence and creation stories act as sources that link the physical and metaphysical to accommodate and provide the basis for conceptualizing the ethos, norms, and behaviors, collectively termed ethnopsychology ${ }^{4}$, that structure social organization. However, it is important to note that, creation and emergence stories like any other part of Native American culture are not stagnant and often are reorganized or modified to account for alterations stemming from events that initiate environmental or social stresses.

For instance, it is historically recognized that the Siouan tribes (Lakota, Dakota, and Nakota) were at one time geographically situated further east, within Minnesota nearer the shores of the Great Lakes, than their present day location in the Great Plains. Historian Richard White (1978; 220-221) attributes the Western movement of the Siouan tribes, especially the Lakota, as a complex migration resulting from more than 'White' advancement in the eighteenth and nineteenth centuries or increasing intrusion from neighboring indigenous cultures such as: the Ojibwas ${ }^{5}$, Crees, or Assiniboine ${ }^{6}$. Rather,

\footnotetext{
${ }^{4}$ Thomas F. Thornton (2008) utilizes the term ethnopsychology to conceptually link psycho-social behaviors, norms, and etc... to rootedness in place.

${ }^{5}$ Ojibwa is more commonly referred to as Chippewa.
} 
White (1978) emphasizes that the migration of the Lakota occurred multi-temporally;

pushed by economic, political, and environmental conditions affecting social organization.

White (1978; 321) describes this movement west as occurring in three identifiable stages:

'.... initially a movement during the late seventeenth and early eighteenth centuries onto the prairies east of the Missouri, then a conquest of the middle Missouri River region during the late eighteen and nineteenth centuries, and, finally, a sweep west and south from the Missouri during the early and mid-nineteenth century. Each of these stages possessed its own impetus and rationale. Taken together they comprised a sustained movement by the Sioux that resulted in the dispossession or subjugation of numerous tribes and made the Sioux a major Indian power on the Great Plains during the nineteenth century.'

These movements west resulted from a combination of multiple social, economic and political developments within the region. White (1978; 322) attributes the causes for the major events leading to modifications in geographic placement from the acquirement of guns from the French, the economic gains procured through fur trapping and trade, and the abundant food supply offered from the buffalo herds.

Once situated within the Great Plains, several factors were responsible for maintaining the western placement of the western Sioux such as the acquisition of large horse populations allowed for the advancement and improvement of hunting techniques and also brought increased economic gains in trade. In combination with the horse, the introduction of guns allowed these western Siouan tribes to profit from hunting and also raiding indigenous societies without this technology. And the movement of European

\footnotetext{
${ }^{6}$ Collectively, the Ojibwas, Crees, or Assiniboine are known as Anishinabek (plural of Anishinaabeg) and belong to the Algonquian linguistic stock.
} 
traders (Spanish and French) up the Missouri River that increased and diversified trading, and promoted opportunities in economic gains.

You might be asking yourself or wondering why the preceding discussion was introduced within the section on cosmology. The socio-economic, political, and environmental influences affected by geographic mobility and sustainability are significantly influenced by cosmological arrangement. As stated by Gonzales, T. and Nelson, M. (2001; 499):

Land is everything to Native American peoples for several reasons. First of all, indigenous land-bases spiritual practices are rooted in an understanding of culturally and ecologically specific creation stories and oral histories.

Essentially, creation and emergence stories are tied to particular or specific environmental/geographic localities. So while historical evidence as revealed by White (1978) and other historians situates the Western Siouan tribes, such as the Oglala-Lakota, at one time further east of their present day location in the Great Plains region, it should be noted that the creation or emergence story historically perpetuated and communicated through oral tradition situates the geographic locality of emergence as Wind Cave. Wind Cave is located in the Black Hills National Park (Figures 6-7). 


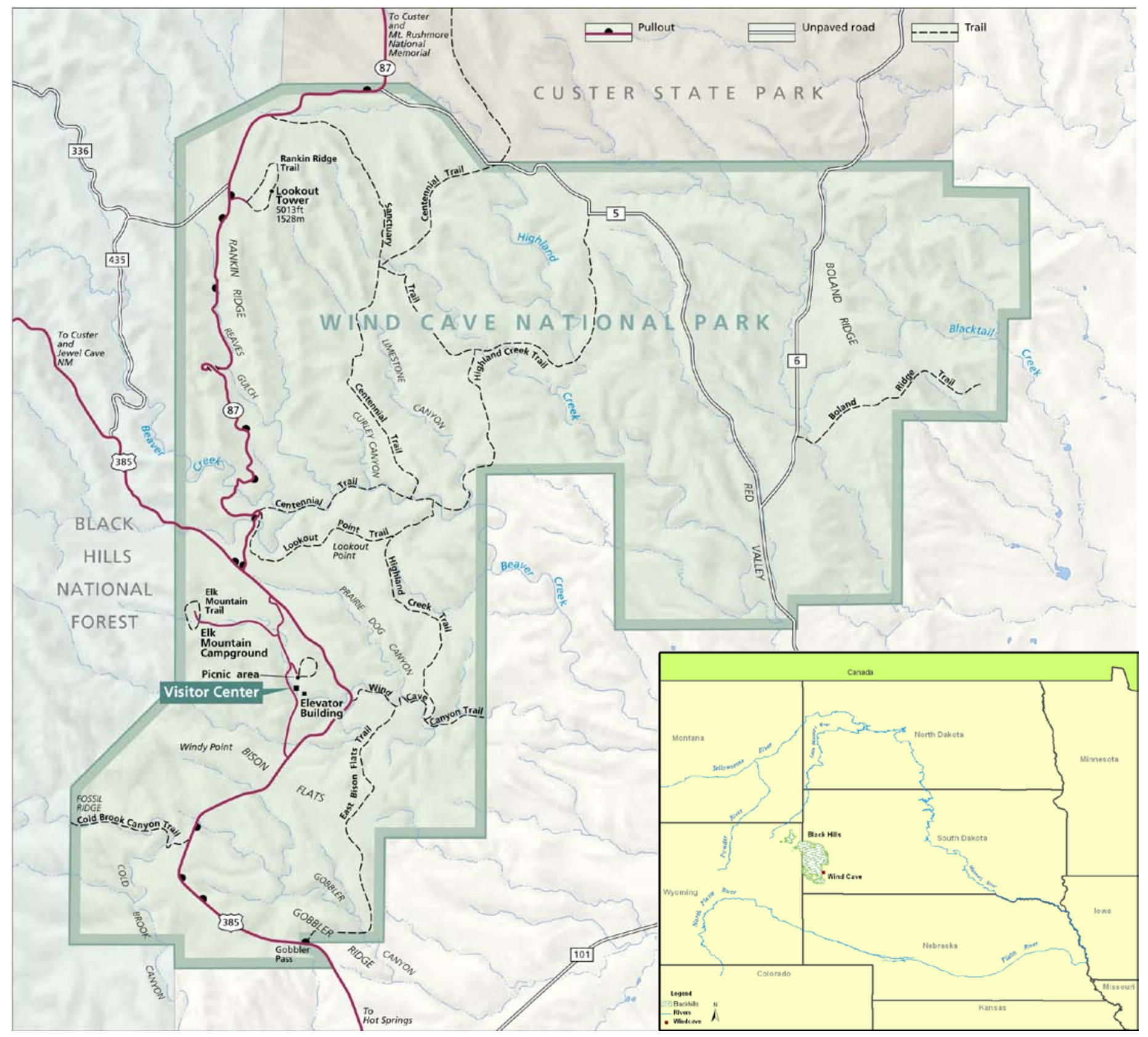

Figure 6: Wind Cave National Park. Source:

http://www.nps.gov/pwr/customcf/apps/maps/showmap.cfm?alphacode=wica\&parkname =Wind\%20Cave\%20National\%20Park 


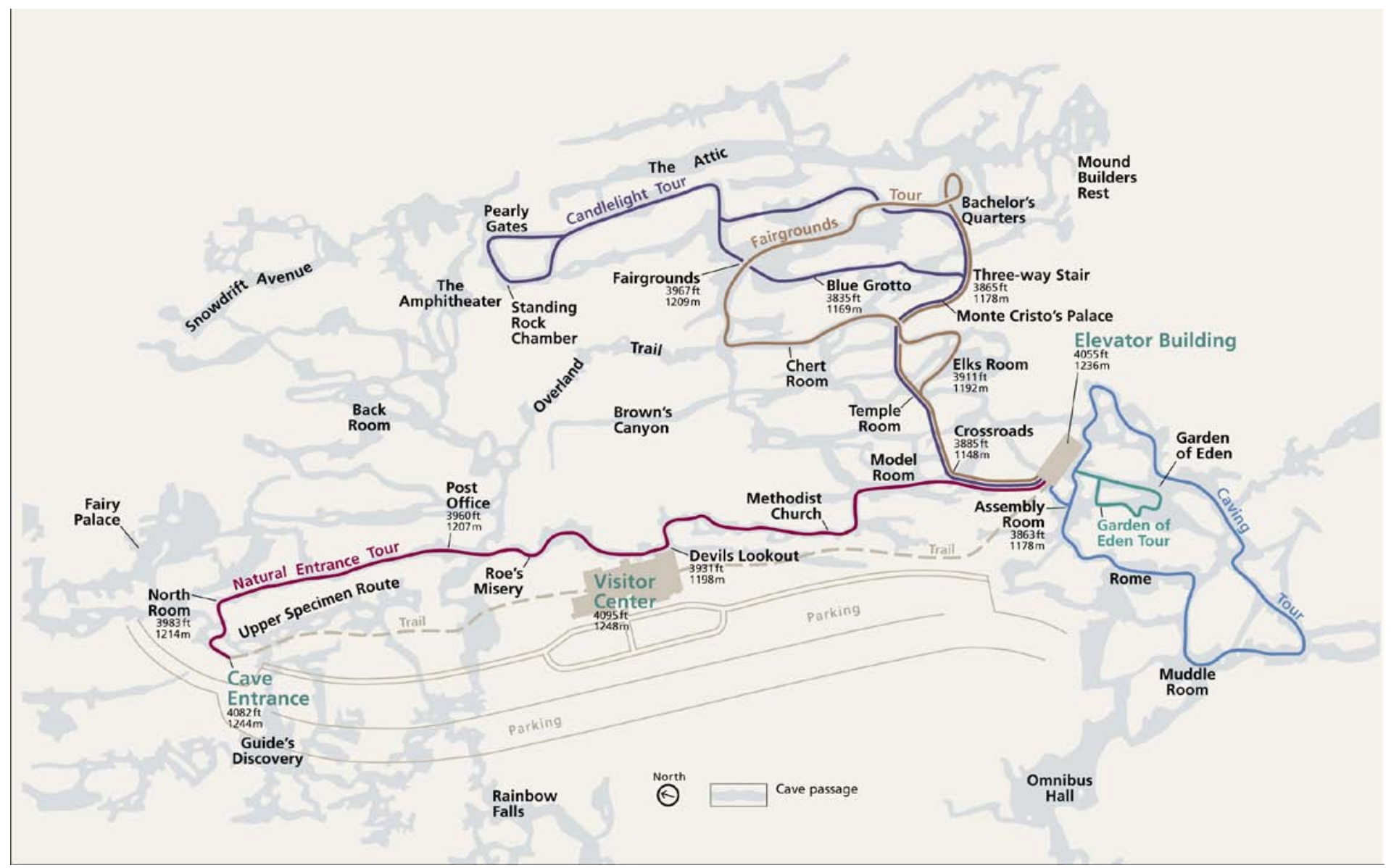

Figure 7: Detailed Map of Wind Cave National Park. Source:

http://www.nps.gov/carto/PDF/WICAmap3.pdf

As seen in Figure 5 Wind Cave is not situated in the east where historical

evidence indicates the Lakota, such as the Oglala, where first situated. Rather, the emergence story situates the spiritual and physical center of the culture in the Great Plains region. No documentation or research was discovered to determine if a previous sacred geographic point of emergence was identified when the western Siouan peoples were situated further to the east. What is significant is the evolution and development that Native American societies undergo in response to socio-economic, political, and environmental alterations that effect social organization as those discussed by White (1978). Cosmologies become integral sources to comprehending changes in social organization and reorganization as the contexts in which social, economic, political, and environmental conditions become manifest and vary spatio-temporally. 
As stressed throughout the previous section, the societal knowledge communicated through cosmologies are intimately connected with Native American perceptions of place and identity. These stories are utilized as sources revealing the intimate physical, environmental, spiritual, and social connections of Native American lifeworlds and lifeways in relation to geographic surroundings, essentially place. This idea is further developed by Peggy Sandy who states:

'Creation stories contain within them a conception of the natural or initial order of things. By articulating how things are in the beginning, people apply more than a logic for life styles - they make a basic statement about their relationship with nature and about their perception of the source of power in the universe. This relationship, and its projection into the sacred and secular realms, holds the key for understanding identities.' (In Powers, 1986; pgs. 4-5)

So, essentially the spiritual wisdom of Native Americans is not found in a set of "scriptural” materials, instead it is a part of the fabric of daily life and experience (Nerburn, K., 1999).

Cosmologies also allude to the perspective of time in relation to a indigenous peoples' ‘sense of place’. As communicated by Tuan (1977; pg. 198), time and cultivating sense of place are interconnected in that, to evoke a 'sense of place' often requires a deliberate and conscious effort to link with the past. Therefore, within this research, developing a 'sense of place' is understood as a dialectical process where the surrounding world acquires organized meaning by establishing interrelated connections with time (present, past, and future) that influence the perspective of experience within given environmental surroundings (topophilia). I argue that cosmologies, within Native American societies, provide a dialectical interconnectedness between time, experience, and perspective that intimately contributes to the development of 'sense of place' as 
reflected in the organization of tribal lifeworlds and lifeways. This discussion aids in further clarifying the goal of this research, that accumulation by dispossession has significantly altered Native Americans perceptions of place and identity, by establishing a basis to view what the ideological 'traditional' socio-economic and political organization should represent in relation to the to the effects dispossession and uneven development has had upon, often times forcibly, modifying native lifeworlds and lifeways.

The objectives for the remainder of this section are: to further explore the relational concept of cosmology as it relates to Native American place and identity development; examine the relational concept of cosmology more intimately by analyzing specific cosmologies, in the form of emergence and creation stories, recognized as traditional tribal versions and reliable sources; discuss the methodology for determining the reliability and accuracy of the selected textual sources; and, lastly, critically examine the robustness of Harvey’s (2006) matrix ability to accommodate the Native American spatio-temporal experiential. If the reader recalls, discussion concerning the last objective was initiated near the start of this chapter. The purpose in concluding with this final analysis of Harvey's (2006) matrix is to critically examine if the amended matrix specifically captures the Native American spatio-temporal experiential or if these additional categories merely, once again, represent an attempt, on the behalf of this researcher, to compartmentalize Native American ideologies within the parameters of Western conceptualizations.

Setting the scene for this dialogue, the cosmological section initiates a discourse surrounding Native American perceptions of place and identity from the three case study societies specific to this research: the Oglala-Lakota, the Tlingit, and the Tewa Pueblos. 
Introducing first person historic and contemporary perceptions at this juncture is a means to include the 'missing voice' within this research. The following section is a critical component to this research because in addition to including the 'missing voice' it also represents the first instance within this research where the foundations for Native American perceptions of place and identity are discussed at depth. The concluding portion of this chapter more clearly demonstrates how dialectics, in combination with the conceptual framework organizing this dissertation, presents the optimal framework in which the development of Native American perceptions of place and identity should be explored.

\section{Cosmologies and Undertaking Textual Analysis}

This research relied upon textual documentation to conduct analysis of the cosmologies for those indigenous societies selected as case studies within this research. While direct oral communication of these cosmologies from a respected tribal elder to this researcher represents the optimal method for the transference of knowledge, this was not part of the established parameters for this research. When selecting specific cosmologies stringent criteria were established to ensure the rigour of this research was not compromised. Rigour was maintained within the textual analysis portion of this research by establishing criteria that ensured the accuracy of authorship, the reliability of context, and the author's motivational integrity for each of the selected historic documents utilized in the textual analysis ${ }^{7}$.

The objective of obtaining accuracy of authorship within textual documentation was approached from the ideology established by historical geographers that seek to

\footnotetext{
${ }^{4}$ Refer to the Appendix for full text versions of all cosmologies utilized in the textual analysis portion of this research.
} 
understand how knowledge is created, circulated, and consumed. This ideology assumes that as a researcher undertaking textual analysis it is apparent that the ways in which knowledge operates across different scales and manifests itself in particular situations is critical to understanding the subjective meanings derived from the author of the text. For example, as explained by Hine (2000 in Crang, 2005), a new geographical sensitivity is needed to utilize and move from a notion of field as bounded site to field of relations:

Ethnographers might still start form a particular place, but would be encouraged to follow connections, which were made meaningful from that setting. The ethnographic sensitivity would focus on the ways in which particular places were made meaningful and visible. Ethnography in this strategy becomes as much a process of following connections, as it is a period of inhabitance. (Hine, 2000, in Crang, 2005)

Crang (2004) suggests this awkward sense of scale means that almost everything occurs on a scale that does not yield easily to received methods and our 'subjects' or ‘others' no longer inhabit coherent bounded social contexts for which we have a persuasive lexicon. Therefore, in order to establish rigour within textural analysis it becomes the challenge of the researcher to overcome the boundaries of positionality, temporal context, social context, and linguistic variation when addressing the authorship of textual documents.

The reliability of context was approached from the perspective of Naylor (2005). Naylor (2005) addresses the hermeneutic dimensions of textuality and considers the geographies of writing and reading as distinguished by place. He suggests that when a researcher uses historical documentation they must consider the ways textual meanings and authorities change from place to place. This theory also suggests that textual meaning must be placed within its appropriate social context. Therefore, the researcher 
must not only question the authorship of the document but also the social and temporal context in which it was created.

Undertaking textual research also requires understanding how the author's subjective opinions are communicated through manuscripts and other historical documents. For instance, the researcher must ask what the author's motivation wass for creating the document in order to determine its historical accuracy. Fairclough (2003) suggests the use of triangulation when attempting to gather historical facts to determine the author's accuracy. This is a tedious and time consuming process but must be incorporated within textual research in order to ensure utmost accuracy and rigour has been maintained.

Following these established criteria, cosmologies (creation and emergence stories) were selected for each case study society. Brief discussions are included at the start of each indigenous culture's cosmology section to communicate why each textual source met the criteria established for this analysis. In addition to utilizing primary textual sources, secondary ethnographic interpretations are used as additional sources to triangulate the accuracy of authorship, the reliability of context, and the author's motivational integrity for each of the selected historic documents.

For example, extensive research pertaining to the influential role of cosmologies in shaping social organization and development has been addressed by respected ethnographers and anthropologists such as: Ella Deloria, Aurel Krause, Simon Ortiz and Elsie Clews Parsons who set the standard for rigourously documenting Native American oral histories and culture. In many instances research and interpretations, such as those conducted by Ella Deloria (Lakota) or Simon Oritz (Pueblo), included in the analysis 
derive from tribal members of the cosmology under study. These secondary sources,

especially those made by tribal members, further aid in overcoming the barriers of

positionality, temporal context, social context, and linguistic variation when addressing

the accuracy, reliability, and integrity of textual documents (Fairclough, 2003).

\section{Cosmologies of the Oglala-Lakota}

From Wakan Tanka, the Great Spirit, there came a great unifying life force that flowed in and through all things - the flowers of the plains, blowing winds, rocks, trees, birds, animals and was the same force that had been breathed into the first man. Thus all things were kindred, and were brought together by the same Great Mystery.

Kinship with all creatures of the earth, sky, and water was a real and active principle. In the animal and bird world there existed a brotherly feeling that kept the Lakota safe among them. And so close did some of the Lakota come to their feathered and furred friends that in true brotherhood they spoke a common tongue.

The animals had rights - the right of man's protection, the right to live, the right to multiply, the right to freedom, and the right to man's indebtedness - and in recognition of these rights the Lakota never enslaved an animal, and spared all life that was not needed for food and clothing.

This concept of life and its relations was humanizing, and gave to the Lakota an abiding love. It filled his being with the joy and mystery of living; it gave him reverence for all life; it made a place for all things in the scheme of existence with equal importance to all.

That Lakota could despise no creature, for all were of one blood, made by the same hand, and filled with the essence of the Great Mystery. In spirit, the Lakota were humble and meek. "Blessed are the meek, for they shall inherit the earth" - this was true for the Lakota, and from the earth they inherited secrets long since forgotten. Their religion was sane, natural, and human.

$$
\text { Bear }^{8}
$$

- Chief Luther Standing

\footnotetext{
${ }^{8}$ Chief Luther Standing Bear (1868-1939) was a member of the Oglala band of the Teton Sioux. Wished for his people to live a nomadic lifestyle, but tried to accommodate to white way by attending the Carlisle Indian School and encouraging his people to take up farming. Turned away from white culture after witnessing the slaughter of unarmed, men, women, and children at Wounded Knee in 1890. In 1933 he
} 
Teton Sioux

(In Nerburn, K., 1999; pgs. 36-37)

\section{Critical Evaluation of Source Material (Accuracy, Authorship, and Positionality)}

Three traditional cosmologies, transcribed to English, informed the textual analysis for the Oglala-Lakota: Maka’s Story, The Lakota Creation Story, and The Story of the White-Calf Buffalo Woman ${ }^{9}$. Maka’s Story is the traditional Oglala-Lakota history conveying the mythological ${ }^{10}$ development of their universe. The Lakota Creation story is the recount of the emergence of the Pte Oyate ${ }^{11}$ from under the ground to the earth. The story of the White Calf Buffalo Woman reveals the origin of the sacred pipe.

Collectively these three stories represent the foundation on which Oglala-Lakota society was formed $^{12}$. These stories are influential within Oglala-Lakota society because they are sources providing logic for the organization of their lifeworld and lifeways. These stories project and clarify the intimate relationships and connections the OglalaLakota share with nature, in addition to providing the ideological foundation organizing their understanding of the spatio-temporal construction of place and identity formation.

published a book, My Indian Boyhood. Biographic excerpt acquired from Nerburn, K. and Mengelkoch, L., 1991.

${ }^{9}$ The full text versions of these stories utilized in this research are found in Appendix C.

${ }^{10}$ Mythological is utilized in this context to describe those processes pertaining to the origin of supernatural god(s) and their function in the organization of the Lakota-Oglala universe.

${ }^{11}$ Pte Oyate literally translates as buffalo people. The Oglala-Lakota are known as the Buffalo Nation (Powers, 1986; pg. 69).

${ }^{12}$ It is important to note that numerous stories not explored in this research exist that contributes to providing a holistic understanding of Lakota-Oglala society and the many intricacies governing the development of social norms, ethos, values, and behaviors. It is beyond the scope of this research to collectively examine the Oglala-Lakota's entire cosmological record rather; those stories included within this dissertation provide the ideal foundation in which the objective of this research can be critically analyzed; i.e. dialectically formulating the impact and influence of capitalist accumulation by dispossession to Native American place and identity formation. 
The accuracy and integrity of the three stories included in the textual analysis was verified through the method of triangulation. Simply put, searching for other versions of the same story and crosschecking for the intertextuality of integral themes and plot sequences determined each story utilized in the analysis as accurate and reliable. In addition, all stories included in the analysis were acquired and translated by well-known and respected ethnographers of the Lakota ${ }^{13}$.

\section{Triangulating Space, Place, and Identity}

Textual analysis revealed that several themes are intertextually communicated between stories. Utilizing the software $\mathrm{Nvivo}^{14}$, themes were identified by abstracting the data: stories, based upon the redundancy of specific words that gave way to establishing specific codes identifying key concepts communicating or specifying references to space, place, and identity. For instance, within each story, reference to the concepts of buffalo, earth, spirit, time, and seven were intertextually identified. The remainder of this section discusses the intertextuality of these concepts between stories and how these concepts inform the argument that place, identity, and dispossession are dialectically interrelated.

\footnotetext{
${ }^{13}$ An exception to this statement is the version of Maka's Story used in the textual analysis. The author of this version of the traditional Lakota-Oglala history conveying the mythological development of their universe is J.R. Walker. J.R. Walker was a physician who worked and lived on the Pine Ridge Reservation from 1896-1914. Walker's version of Maka’s story was communicated to him by George Sword, an Oglala police officer on the Pine Ridge Reservation, upon which the English translation is based upon. While J.R. Walker was not a trained ethnologist, his documentation of Maka's story is recognized by the American Ethnological Society as accurate and reliable. Some contestation exists as to Walker's literal translation of words from Lakota to English but, the themes communicated throughout the story are contiguous with traditional Oglala-Lakota perceptions of these events.

${ }^{14}$ NVivo is a type of CAQDAOS (computer-assisted qualitative data analysis software). The NVivo qualitative software package that aids the process of code based theory building through textual analysis. This software package, and others like it, is designed with the capacity for retrieval, coding, annotating, memo-making, and cross-questioning (Cope, 2005).
} 
The concept of buffalo ${ }^{15}$ is the most prominent and identifiable theme within this collection of stories. The importance of this concept within the Oglala-Lakota perception and development of a collective identity is paramount. As revealed in the three stories, this concept (buffalo) links the experienced, conceptualized, lived, and perceived to aid in the collective understanding of Oglala-Lakota identity and social organization. For instance, viewing this story from the context of Harvey's (2006) matrix the following passage from Maka's Story describes the relational and conceptual origin for the concept of buffalo:

'Skan then created the Oyata Pte (Buffalo People). Their bones
were made from Inyan, their flesh came from Maka and their
entrails were fashioned from the white fruit. Skan gave each of the
first two buffalo a spirit that was a little lower than that of the
gods. The Nagi (Spirit) of the Buffalo People he took from himself.
(As such, the Nagi "advises the conduct of each being.") Skan
commanded Wi to give them warmth and Tate breathed into them a
Niya, a ghost. (The Niya is the breath of life, and a witness to the
advice which the Nagi gives.) Ksa gave them intelligence while
Wakinyan, as Heyoka, offered growth and increase. Wi-win made
them affectionate, and Wohpe bestowed upon them a longing and a
love for offspring. Skan then instructed the Pte People. Anp and
Han governed them, and they were obeyed in all things' (Melody,
1977).

From this passage it is reasonable to discern that the term buffalo, within the context of the Oglala-Lakota cosmology, refers more to the conceptual beginning of mankind or, more specifically, the origin of the Oyate Pte or Buffalo Nation. Maka's Story represents the first instance in which conceptual foundation for the construction of Oglala-Lakota identity is mentioned.

\footnotetext{
${ }^{15}$ There are several variations within the Lakota dialect that refer to the term buffalo. In order to more definitively identify all instances where the concept of buffalo was mention within the stories additional search terms were utilized in the analysis: pte 'buffalo cow' and tatanka 'buffalo bull' (Powers, 1986; pg. $69)$.
} 
The relational concept of, buffalo, is further communicated in the story of the Oglala-Lakota's Emergence from the underworld to the earth. The Emergence story connects the conceptual foundation explored in Maka's story and develops into that of experienced and lived spaces, establishing more absolute understandings of the physical components comprising the Oglala-Lakota world and, in turn, influencing social organization. Within the Emergence story it is preconceived that the peoples emerging from the underworld to the earth are those known as the Oyate Pte; those created by Skan while the universe was under design.

This story, although brief, communicates several concepts integral to understanding traditional Oglala-Lakota perceptions of place and identity. From a dialectical perspective, the Emergence story is key in comprehending the intimate connections shared between sacred conceptual space and that of experienced and lives spaces. The following passage from the Emergence story helps clarify the argument:

'Tokahe ${ }^{16}$ does so and upon reaching the surface through a cave (Wind Cave in the Black Hills), marvels at the green grass and blue sky. Inktomi and Ite introduces Tokahe to buffalo meat and soup and shows him tipis, clothing, and hunting utensils' (Melody, 1977).

This passage illustrates the intimate relationship linking the concepts found in the cosmologic arrangement and order of the Oglala-Lakota universe to that of the experienced and lived spaces. Together the conceptual, experienced, and lived spaces communicated in these two stories illuminate the foundation in which the Oglala-Lakota perceptions of place and identity are grounded and communicated in perceived space, therefore, spatio-temporally developed.

\footnotetext{
${ }^{16}$ Tokahe is the first member of the Oyate Pte to emerge from the underworld to the surface of the earth. The sacred place of emergence is known by the Oglala-Lakota to be Wind Cave located in the Black Hills of South Dakota.
} 
The third story, the story of The Coming of the Pipe, further contributes to an understanding of the ideological components informing place and identity development within Oglala-Lakota society by bringing the conceptual foundations introduced in the previous stories full circle. The premise of The Story of the Pipe is the introduction of the cosmologic figure of the White Buffalo Calf Woman. The White Buffalo Calf Woman is a powerful and sacred figure in Oglala-Lakota society. She is known for bringing with her the sacred pipe, in addition to communicating the seven sacred rites and rituals of the Oglala-Lakota. Within this story the interrelationship shared between the four spaces, experienced, conceptualized, lived, and perceived, are firmly established. This binding of spaces is relationally conveyed as the sacred cosmological and conceptual intimately inform the experienced and lived, creating perceived space that governs a cosmological order which guides social perceptions informing the organization of the Oglala-Lakota lifeworld and lifeways.

Several plot sequences within The Coming of the Pipe, reveal the origin for the close relationships shared between the sacred cosmological and physical world. The binding of the spaces is achievable as the conceptual becomes married to the experienced and lived. For instance, the White Buffalo Calf Woman states:

'My relatives, brothers and sisters: Wakantanka has looked down and smiles upon us this day because we have met as belonging to one family' (Melody, 1977).

This passage clarifies the linkage of the sacred cosmologic to the physical as the relationships between the two are traced through a shared genealogy. For instance, a literal relationship exists between the Earth (Maka) where she is your Grandmother and Mother. These plot sequences cultivate the relationship between the cosmologic and the 
physical to explain the connection of the Oglala-Lakota to the 'earth' (Maka) and their surrounding environment. The closing passage of the story is as follows:

As they bade her (White Buffalo Calf Woman) farewell she left the lodge, still walking clockwise. As she reached the edge of the camp the people were amazed to see her turn into first a red buffalo (north, where woman comes from), then brown (actually yellowish brown, representing the east sunrise), then white (south at the center), and finally a black buffalo as she passed over the hill (west sunset)' (Melody, 1977).

This passage, in addition to further proving the ideological link between the cosmologic and physical, also brings into focus the concept of the buffalo. Buffalo has guided this discussion and revealed the importance Native American cosmologies play in organizing and developing a collective Oglala-Lakota perception of place and identity.

Through the critical analysis of these three Oglala-Lakota cosmologies the original goal of determining the effect of dispossession upon Native American perceptions of place and identity, made at the start of this research, is understood as the interrelationships between experienced, conceptualized, lived, and perceived spaces are placed in relational context. Identifying the conceptual origin for the foundation of place and identity construction, as through the concept of buffalo, are carried into the following chapters where the intricacies of societal organization are explored through a spatiotemporal lens as dispossession becomes a prominent factor in redefining traditional patterns of social organization. For instance, dispossession occurring from the elimination of the buffalo herds initiates the question of cultural continuance as the traditional norms and values guiding social organization become distanced from the ideologies communicated through cosmologies. 


\section{Cosmologies of the Eastern Tewa ${ }^{17}$ Pueblos}

In the very beginning we were one people. Then we divided into Summer people and Winter people; in the end we came together again as we are today. (Excerpt from the Tewa cosmology as communicated from an unidentified Tewa, In Ortiz, 1969; pg. 29)

\section{Critical Evaluation of Source Material (Accuracy, Authorship, and Positionality)}

Three traditional cosmologies, transcribed to English, informed the textual analysis for the Eastern Tewa Pueblos of New Mexico ${ }^{18}$ : The Emergence as recorded by Elsie Clews Parsons (1926), The Emergence as recorded by Simon Ortiz (1969), and The Migration as recorded by Elsie Clews Parsons (1926). Two emergence stories are included in this textual analysis because the stories collected by Parsons ${ }^{19}$ and Ortiz ${ }^{20}$ contain slight variations in the conclusions. The Emergence stories communicate the

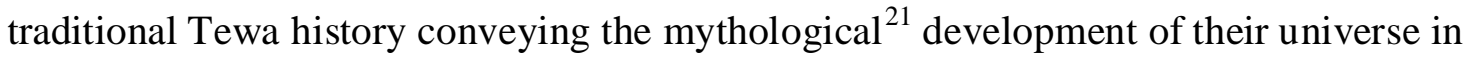
addition to, their emergence from the underworld to the earth. Importantly, the emergence stories convey the origin of traditional Puebloan social structures informing societal practices and structures organizing everyday life and the afterlife.

\footnotetext{
${ }^{17}$ There are three primary linguistic stocks that differentiate the Puebloan languages: Keres, Tanoan and Zuni. The term Tewa characterizes one of the substocks from the primary Tanoan linguistic stock (Tewa, Tiwa, and Towa) associated with the pueblos situated in New Mexico.

${ }^{18}$ Clarification is made in the following chapter to explain the inclusion of the Tewa Pueblos in respect to the other Pueblo cultures located in New Mexico as differentiated according to linguistic stock.

${ }^{19}$ Elsie Clews Parsons (1875-1941) is a noted anthropologist of the Puebloan peoples of the American Southwest. Her most noteworthy work is the encyclopedic Pueblo Indian Religion that contains hundreds of traditional Puebloan tales.

${ }^{20}$ Simon J. Ortiz is a renowned Native American writer, poet, and activist. He is a full blood member of the Acoma Pueblo.

${ }^{21}$ Mythological is utilized in this context to describe those processes pertaining to the origin of supernatural god(s) and their function in the organization of the Tewa Puebloan universe.
} 
The Migration story was included within this analysis because it clarifies the specific organization of Tewan pueblos, in relation to those within close vicinity. In addition, the Migration story accurately reveals to the reader the spatial proximities or boundaries organizing Tewan pueblos. It is important to note that the Emergence and Migration stories elucidate the importance of dialectical tension as expressed through environmental dualities and the concept of she $t^{\prime} a^{22}$. Understanding the ideological foundation for the role that dualities play within Tewan society is paramount to understanding the organization, development, and operation of Puebloan social structures.

Similar to the Lakota-Oglala, these stories are considered influential within because they represent sources providing the fundamental basis organizing the Tewa lifeworld and lifeways. The following section analyzes these stories and reveals the connections between the experienced (absolute/earth), conceptual (cosmologic), lived (holistic knowledge), and perceived (dualities) communicated as ideology through Tewan cosmologies. These stories project and clarify the intimate relationships and connections the Tewa share with the environment, in addition to providing the ideological foundation organizing their understanding of the spatio-temporal construction of place and identity formation.

As with the cosmologies previously analyzed, the accuracy and integrity of the three stories included in the textual analysis was verified through the method of

\footnotetext{
${ }^{22}$ The term she t'a is used to express the Tewan transition from the mythical time before emergence to the present historical time (Ortiz, A.; 1969, pg.16). Having a firm grasp of the concept of she t'a becomes important as the duality between the sacred-profane is integral to comprehending the origin for the hierarchy of Tewan social structures.
} 
triangulation. Crosschecking for the intertextuality of integral themes and plot sequences determined each story utilized in the analysis accurate and reliable.

\section{Triangulating Space, Place, and Identity}

Textual analysis revealed several themes are intertextually communicated between stories. Similar to the analysis conducted for the Oglala-Lakoa cosmologies, Nvivo aided in identifying themes by abstracting the data, stories, based upon the redundancy of specific words. This redundancy established specific codes for recognizing concepts communicating or specifying specific references to space, place, and identity; she t' ${ }^{23}$, earth, god, time, water ${ }^{24}$, land, and corn were intertextually identified. The remainder of this section discusses the intertextuality of these concepts between stories and how they inform the argument that place, identity, and dispossession are dialectically interrelated.

The Tewa relationship to experienced/absolute space is firmly established in the Emergence and Migration stories. The below passages demonstrate the Tewa relationship to specific places as described through topographic detail.

Passage from The Emergence:

'Those who were to follow the Summer chief would proceed south along the mountains on the west side of the Rio Grade. The Winter chief and his group would proceed along the mountains on the east side of the river' (Ortiz, A.,1969; pg. 15).

Passage from The Migration:

\footnotetext{
${ }^{23}$ The term she t'a is not verbatim found in those cosmologies included in the analysis. The term is used to describe the many dualities communicated in these cosmologies that clarify the connections shared between the mythical and present, and how these dualities inform Tewan social organization.

${ }^{24}$ Water is an important component in Tewan cosmologies. The term water is used in this analysis to capture all instances when water is used literally, describing a topographic feature (lake or river), or place of occupation prior to emergence.
} 
'Oweweham'baiyo lived at Uwipinge all the people (t'aekitwa.) The people had moved along Pingkwaiye (Sangre de Cristo Mountains) and along Tsampiripingkwaiye, the west side range (Jemez Mountains). The eastern mountains belonged to the Winter People and the western Mountains belonged to the Summer People Mo. Those on the Eastern mountains, The Winter People, were eating deer, elk (the meat of wild animals); and the Summer People were eating jucca fruit (pahhe), mantsanitabe (apples), berries (puhpahbe), okumbe, prickly pear (saebe) all different kinds of fruit' (Parsons, 1926; pg.15).

Within these passages spatial boundaries are drawn to indicate the historic and present extent of the Tewan pueblos within the Rio Grande River Valley, the topographic barriers guiding settlement patterns, and, interestingly, perhaps the environmental descriptions for the flora and fauna within this area that mediated differences in subsistence. These passages, as well as numerous others, within the Emergence and Migration stories provide the conceptual origin for the Tewan relationship and attachment to place that constitute an intimate relationship with the environment as a source for developing their lifeways and organization of their lifeworld.

The next step in this analysis goes beyond the experienced or absolute and focuses upon the conceptual relationships within these cosmologies that inform the lived and perceived spaces. The Tewan concept of she t'a is explored within this section as the ideological foundation organizing the shared connections between experienced, conceptualized, lived, and perceived spaces informing the Tewa lifeworld and lifeways.

The concept of she t'a is the most prominent and identifiable theme within this collection of stories. The following passage from the Emergence (Parsons, 1926; pg. 9) clarifies the use for the concept of she t'a in this analysis:

There was a big lake, Ohange pokwinge, Sand Lake. There were lots of people in there. They stayed underneath the water. Then they were talking about it, how to go up from the water, how to get 
ready to group. And so our mother was born, Kutsaebukwi payokaga, corn blue our summer mother. In four days after our mother was born, our ice mother, Kutsaebukwi oyikaga, was born. Where she was born there was a little green grass (tatsauwe behge, ta, grass, tsauwe, green-blue). And so they said, those people, "This is our mother, summer one," said the people. When our corn white mother, ice mother, was born there was just the same round place. So the people said, "This is our mother, winter mother."

Within this passage the concept of she t'a personifies the dualities held in dialectical tension. As described, the mothers of the Tewa are the Summer and Winter corn mothers who bring with them specific characteristics associated with seasonality. The birth of the corn mothers occurred prior to the emergence of the Tewa from the lake, here called Sand Lake $^{25}$. The Tewa occupation in Sipofene ${ }^{26}$ is an important temporal note. This division in time (mythical-present) and place (sacred-profane) also dictates the hierarchical organization of the Tewa universe and social structure. According to the cosmologic division in time and place the Tewa developed levels of being (Figure 8).

\section{Temporal Levels of Being Space}

\begin{tabular}{|c|c|c|}
\hline $\begin{array}{l}6 \mathrm{Dr} \\
\text { Mythological }\end{array}$ & $\begin{array}{l}\text { y Food Who Never Did Become } \\
5 \text { Towa é } \\
4 \text { Dry Food Who Are No Longer }\end{array}$ & Sacred \\
\hline Present Historic & $\begin{array}{l}3 \text { Made People } \\
2 \text { Towa é } \\
1 \text { Dry Food People }\end{array}$ & ine \\
\hline
\end{tabular}

Figure 8: Tewa levels of being. Modeled after: Ortiz, A.1969; pg. 17

These divisions in being, and the dualities in nature, inform the hierarchical structure of pueblo social organization. This sacred cosmological division (duality)

\footnotetext{
${ }^{25}$ Sand Lake is the name given to the mythic place of emergence for the Tewa. Other emergence stories simply refer to this place of emergence as a location further north of their present locale or as Sandy Place Lake.

${ }^{26}$ Sipofene is the place below the place of emergence occupied by the Tewa during mythical time.
} 
influenced the social organization for each Tewan pueblo where the basic familial division was separated according to moiety. For instance, within in each Tewan pueblo the basic division in lineage is based upon the duality of the Summer and Winter moieties. Underlying the organization of the Summer and Winter moieties are hierarchical societies established according to temporal sequencing within the order of cosmologic creation ${ }^{27}$. The hierarchical organization for societies is as follows: Hunt, Ke Medicine Men, Kossa and Kwirana clowns, Scalp, and Kwiyoh Women’s society.

Chapter five discusses the hiearcharical organization and operation of each society within Tewan pueblos. The purpose for introducing these societies at this juncture is to further clarify the emphasis placed upon social divisions as a foundational ideology for the conceptual hierarchy, discussed in cosmologies, founded on dualities placed in dialectical tension.

This discussion has demonstrated the importance of the concept she t'a within the Tewan perception and development of a collective identity. This concept reveals the tightly woven relationships shared between the conceptual, lived and perceived. She t'a' as in the Oglala-Lakota concept of buffalo, are ideological themes communicated through traditional cosmologies revealing the origins for the conceptual foundations organizing native lifeworlds and lifeways and, in turn, native perceptions of place and identity.

She t'a links the experienced, conceptualized, lived, and perceived to aid in the collective understanding of Tewan identity and social organization. Identifying the conceptual origin for the foundation of place and identity construction, as through the concept of she t'a, carry through to the following chapters where the intricacies of

\footnotetext{
${ }^{27}$ Please refer to either emergence story in the Appendix for a detailed account of temporal sequence in which each society was created.
} 
societal organization are explored through a spatio-temporal lens as dispossession becomes a prominent factor in redefining traditional patterns of social organization. For instance, dispossession resulting from the United States reorganization and elimination of traditional Tewa land tenure practices and water rights usage interferes with the she t'a ideological foundation. The following chapter explore in-depth the complexity surrounding the she t'a hierarchical arrangement of Tewan social structure and initiates discourse concerning the issue of land tenure assimilation, as a form of dispossession, and the effect this form of dispossession has upon cultural continuance as the traditional norms and values guiding social organization become distanced from the ideologies communicated through cosmologies.

\section{Cosmologies of the Tlingit}

It was Raven who showed us how to get our food. Raven knew what was good for us, and taught the Tlingit how to live. Raven exists in our legend and our lives. (Lukaax.ádi leader Austin Hammond, In Thornton 2008; pg.59)

\section{Critical Evaluation of Source Material (Accuracy, Authorship, and Positionality)}

Four traditional cosmologies, transcribed to English, informed the textual analysis for the Tlingit of Southeastern Alaksa: The Story of El, The Raven, The Wolf, and Creation of the Moon and Tides. Unlike the previously explored cosmologies that were well documented, relatively easily understood, and appeal to the perspective of a collective audience; this researcher found it difficult to locate Tlingit cosmologic stories communicating the necessary knowledge base in which a holistic understanding of place and identity could be explored. 
Several factors contributed to this issue: (i) the level of abstraction in which the stories are communicated is extremely complex and difficult to decipher without a thorough understanding of the historic socio-political components influencing societal organization; (ii) the concept of time was less discernable ${ }^{28}$; (iii) important themes were simply lost in translation ${ }^{29}$; (iv) and scarcity of Tlingit interpretation. While these factors were limiting it did not impair the ability to conduct a thorough textual analysis and critical examination of those included cosmologies included within this research. Overcoming these hurdles was accomplished by referring to the works of Mansvelt and Berg (2005) and Bradshaw and Strafford (2005). Acknowledging research limitations and informing the reader of these constraints is an important step. In addition, informing the reader of the reflexive positonality taken within the analysis discloses the constraints of interpretation.

These limitations, specific to the Tlingit cosmologies, did not inhibit the ability to conduct a critical analysis of these stories. The reader my refer to the Appendix and notice the many similarities and intertexuality of themes communicated between stories. For example, the story of $\mathrm{El}^{30}$ is a traditional Tlingit cosmology conveying the

\footnotetext{
${ }^{28}$ The concept of time within the cosmologies of the Oglala-Lakota and Tewa, while abstract, was identifiable. For instance, the Tewa differentiate between mythological and present day time based upon their emergence from Sipofene. Within Tlingit cosmologies this separation was not evident, therefore it is difficult to determine the level of abstraction being utilized in reference to interactions occurring between human and mythical beings.

${ }^{29}$ Native American language is rich in content and history. Words within indigenous cultures typically communicate more information beyond simply referring to the physical material. Rather, words become sources to communicate history, ownership, descriptive factors about environmental conditions, subsistence information and etc...

${ }^{30} \mathrm{El}$ is the name for the origin of supernatural being that constructed and organized the Tlingit universe . The name El is a translation; there are strong similarities between the themes communicated in the stories of El and the Raven. This researcher purposes that this early translation of the story of El, due to the many contextual similarities between the characters El and Raven, could represent a the same being, Raven.
} 
mythological ${ }^{31}$ development of their universe however, similar themes are communicated in The Raven ${ }^{32}$, The Wolf ${ }^{33}$, and The Moon and Tide ${ }^{34}$.

Collectively these four stories communicate foundational ideologies informing the basis on which Tlingit society was organized. These stories are influential within Tlingit society because they provide the logic organizing their lifeworld and lifeways. These stories project and clarify the intimate relationships and connections the Tlingit share with nature, in addition to providing the ideological foundation organizing their understanding of the spatio-temporal construction of place and identity formation. The following section dialectally demonstrates that connections can be drawn between cosmologic themes and those ideologies influencing place and identity development.

\section{Triangulating Space, Place, and Identity}

Textual analysis indicated several themes are intertextually communicated between stories revealing the close interrelationship shared between cosmology and the Tlingit ideologies informing place and identity formation. This redundancy established specific codes for identifying concepts communicating or specifying specific references to space, place, and identity. For instance, within each story, reference to the concepts of earth, watercraft ${ }^{35}$, environmental characteristics ${ }^{36}$, water ${ }^{37}$ land $^{38}$, and fish ${ }^{39}$ were

\footnotetext{
${ }^{31}$ Mythological is utilized in this context to describe those processes pertaining to the origin of supernatural god(s) and their function in the organization of the Lakota-Oglala universe.

32 The Raven is predominately referred to in Tlingit cosmologies as the mythical creator of the earth. Within many Tlingit cosmologies the Raven is the dominant protagonist and his character traits often coincide with that of the trickster. Also, the Raven is one of the two moieties forming the basis of Tlingit social organization.

${ }^{33}$ The story of The Wolf is communicates the Wolf's influence in constructing the Tlingit universe. The Wolf is the second moiety comprising the foundation of Tlingit social organization.

${ }^{34}$ The story of the Moon and Tide is included to demonstrate blurriness of the spatio-temporal boundaries and contexts between mythological protagonists and human beings. This story clarifies the intimate relationship shared between the sacred and profane.

${ }^{35}$ Watercraft is mentioned several instances within the stories, the prominent usage is in reference to canoe type vessels.
} 
intertextually identified. The remainder of this section discusses the intertextuality of these concepts between stories and how they inform the argument that place, identity, and dispossession are dialectically interrelated. The theme of anthropomorphism is used within this analysis to organize and link the aforementioned concepts to place and identity.

Anthropomorphism was chosen as the organizing theme within these cosmologies due to two fundamental factors. First, the central protagonists, that function as creators in each story, are related to animal spirits or beings, such as the Raven or Wolf, and are described as having anthropomorphic ${ }^{40}$ qualities. The following passage from the story of the Raven illustrates this observation:

'After a while he (Raven) came to an abandoned camp where lay a piece of jade (s! û) half buried in the ground, on which some design had been pecked. This he dug up. Far out in the bay he saw a large spring salmon jumping about and wanted to get it but did not know how. Then he stuck his stone into the ground and put eagle down upon the head designed thereon. The next time the salmon jumped, he said, "See here, spring salmon jumping out there, do you know what this green stone is saying to you? It is saying, 'You thing with dirty, filthy back, you thing with dirty, filthy gills, come ashore here.'

'...Just then the big spring salmon also started to come ashore, so Raven said, "Just wait, my friend, don't come ashore yet for I have some business to attend to." So the salmon went out again. Afterward Raven took a piece of wild celery (yâ'naet), and, when the salmon did come ashore, he struck it with this and killed it. Because Raven made this jade talk to the salmon, people have

\footnotetext{
${ }^{36}$ Environmental characteristics are those instances in which the protagonists, such as Raven and Wolf, are given credit for creating fire, fog, water, and etc...

${ }^{37}$ Water is an important component in Tlingit cosmologies. The term water is used in this analysis to capture all instances when water is used literally, describing a topographic feature (lake, river, sea, bay, inlet, ocean, and etc...).

${ }^{38}$ There are important distinctions made between the creation of land, as in mainland, and islands. Refer to The Raven in Appendix C for additional clarification.

${ }^{39}$ Fish, especially salmon, and all forms of marine life are typically assigned anthropomorphic qualities when mentioned in these cosmologies.

${ }^{40}$ Anthropomorphism or the quality of assigning human traits, characteristics, qualities to non-human being is common in Native American cosmologies.
} 
since made stone axes, picks, and spears out of it' (Alaska Native Knowledge Network, 2011).

These passages elucidate typical anthropomorphic themes communicated in Tlingit cosmologies where the Raven has the ability to function with human attributes such as: talking, fashioning and inventing tool technologies, or functioning with a heightened level of human cognizance. These attributes and other human qualities are not specific to the Raven, other non-human beings or entities as defined by Western conceptualizations are given similar abilities such as the Wolf, Eagle, or Salmon. Second, interactions between creator entities such as the Raven or Wolf and humans often involve instances of shape shifting where the creator entity becomes human. The following passages from the Raven illustrate an instance of these interactions between creator and human.

'Raven thought over all kinds of plans for getting this light into the world and finally he hit on a good one. The rich man living there had a daughter, and he thought, "I will make myself very small and drop into the water in the form of a small piece of dirt." The girl swallowed this dirt and became pregnant. When her time was completed, they made a hole for her, as was customary, in which she was to bring forth, and lined it with rich furs of all sorts. But the child did not wish to be born on those fine things. Then its grandfather felt sad and said, "What do you think it would be best to put into that hole? Shall we put in moss?" So they put moss inside and the baby was born on it. Its eyes were very bright and moved around rapidly.

'Round bundles of varying shapes and sizes hung about on the walls of the house. When the child became a little larger it crawled around back of the people weeping continually, and as it cried it pointed to the bundles. This lasted many days. Then its grandfather said, "Give my grandchild what he is crying for. Give him that one hanging on the end. That is the bag of stars." So the child played with this, rolling it about on the floor back of the people, until suddenly he let it go up through the smoke hole. It went straight up into the sky and the stars scattered out of it, arranging themselves as you now see them. That was what he went there for.' 
'Some time after this he began crying again, and he cried so much that it was thought he would die. Then his grandfather said, "Untie the next one and give it to him." He played and played with it around behind his mother. After a while he let that go up through the smoke hole also, and there was the big moon.'

'Now just one thing more remained, the box that held the daylight, and he cried for that. His eyes turned around and showed different colors, and the people began thinking that he must be something other than an ordinary baby. But it always happens that a grandfather loves his grandchild just as he does his own daughter, so the grandfather said, "Untie the last thing and give it to him." His grandfather felt very sad when he gave this to him. When the child had this in his hands, he uttered the raven cry, "Gâ," and flew out with it through the smoke hole. Then the person from whom he had stolen it said, "That old manuring raven has gotten all of my things' (Alaskan Native Knowledge Network, 2006).

These instances where the creator entity physically alters appearances to become human, engender the ideology of the intimate connections shared between the sacred (mythical/creator) and the profane (human/material).

The close interrelationships shared between mythical protagonists and human(s) facilitate the interpretation that Tlingit ideology concerning identity and place is directly related to their cosmologic interactions. For instance, as with the Tewa, the foundation for the basic division in social organization is the moiety. Two superlinages, Raven and Wolf ${ }^{41}$, organize this system. The origin of these moieties are tied to the mythical protagonists in Tlingit cosmologies.

While this discussion has been more limited due to the constraining factors listed in the previous section. The concept of anthropomorphism was utilized as the primary theme in which to organize the analysis due the perspective in which knowledge is communicated through the cosmologic protagonists of the Raven, Wolf, or El. Within

\footnotetext{
${ }^{41}$ Depending upon the spatio-temporal context in some instances the Raven moiety is also known as the Crow and the Wolf moiety is known as the Eagle. See Krause, 1956 or Thornton, 2008 for further clarification.
} 
this analysis several preliminary deductions were drawn in regard to Tlingit ideologies concerning place and identity formation as revealed through interactions within experienced, conceptualized, lived, and perceived spaces.

For instance, the Tlingit development of a collective identity is based on a two moiety system (Raven/Wolf) linking the mythological to the human. The Ravan/Wolf Cosmologic protagonists are viewed as the creators of the Tlingit universe, i.e. creators of the moon, tide, fire, lakes, rivers, stars and etc... These cosmological creators also participated in the transference of knowledge related to subsistence, such as tool technology, watercraft, fishing, and etc..., aiding in the construction of a collective identity. Viewed holistically, these ideological themes communicated through traditional cosmologies reveal the origins for the conceptual foundation organizing the Tlingit lifeworld and lifeways and, in turn, perceptions of place and identity.

Critical analysis of these Tlingit cosmologies aid in exploring the effect of dispossession upon Native American perceptions of place and identity as the conceptual foundation for the ideological understanding of Tlingit perceptions of place and identity are situated in relational context as informed through cosmologies. Identifying the conceptual origin for the foundation of place and identity construction, as through the anthropomorphism, informs the following chapters where the intricacies of societal organization are explored through a spatio-temporal lens, as dispossession becomes a prominent factor in redefining traditional patterns of social organization.

The Tlingit, in comparison to the Oglala-Lakota, Tewa, and most other indigenous cultures situated within the spatial extent of the lower forty-eight states, spatio-temporal pattern of dispossession is somewhat unique. Typically, the majority of 
indigenous peoples in the contiguous United States experienced a pattern of dispossession identifiable through the enactment of federal legislation aimed at reducing their traditional subsistence territory, forcible assimilation, and essentially cultural termination. Tlingit society and other indigenous peoples of Alaska were able to avoid the typical pattern of dispossession due to the relative lateness of Alaska's acquisition as a United States territory and later statehood, harshness of the environment, and lack of transportation infrastructure. It was not until the canning industry began to emerge that Tlingits and other indigenous peoples of Alaska experienced the effects of capitalist dispossession to their traditional lifeway as fishing became commercialized and federally regulated.

Chapters eight and nine explore more in-depth the complexity surrounding the forms of dispossession effecting the Tlingit and their response to capitalist socioeconomic and political hegemonies threatening the continuance of traditional lifeways. Additional attention is directed toward the unique spatio-temporal context of Tlingits in relation to their integration into the United States capitalist socio-economic and political system.

\section{Conclusion}

\section{Dialectically Connecting Cosmology, Place, Identity, and Dispossession}

The Lakota was a true naturalist - a lover of Nature. He loved the earth and all things of the earth, and the attachment grew with age. The old people came literally to love the soil and they sat or reclined on the ground with a feeling of being close to a mothering power.

It was good for the skin to touch the earth, and the old people liked to remove their moccasins and walk with bare feet on the sacred earth.

Their tipis were built upon the earth and their altars were made of earth. The birds that flew in the air came to rest upon the earth, 
and it was the final abiding place of all things that lived and grew. The soil was soothing, strengthening, cleansing, and healing.

This is why the old Indian still sits upon the earth instead of propping himself up and away from its life-giving forces. For him, to sit or lie upon the ground is to be able to think more deeply and to feel more keenly; he can see more clearly into the mysteries of life and come closer in kinship to other lives about him.

-Chief Luther Standing Bear

Teton Sioux

(In Nerburn, K., 1999; pgs. 5-6)

What is place and how is a 'sense of place' or identity developed? Researchers such as Basso (1988 and 1996) Feld and Basso (1996), Merrifield (1993), Thornton (2008) and Tuan (1974, 1977, 1984, 1991, 2002, and 2004) have devoted considerable research to understanding how from multiple perspectives and scales (individual, tribal, community, city, nation, global) humans comprehend and acquire knowledge of their surrounding space. This chapter developed a dialectic dialogue to initiate discussion concerning the proper ontological inquiry in which to carry out this research. Textual analysis enabled themes and concepts to emerge from the selected literature. The dialectical component to this critical textual analysis was explored through identifying the intertextuality and interrelationship of concepts as the ideological foundation guiding social organization. The concepts of buffalo, she t'a , and anthropomorphism revealed the ideological foundation and relationships shared between multiple spatialities. In brief, critical textual analysis provided the foundation in to which the spatio-temporal development of place and identity can be viewed.

Critical analysis of these stories disclosed an untapped source containing a plethora of knowledge viewable from multiple spatialities. Ideological richness was discovered when viewing these cosmologies within the spatialities of the experienced, conceptual, lived, and perceived. Identifying the dialectical interrelationships of 
concepts (buffalo, she t'a, and anthropomorphism) disclosed the building blocks for comprehending the foundation for the development of holistic collective identities within these specific Native American societies. The above passage from Chief Luther Standing Bear and the following assist in conveying the ideological message:

These lands are vital not only to our subsistence, but also to our sense of being as Tlingit people. (Gabriel George, In Thornton, 2008; pg. 3)

Both passages highlight the importance of land in developing a sense of being or identity. There is no doubt a strong physical attachment to land but, as discussed, the connection to land has a conceptual foundation found in cosmologies that generate the ideological framework for the formulation of collective identities that, inherently, also inform and solidify the interrelationships shared between perceived and lived spaces. For instance, the example given in chapter three regarding the Tlingit relationship to land was characterized as a collective understanding of the surrounding physical environment with no consideration for the basic foundation for the conceptual origin for Tlingit social organization or underpinnings for their understanding of perceived space was considered. What the critical textual analysis of cosmologies revealed, is that in order to comprehend the Tlingit attachment to place, the typical land subsistence relationship does not provide an adequate explanation. Instead, the conceptual building blocks for place and identity requires an exploration of the ideological underpinnings organizing social practice; accomplished here through a critical examination of cosmologies. Recognizing this connection confirmed the ontological complexity comprising holistic ideologies concerning place. 
Another important challenge of this chapter was to engage Merrifield's (1993:

516) argument concerning the ontological shortcomings of ideologies concerning place within the discipline of geography by dialectally demonstrating the dynamic interrelationships comprising place and identity as examined through the native knowledge source of cosmologies. This argument was put to work within this chapter by engaging those knowledge sources (cosmologies) and investigating their ideological foundation as related to experienced, conceptual, lived, and perceived spaces within Harvey's (2006) matrix of spatialities.

Exploring cosmologies within the schema of Harvey's matrix aided in organizing the ideological foundation of the 'object' of inquiry within this research; understanding Native American evolving perceptions of place and identity. This chapter signified the initial step within this research to go beyond the surface and to dialectally reveal associations as internal relations that seek to establish, from multiple vantage points, connections between the social relations that comprise societal organization, development, and stability.

This objective was achieved by invoking discourses surrounding the complex subject of Native American constructs of place and identity as communicated through Native American knowledge sources such as cosmologies. Cosmologies are approached within this research as constructive sources that provide the 'missing voice' and as sources for identifying foundational differences between Western and Native understandings of space, place, and identity. Specifically, Harvey’s (2006) general matrix of spatialites is employed to aid in identifying these differences and is also 
modified to include Native American spatialities and the concept of sacred space as it operates and relates within the matrices (Figures 3, 4, and 5).

The significance of this critical analysis is further developed in the following case study chapter six. This chapter sets the scene for a more holistic understanding of these Native American societies social organization as revealed in the dialectical examination of specific emergence and creation cosmologies which, conveyed the complex interrelationships comprising Native ideologies when examined through Harvey’s (2006) matrix of spatialities. For instance, within this research the term 'tribe' and 'nation' have been loosely used in reference to those Native American societies included within this research. The Western connotation for the use of 'tribe' and 'nation' implies a basic unit of collective identity based on general characteristics or traits culminated along Western perceptions. The following chapter initiates discourse questioning these basic 'grouping' terms and utilizes the information obtained within the critical textual analysis of these cosmologies to explore a more appropriate means to describe Native Americans who share a similar collective identity. 


\section{Chapter 6: Oglala-Lakota}

'His people (Sitting Bull) had never understood the Wasichu (peoples of Western European descent) word for their lands where they lived. In Lakota, there is no word for wilderness.' (Starita, 2002;11)

\section{Introduction}

Chapters six, seven, and eight contain analyses of historic and contemporary ethnographic research pertaining to the Native American societies included in this research. The purpose for including these descriptions are to illustrate to the reader how capitalism has affected traditional conceptualizations of Native American lifeworlds and lifeways, and to highlight the variances within the socio-historic responses of these societies. For instance, the traditional versus modernist debate circulating throughout inter- and intra-tribal discourses demonstrates that contemporary Native American perceptions of lifeworld and lifeway are malleable concepts subject to conflicting opinions. It is an objective of this research to determine what underlying capitalist factors contribute to these varying responses and perceptions concerning the development of contemporary ideologies informing the development of lifeworld and lifeway within Native American societies. The analyses and descriptions organized in chapters six, seven, and eight delineate pertinent discourses dictating the role capitalism has played in sponsoring the uneven development of the socio-political and economic systems within these societies, as reflected in the shaping of their lifeworlds and lifeways.

The following chapter, explicitly and implicitly, discusses the ideological connections informing the Oglala-Lakota perception of place and identity as informed through the spatio-temporal lenses of traditional social organization (place as a humanist construct), geographic location (place as scaled space), and spatial organization (place as 
spaces of flows and networks of spatial practice). The Oglala-Lakota cosmologies are discussed throughout this chapter in order to provide a conceptual roadmap dialectically linking the socio-spatial (Soja's third space) to Harvey's spatio-temporal vantage point of human experience within expereinced, conceptualized, live, and perceived space.

\section{Traditional Social Organization}

The Oglala-Lakota lifeworld developed in the environment and ecosystems available in the Northern Great Plains, extending in modern day terms within the borders of North Dakota, South Dakota, Montana, Wyoming, Missouri, Nebraska and Kansas. Revealed in the textual analysis of the Oglala-Lakota emergence and creation cosmologies, and discussed by anthropologists Basso (1996) Feld and Basso (1996) and Gulliford (2000), ethnologists Nerburn (1994) and Powers (1986), and Lakotas Vine Deloria Jr. (1988 and 1999), Ella Deloria (1988 and 1993) and James Starita (2002), the traditional Oglala-Lakota lifeworld centered on the buffalo 'tatanka'. It was through the tatanka that the Oglala-Lakota developed the social, economic, and political structures comprising their society. The significance of the tatanka within the Oglala-Lakota society is evidenced in the spiritual ${ }^{42}$, physical/utilitarian ${ }^{43}$, and social ${ }^{44}$ connections embedded within the society's perceived sacred space that ensures survival and development. These connections are more thoroughly explored within the section concerning the role of the Sun Dance within Oglala-Lakota society.

\footnotetext{
${ }^{42}$ For instance, refer to the Lakota emergence myth in which the medicine man turns himself into a buffalo to feed the society.

${ }^{43}$ The utilitarian function of the buffalo within Lakota society was numerous for instance: meat for sustenance, tools were made from its bones, rattles from its hooves, tipis and clothing from its hide, and etc...

${ }^{44}$ Numerous rituals and celebrations center on the buffalo such as: the Sun Dance and the Seven Sacred Rites. Rituals and celebrations such as these provide a nexus in which the Oglala-Lakota can collectively commune to participate, share, and reinforce their sense of place and identity.
} 
More commonly classified within the generalized category of Sioux ${ }^{45}$, the Oglala are actually one of the seven oyates comprising the Teton division of the Lakota assembled according to variances in linguistic and political organization ${ }^{46}$ (Figures 9 12) (Powers, 1986; 22-36). The traditional hierarchical divisions organizing the 'Sioux' are often obscured by the profuse and broad generalization of the term 'tribe.' The Western conceptualization and popularization of 'tribe,' as the vernacular equivalent of expressing a unique social unit capable of describing the entirety of Native American and indigenous peoples socio-political and economic organization, is singular and simplistic. Chapter five discusses the alternative methods in which indigenous societies as the Oglala-Lakota, Tewa, and Tlingit exchange or transference of knowledge occurs through the non-western tradition of oral communication. Cosmologies effectively provide the societal 'glue' or structure binding the experienced, conceptual, and lived spaces of experience to the perceived construction of the routine spatial practices instructing lifeways.

${ }^{45}$ According to Powers (1986; 23) the term Sioux is a misnomer, being a French corruption of the Algonquian nadowesiih 'little adders (snake),' a derogatory term applied by various indigenous societies and the French, during the seventeenth century, to a loose affiliation of Siouan (sic) speakers calling themselves Oceti Šakowin 'Seven Fireplaces.'

${ }^{46}$ Comprising each of these social units seen in Figures (9-12) are separate governing or political bodies in which the criteria for obtaining political power is clearly defined. See Powers (1986; 25-27). 


\begin{tabular}{|c|c|c|}
\hline Socio-Political Units & Equivalent Example & Generality \\
\hline Division & Seven Fireplaces ex.Teton & \multirow{5}{*}{ most general } \\
\hline Tribe or Oyate & Oglala & \\
\hline Band or Tiyošpayes & Payaba & \\
\hline Wicoti & $\begin{array}{l}\text { Smaller camps usually } \\
\text { composed of } \sim 25 \text { individuals }\end{array}$ & \\
\hline $\begin{array}{c}\text { Sodalities 'typically six per } \\
\text { wicoti' }\end{array}$ & $\begin{array}{l}\text { Soldier Society or Akicita, Chief } \\
\text { Society, Warrior Societies, Feast } \\
\text { and Dance Associations, Religious or } \\
\text { Dream Cults, \& Women’s Sodalities }\end{array}$ & \\
\hline
\end{tabular}

Figure 9: The traditional socio-political units of the Sioux as distinguished according to generality. This table deviates from the popular Western usage of the term 'tribe' used to generalize identity often according to location within arbitrarily assigned spatial boundaries, physiological traits, linguistic stock, and etc...

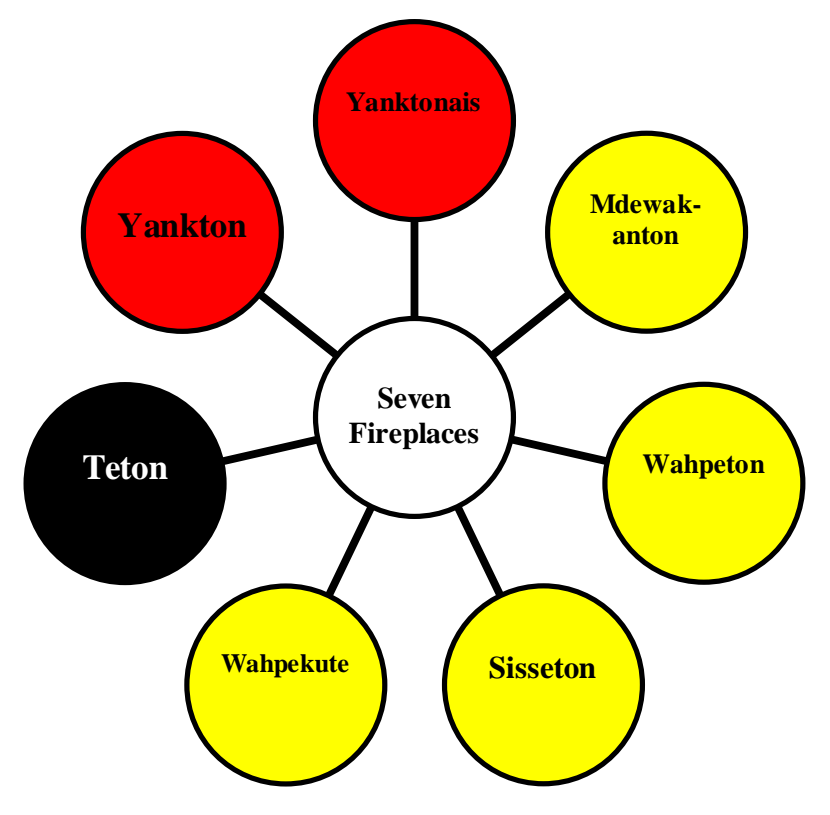

Figure 10: Council of the Seven Fireplaces organized according to linguistic dialect within the Siouan language: yellow: Dakota, red: Nakota, and black: Lakota. Source: Modified from: Powers, 1988; 24. 


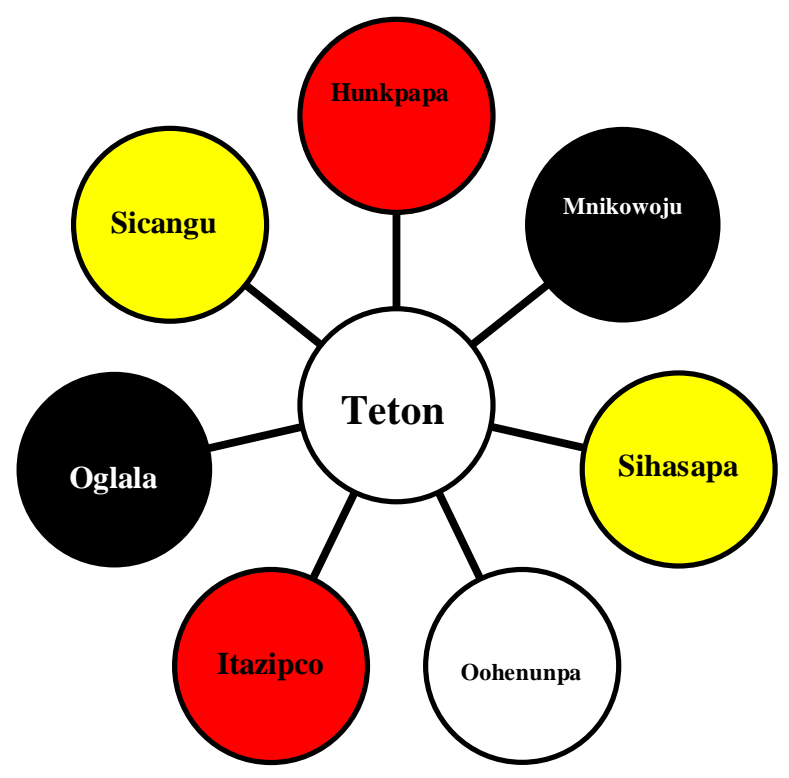

Figure 11: The seven tribes (oyates) of the Teton who share the Lakota dialect. The colors used in the diagram are symbolic of the traditional assignment specified in the creation story for the cardinal directions: black:west; red:north; yellow:east; and white:south.

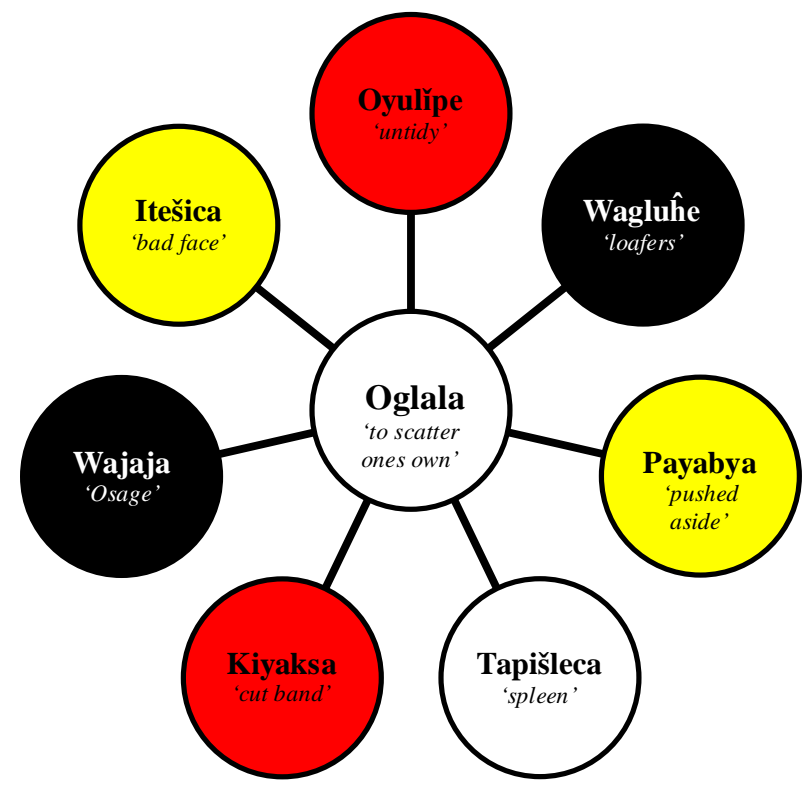

Figure 12: The seven original (tiyošpayes) bands of the Oglala-Lakota.

Tribe, while a valid term when used in the proper context (Figure 9), grossly compartmentalizes the complexity encompassing the socio-economic, political, and 
environmental components informing and constructing Native American identity (Boulware, 2006). Utilized within the popular Western vernacular, 'tribe' marginalizes the dialectical connections communicating the socio-political and economic linkages expressed through the practice of lifeways. The following discussion clarifies the traditional socio-political units comprising the more popularized generalization of the Sioux 'tribe.' Specific attention is directed toward the Oglala-Lakota and their relationship within this greater socio-political organization, in addition to the spatiohistoric derivation and development of this unit in response to exterior pressures from domestic and foreign neighbors.

\section{Traditional Social Organization -The Seven Fireplaces}

Prior to the start of the eighteenth century the organized political units of the Council of the Seven Fireplaces had yet to come into being (Figures 9 - 12) (Powers, 1986; 25-31). The discussion initiated in chapter five surrounding the concept of cosmology as cultivated history, specifically pages 53-60, explains that creation and emergence stories like any other part of Native American culture are not stagnant and instead are often reorganized or modified to account for alterations stemming from events initiating environmental or social stresses.

The discussion details the prominent theory communicated by White (1978) that the Siouan (Lakota, Nakota, and Dakota) people during the sixteenth century occupied the woodland forest areas within modern day Minnesota until the turn of the early eighteenth century when, during a three phased spatio-temporal movement, the Siouan peoples were pushed and pulled westward into the north central Great Plains. Powers 
(1986) ascertains this westward movement of the Siouan peoples resulted from pressures from their French armed Cree and Chippewa neighbors ${ }^{47}$.

White (1978) critically questions theories, such as that of Powers (1986) which, attribute the complete relocation of the Siouan people as a result of external pressures from their Ojibwas, Crees, or Assiniboine neighbors or 'white' advancement into the region. Rather, White $(1978 ; 322)$ seeks to dialectically link the relocation or advancement of the Siouan peoples to the Northern Great Plains as a spatio-temporal reaction influenced by three predominate and interrelated socio-economic factors: the acquirement of guns by the Ojibwas, Crees, or Assiniboine from the French; the economic gains procured through fur trapping and trade; and the abundant food supply offered from the buffalo herds.

Combined, these three variables induced a massive shift in a collective peoples ethnopsychology and spurred a reformation in lifeways providing a catalyst to alter preconceived perceptions of place and those socio-political, economic, and environmental components influencing their lifeworld, as evidenced in the cosmologies of Maka’s Story, The Lakota Creation Story, and The Story of the White-Calf Buffalo Woman analyzed in chapter five. These cosmologies produce a narrative of how the Siouan people, specifically the Lakota, reconstructed their perceptions of place and identity in response to socio-economic pressures and changes to their local environment. These alterations, in turn, generated distinct socio-political organizations, such as the Council of the Seven Fireplaces, that were better suited to emerging lifeways constructed for a lifeworld situated in the North Central Great Plains.

\footnotetext{
${ }^{47}$ Throughout the literature review I attempted to locate nareliable primary source to include the OglalaLakota perspective and interpretation of this migration, I was unable to locate such source.
} 


\section{Geographic Placement \& Spatial Organization}

The Siouan relocation during the early part of the eighteenth century reconnoitered their historic territorial extent from that of the Upper Great Lakes woodlands to that of much of the area comprising the North Central Great Plains region (Figure 13) (North Dakota, South Dakota, Montana, Wyoming, Colorado, and Nebraska), resulting in the formation of the Council of the Seven Fireplaces ${ }^{48}$. Researchers and Oglalas such as Ambrose (1996a and 1996b), Brown (1970), Dunbar-Ortiz (1984), Prucha (1984 and 1994), Starita (2002), White (1978) and Wilkinson (2005) describe the spatial extent of the divisions comprising the Council of the Seven Fireplaces within the following topologic boundaries north to the Yellowstone River basin; south to the Platte River basin; east to the Missouri River basin; and west to the Powder River basin (Figure 13).

\footnotetext{
${ }^{48}$ Slight variations exist in the topographic markers detailing the traditional territorial extent of the TetonLakota. The topographic marked used to construct the spatial boundaries illustrated in Figure 13 were, according to this researcher, the most consistently mentioned by ethnologists, anthropologists, and Lakotas.
} 


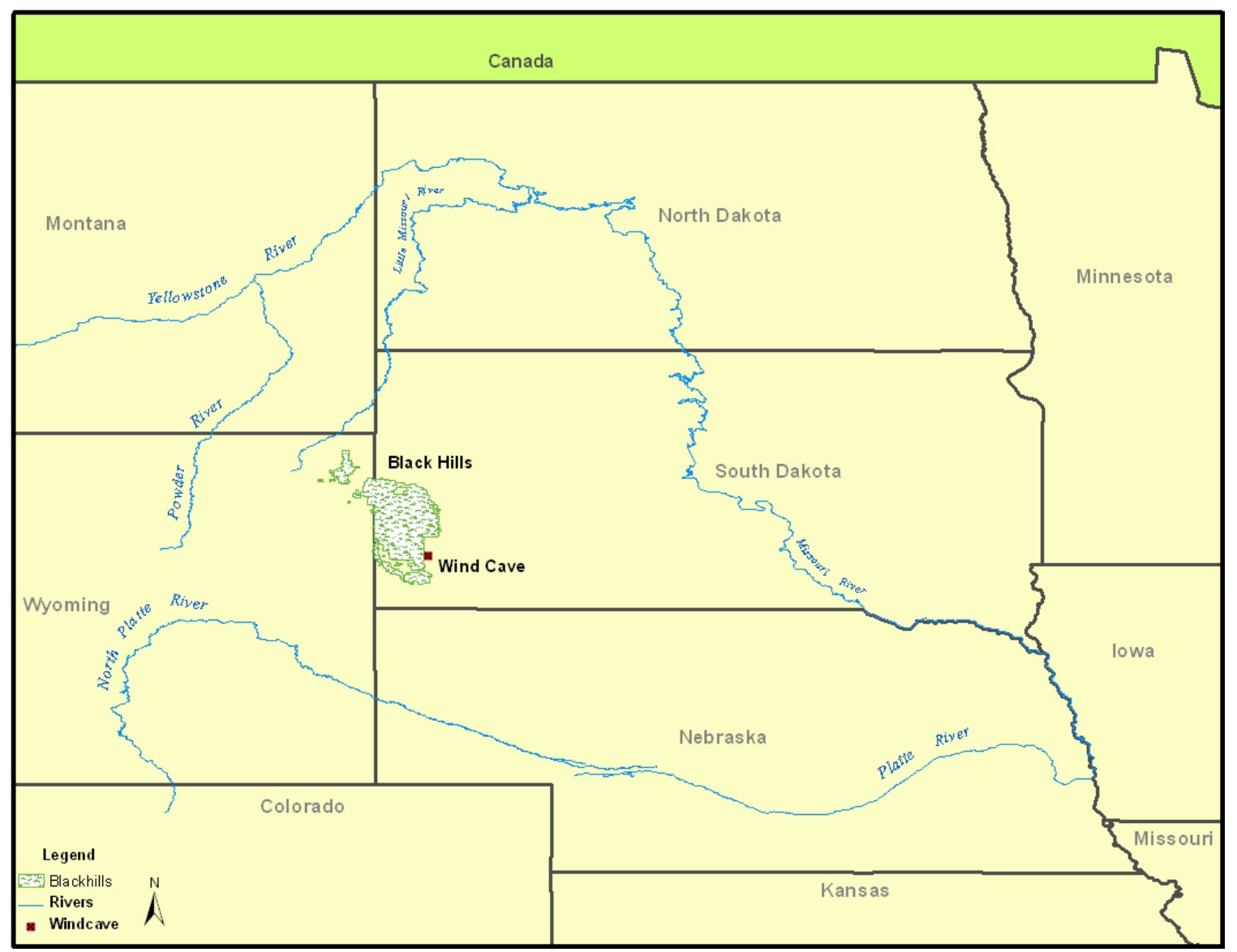

Figure13: Eighteenth century Siouan (Lakota, Nakota, and Dakota) spatial extent within associated river basins in the contemporary boundaries of North Dakota, South Dakota, Montana, Wyoming, Colorado, and Nebraska.

The Great Plains, for the Oglala-Lakota, is the geographic place where their native concepts of lifeworld and lifeways evolved in relation to the surrounding environment. Existence on the Plains was not conducive to supporting dense localized populations for extensive periods of time as compared to those found in other Native American societies. Rather, reinforced through cosmology and the prevalent environmental conditions, the Oglala-Lakota social organization centered upon smaller familial units or bands sustained through hunter/gather activities. Typically, OglalaLakota society consisted of several tiyošpayes that came together during the spring/summer months when food sources were more readily available to support denser 
settlements, and then disband again in the fall/winter months when food availability

became sparse.

Periods of congregation are often spiritually linked to tatanka and involve ceremonial events, such as the Sun Dance ${ }^{49}$ which celebrate a unified lifeworld reinforced by communal lifeways perpetuated through a living oral history of a shared cosmology. Ceremonial events, such as the Sun Dance, fortify the socio-political and economic linkages informed through cosmology, and communicated through the practice of lifeways, culminate in a shared perception of the Oglala-Lakota lifeworld.

\section{Cosmologic Influence Upon Social Organization}

As introduced in chapter five, the cosmologic importance of tatanka or buffalo for the Oglala-Lakota is orally communicated in the society's creation story. The creation story, as discussed by Powers (1986) and Ella Deloira (1993), gives life and meaning to the people, endows them with a shared perception of their universe, and establishes a common unity for the development of a shared lifeworld. Numerous aspects important

\footnotetext{
${ }^{49}$ According to Powers (1986; 72-73) the Sun Dance was held in summer when all the Lakota bands gathered for the annual buffalo hunt. The purpose of the dance was to fulfill a vow taken in a time of duress such as on the battlefield or during an illness. Often a person would pledge that if he survived an ordeal he would give thanks to Wakantanka by performing the Sun dance. There were four forms of the Sun Dance: one might simply dance gazing toward the sun; one might be fastened by skewers of wood inserted through the breast to a tall cottonwood pole called canwakan and dance until the skewers broke through the flesh; one might be suspended off the ground from four posts by thongs attached to skewers inserted through the breast and the flesh over the scapulae; or one might pledge to drag one or several buffalo skulls attached to the flesh of the back by skewers and thongs.

Both sexes participated in the Sun Dance ceremony, slight variations did exist in order to retain female modesty. Preparation for the Sun Dance lasted several weeks, during this time detailed ceremonies entrenched in renewing the spiritual connection between the sacred/cosmologic and profane/existence were carried out.

Starita (2002; 23-24) remembers the Sun Dance as being the most important event in Lakota life. It was a time of feasting and dancing, of renewing friendships and rejoicing in their customs and traditions. For the dancers, it was a time of sacrifice, a time when they offered their bodies in the hope that their pain and suffering would make the people stronger. Their sacrifice complete, their faith restored, the Lakota scattered back across the open plains, returning again during the moon when the turnips bloom, the moon when the cherries ripen. Upon completion of these sacred rites, the annual buffalo hunt commenced.
} 
the organization and function of Oglala-Lakota society are found in the creation cosmology.

The creation story of the Oglala-Lakota provides a source of clarity when attempting to understand the intricacies of place and identity development, in addition to the fundamental building blocks constructing social organization. The Oglala-Lakota literally refer to themselves as the 'Buffalo People' who were 'born of the woman'. For instance, cosmologic figures such as the White Buffalo Calf Woman provided the OglalaLakota their most sacred rites ${ }^{50}$ influencing societal norms and social organization.

The White Buffalo Calf Woman is revered in Oglala Lakota society as not only the conveyer of the Seven Sacred Rites, but also the source of their most important ceremonial object, the Sacred Calf Pipe, and their four great virtues: courage, wisdom, generosity, and fortitude. As explained by Guy Dull Knife Jr., through the perpetuation of the White Buffalo Calf Woman, women and buffalo came to represent life itself within Oglala-Lakota society providing the sacred link between woman and the buffalo in their lifeworld and lifeways (Starita, 2002; 217-244).

It is important to note that while Western historical texts favor and convey the importance and significance of the man as the warriors and leaders of Oglala-Lakota society, this representation is skewed and incomplete. The history of Native American societies, as the Oglala-Lakota, Eastern Tewa Pueblos, and Tlingit told within the perspective of Western European constructs of time and experience has severely

\footnotetext{
${ }^{50}$ The story of the White Buffalo Calf Woman provided the Oglala-Lakota the origin, puropose, and instruction in the performance of the Seven Sacred Rites: wanagi wicagluha 'spirit-keeping ritual,' wiwanyang wacipi 'sun gazing dance,' hanbleceya 'vision quest,' inikagapi 'sweat lodge,' išnati awicalowanpi 'female puberty ceremony, hunka 'the making of relatives,' and tapa wankaiyeya 'the sacred ball game. See Powers (1986) and Starita (2002) for a more detailed explanation of the Seven Sacred Rites.
} 
constrained the ability to dialectically conceptualize the holistic socio-historic

connections shared between the physical, environmental, spiritual, and social connections constituting Native American lifeworlds and lifeways.

Incidentally the Western depiction of Indigenous Peoples has resulted in the marginalization of women, in addition to, children and the elderly within these cultures. For the Oglala-Lakota, especially prior to the reservation era, social roles based upon sex and age were clearly defined within the duties of daily life intertwined throughout a social structure that ensured the continuation of society within the inclement environmental conditions of the Great Plains. In brief, life on the Great Plains insisted upon social cohesion where gender and age roles were intertwined ensuring the collective health/good of the society was maintained.

Once again, the cosmologic significance of the White Buffalo Calf Women story enables connections to be drawn between the conceptual and lived spaces structuring Oglala-Lakota society through the insertion of the seven sacred rites within their lifeworld and lifeways. The seven sacred rites, taught by the White Buffalo Calf Woman, are described by Powers (1986; 48) in the following passage:

She (White Buffalo Calf Woman) then took a sacred stone from her bundle, inscribed with seven circles. These seven circles stood for seven very important rituals that would eventually be revealed to the people. She stayed with them four days, and during this time she taught them the first ritual, wanagi wicagluha ${ }^{51}$ 'spirit-keeping

\footnotetext{
${ }^{51}$ Wanagi wicagluhapi was perpetuated through the ritual of the Ghost-Keeping Ceremony, not to be confused with the Ghost Dance Ceremony and movement that originated in 1889. The Ghost-Keeping Ceremony is a structured means for the Oglala to mourn, learn, and keep the remembrance of a member of the family who has deceased. Spirits, such as through of the deceased, represent an important connection between cosmologic and lived spaces. Spirits of the deceased linger between the these spaces for a year, during this time the direct family maintains the spirit of the deceased as though they are still physically present and alive. Strict adherence to the rites of the ceremony also meant the person or people participating in the ceremony of the deceased must forgo their daily duties such as hunting for the man or cooking for the woman. Due to the longevity of the ceremony and strict adherence to the ceremonial rites,
} 
ritual.' The other six that she would teach then were wiwanyang

wacipi 'sun lodge or sun gazing dance'; hanbleceya ${ }^{52}$ 'vision

quest'; and inikagap ${ }^{53}$ 'sweat lodge' - old ceremonies to which the

ceremony of the pipe would be added; išnati awicalowanpi ${ }^{54}$

'female puberty ceremony'; hunka ${ }^{55}$ 'the making of relatives'; and tapa wankaiyeya ${ }^{56}$ 'the sacred ball game.'

Within these rites, the participants are constantly reminded of the spiritual and physical

connections connecting their people to the earth (Maka), buffalo (Tanaka), and more

importantly, each other.

This juncture, at which the Siouan peoples, specifically the Teton division of the

Council of the Seven Fireplaces (Figure 10), transferred and reconstructed their

perceptions of place and identity in order to better suit their new environmental

surroundings, delineates the spatio-temporal identifier informing the discussion

comprising the 'traditional' organization of Oglala-Lakota society within this research.

Organized according to a scale of generality, Figures 9 - 12 illustrate the socio-political

organization constructed to suit life in the northern Great Plains.

\footnotetext{
individuals, within the tiyošpayes or wicoti, typically absorbed the hardships of losing the participation of those in the community's daily lifeways.

Within the present, this ceremony is often celebrated as the Memorial Feast that removes several of the temporal and physical restrictions of the original Ghost-Keeping ceremony.

${ }^{52}$ Originally, males fasted on hill for four days and nights until they received a vision confirming their faith. Presently, women also participate in the vision quest rite.

${ }_{53}$ Participants in the sweat lodge ceremony were originally men only and used as a means to communicate with spirits and revive themselves spiritually and physically. Women now also participate alongside the men in this ceremony while observing certain ceremonial restrictions.

${ }^{54}$ Unlike men, the lifecycle and maturation women were closely observed through ceremonies; one of the most important being the announcement of a girl reaching "womanhood" during the female puberty ceremony. This rite is also known as the Buffalo Ceremony due to the close affiliation of woman and the buffalo spirit within Oglala-Lakota culture. By invoking the spirit of the buffalo women are able to obtain the virtues of chastity, fecundity, industry, and hospitality.

${ }^{55}$ Hunka functions as a means to establish a bond or relationship greater than that of a friend or family member between a child and an unrelated person within the tiyošpayes. This person functioned as a significant influence in a child's life teaching the derivation of ceremonial practices, explaining their role within the greater function of the society, and, in general, instructing the individual within the overall social structure throughout life.

${ }^{56}$ Games within Oglala-Lakota culture function as means for fun, to teach correct behavior to children, and to convey spiritual and physical connections. Within the sacred ball game the ball represented Wakantanka in the act of moving away from the people, then coming back to join them.
} 
Scale in this context refers to the social break down or organization of society as viewed from the most generalized form of social identification to that of the most specific. For example, a person of Siouan decent may identify themselves to a person outside the ‘tribe’ as Sioux or perhaps along linguistic variance as Lakota, Nakota, or Dakota. However, more refined terms of identification become necessary when engaging with persons of similar Siouan decent. This is where Figures 9 - 12 become valuable in comprehending the complex historic socio-political, economic, and environmental connections communicated through native discourse.

For instance, a person identifying themselves as Oglala-Lakota is communicating more than membership into a specific oyate of the Teton (Figure 11). Identifying oneself at this social scale conveys a shared or collective sense of place and identity cultivated through a common history. In brief, the more refined scale, in which social identification occurs, establishes spatio-temporal connections communicating a shared understanding of lifeways and perception of lifeworld. Therefore, an individual of the Oglala-Lakota and member of the Itešica tiyošpaye shares a more intimate and, perhaps, privileged knowledge of the socio-political, economic, and environmental intricacies developed or linked through a shared history at this particular social scale (Figure 21).

Individuals of the Itešicatiyo špaye ${ }^{57}$ share a more intimate knowledge of the socio-political and economic connections linking the members of this particular tiyošpaye

\footnotetext{
${ }^{57}$ Individuals of the Itešica tiyošpaye, contemporarily, are better known as members of 'Chief' Red Cloud's band. While denoted and identified as a 'Chief' according to Western authority, Red Cloud was never a true Chief of the Oglala. Rather, according to the Oglala political structure Red Cloud was a member of the Warrior Sodality and a war leader. The misidentification and misappropriation of political power was a common occurrence during treaty negotiations with the federal government. The federal government and those official sent to represent and communication the intensions of Congress and the President did not comprehend the socio-political structure, organization, ethos, or etiquette comprising Native American society. Typically, the federal government and these representing officials arbitrarily assigned a treaty chief to represent the interests of an entire nation of people during important treaty
} 
and their associated wicoti (Figures 9 and 12). Persons of another tiyošpaye, such as the Oyulı̌pe ${ }^{58}$ tiyošpaye, are not privilege to specific socio-political and economic knowledge

revealed through the organization, practice, and oversight of other tiyošpayes social

structures. The following section clarifies this issue of social scale in relation to access of 'privileged' knowledge communicated at particular levels of Oglala-Lakota organization.

\title{
The Oglala Band
}

As revealed in the previous section, the complexity associated with Native

\begin{abstract}
American scalar social organization and development is often reduced to the common
\end{abstract}
misuse of the term 'tribe.' Popularly used within Western culture, 'tribe’ is utilized as a

negotiations concerning issues pertaining to land cessions, trade, war, and etc... Contemporary issues concerning land allocations are traceable to the induction of Treaty Chiefs, such as Red Cloud, as official representatives or voices of entire Native American populations. The Oglala, one of many Native American societies, adamantly refuse to acknowledge the stipulations outlined in historic treaties where they view inadequate representation, perpetuated through the gross misappropriation of power from a foreign power, did not adhere to traditional socio-political ethos concerning equal representation and, therefore, nullifying any agreement made between the United States and sovereign Native American societies.

Red Cloud was one of many distinguished Oglala warriors adamantly opposed to the United States federal government's intrusion and later dispossession of their lands. Red Cloud was an active participant in and advocate of the Plains Indian Wars until the creation of the Red Cloud Agency. The Red Cloud Agency was created after Red Cloud signed the Fort Laramie Treaty of 1868. Upon signing this treaty, the United States federal government promised to secure a parcel of territory, provide provisions, deter further reductions in land, and allow traditional hunting practices. In exchange, Chief Red Cloud was to ensure his people would remain within the boundaries of the lands allocated and attempt to live or acculturate themselves into agricultural livelihoods and, of course, discontinue all warring campaigns against the United States. Red Cloud's people, in response to the United States government's inability to successfully fulfill those promises outlined in the Fort Laramie Treaty of 1868, were never able to acculturate themselves into Western culture and often left the agency to rejoin other tiyošpayes in the Plains Indian Wars. See Ambrose (1996a and 1996b), Brown (1970), Dunbar-Ortiz (1984), Prucha (1994), Starita (2002), White (1978) and Wilkinson (2005) for detailed discussion of treaty organization and development during the era of the Plains Indian Wars.

${ }^{58}$ Individuals of the Oyulǐpe tiyošpaye, contemporarily, are better known as members Chief Crazy Horse's band. Similar to Red Cloud, Crazy Horse adamantly opposed the United States federal government's intrusion into their lands and attempts at forced acculturation. Unlike Red Cloud, Crazy Horse never signed a treaty with the United States acquiescing to Western perceptions of 'civilized' society. Crazy Horse remained an active participant in the Plains Indian Wars until his death in September 5, 1877 in the Fort Robinson, Nebraska army prison were he was bayoneted in the back and later died from complications resulting from the injury. Crazy Horse is best known for his defeat of famed Lt. Colonel George Custer and the United States Seventh Calvary at the Battle of the Little Big Horn. See Ambrose (1996a and 1996b), Brown (1970), Dunbar-Ortiz (1984), Prucha (1994), Starita (2002), White (1978) and Wilkinson (2005) for detailed discussion of Crazy Horse's role and impact during the era of the Plains Indian Wars. 
means to categorically lump together peoples from similar geographic regions, sharing similar patterns of subsistence, common linguistic origins, or physiological similarities. Hopefully, the previous section proved or at the very least expanded the reader's conceptual foundation regarding the intricate social-political and economic dynamics informing Native American societies, specifically that of The Council of the Seven Fireplaces.

The Council of the Seven Fireplaces delineates the coarsest level of social identification (Figure 9). Figure 10, illustrates the relationship individuals share as members of this social organization at the most basic or fundamental level of identity. Investigation into Oglala-Lakota identity, at this general level, is initiated in order to demonstrate the influence of cosmology in the cultivation of their lifeworld and development of lifeways. Chapter five, cosmology as ideology, reveals the intimate connections communicated through cosmologies as seen in The Emergence story:

Alone on the newly formed Earth, some of the gods become bored, and Ite prevails upon Inktomi to find her people, the Buffalo Nation. In the form of a wolf, Inktomi travels beneath the earth and discovers a village of humans. Inktomi tells them about the wonders of the Earth and convinces one man, Tokahe ("the first"), to accompany him to the surface.

Tokahe does so and upon reaching the surface through a cave (Wind Cave in the Black Hills), marvels at the green grass and blue sky. Inktomi and Ite introduces Tokahe to buffalo meat and soup and shows him tipis, clothing, and hunting utensils. Tokahe returns to the subterranean village and appeals to six other men and their families to travel with him to the Earth's surface.

When they arrive, they discover that Inktomi has deceived them: buffalo are scarce, the weather has turned bad, and they find themselves starving. Unable to return to their home, but armed with a new knowledge about the world, they survive to become the founders of the Seven Fireplaces. 
Detailed in the above passage from The Emergence are the spatio-temporal connections linking shared perceptions of place and identity through a communal history. This passage, along with the other cosmologies examined in chapter five, more cohesively and holistically identify how perceptions of place and identity are conceptually organized, developed, and disseminated within Native American cultures as the Oglala-Lakota. Figures 10 - 12 become especially useful at this juncture in that they situate, link, and contextualize those connections communicated through a shared cosmology in relation to the social 'scale' or level of generality, as understood within dialectics, in which place and identity is examined.

It is beyond the scope of this research to examine each of the seven divisions of The Council of the Seven Fireplaces. Instead, focus is directed to the Oglala oyate of the Teton division of the Council of the Seven Fireplaces. The logic for examining this particular level of generality, the Oglala oyate, is as follows: the oyate, while not the finest scale in which identity is examinable, provides the ability to examine the socioeconomic and political functions of the tiyošpayes as dialectically intertwined entities influencing and linking the whole; the oyate establishes the cosmologic foundation linking place and identity to a shared history communicated through the exercise of lifeways that provide connections to the continuance and development of the Oglala lifeworld; the oyate is, for the purpose of this research, the most manageable in regard to spatio-temporal era (1871 to the present) in which the majority of the federal acts, legislation, and court rulings utilized within this research are aimed.

For instance, examining the impact and affect of particular federal policies as the predominant component sustaining accumulation by dispossession and, in turn, 
influencing Native American lifeworlds and lifeways becomes obscured by minute detail when examined at a finer scale such as the wicoti, and the opposite occurs when approaching the subject from a coarser scale as division, like the Teton. Oyate presents the optimal level of generality in which questions concerning alterations in the Oglala lifeworld and lifeways, in response to federal policies, are examinable because collectively the Oglala oyate has a unique history of coalescing during eras of political turmoil, still observable in the present day, in order to secure, maintain, and ensure the propagation of traditional lifeways in relation to the their understanding of the Oglala Focusing on accumulation by dispossession, a key component of uneven development, and the spatio-historic effects this form of dispossession has had on Native American lifeworlds the proceeding discussion pursues this goal by first examining the traditional political organization of the Oglala oyate in relation to its function in the maintenance, support, and dissemination of those lifeways informing their lifeworld.

\section{The Oyate: Socio-Political and Economic Organization and Function}

One must consider that the Lakota man and woman comprised an economic unit whose basic goal was survival. Each benefited from the other, and both found it extremely difficult (but not impossible) to live singly. (Excerpt from Lily Shangrew, Oglala-Lakota, In Powers,1986; 17.)

The above passage made by the Oglala Lily Shangrew exemplifies a foundational principle communicated and articulated by the Oglalas in their everyday pursuit of a shared perception of place and identity achievable through established lifeways organizing their lifeworld. Discussed in-depth by Powers (1986), in her comprehensive study of Oglala society, specifically viewed from the vantage point of Oglala women, she details the complex interconnections linking lifeways to Oglala cosmologies articulating 
the organization of their lifeworld. Situated within spatio-historic context Powers (1986), and to a lesser extent Starita (2002), reveal that the elaborate Oglala social system developed in unison with their movement and migration westward during the eighteenth century. White (1978), and to a lesser extent Powers (1986), denote a combination of variables specifically encountered during the Siouan migration westward, and reinforced through shared cosmologies, created the politically discrete social units comprising Siouan society.

For instance, migration into the environment of the High Plains required redeveloping and reorganizing the Siouan socio-political and economic systems to reflect alterations in lifeways reinforced through the structure and conceptual understanding of their lifeworld. Discussed by Powers (1986) and White (1978), the movement of the Siouan peoples west from their semi-sedentary villages situated within the modern day boundaries of Minnesota, initiated a spatio-temporal reconstruction of Siouan society. Essentially, this movement initiated the reinvention, restructuring, and reconceptualization of the socio-cultural ethos, norms, and behaviors ${ }^{59}$, contributing to a shared perception of place and identity perpetuated through shared lifeways and understanding of their lifeworld. The greater Siouan peoples developed a socio-political system more conducive to dealing with the surrounding physical (encouraged new forms of subsistence and subsistence patterns, and lifeways based on the migration of buffalo herds), political (such as contacts with new ‘tribes’ or Western European cultures (White, 1978; 322)), and economic environments encountered in the Plains (such as new forms of

\footnotetext{
${ }^{59}$ Refer to chapter five, Cosmology as Ideology, for a more detailed discussion of ethnopsychology.
} 
trade, trade relations, and raiding influenced by the acquisition of large horse populations and introduction of guns) (White, 1978; 322).

The Siouan peoples reaction to their movement West encouraged the development of the political system illustrated in figures 8 and 13. The remainder of this section discusses the socio-economic and socio-political function of the Oyate, as it relates to the collective grouping of tiyošpayes comprising the Oglala. In addition, this discussion provides a conceptual foundation linking perceptions of place and identity to those lifeways, visible/apparent at this scale of social-political interaction, expressed through a shared lifeworld interrelated and cultivated through cosmology.

Concisely, movement onto the Plains sparked socio-political reorganization sustained and supported through a highly developed system of institutions visible at each level of organization (Powers, 1986; 23-34). Characterized as sodalities (societies) by Powers (1986), several existed within Lakota culture to ensure social cohesion was maintained through the establishment of defined cultural ethos, norms, and behaviors.

While the oyate exists as a larger political unit organizing Lakota society, the seven tiospayes comprising the Oglala are viewed as the basic building blocks contributing to the continuance of Oglala lifeways. Tiospaye has been utilized thus far to characterize a unit of socio-political scale within Lakota society. Tiospaye is also a term signifying social cohesion. Described in-depth by Starita (2002; 155-156):

'For as long as any could remember, Lakota society had been rooted in the tiospayes...The tiospayes were/are an extended family, close knit group of husbands and wives, sons and daughters, grandparents, in-laws, cousins, aunts and uncles and close friends. It is how many of the plains tribes had survived for generations. The origins of the tiospayes lay in the tribe's early need for a cohesive hunting unit capable of providing food and protection for all its members. To survive the tribe needed to 
follow wild game across vast areas. To provide enough food for everyone, single families had to mere into larger hunting groups. Eventually, these extended hunting groups, the tiospayes, became the fundamental social unit of Lakota society. For generations, the strength of an individual family had increased with its bond to the larger tiospaye. The tiospaye, by creating a larger pool of hunters and warriors to draw on in emergencies, further enhanced the overall strength of the tribe.'

Within the tiospayes existed hierarchal socio-political sodalities/societies to ensure, maintain, and secure social cohesion (Figure 14). The scalar socio-democratic organization of the men and women sodalities/societies provided a means to effectively communicate and maintain the collective wellbeing of the tiospaye through activities defined by social boundaries ${ }^{60}$. Two societies, the akicita and civil, specifically chief, are the most influential in that their predominate role is to maintain social cohesion through discipline. It is important to note, absolute authoritative power within these societies is nonexistent. Instead, leadership status within these societies are maintained through a system of checks and balances. For instance, six akicita societies exist to ensure one specific society never maintained disciplinary power for consecutive terms. The continuous switch and turn over in disciplinary power and authority helped ensure and minimize conflicts concerning favoritism, absolute authority, or abuse of power.

\begin{tabular}{|c|c|c|c|}
\hline \multirow{3}{*}{ Men's Societies } & $\begin{array}{l}\text { Oglala-Lakota } \\
\text { Societies }\end{array}$ & $\begin{array}{l}\text { Primary Function of } \\
\text { Societies }\end{array}$ & $\begin{array}{l}\text { Specific Examples of } \\
\text { Oglala-Lakota } \\
\text { Societies }\end{array}$ \\
\hline & $\begin{array}{l}\text { Akicita 'Solider } \\
\text { Societies' }\end{array}$ & Maintain law and order & $\begin{array}{l}\text { Acting authority was } \\
\text { rotated yearly amongst } \\
\text { the six Akicita societies }\end{array}$ \\
\hline & Civil Societies & $\begin{array}{l}\text { Ultimate policy making } \\
\text { body }\end{array}$ & $\begin{array}{l}\text { Chief Society, Shirt } \\
\text { Wearers, Wakicunze }\end{array}$ \\
\hline
\end{tabular}

${ }^{60}$ Disciplines such as anthropology and ethnography seek to explain and understand the differences and similarities that exist between Western and Indigenous social organization. 


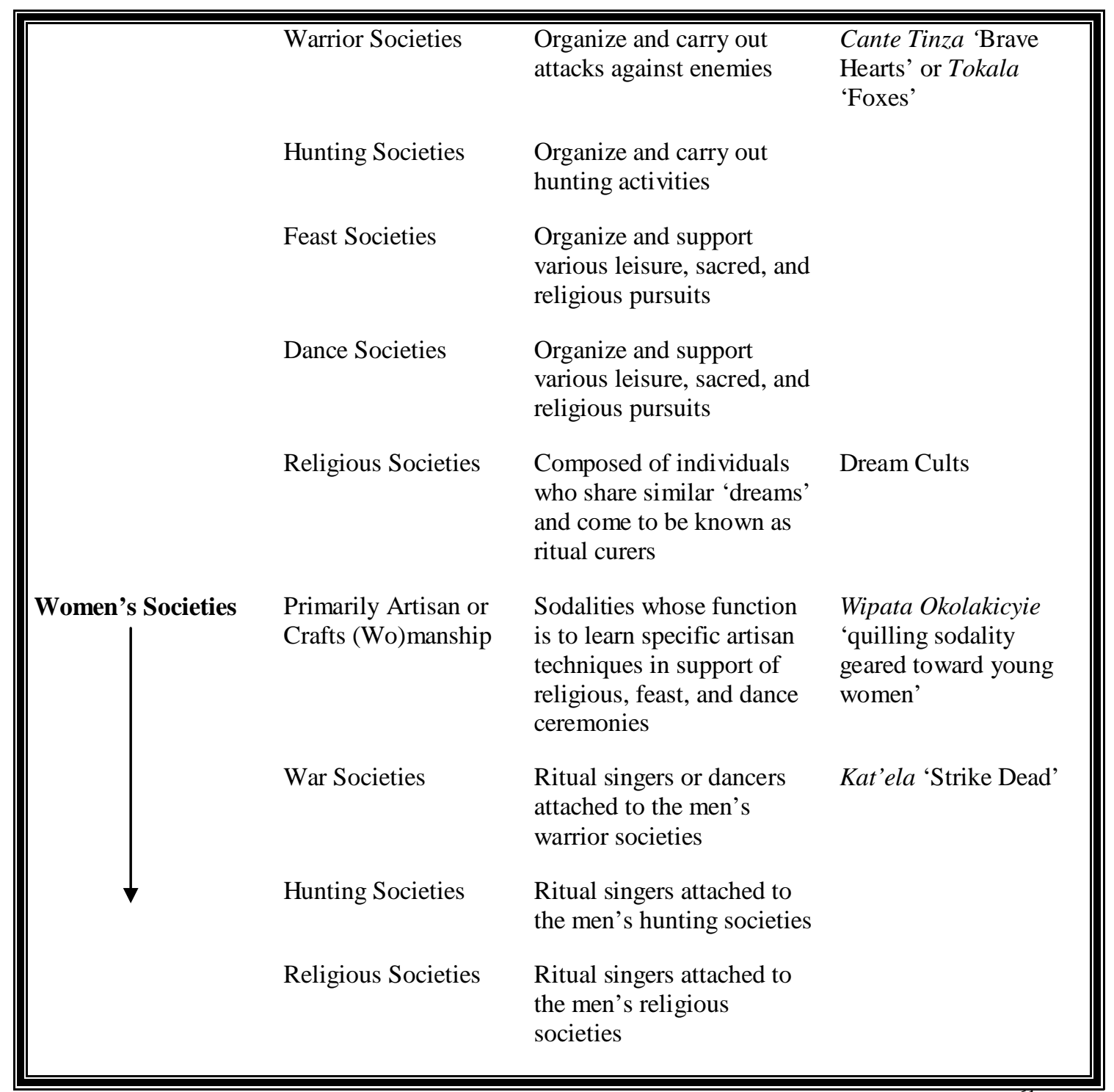

Figure 14: Greater societies comprising the Oglala-Lakota social structure ${ }^{61}$.

\section{Conclusion}

This chapter analyzed the complex scalar organization of the Oglala as

dialectically interrelated socio-economic units that together function in order to ensure, maintain, and propagate societal cohesion through shared lifeways reinforced through a common understanding of the Oglala lifeworld. Examined collectively, these

\footnotetext{
${ }^{61}$ Information included in figure 14 was acquired through the descriptions found in Powers (1986), Starita (2002), and Her Many Horses (2001/2002). Danielle Her Many Horses (2001/2002) University of New Mexico School of Law Tribal Law Journal Volume 2. http://tlj.unm.edu/archives/vol2/index.php
} 
societies/sodalities reveal the intense sense of place cultivated through the bond with their surrounding environment. This statement is in no way advocating an environmental deterministic $^{62}$ model of cultural development for the Oglala-Lakota. Rather, within the framework of dialectics it is a reciprocal one to many relationships cultivated through environment, economic, and political interactions contributing to the development of the social.

This chapter provided a dialectic interpretation of the socio-economic and political connections comprising 'traditional' Oglala-Lakota lifeways and lifeworld prior the termination of formal treaty organization between Native American societies, as the Oglala-Lakota, and United States government. Following the steps in Ollman's Dance of the Dialectic, this section analyzed, historically contextualized, and placed in perspective the Oglala-Lakota culture as viewed within a traditional cosmologic interpretation. Doing so allowed connections to be drawn from the past to understand the socioeconomic and political conditions of the present, discussed in chapter nine. Recall, historicizing is a key component to conducting this analysis as it lends credence to the next steps in the Ollman’s ‘dance', visionize and organize.

Conceptually, this analysis examined the historic socio-political and economic assemblages within the traditional Oglala-Lakota perspective by dialectically linking the cosmologic and lived space (perceived sacred space). The emphasis placed upon these connections become more useful in conceptualizing the preconditions of uneven development. Chapter nine examines linkages in the blueprint of uneven development,

\footnotetext{
${ }^{62}$ Environmental determinism is traditionally known as the doctrine that advocates the 'environment' as the predominate factor controlling human activities and shaping culture. See Johnston, Gregory, Pratt, and Watts (2000; 212-215).
} 
achieved through accumulation by dispossession, by analyzing the impact of specific federal legislation, acts, treaties, and court ruling specifically geared toward: modifying and reducing Oglala-Lakota land holdings: forced acculturation; and establishing a federal precedence of ambiguity that continues to mire the political navigability of Native American society through regulatory contradictions enacted by the judicial and legislative branches.

Federal legislation pertinent to advancing to the next step, visionize, within Ollman’s dance include the federal statue appropriated February 28, 1877 confirming the selling of the Black Hills, hence forth this statue is referred to within this document as the Black Hills Act, the Dawes General Allotment Act of 1877, Lonewolf vs. Hitchcock 1903 supreme court decision; Indian Citizenship Act 1924, the Wheeler Howard Indian Reorganization Act 1934, Public Law 280 circa 1953, Indian Civil Right Act 1968, Indian Self-Determination and Education Assistance Act 1974, Indian Child Welfare Act 1978, and the Indian Gaming Regulatory Act 1988. Analyzing these forms of regulatory legislation aids in identifying specific mediums through which social contradictions become historically embedded, developed, and projected into the present for the OglalaLakota. 


\section{Chapter 7: Eastern Tewa Pueblos}

In the picturesque mountain villages a simple folk culture and subsistence economy stubbornly persisted in the face of the great drive toward Americanization. Nearby, in their unique storied apartment communities, those grand masters of cultural isolation, the Pueblo Indians, exercised their own arts of living as if the white man did not exist at all...(Lamar, Howard In Dunbar-Ortiz, 2007; introduction)

\section{Introduction}

The conceptual framework followed in chapter 6 is adhered to in the ensuing analysis of the Eastern Tewa Pueblos of New Mexico. outline structuring the analysis of this chapter. The amended version of Harvey's (2006) matrix including the concept of spatial/practice (Figure 5) established the conceptual foundation in order to analyze the spatio-temporal connections informing the Eastern Tewa perspective of experience. Similar to chapter 6, this chapter explicitly and implicitly, discusses the ideological connections informing the Eastern Tewa perception of place and identity as informed through the spatio-temporal lenses of traditional social organization (place as a humanist construct), geographic location (place as scaled space), and spatial organization (place as spaces of flows and networks of spatial practice). The Eastern Tewa cosmologies are discussed throughout this chapter in order to provide a conceptual roadmap dialectically linking the socio-spatial (Soja's third space) to Harvey's spatio-temporal vantage point of human experience. Throughout the analysis of this chapter the reader is asked to mentally conceptualize the spatio-historic connections influencing the Tewa's lifeworld and lifeway, especially in reaction to the interjection of early colonial and Western methods accumulation by dispossession. Throughout this analysis, as Harvey's 
conditionalities are utilized as the prominent variables to explain the embedding of uneven development within the societies included within this research, this exercise proves useful in holistically understanding the similarities and variance in reaction expressed by these, at one time socio-spatial disconnected, Native American groups.

\section{Traditional Social Organization}

Pueblo is a generalized term, introduced by the Spanish, and used when referring to those sedentary peoples occupying the multistory adobe or stone communal apartment communities located in the American Southwest. These similarities, however, in architecture do not lend credence to the complex socio-historic, economic, and political differences that characterize each individual Pueblo community.

The extent of Puebloan culture within the territorial bounds of the United States occupies much of the American Southwest (Arizona, New Mexico, Colorado, and Utah) and extends further south into Mexico. New Mexico is home to Puebloan culture where these societies continue to function and evolve within the developing socio-economic and political climate of the acting state and federal governments. Twenty-six ${ }^{63}$ active $^{64}$, Pueblos are located in the United States, nineteen ${ }^{65}$ of which are found in the state of New Mexico (Figure 15).

\footnotetext{
${ }^{63}$ Number of 'active' Pueblos was derived from the Census Characteristics of American Indians by Tribe and Language1990 United States Census of Population (http://www.census.gov/population/socdemo/race/indian/cp-3-7/tab01.pdf).

${ }^{64}$ The term active is used to recognize these Pueblos as functioning communities in comparison to those surviving abandoned architectural complexes. Some of the most noted examples are Cliff Palace, located in Mesa Verde National Park, White House Ruins, located in Canyon de Chelly National Monument, and Chaco Canyon, located in Chaco Culture National Historic Park.

${ }^{65}$ Number of 'active' Pueblos within the state of New Mexico was derived from Tiller (2005).
} 


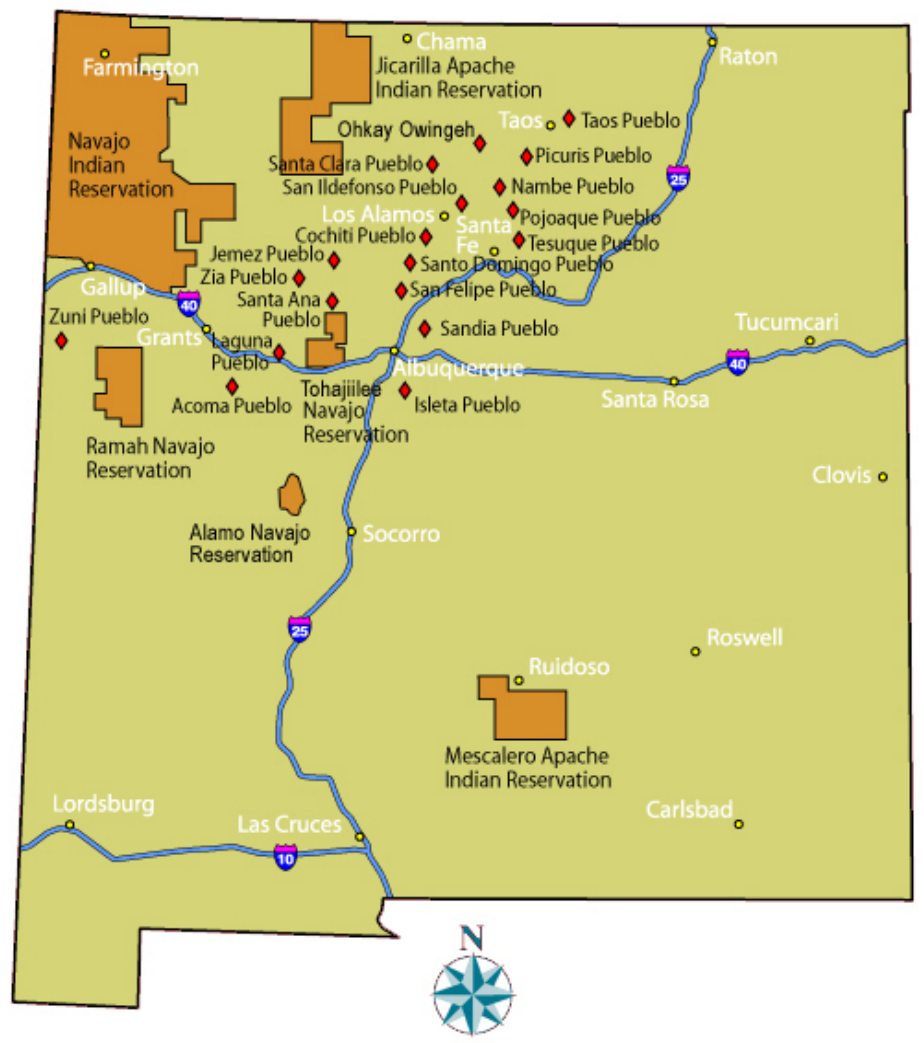

Figure 15: Contemporary Location and Spatial Extent of Pueblos and Reservations within New Mexico. Source:

http://www.newmexico.org/go/loc/nativeamerica/page/nativeamerica-bymap.html

Variance in linguistic stock is the most common variable used to differentiate

between pueblos. Linguistic stock is chosen as the most common identifier that attributes

variance in social organization between Pueblos as historic alterations occurred resulting in deviances, reorganization, splintering, and diffusion from specific origins of ancestry $^{66}$.

It is beyond the scope of this research to examine each of the twenty-six Pueblos therefore, the Eastern Tewa pueblos of New Mexico were chosen as the focus for this

\footnotetext{
${ }^{66}$ According to Dunbar-Ortiz (2007; 18-19) in earlier times, prior to the Spanish invasion of Mexico, the puebloan peoples were apart of a much larger socioeconomic community descendent from the earlier "Mogollon," "Anasazi," and "Hohokam" civilizations extending from the west and southwest of the northern Rio Grande area. The Eastern Tewa Pueblos are thought descendent of the early "Anasazi” civilization.
} 
dissertation. Of the nineteen 'active' Pueblos located in New Mexico, six are classified as Tewan speaking: Nambe, Pojoaque, San Ildenfonso, San Juan, Santa Clara, and Tesuque (Dana and Anderson, 2007 and Tiller, 2005) (Figure 16). In addition to sharing a similar linguistic derivation, the purpose for choosing these specific Pueblos are numerous. As explained in the remainder of this section, the historic socio- economic and political interactions occurring amongst the Eastern Tewa Pueblos and the United States federal government offers valuable insight into the emerging types or forms of dispossession imposed upon a 'conquered' people with differing views concerning the social function and organization of ownership (i.e. economy) and leadership (i.e. politics). 


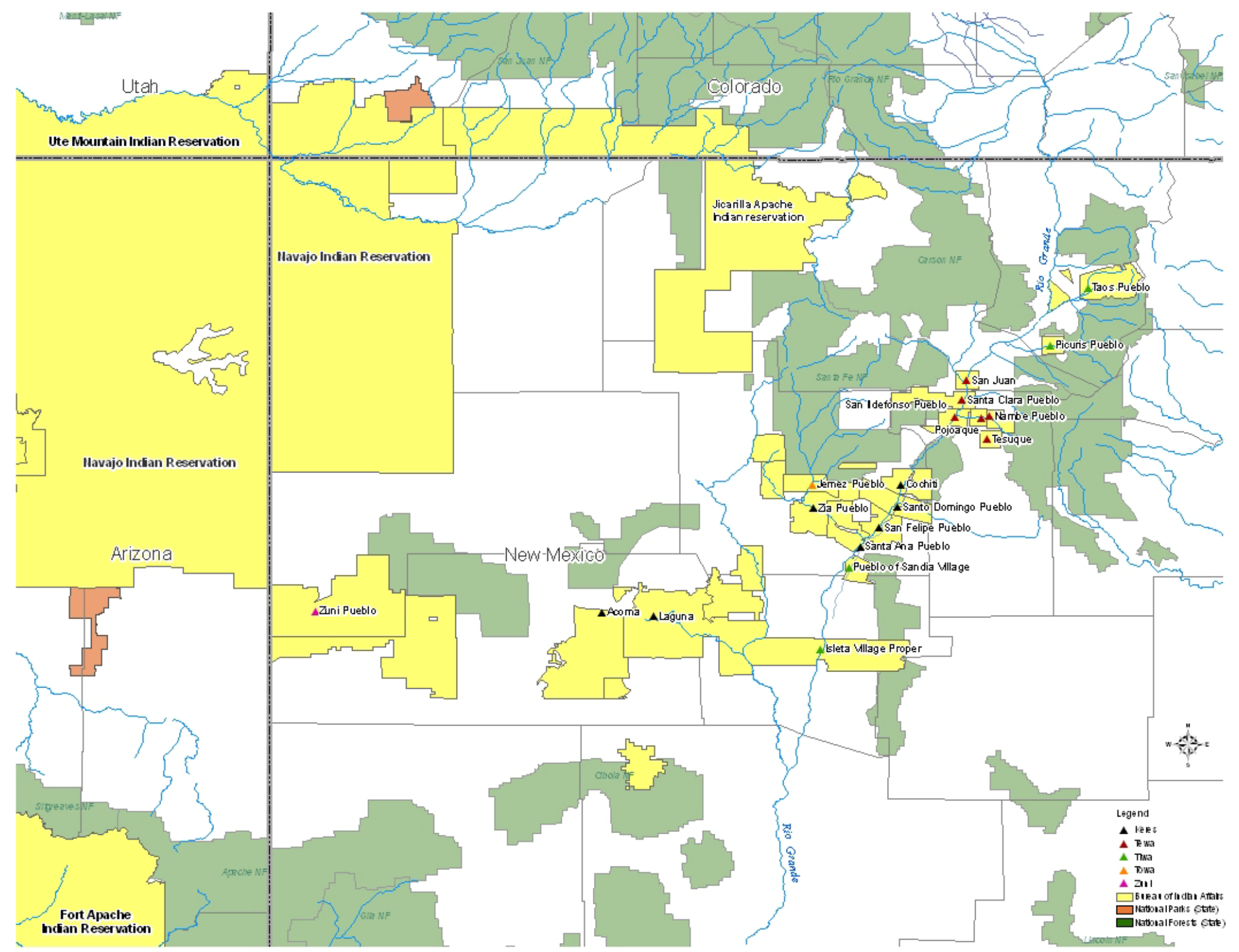

Figure 16: Spatial Extent of Pueblos located in New Mexico according to variation in linguistic stock.

As prescribed by dialectics, looking deeper to draw these connections provides the opportunity to examine capitalism as it emerged as the exploratory, and later dominant, socio-political and economic model shaping the ideology governing the value based system guiding social development and organization. For instance, the inclusion of Eastern Tewa Pueblos within this research is used as a means to extend discourse concerning alternative land tenure systems and economies prior to the introduction of U.S. based capitalist market. Roxanne Dunbar-Ortiz’s (2007) research into pre-colonial 
and colonial land tenure systems in the Pueblo culture of northern New Mexico offers valuable insights into the transformation this culture underwent with the introduction of a capitalist fee base land system.

As conducted with Oglala-Lakota discussed previously, the dialectical investigation continues with the Tewa Pubeloan peoples. The following sections contain an abbreviated recount of traditional Eastern Tewan Pueblo social organization and interconnections are drawn between the foundations or ideologies structuring societal norms and values communicated through the Tewa cosmologies analyzed in chapter five.

Revealed in the above discussion of the Oglala-Lakota, the lifeways of this society was place based and centered on subsistence patterns supporting semi-sedentary cultures. The Pueblo culture of Northern New Mexico (Figure 16) are strikingly different in that these people were predominantly sedentary and resided in, as described by Lamar above, 'storied apartment communities.' Numerous similarities and differences exist between the Oglala-Lakota and Tewa societies. Throughout this research focuses upon the connection or identity markers these societies share, in relation to their conceptualization of place, informing the foundation for the construction of social organization, norms and values that characterize their lifeworld and lifeways.

The following section outlines the traditional lifeworld and lifeways of Tewa Puebloan culture and relies heavily upon the prominent works of Simon Ortiz (1969), Elsie Clews Parsons (1939a and 1939b) and Joe Sando (1992 and 1998) who have extensively documented the intimate interrelationships shared between religion/Tewa spirituality, environment, social organization, and cultural development. Utilizing the 
works of these researchers and natives of these Tewa Pueblos contributes to a holistic understanding of the 'traditional' form and organization of socio-economic and political interrelations are attempted.

\section{Geographic Placement and Spatial Organization}

Figure 17 illustrates the historic spatial extent, placement, and orientation of the New Mexico pueblos in relation to Spanish occupation. In addition, this figure delineates an important north-south topographic division between the Rio Arriba and Rio Abajo. As pointed out by Dunbar-Ortiz (2007; 10-12), this north-south classification of pueblo areas marks a geographic divide in climate that influenced land-use patterns. The six Tewa Pueblos are situated in the area encompassing the Rio Arriba. While both the Rio Abajo and Rio Arriba regions are classified as arid to semi-arid, the Rio Arriba receives more annual precipitation in the form of rain and snowfall than its southern counterpart and, historically, supported more intensive forms of irrigation agriculture ${ }^{67}$, in comparison to lifeways centered predominantly on subsistence hunting and gathering (Dunbar-Ortiz, 2007; 10-12).

\footnotetext{
${ }^{67}$ For a more detailed account of the historic development of Pueblo irrigation agriculture see Vlasich (2005). Specifically, Vlasich (2005; 1-8) differentiates three types of irrigation agriculture existing amongst New Mexico Pueblos : floodwater farming (not pure irrigation); hydraulic irrigation farming; combination of floodwater and canal farming. Vlasich notes that Pueblos within the Rio Grande River Valley typically employed a combination of floodwater and canal farming; spatial variance identifies one method being more dominant than the other according to placement on either the east or west side of the river valley. For instance, Vlasich (2005; 7-8) notes the eastern side of the river valley relied more upon irrigation through a system of canals whereas, the western side relied more upon floodwater farming dictated by the ambiguities in rainfall.
} 


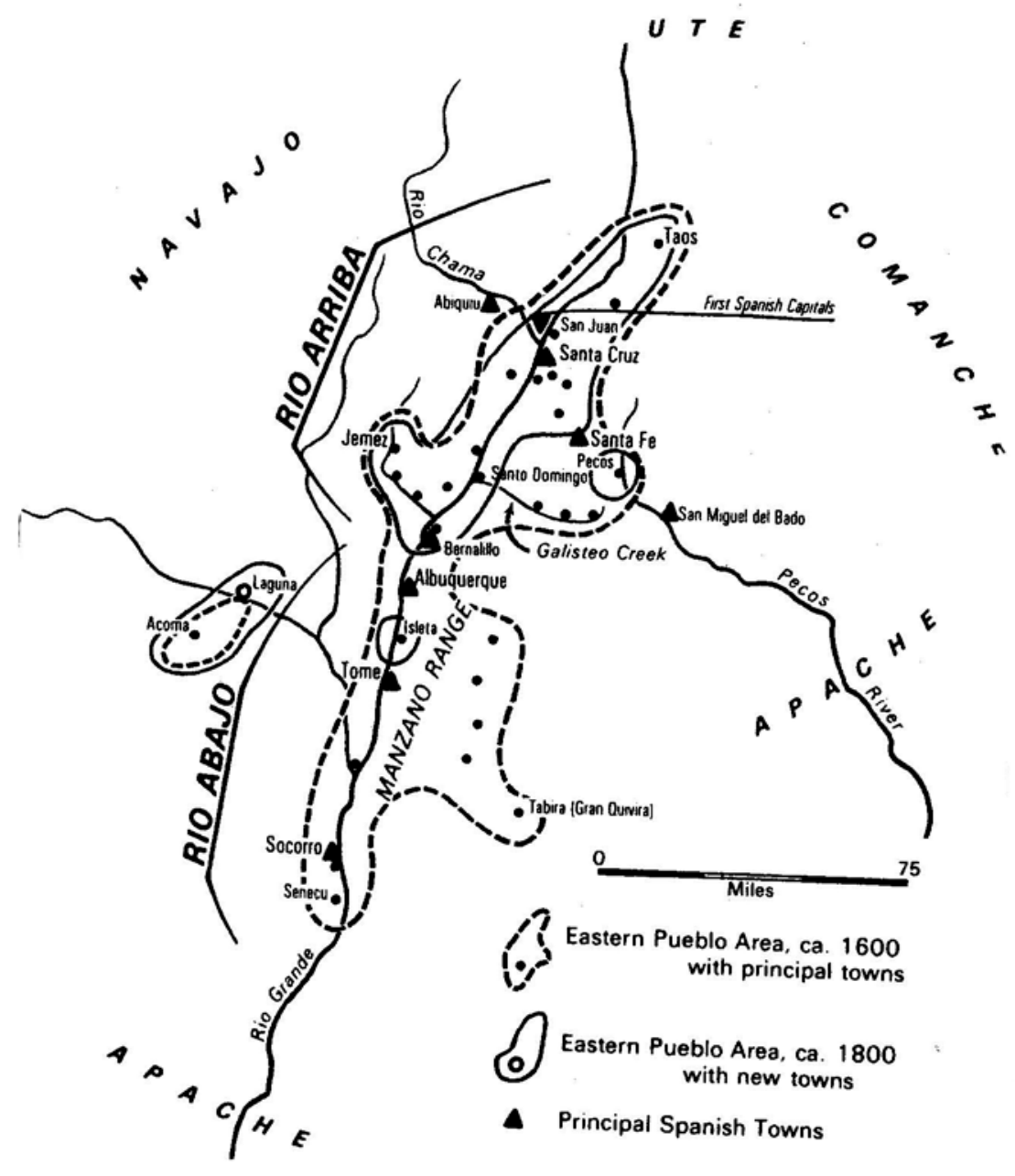

Figure 17: The Pueblos and the Spanish. Source: Dunbar-Ortiz, 2007, Roots of Resistance: A History of Land Tenure in New Mexico, pg. vii.

Connections between traditional forms and patterns of subsistence in relation to spatial location are also mentioned in Tewa cosmologies, specifically within The Emergence and Migration stories ( Chapter 5 and Appendix). Concisely, after emerging from Sipofene the Tewa were divided into two moieties or groups. 
'Those who were to follow the Summer chief would proceed south along the mountains on the west side (Jemez Mountains) of the Rio Grande. The Winter chief and his group would proceed along the mountains on the east side (Sangre de Cristo Mountains) of the river. The Summer People, as the former group came to be called, subsisted by agriculture and by gathering wild plant foods, while the Winter People subsisted by hunting.' (In Ortiz, 1969; 16)

The themes communicated in the above passage are common within Native American cosmologies. Passages such as these demonstrate the importance placed upon shared oral cosmologies in articulating the relational connection between Tewa's physical geographic, environmental, spiritual, and social surroundings. Essentially those components informing the Tewa lifeworld and lifeways communicate a communal 'sense of place' through a shared perception of perceived sacred space.

Reiterating two key points made in chapter five provides a clearer understanding of the interrelationships shared between cosmologies and Native American perceptions of place and identity. First, cosmologies are useful because they can be utilized as sources to discern the intimate physical, environmental, spiritual, and social connections that inform Native American conceptualizations of their lifeworlds and lifeways. Second, sacred space(s) within cosmologies become significant because interrelationships and connections established with the environment and geographic reveals a 'logic for lifestyle ${ }^{68}$, linking the sacred cosmologic to the historic present to become according to Nerburn (1999) a part of the fabric of daily life and experience. Within the Tewa lifeworld this meshing of the sacred and profane within the fabric of daily life is expressed through the concept of she t'a. ${ }^{69}$

\footnotetext{
${ }^{68}$ Peggy Sandy coined the phrase 'logic for lifestyle.' (In Powers, 1986; pgs 4-5)

${ }^{69}$ Refer to chapter five for a more detailed explanation and discussion of the Tewa concept of she t'a.
} 
The physical spatial organization of the Tewa world provides an excellent example to demonstrate the importance of the she t'a. Within Figure 18 Ortiz $(1969 ; 18)$ illustrates the spatial blueprint organizing each Tewa Pueblo. The outer most ring (A,B,C, and D) depicts the spatial boundary bounding the Tewa world. These letters represent the four sacred peaks (Figures 18 and 19) seen by the first four pairs of sibling deities as they were sent out to explore the world in the Tewa Emergence myth ${ }^{70}$ (Ortiz, 1969; 19).

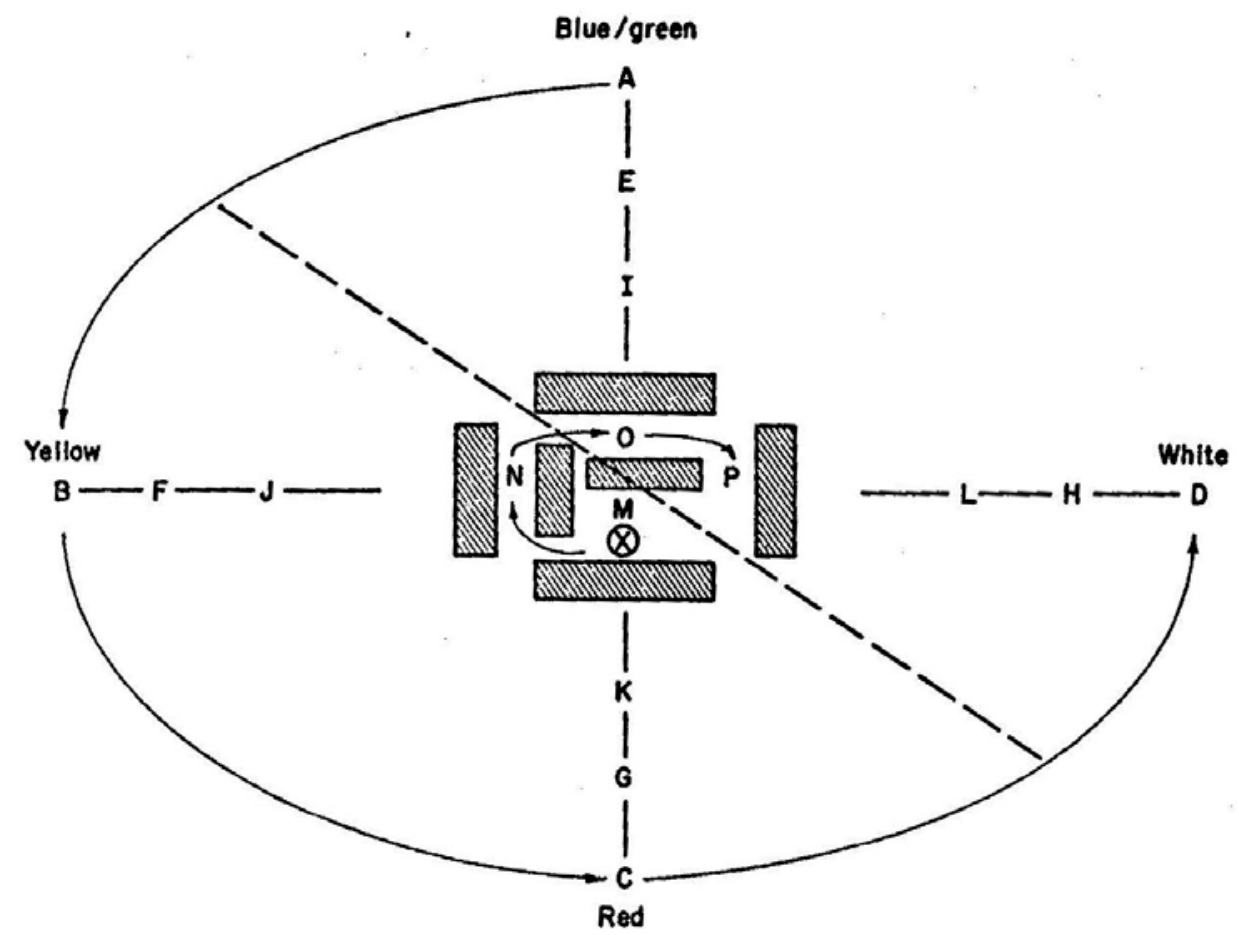

Figure 18: Principal reference points in the Tewa world. Source: Oritiz, 1969; pg. 18.

\footnotetext{
${ }^{70}$ In addition, cardinal directions with specified colors were created to orientate the Tewa (Ortiz, 1969; 18).
} 
also a type of portal for the dead for those individuals occupying the Dry Food People level of being in their journey to the sacred ${ }^{73}$ (Ortiz, 1969; 20 and 50-56).

This connection between the sacred and present further reinforces the conceptual importance of she t'a as an ideology informing Tewa social organization. Within the context of the spatial organization of Tewa Pueblos, and viewed from the relational perspective, she t'a clarifies and illuminates those connections between the experienced (shrines), conceptual (metaphysical connections between shrines and Pueblo spatial organization) experiential (function of these shrines within Tewa ritual) spaces that inform the perceived (shrines as a component sponsoring societal cohesion), and providing insight into the Tewa societal structure communicated through a shared collective identity. The final level M, N, O, and P comprise or represent the dance plazas within the village where all rituals must be performed ${ }^{74}$ (Ortiz, 1969; 20). The Tewa believe this to be the true center (Figures 20 and 21 ) of the Pueblo and the source of all blessings and connections to the sacred ${ }^{75}$ (Ortiz, 1969; 22).

\footnotetext{
${ }^{73}$ The Tsin and sacred peaks also function as a type of spiritual portal for the dead of the Towa é and Made People. Following the Tewa hierarchial arrangement the Towa é spirits return to Tsin and the Made People to the sacred peaks.

${ }^{74}$ This means that during ritual cycles each ritual or dance must be performed in these areas, in addition to, the sacred center of the Pueblo (Figure 19 and 20).

${ }^{75}$ Notice the discrepancy within the statement or the opposition of the sacred to the sacred. According to Ortiz (1969: 19-22) the center of the pueblo represents mother earth's navel or the center for all being. While Tewa ideology functions according to a hierarchal conceptualization and organization of society arranged according to the six levels of being, spatially the outermost being the most sacred and working inward becoming less. The center of the Pueblo acts as the source for all blessings and source for all the sacred in that those blessings given at the sacred peaks, Tsins, and shrines are collected inward and brought too the earth navel where they become projected outward for the cycle to repeat. Although the earth's center might be viewed as an opposition of the to the sacred if strictly viewed from the hierarchal arrangement of Tewa spatial organization. From the perspective of this researcher the sacred function of the center of the Pueblo does not act in opposition to the sacred but, rather, further demonstrates the importance of the concept of she t'a as the conceptual building block structuring the Tewa relationship between the sacred and historic present as cyclical type of processes.
} 
Dry Food People Who Never Did Become

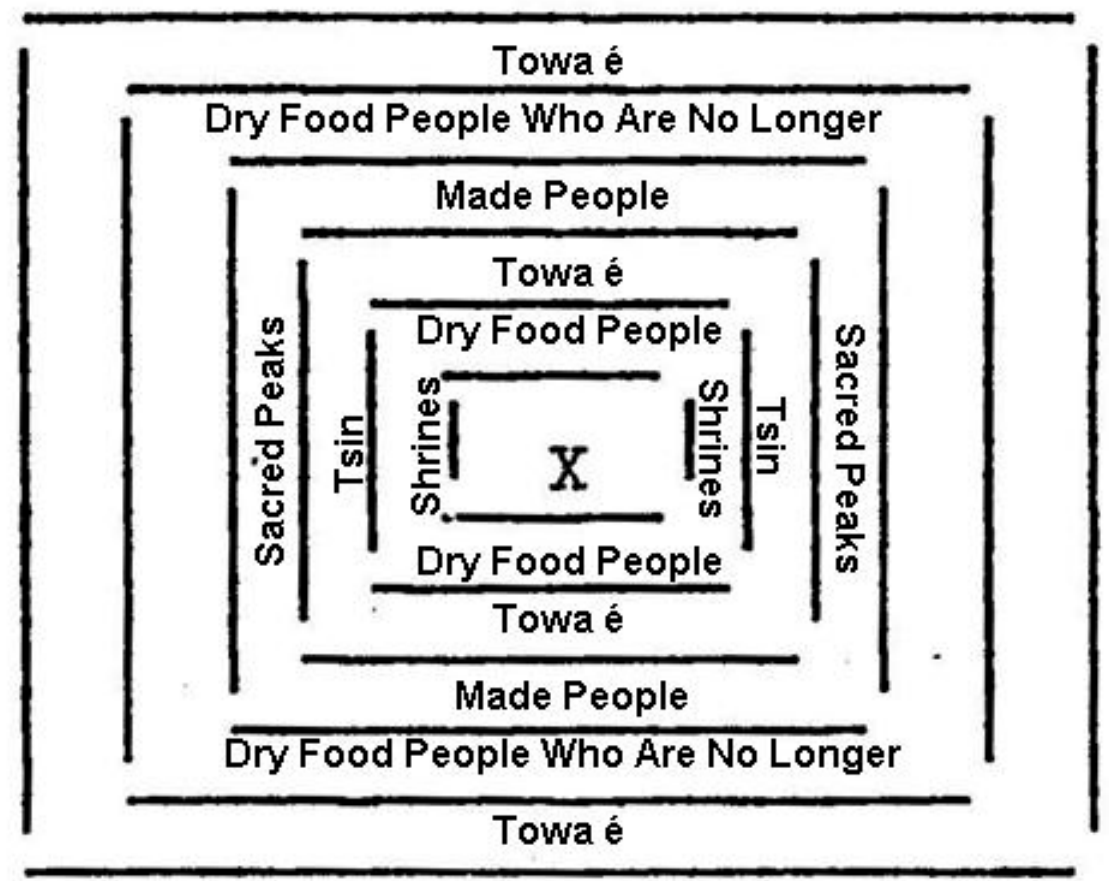

Dry Food People Who Never Did Become

Figure 20: Sacred and profane levels of being within the Tewa world. The $\mathrm{x}$ represents the sacred center of the Pueblo, moving outward the first level is represented by the cardinal shrines surrounding Pueblos, followed by the Tsin, and then the sacred peaks or mountains ${ }^{76}$. The same sequence is follows for the sacred levels of being. Modified from: Ortiz, 1969; pg. 22.

\footnotetext{
${ }^{76}$ As discussed horizontal orientation to the Tewa world is well defined. The vertical orientations less so; below, middle, and above exist. Below represents the sacred (Sipofene), middle is understood as the earth or historic present, and above is less well defined and subject to debate within Tewa literature.
} 


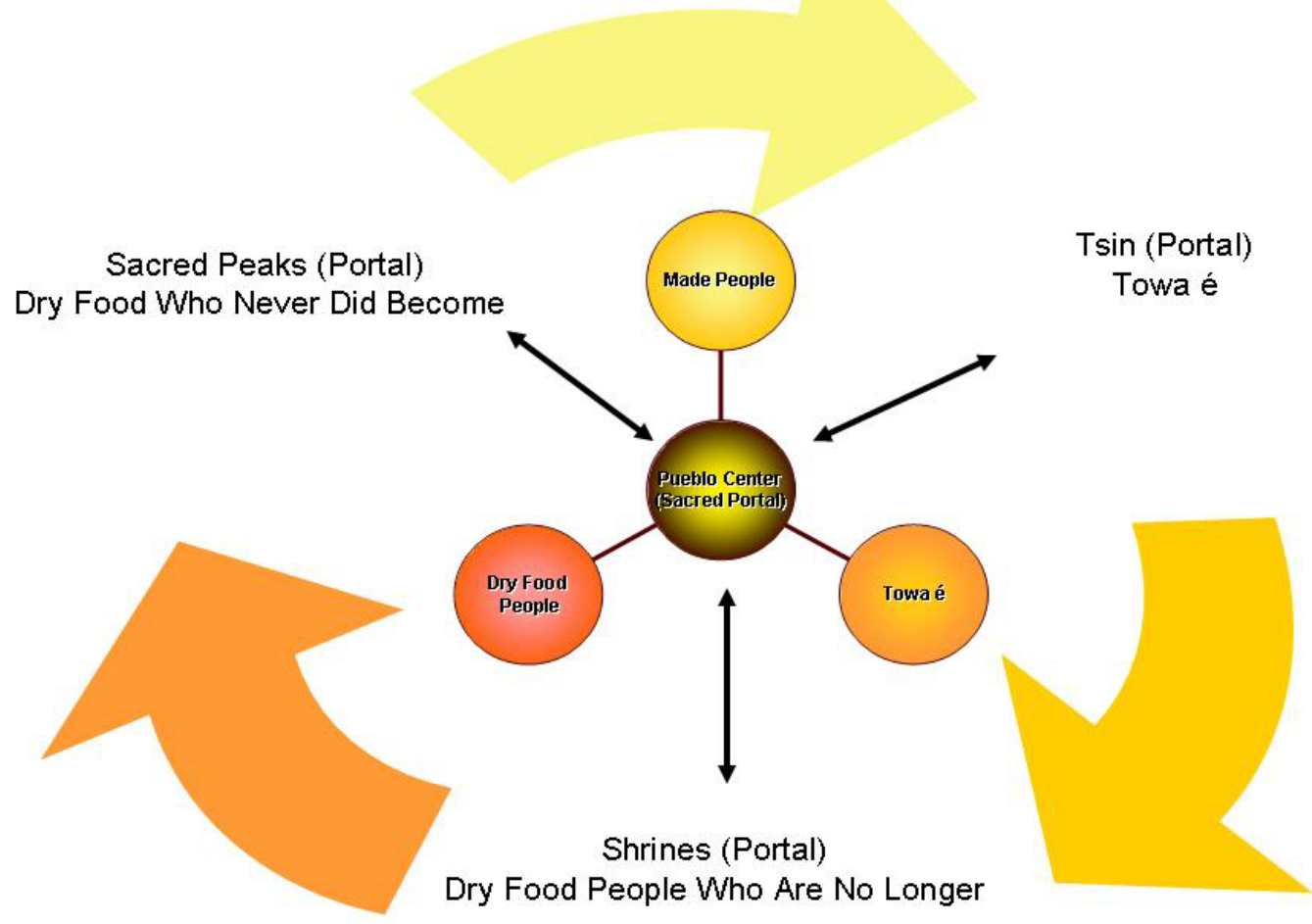

Figure 21: The flow of blessings as communicated through the Tewa cosmological hierarchy and spatial arrangement. Notice the connection between the sacred cosmologic and the historic present in relation to the cycle of communication.

Examined thus far, she t'a provides a conceptual foundation for the development and organization of two components of Tewa society, geographic placement and spatial organization. Utilizing the concept of she t'a is integral to the discussion in that an alternative perspective, deviating from traditional Western ideologies which negate the cosmologic influence of geographic placement and spatial organization of indigenous societies, is dialectically explainable. In addition to providing an alternative perspective, she t'a established a point of reference to investigate Tewa identity.

This section initiated discussion surrounding the spatio-temporal relationships articulating the Tewa dialectical connections between geographic placement and spatial organization. Rather than reciting empirical descriptions of the geographic surroundings 
and spatial arrangement of Tewa Pueblos, this discussion provided the impetus to look deeper into the interrelationships informing the Tewa conceptualization of the perceived world. Utilizing cosmologies, interrelationships between the experienced, conceptualized, lived, and perceived spaces, articulated through the concept of she t'a, revealed dynamic spatio-temporal connections the Tewa share with their environment.

Geographic placement clarified the Tewa's relationship to their environment as multilayered associations with their absolute physical surroundings communicated through a shared cosmology that provides a 'sense of place,' as through common patterns of subsistence, sustainable through a hierarchal social arrangement. Inseparable from geographic placement, the spatial organization of Tewa Pueblos reflects the conceptual and cosmologic order of things providing the foundation for social organization and societal cohesion.

\section{Traditional Social Organization and Cosmologic Influence}

The Tewa, like the Oglala-Lakota, constructed their lifeworld upon a mutual interrelationship connecting cosmology to lifeways. While social organization for the Oglala-Lakota was traditionally constructed along familial relations and corresponding to cosmologic understandings for the construction of their lifeworld that sponsored more semi-sedentary lifeways. The Tewa developed a hierarchical social organization structured by moiety and society affiliation informed through cosmology. Utilizing the informative and classic works of Simon Ortiz (1969) and Elsie Clews Parsons (1939a and 1939b) the following section examines ideologies informing Tewan social organization as communicated through shared cosmologies. 
Focusing upon the concept of she t'a, two dialectically related lines of thought were pursued in the previous section, geographic placement and spatial organization, in relation to Tewa social organization. A more in-depth discussion of she t'a and the dialectical interrelationships communicated through cosmologies informing Tewa social organization occurs in the following section.

Communicated through cosmology, the Tewa established a hierarchical society to ensure cultural continuance within what may be described as an inclement region for the development of a sedentary agricultural based society. Reinforced through cosmology, the Tewa constructed their lifeworld to center lifeways upon subsistence cycles (Figure 22). Corresponding with the subsistence cycle, the Tewa ritual calendar (Figure 23) adheres to the seasonal lifeways that structure social organization, cohesion, and contribute to the continuance of their lifeworld. The interrelationships between lifeways organized by subsistence, seasonality, and ritual are first mentioned in the Tewa cosmologies. 


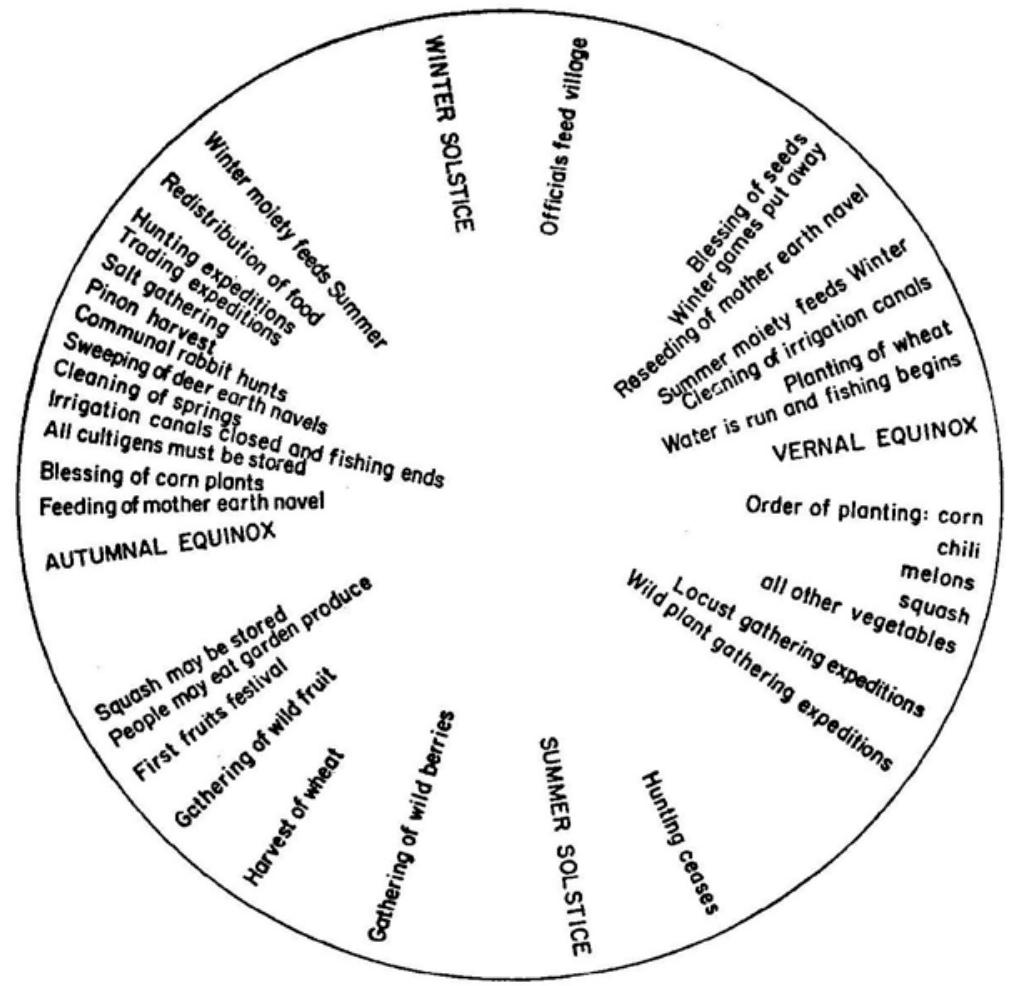

Figure 22: The Tewa subsistence cycle. Source: Oritiz, 1969; pg. 116.

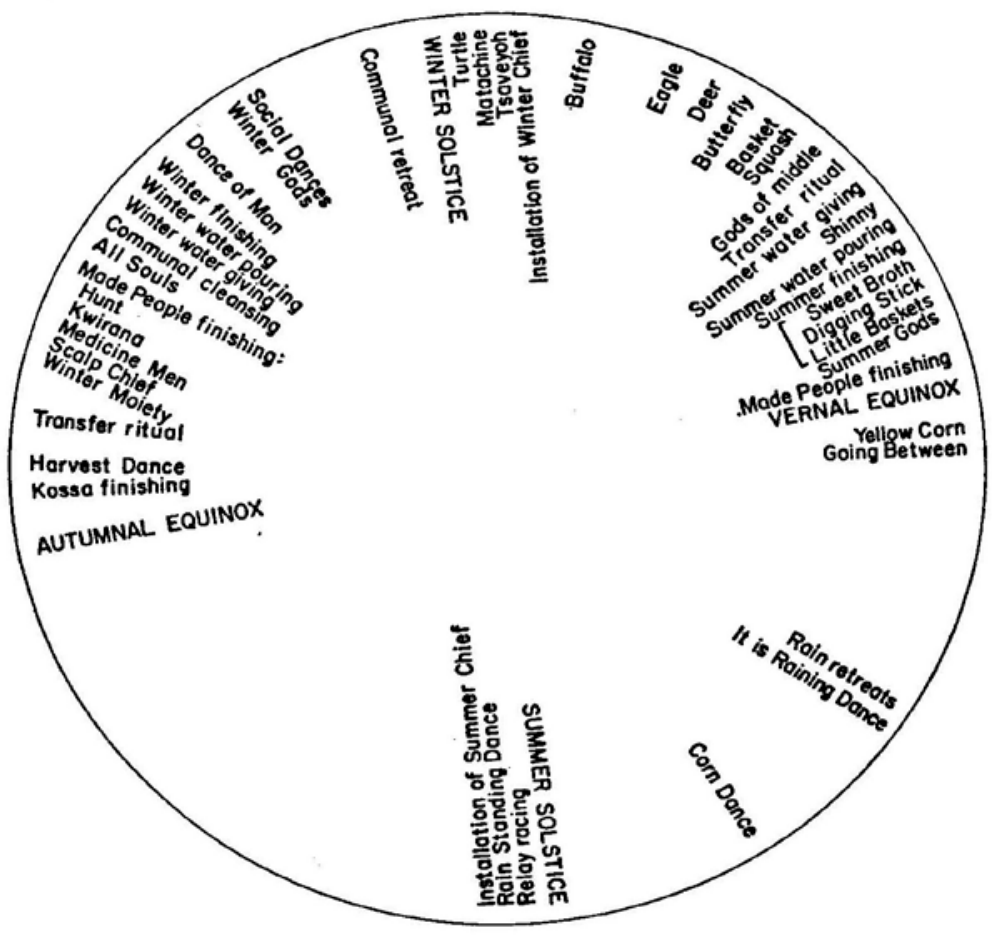

Figure 23: The Tewa ritual calendar. Source: Oritiz, 1969; pg. 104. 
For instance, referring to the following passage in chapter five provides an excellent point of reference to initiate dialogue concerning the interrelationship shared between cosmology and the Tewa lifeworld.

"In the very beginning we were one people. Then we divided into Summer people and Winter people; in the end we came together again as we are today." (Excerpt from the Tewa cosmology as communicated from an unidentified Tewa, In Ortiz, 1969; pg. 29)

This passage identifies the basic unit of social organization within Tewa Pueblos, the moiety ${ }^{77}$. The Puebloan conceptualization of moiety exists to reinforce the spatiotemporal connection between the mythical/sacred communicated in cosmologies to the present/profane physical reality. Embedded within each Tewa Pueblo are two moieties as outlined in the above passage, summer and winter ${ }^{78}$. Essentially, within each Tewa pueblo community the population is constructed so that every individual belongs to one moiety.

An individual's enrollment into a moiety is assigned during a child's first year in the ritual 'water giving' ceremony ${ }^{79}$ (Figure 23). The child's enrollment into a moiety is typically determined by the father's affiliation but is not static and is subject to change throughout life as the person chooses ${ }^{80}$. This example provides initial evidence of the

\footnotetext{
${ }^{77}$ Moieties are also the basic unit of social organization within Pueblos of other language stocks.

${ }^{78}$ Summer and winter moieties also exist for Pueblos of alternate language stocks.

${ }^{79}$ The enrollment into a moiety marks the second rite of passage for an infant or child, the first being the naming ceremony held during the week of one's birth this ritual is intended to bring the individual out of the dark and into society as a whole (Ortiz, 1969 and Parsons, 1939a and 1939b).

${ }^{80}$ For instance, a bride who wishes to marry a man of another moiety must go through the ritual 'water giving' ceremony to change her affiliation and obtain access to her husband's moiety rituals, ceremonies, and societies (Ortiz, 1969 and Parsons, 1939a and 1939b). However, if prior to marriage, a woman is a member of one the Made People societies within her moiety she is not expected to change her affiliation to that of her husband and her husband is giving the choice to either stay a member of his birth moiety or change to that of his wife. There are many instances within Tewan society in which a person may change moiety affiliation (Ortiz, 1969 and Parsons, 1939a and 1939b). The main point to grasp is that while
} 
interrelationships informing the organization and development of the Tewa lifeworld as communicated through cosmology.

Specifically, examining moieties from the relational perspective corroborates multiple connections in space and time to contrive holistic understandings of social, or in this case Tewan, development explainable through geographic experiential perspectives $^{81}$. From the relational perspective connections are identifiable between the cosmologic and present historic which inform and organize native social organization; i.e. how the cosmologic informs present historic social organization as through moieties. This also reinforces the ideology of Tuan (1977), conveyed in the previous chapter concerning the development of a 'sense of place' in relation to conceptualizations of time.

Tuan (1977; pg. 198) understood the relational perspective involved in that, to evoke a 'sense of place' often requires a deliberate and conscious effort to link with the past. Within this research, the spatio-temporal relationships integral to cultivating a 'sense of place' involves recognizing these multiple spatio-temporal interconnections Native American societies, such as the Eastern Tewa, utilize as identity markers that project and influence their conceptualizations and perceptions of the past, their interpretations of the present, and their projections of the future. Viewing this relational spatio-temporal conceptualization of the cosmologic and perceived from any other

familial ties do influence an individual's 'place' within the social organization of the Pueblo, especially at birth, the individual no matter gender or familiar status is ultimately indeterminate or malleable throughout life.

${ }^{81}$ Refer to chapter three's discussion of Harvey's matrix of spatialities concerning the temporal spatiosocial connections informing experienced, conceptualized, lived, and perceived spaces. 
perspective nullifies or reduces a tribe’s, society's, moiety's, or clan’s evolving history or development of place and identity to one-to-one absolute relations.

For instance moieties, viewed from a relational perspective, operate as entities defining, developing, and mediating social organization by grounding the cosmologic and ritual (sacred) to the lived (profane), congruent with the Tewan concept of she t'a. Figures 22 and 23 illustrate she t'a as revealed through the connection between the cosmologic and lived, explainable by the intricately intertwined relationships shared between the Tewan ritual and subsistence cycles. These cycles operate to orientate, organize, and oversee the ritual and subsistence (seasonal) changes that also demarcate a shift in social authority. For instance, the ritual calendar is aligned so that the winter moiety resends authority to the summer moiety when spring arrives and planting season begins according to the subsistence cycle as reinforced through the following passage from chapter five.

'The Winter People, were eating deer, elk (the meat of wild animals); and the Summer People were eating jucca fruit (pahhe), mantsanitabe (apples), berries (puhpahbe), okumbe, prickly pear (saebe) all different kinds of fruit' (Parsons, 1926; pg.15).

In congruence with the subsistence cycle, the summer moiety also takes charge of those ritual activates, such as the corn dance, required to ensure a prosperous harvest.

The delineation of subsistence and ritual activities according to moiety leads to the second basic unit of Tewan social organization, societies ${ }^{82}$. Continuing with the thread of logic in which the relational perspective situates the researcher with an

\footnotetext{
${ }^{82}$ Both the Winter and Summer moieties operate according to similar hierarchical organization concerning societies. Functional differences between similar societies of different moieties are delineated according to seasonality that affects subsistence and ritual cycles.
} 
opportunistic view or insight into the complex interrelationships informing tribal social organization, and, therefore, also provides insight into those spatio-temporal relations important to conceptualizing place and identity development, societies are explored as the second building block comprising Tewan culture.

Social organizations, like moieties, are relationally linked through a shared cosmology informing social organization. The hierarchal arrangement of Tewan societies and their function within the schema of social organization are outlined in The Emergence myth discussed in chapter five. Within this cosmology the mythical/sacred derivation for the emergence of the Tewa is communicated, in additional to, the framework providing the conceptual foundation for Tewan social organization at the society level is outlined in the Appendix.

Following the Tewa spatio-temporal conceptualization of the mythical interconnection with the present, societies are hierarchically organized according to their relative level of being, differentiated according to connections from that of the sacred to profane. Figure 7, illustrates the six hierarchical levels of being structuring social organization within each moiety. As with moieties, noticeable in Figure 7 is the communication of the Tewa concept of she t'a used to corroborate the interrelationships that clarify the connections shared between the mythical and historic present that inform social organization.

The Tewa six levels of being are separated according to a spatio-temporal boundary signifying their Emergence from Sipofene. The time in which they lived under the water in Sipofene demarks the sacred spatio-temporal that is perpetuated through the 
oral communication of cosmologies structuring Tewa social organization and

development after emergence, in the era of the present historic profane. Separated by this spatio-temporal barrier, the six levels of being are divided in such a way that the three levels within the profane are hierarchically organized to reflect the same structure as that of the sacred. Each level of being is comprised of societies. Duplicate societies exist between the sacred and the present historic levels of being. However, it is the specific function and responsibility of societies situated within the realm of the present historic to ensure the connection with the sacred is maintained.

Following the Tewa conceptualization of she t'a, the hierarchical organization of societies within the summer and winter moieties mirror the categorization of the other. In short, equality in governance between the moieties and their societies is dictated by seasonality, in congruence with the Tewa subsistence and ritual cycles ${ }^{83}$. For instance, it is the responsibility of the summer moiety chief to oversee the order of planting and the winter chief to oversee hunting expeditions ${ }^{84}$.

The hierarchical organization of Tewa societies outlined in The Emergence myth (Appendix) is dictated by their relative relation or distance from the sacred. For instance, those persons occupying positions within the Made People societies will, in death,

\footnotetext{
${ }^{83}$ The Tewa view the concept of equality as in important characteristic of societal construction and vital to maintaining social organization. Discussed by Ortiz (1969), misconceptualization concerning the importance of the Winter and Summer moieties, especially the role of chief, has been unduly perpetuated. While equality is an important concept within Tewa society, it is known that the Summer chief and societies maintain control of rituals and social governance for seven months, in contrast to the Winter chief and societies who rule for less than five (Ortiz, 1969; 82-83). While this might be viewed as a discrepancy in the Tewa conceptualization of equality, the Tewa do not view this temporal discrepancy as a power or prestige marker. Both moieties and their associated societies are assigned equal representation during their tenure of rule and viewed with equal power, prestige, and importance in maintaining Tewa social organization, development, and spirituality.

${ }^{84}$ In addition to ritual tasks, subsitence duties according to moiety are also assigned or laid out within The Emergence myth (Appendix).
} 
transition to the highest level of being within the sacred, the Dry Food People Who Never

Did Become. The same relative spatio-temporal relationship between the past (sacred), present (profane), and future (sacred) is embedded within the two lower levels of being, Towa é and the Dry Food People. It is beyond the scope of this research to comprehensively discuss each society comprising the Tewa levels of being and their functions in maintaining Tewa social organization, development, and spirituality ${ }^{85}$.

Feasible within the scope of this research is a brief collective discussion of the function of these societies in reference to their roles contributing to a more holistic understanding of the relational connections comprising the spatio-historic conceptualization, organization, and development of perceptions of place and identity. Beginning from the top down, within the historic present, a concise examination of the societies comprising the Made People proceeds ${ }^{86}$.

Following the sacred cosmologic recount for the organization and function of Tewa societies within the hierarchal levels of being the Made People, uppermost societies within the historic present era, coordinate, oversee, and ensure the ritual calendar is adhered. Keeping to the ritual cycle is necessary to maintaining social cohesion and

\footnotetext{
${ }^{85}$ For a comprehensive discussion and analysis concerning the traditional role of those societies comprising the Tewa levels of being see Ortiz (1969) and Parsons (1926, 1939a, and 1939b.)

${ }^{86}$ Similar discussion of those societies comprising the sacred era is not made. Reasoning for this omission falls along the ideology that in discussing the societies within the context of the historic present also lays the groundwork for the interpretation of the sacred, as they mirror one another. The historic progression concerning the sacred formulation and function of these societies is found in The Emergence myth. Refer to the appendix for a detailed recount. According to this researcher it seems as though the primary component differentiating the societies of the sacred era from that of the historic present is enrollment. For instance, within the sacred era those people' belonging to specific societies appears to be primarily determined by the temporal sequence revealed in The Emergence myth in which specific individuals or groups emerged from Sipofene. In contrast, recruitment of enrollment into societies within the context of the historic present occurs as a result of three processes: dedication, trespass, and trapping (Ortiz, 1969; 86-87).
} 
organization in that subsistence quality and quantity are deemed directly related to successful ritual practice and participation (Ortiz, 1969).

For instance, Figure 24 illustrates the hierarchical placement of the eight societies comprising the Made People, in addition to, the number of members typically found within each society, the gender of those members, and the method of promotion ${ }^{87}$. There also exists a hierarchical social structure within the Made People societies typically differentiated according to the order of creation in The Emergence Myth. Ortiz (1969; 82-83) notes that subtle differences do exist in the hierarchical structure of these societies when the seasonal change in moiety occurs. The only societies to interchange levels are the Kwirana (cold) and Kossa (warm) clowns ${ }^{88}$. Associated with seasonality, the Kwirana (cold) move above the Kossa (warm) when the winter chief takes office and the same shift occurs for the Kossa (warm) ${ }^{89}$.

\footnotetext{
${ }^{87}$ Important to note is the inclusion of lay people within the Made People societies. The upper positions are known as Sehshu, these individuals are incorporated typically as life long members whose duties are to assist the moiety chiefs in ritual and daily activities. The lower positions are known as, the” Keepers to the Entrance to the Lake.” These people impersonate the deities of each moiety and serve for as long as they are able to perform this ritual task. (Ortiz, 1969; 80-87)

${ }^{88}$ Described by Ortiz (1969; 83-84), within the Tewan social hierarchy the Kwirana and Kossa are described as "cold" and "warm" clowns in congruence with their association with the weather and therefore, exchange positions alongwith the moiety societies. The etymologies are unkown.

${ }^{89}$ Ortiz (1969; 82-83) notes this is an excellent marker to identify moiety when an individual is retelling the Emergence myth. A person belonging to the winter moiety will specify the Kwirana as being made before the Kossa and the reverse occurs for an individual of the summer moiety.
} 


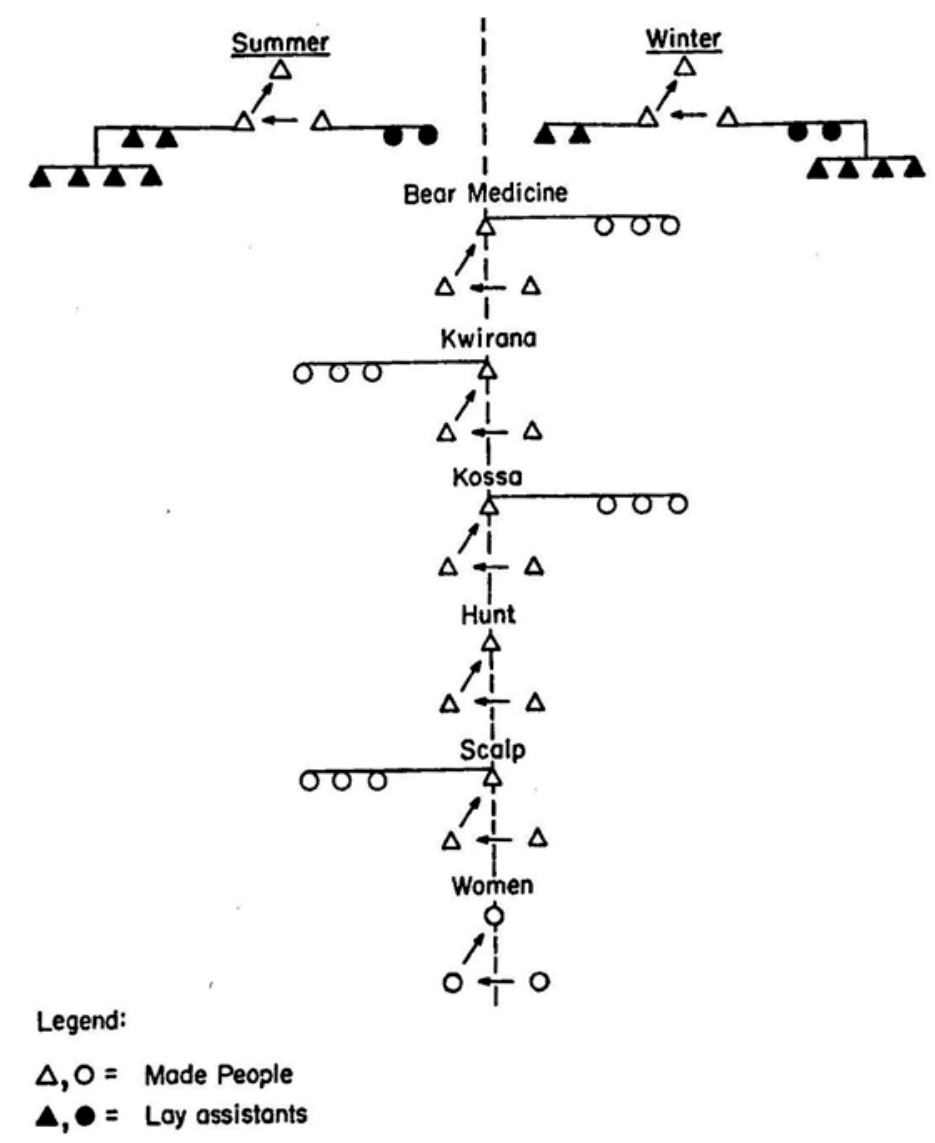

Figure 24: Societies comprising the Made People in the Tewa world. Source: Oritiz, 1969; pg. 81.

Overall, it is the responsibility of these Made People societies to oversee the social, political, and ritual activities of the Tewa are properly conducted. Ortiz (1969; 98), describes the basic fundamental structure and organization to those activities comprising the Tewa lifeworld and informing their lifeways is observable through the annual cycle of works (Figure 25) overseen by the eight societies of the Made People. 


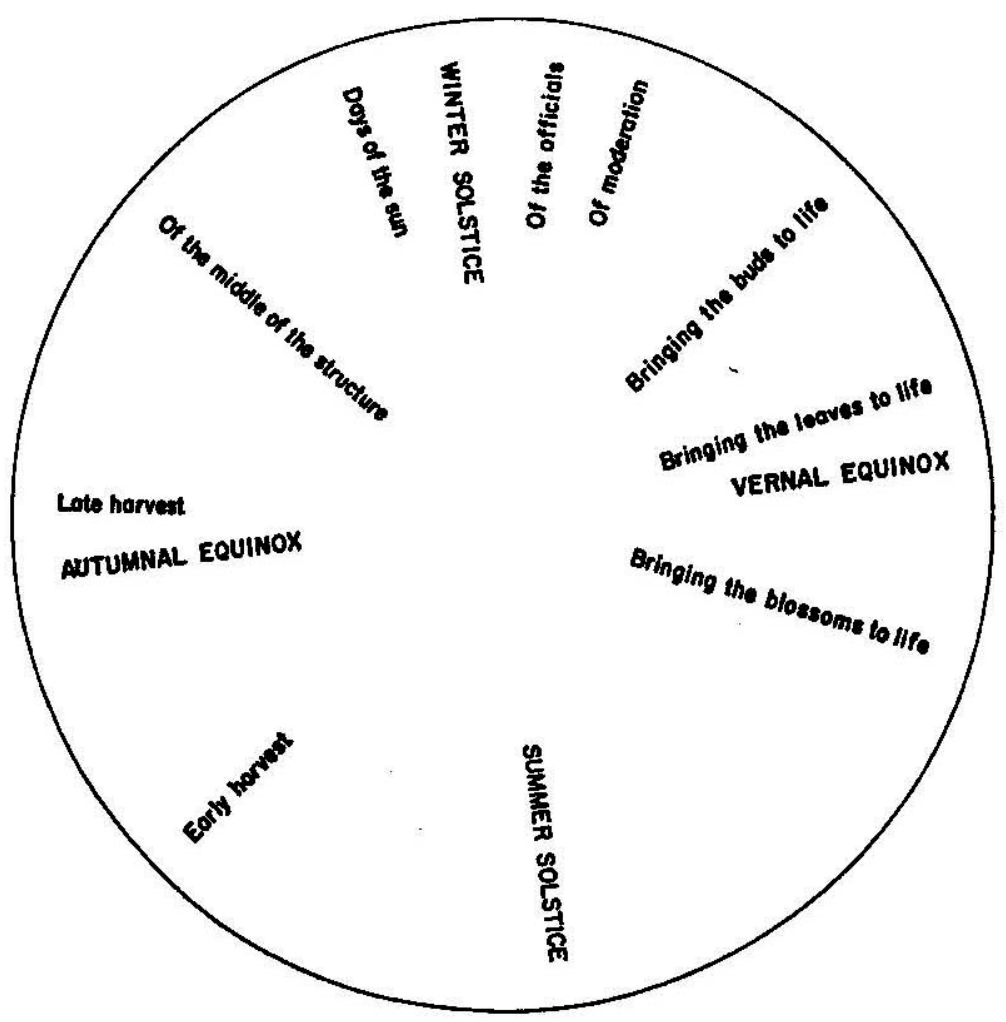

Figure 25: The annual cycle of works of the Made People. Source: Oritiz, 1969; pg. 98.

The purpose of the annual cycle of works is to harmonize people's relations with the spirits, and to insure that the desired cyclical changes will continue to come about in nature (Ortiz, 1969; 98-99,. Ortiz (1969; 98-99) continues by stating the Tewa cyclical changes are ensured through devoted prayer sessions and day-long retreats conducted by each of the eight Made People's societies. Each work within the cycle requires the eight societies to gather all members and perform the need songs, dances, and prayers. The order in which each society conducts these rituals is hierarchically based according to the societies creation in The Emergence story.

Apart from the Made People, the Towa é also are important actors ensuring that the cycle of works rituals are maintained. The sacred origin and purpose for the Towa é is clearly defined in The Emergence stories (Appendix). During the era of the sacred, the 
Made people created six pairs of brothers known as Towa $e^{90}$ to serve three primary purposes as the establishers of the four cardinal directions, zenith, and nadir; the creators of Tsin; and the testers of the earth ${ }^{91}$ (Appendix).

Following the structure of the order of creation specified in the The Emergence myth, the Towa é within the context of the historic present are named or nominated by the Summer and Winter chiefs. Annually chosen from among the population of Dry Food People, the Towa é most notably function in four primary capacities within Tewa society: as mediators between the Made People and Dry Food People; as protectors of the Made People; as coordinators of all rituals planned and directed by the Made People and participated in by the Dry Food People; and as insurers of check and balance of power (Ortiz, 1969; 62-77).

In accordance with she t'a, the Towa é are able to maintain the spiritual/human connection through their deemed or assigned societal roles. For example, the role of the Towa é within the historic present as the insurers of checks and balances of power is associated with their sacred spiritual connection to the Tsin created by the sacred Towa é brother pairs in The Emergence myth. The Tsave Yoh ${ }^{92}$ also occupy the Tsin where the sacred Towa é overlook the Tewa people.

\footnotetext{
${ }^{90}$ Each brother pair was designated a color that is associated with each cardinal direction, nadir, and zenith. (Appendix)

${ }^{91}$ Waiting for the time when the Made People and others could emerge from Sipofene, the Towa é were assigned the role of emerging first to determine if the earth was ready. Successive visits by five brother pairs the surface proved the earth too soft and not ready. The emergence of the last brother pair, nadir, proved the earth hard and ready for the people's emergence. This news brought by the nadir brothers, to the Made People, initiated the twelve sacred steps taken by the people in their emergence from Sipofene to the earth's surface, establishing the spatio-temporal boundary between the sacred and historic present. ${ }_{92}$ The Tsave Yoh or masked supernatural whippers and are impersonated by the Towa é during ritual occasions. Ortiz, 1969; 18-28.
} 
The Towa é are able to enforce their role as insurers of checks and balances annually during the Turtle Dance. Acting as a pair impersonating the Tsave Yoh the Towa é are allocated the authority to publicly whip across the legs anyone, including Made People, they deem not appropriately following accepted societal codes, ethos, or duties $^{93}$ (Ortiz, 1969; 74-77). Inappropriate behavior is deemed anything from a person drinking too much, not participating in ritual activities, to a home not kept within Tewa standards of cleanliness. This ritual act reinforces societal cohesion through she t'a that provides and procures ramifications for individual's actions through the sacred/human connection.

Individual's recruited, enrolled, or designated a position within either the Made People or Towa é societies were at one time a member of the lowest level of being, the Dry Food People ${ }^{94}$. Individuals belonging to the Dry Food People serve no official capacity within the Tewa ritual or political system (Ortiz, 1969; 17-18). The primary responsibility of the Dry Food People during ritual ceremonies is to impersonate the deity, assigned during the water-giving ceremony, of the Dry Food People Who Never Did Become (Figure 26) (Ortiz, 1969; 35).

\footnotetext{
${ }^{93}$ The identities of the Towa é impersonating the Tsave Yoh is closely guarded during the Turtle Ceremony so no repercussions exist for those individuals taking part.

${ }^{94}$ The Dry Food People Who Never Did Become, the sacred version of the Dry Food People, are those deities present before emergence but, who never walked the earth when it became hardened. Ortiz, 1969; 18
} 


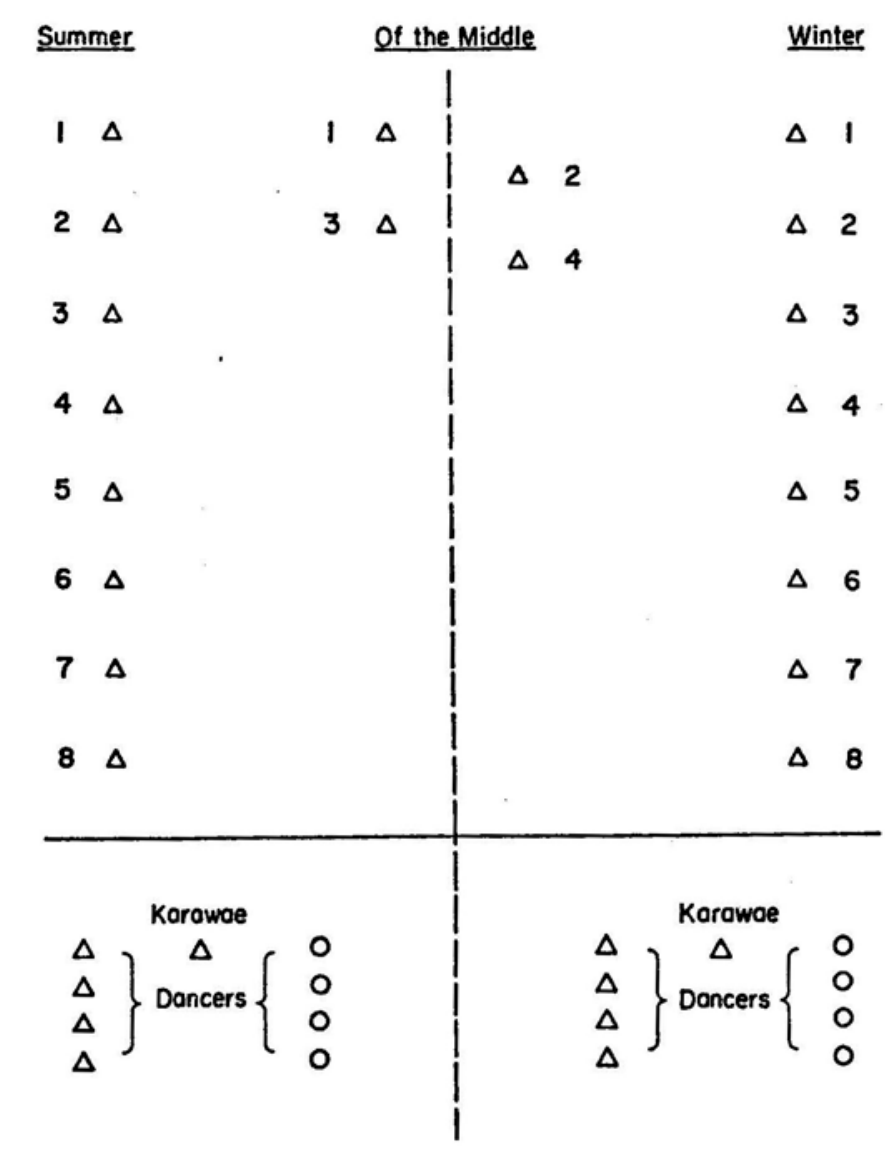

Figure 26: Societies comprising the Dry Food People Who Never Did Become in the Tewa world. Source: Oritiz, 1969; pg. 92.

The lifetime of a Tewa is comprised of several rites of separation, transition, and incorporation. When born, each individual begins the process of becoming a Tewa through several rites before included first as a Dry Food Person. Typically, an individual is still of child age when initiated and incorporated as a Dry Food Person; the event is marked by the rite of transition given during the water pouring ceremony (Ortiz, 1969). Ortiz (1969) notes that while all Tewas originally are Dry Food People, a majority of people will at sometime in their life become members of the Towa é and Made People. 
Discussed throughout this section, the primary difference between the three levels of being, within the context of the historic present, is the individual's relationship or capacity to communicate with the sacred and carry out those rituals that ensure the Tewa's spiritual relationship with the sacred is maintained. Expressed through the Tewan concept of she t'a, the cosmologic ties between the sacred and historic present best illuminate the intricate connections traditionally linking Tewa lifeways to the conceptual foundation constructing and organizing their lifeworld. Throughout an individual's life, intricate rites of incorporation, transition, and separation are utilized as mediums for societal maintenance, tools of indoctrination, and as a means to ensure cultural continuality through oral and ritual communication.

\section{Reformation: Spanish Colonial Influence}

The following section begins the historic overlook of uneven development through accumulation by dispossession by first examining the influence of two periods of Spanish occupation within Tewa territory. Followed by a glossary examination of the short live Mexican influence and impact on Tewan society once independence from Spain was achieved. Chapter nine will examine the impact the United States had upon transforming the Tewa lifeworld through enactment of specific federal acts and legislation impacting traditional lifeways.

Prior to United States encroachment and influence in northern New Mexico, the Pueblo people were not alien to foreign occupation. Before the United States gained ownership of the region through the Treaty of Guadalupe Hidalgo of 1848, northern New Mexico formally belonged to Mexico, who remained under the influence of the Spanish until Mexican Independence in 1821. It is beyond the scope of this research to 
exhaustively recount the historic socio-economic and political interactions between the

Tewa Pueblos and Spanish when considerable examination of the topic has been thoroughly investigated ${ }^{95}$. However, four important relics of Spanish influence in Puebloan culture are integral to contextualizing the reorganization of their traditional conceptualization of their lifeworld and lifeways in response to colonial autocratic doctrines, and prior to the United States introduction of capitalist ideologies.

\section{Spanish Conquest \& Colonization (1598-1680)}

During the first era of colonization (1598-1680), the Spanish, through the implementation of the encomienda and repartimiento systems, introduced early forms of dispossession. Sando ${ }^{96}$ (1998; 5) describes the encomienda system as the forced involuntary donation of part of the crops of certain pueblo families every year to support the Spanish missions, military forces, and civil institutions. This form of tithing, enforced by the conquering Spanish explorers, reinforced the capitulación ideology communicated in legal memoranda ${ }^{97}$ assuring the Crown received its appropriate share of the 'profits' acquired through discovery and conquer expositions (Dunbar-Ortiz, 2007).

Described by Sando $(1998 ; 5)$ repatimiento was somewhat similar to the encomienda in that both systems were forcible forms of tribute imposed by the Spanish. However, instead of tithing, as enforced in the encomienda system, the repatimiento system required Puebloans to labor in Spanish households and fields (Sando, 1998; 5).

\footnotetext{
${ }^{95}$ For comprehensive analysis and discussion of Pueblo and Spanish interrelations see: Dunbar-Oritz, R. (2007) and Sando, J. (1992 and 1998).

${ }_{96}$ Joe S. Sando was born and raised at Jemez Pueblo, he is a recognized authority and respected writer on Pueblo history and has been a voice in the affairs of the nineteen New Mexico Pueblos over several decades (Sando, 1992 and 1998).

${ }^{97}$ To ensure the Spanish Crown received its appropriate share from explorers employed under its flag to conduct explorations of discovery, legal documentation was created to contractually obligate explorers to report sources of 'profit' and send the Crown its required share; otherwise penalties and persecution would ensue. Examples of such documentation are: the Laws of the Indies, Laws of Castille, and the Novissima recopilación de las leyes de Espana ( Dunbar-Ortiz, 2007).
} 
Both these systems characterize the means by which the Spanish attempted to control Pueblo land and labor as their influence and occupation of the region continued to gain hold.

While the encomienda and repatimiento systems sought to obtain economic and political control of the Pueblos by restructuring their traditional lifeways to that of a feudal servitude, the third mechanism foreign imperialism and control over indigenous people centered on spiritual cleansing and reorganization; essentially acculturation. The Spanish Crown, heavily influenced by the Catholic Church, sought to rid the Pueblos of their pagan ideologies through ecclesiastical reorganization and through the establishment of missions in the borderland region.

In combination with the encomienda and repatimiento systems, the introduction of missions finalized the tripartite approach or attack taken by the Spanish, during their first era of colonization, in dealing with the Pueblos. This approach emphasized separation from traditional lifeways that embodied the inseparable connections to land, society, and religion within Puebloan culture. As stated by the cacique ${ }^{98}$ Juan de Jesus Romero, of the Taos Pueblo:

"If our land is not returned to us, if it is turned over to the government for its use, then it is the end of Indian life. Our people will scatter as the people of other nations have scattered. It is our religion that holds us together (In Wilkinson, 2005; 206). ${ }^{99}$ "

Effectively the Spanish, operating under the spiritual ideology communicated by church officials, saw it as their ethical responsibility to reform these pagan believers.

\footnotetext{
${ }^{98}$ Cacique is the highest spiritual leader within each Pueblo society. Debate ensues as to the importance or ranking of the cacique within the Pueblo hierarchy as historic and contemporary influences have modified Puebloan social organization (Ortiz, 1969).

${ }^{99}$ The context of this statement made by Juan de Jesus Romero was in response to the United States federal government's acquisition of Blue Lake as a federal forest reserve under control by the Forest Service. Blue Lake is considered a sacred place to members of the Taos Pueblo (Wilkinson, 2005).
} 
Authority to conquer was grounded in spiritual divinity and superiority becomes problematic when 'ecclesiastical whiteout' sanctions the use of corrosive and forceful methods of acculturation. Essentially, these modes of acculturation attempted to restructure Puebloan conceptualizations of place and identity through forceful reorganization of the social, political, economic, and religious underpinnings organizing and informing their society. According to Dunbar-Ortiz (2007; 36), together with implementation of encomienda and repatimiento systems, missions or congregaciones, the Spanish were able to control changes in Pueblo land tenure and, in turn, establish a basis for a settler land tenure based on acquiring fortune to establish higher status or ensure continuance familial standings within the colonial structure during their first era of occupation.

Astoundingly, the contemporary strength of Puebloan religion and spirituality is evidence of the Spanish, and later American, inability to completely penetrate, erode, or erase those cosmologic interrelations necessary to ensure cultural continuance. Most notably through a combination of defiance ${ }^{100}$ and secrecy ${ }^{101}$, the Pueblos were able to refuse to or completely adhere to the ideologies governing Spanish doctrines of discovery.

What this means is that during the Spanish occupation, Puebloans were able to carry on traditional religious ceremonies, typically in secrecy, and this was critical to ensuring that their people continued to develop a sense of perspective and identity needed

\footnotetext{
${ }^{100}$ Organized and led by Popé, a member of the San Juan Pueblo, the Pueblos were able to effectively organize themselves in 1680, to kick the Spanish out of their lands and relocate to El Paso. It took the Spanish twelve years to return and repopulate the region (Dunbar-Ortiz, 2007; Ortiz, 1969; Sando, 1992 and 1998 and Wilkinson, 2005). The Pueblo Revolt of 1680 established the historic dividing line for the implementation of the two differing ideologies governing Spanish occupation within this region.

${ }^{101}$ Traditional religious ceremonies were shrouded in intense secrecy during Spanish occupation and were practiced 'underground' out of sight and mind of colonial and religious officials.
} 
in their continuous journey to becoming human (Cajete, 2000). It also meant that concessions were required to reflect the Spanish perception of land tenure during both eras of occupation.

For instance, while the Spanish did not completely rid the Pueblos of their traditional religion, missionaries required compulsory church attendance and introduced the role of attendance officer or fiscale. This person was required to roundup all Puebloans on Sunday, or other holy days, to attend Mass. If a person was missing it was also the fiscale's role to track down the missing person and determine if their reason for absence was valid (Dunbar-Ortiz, 2007; 65).

The culmination of forced tithing and labor, religious or spiritual acculturation, in addition to, the recurrent confiscation of Pueblo food stocks by armed Spanish soldiers eventually sparked the 1680 Pueblo Revolt. The social, economic, and political strains induced upon Pueblos from the foreign ideologies of encomienda, repatimiento and congregaciones created a ideological gap that conflicted with Puebloan traditional understandings concerning the cosmologic organization their lifeworld. Referring to the aforementioned statement by Peggy Sands:

'Creation stories contain within them a conception of the natural or initial order of things. By articulating how things are in the beginning, people apply more than a logic for life styles - they make a basic statement about their relationship with nature and about their perception of the source of power in the universe.' (In Powers, 1986; pgs. 4-5)

The foreign paths introduced by the Spanish conflicted with the Tewan conception of the natural order of their universe and impeded their ability to foresee or develop 'a sense of place' and identity in their path to becoming fully human. The 1680 Pueblo Revolt resulted from this fundamental conflict in ideologies that suppressed the 
Puebloans right to holistically pursue life according to the paths communicated in their cosmologies. The Spanish would not reenter the Pueblo region for twelve years, and when they did a new, less overt, ideology was implemented within the Pueblos.

\section{Spanish Reconquest \& Colonization (1692-1820)}

The second era of Spanish occupation occurred from 1692-1820. The Spanish reconquest of Pueblo country after the 1680 Pueblo revolt also brought a new purpose in the Spanish Crown's goal of territorial expansion and a change in the colonization method which marked an end to the encomienda and repatimiento systems. According to Dunbar-Ortiz (2007; 48) the era of reconquest instituted a policy of maintaining frontier outposts to preserve the outer limits of their empire in order to protect the rich interior from competing powers. This reorganization of the Spanish northern borderlands was accomplished through the establishment of genízaro settlements.

Genízaro settlements were a type of land grant created by the Spanish Crown to aid in keeping the borderlands under control and secure from encroaching nations ${ }^{102}$, through compulsory military participation of all settlers, and to prevent indigenous revolts or Pueblo uprisings as witnessed in 1680. Those settlers occupying the genízaros were considered of lower caste in the Spanish colonial order. So, while the Spanish attempted to restructure their ideology in recolonizing the Pueblo region, the colonial hierarchy or caste system ${ }^{103}$ was still very much in place (Figure 27).

\footnotetext{
${ }^{102}$ The French were the main competitors of the Spanish during this era especially since they were essentially arming Plains Indian societies situated on the northern periphery of the Spanish territorial borderlands such as the Apache and Comanche. As France lost control of its territories in the United States, Spain attempted to establish a trade relationship with those Plains societies situated in the northern territory to create a dependency relationship that would mediate resistance in the future and institute trade relations. (Dunbar-Ortiz, 2007; 47-48)

${ }^{103}$ Known as the casticismo system, racial and hereditary lines were constructed to determine ones placement in Spanish colonial society during the second era of occupation (Dunbar-Ortiz, 2007; 56)
} 
Highest

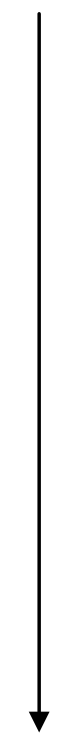

Lowest

\begin{tabular}{|c|c|c|}
\hline Caste & Heritage & Property \\
\hline Spanish Citizens & $\begin{array}{l}\text { Descendents of settlers } \\
\text { from the first colony who } \\
\text { typically intermarry others } \\
\text { of same caste }\end{array}$ & $\begin{array}{l}\text { Private property } \\
\text { owners }\end{array}$ \\
\hline Vecinos or 'Españoles' & $\begin{array}{l}\text { Settlers legally identified as } \\
\text { 'pure }{ }^{104} \text {, Spanish }\end{array}$ & $\begin{array}{l}\text { Private property } \\
\text { owners }\end{array}$ \\
\hline Castas or 'Coyotes' & $\begin{array}{l}\text { Offspring of a non-Spanish } \\
\text { European father and } \\
\text { Vecina or Mestiza mother }\end{array}$ & $\begin{array}{l}\text { Typically private } \\
\text { property owners or } \\
\text { upon equal land } \\
\text { ownership status of the } \\
\text { Vecionos }\end{array}$ \\
\hline $\begin{array}{l}\text { Genízaro } \\
\text { 'Indios' Pueblo Indians } \\
\text { 'Gentiles'Unconquered } \\
\text { Indians }\end{array}$ & $\begin{array}{l}\text { Typically referred to } \\
\text { Indians but also consisted } \\
\text { of other persons of specific } \\
\text { mixed racial heritage such } \\
\text { as: Mulatos of African and } \\
\text { European descent and } \\
\text { Zambos of Indian and } \\
\text { African descent. }\end{array}$ & $\begin{array}{l}\text { The 'landless' who } \\
\text { where endowed, often } \\
\text { without consent, land } \\
\text { grants on the northern } \\
\text { periphery or } \\
\text { borderland of the } \\
\text { Spanish frontier }\end{array}$ \\
\hline
\end{tabular}

Figure 27: Hierarchical arrangement of the Spanish colonial caste system during the second era of reconquest and colonization. Notice the relationship between heritage and property status. Those with more Spanish heritage typically belong to a higher caste and, in turn, own more private property. Source: Based upon descriptions in Dunbar-Ortiz (2007).

While a person's location in the caste system was predominantly determined by descent, blood quantum, or land ownership, this was by no means a closed system. For instance, the casta caste is hierarchaly above the genízaro caste because these person’s mothers were mestiza, ${ }^{105}$ meaning they are descendent of 'pure' Spanish and were of adequate blood quantum to obtain private property ownership rights. Therefore, if blood quantum and heritage determine status and ability to obtain land ownership, a person with

These labels typically delineated a person's ability to obtain land ownership, property rights, and water access.

${ }^{104}$ Although vecions labeled themselves of 'pure' Spanish decent, this was not always the case. (DunbarOrtiz, 2007; 56).

${ }^{105}$ Mestizas are females with a combination of Indian and Spanish descent. Likewise, mestizos are males following the same pattern of mixed descent as mestizas. 
no line of Spanish descent, genízaro, need only marry a person of the casta caste.

According to Dunbar-Ortiz $(2007 ; 56)$ intermarriage between castes was a very common practice and meant that the offspring of that union would obtain the higher social standing. Defining a person's descent and blood quantum would also prove an integral component to determining nationality when the United States acquired the region in 1848 through the Treaty of Guadalupe Hidalgo ${ }^{106}$.

For instance, the United States federal government still questions the citizenship of many Puebloans. The primary discrepancy concerns the correct status or categorization of Puebloans as either Spanish or indigenous citizens at the time of treaty execution. If categorized as Spanish, then according to the treaty their citizenship would simply change to that of American. However, if considered indigenous then Puebloan citizenship status would be that of 'ward' of the United States federal government and not a 'citizen'. The ‘citizen' versus ‘ward' status is further explored in chapter nine, in addition to, the implications associated with these categorizations for Puebloans.

The interrelationship between descent, blood quantum, and land ownership created a unique land tenure system that differed significantly from the more feudal encomienda and repatimiento systems seen during the first era of occupation. First, instead of forced tithing and labor, the landless genízaros, were assigned lands on the periphery of the Spanish boarderlands, where if worked for four years legal ownership transitioned to the worker. This created small settlements or rancheros throughout the Spanish borderlands. Which, as aforementioned, under stipulation of the land grant also

\footnotetext{
${ }^{106}$ Defining Native American's citizenship status in the United States is a historic quagmire strung out through decades of federal legislation and court rulings and remains a topic of debate in the present between indigenous cultures and federal and state governments.
} 
required the settlers to defend the territory from entities such as encroaching foreign nations and hostile Indians.

Second, persons of higher castes located in these northern frontier settlements usually acted in some form of official capacity ensuring Spanish doctrines were abided and laws enforced (Dunbar-Ortiz, 2007 and Sando, 1992 and1998). Still weary from the 1680 revolt, Spanish attempts at forceful acculturation was lessened and the presence of Spanish officials were meant to mediate conflicts and find resolutions to political and economic disputes centered around issues pertaining to land use and water rights such as irrigation or grazing.

This modification in land tenure practice, in combination with Spanish interest in expanding irrigation agriculture and introducing sheep ranching in the area induced the second major alteration in Puebloan social organization. During the first era of Spanish occupation, forced methods of acculturation through tithing, labor, and church attendance proved unsuccessful and led to the successful unification of Pueblos to effectively kick out the Spanish in 1680. The second era of conquest proved more successful in manipulating and altering Puebloan social structure. This was achieved by establishing official offices ${ }^{107}$ within the settlements to oversee water resources, the Spanish inadvertently broached influence into a fundamental component organizing the Puebloan lifeworld by structuring their lifeways, water and communal land use.

Vlaisch (2005) provides evidence for the ongoing conflict surrounding the appropriation of water rights in this region as traceable through the philosophical change

\footnotetext{
${ }^{107}$ The acequia office or community irrigation association provided oversight to ensure colonial law set down general principles for the regulation of irrigation. The Recopilacíon provided these officials with the power to supervise irrigated lands to protect them from damage by livestock and to see that all waters were held in common. (Dunbar-Ortiz, 2007; 61)
} 
concerning land grants allocation in the northern frontier region during the late Spanish

period. For instance, legislation passed in the late Spanish period of occupation sought to break up communal land sharing practices, as exercised by the Pueblos, in favor of individual land holdings. Following the regulatory processes of compoición and denuncia, outlined in the Recopilacío, the office of diputación ${ }^{108}$ was established to allocate land grants, determine the validity of land grants set in earlier periods of Spanish occupation, oversee the sale of native lands, and necessitate resolution concerning conflicts over land grant overlap (Vlaisch, 2005).

However, through the combination of an influx of non-natives to the region intent upon establishing ranches and agricultural farming along with the remoteness of the northern frontier, it was often difficult to strictly enforce the laws and regulations dictating the distribution of land grants ${ }^{109}$. Unable to strictly enforce the laws and regulations encompassing land grant allocation spurred considerable provocations between Puebloans, Spanish officials, and settlers over the issue of land and water rights. Puebloans, relying on the law of prior appropriation for beneficial use ${ }^{110}$ were often able to retain their superseding right to divert water for irrigation use as long as deemed beneficial ${ }^{111}$. Conflicts over beneficial use of water ensued throughout the second era of Spanish occupation as agriculture expansion succeeded for the Pueblos and

\footnotetext{
${ }^{108} \mathrm{~A}$ Spanish official under the control of the governor.

${ }^{109}$ See Vlaisch (2005) for a detailed discussion of the historic development of land grant patterns as allocated through Spanish rule.

${ }^{110}$ As described by Vlaisch (2005; 74), the law of prior appropriation for beneficial use originated with the Spanish, to be later adopted by the Mexican government, dictated that agricultural settlements and pueblos retained the right to water needed for their development. Vlaisch $(2005 ; 74)$ describes how this law pertains to the Pueblos by describing their superseding right over water distribution to lands held in common along unnavigable streams. In short, the law of prior appropriation ensured that Pueblos retained the ability to carry on, and in the hopes of the Spanish expand, farming agriculture by ensuring rights to water use over that of individual settlers.

${ }^{111}$ Beneficial use implies that an equitable portion of water from a source stream must be efficiently used to maintain agriculture. If water use is deemed wasteful, unbeneficial, the community or individual may face fines, taxes, or loss of stream access.
} 
individual landowners throughout the northern frontier region. In addition, the definition of beneficial use evolved to encompass the proper maintenance and building of irrigation ditches and canals with similar penalties incurred for those not participating in the upkeep the water conveyance system.

This successful expansion of agriculture, and later grazing, in the northern frontier region was spurred by the Spanish's introduction of the genízaro ideology that coercively enforced change into the Pueblo social structure. Essentially, a new hierarchical social structure developed to coincide with the new socio-political offices and economic livelihoods introduced by the Spanish. Figures 28 and 29 illustrate the hierarchical placement of these Spanish offices as captured within the perspective of the Pueblo social structure. 


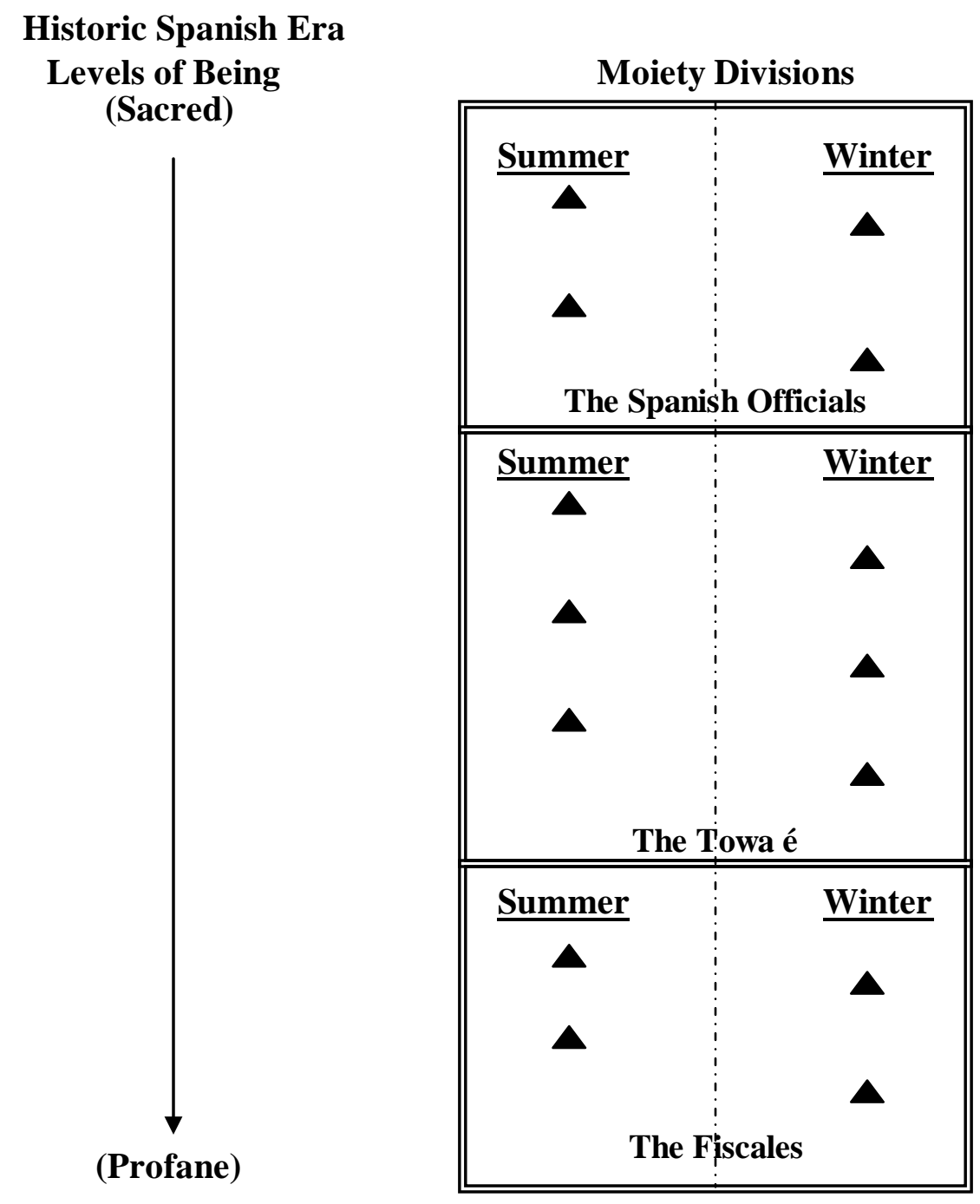

Figure 28: Hierarchical illustration of the structural relations of the three groups that comprise the Tewa political system as influenced by Spanish occupation. Modeled after: Ortiz, A.1969; pg. 63. 
Historic Spanish Era

Levels of Being

(Sacred)

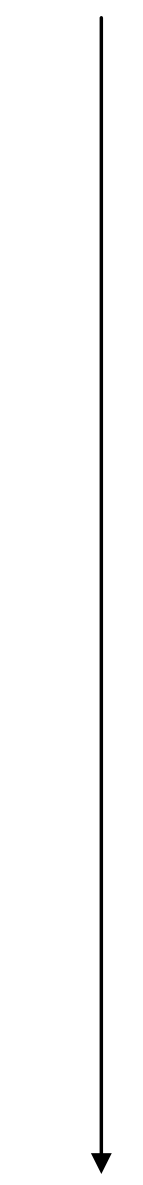

(Profane)

\author{
a
}

Spanish Officials

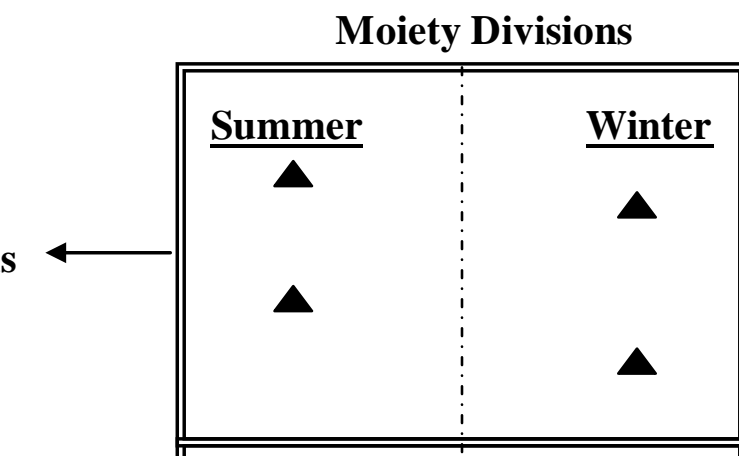

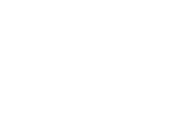

Towa é

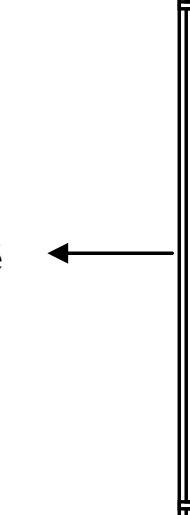

\section{Fiscales}

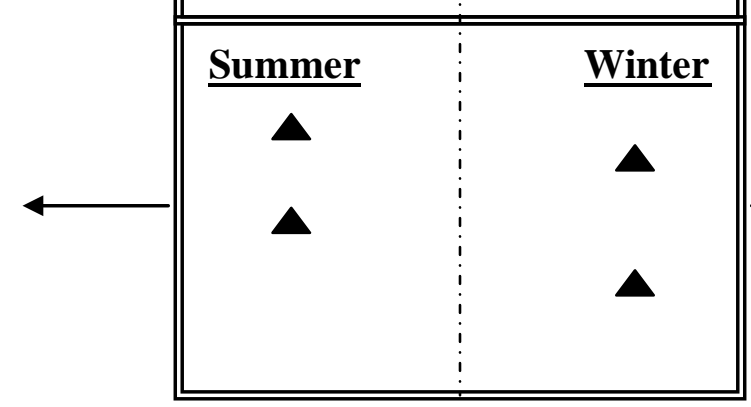

Traditional Pueblo

Levels of Being

(Sacred)

Figure 29: Hierarchical illustration of the structural relations of the three groups that comprise the Tewa political system traditionally and as influenced by Spanish occupation. Modeled after: Ortiz, A.1969; pg. 63.

Visible in figures 28 and 29, are the inclusion of two new political organizations as classified within the Tewa levels of being, the Spanish officials and the Fiscales $^{112}$. While these political organizations are hierarchaly aligned within the tradition Tewa perspective of social organization seen in figure 29 this is more or less to illustrate the

\footnotetext{
${ }^{112}$ In terms of authority, Fiscales were limited. These individuals functioned to assist the Catholic priest, maintain the church and mission grounds and, during the first era of Spanish occupation, functioned to ensure compulsory church attendance of all individuals.
} 
degree of functionally these roles play in informing Tewa society. Observations by Ortiz (1969), Vlasich (2005) and Dunbar-Ortiz (2007) suggest the roles of these 'foreign’ organizations do not command the respect of their parallel traditional counterparts, provide the underpinnings for social cohesion, or contribute to the Pueblo path to becoming a total person.

Rather, Ortiz (1969), Vlasich (2005) and Dunbar-Ortiz (2007) describe these 'foreign' organizations as functional mediators or translators between the external world and the traditional Tewa lifeworld. For instance, the organization of Spanish officials is composed of a governor, two lieutenants, and an aguacil and the Fiscales are composed of four Tewa adult men (Ortiz, 1969; 62-77). Conceptually, these roles are not cosmologically connected with the Tewa socio-spatial understanding of their lifeworld. Thus, being appointed or nominated to one of these positions is not highly sought after and usually meets with considerable protest when nomination occurs ${ }^{113}$.

While these roles are cosmologically disconnected from the Tewa conceptualization of their lifeworld and lifeways. The incorporation of these positions within the Tewa social structure reflect an evolving sense of necessity to interact with the outside world in order to ensure cultural continuance. For instance, those individuals who had a strong command and understanding of the operations of the outside world usually occupied the roles of Spanish officials. The importance of these positions evolved as agriculture and grazing expanded into the Northern frontier regions and interactions between the Pueblos and the Spanish, and later the Americans, necessitated

\footnotetext{
${ }^{113}$ All officials are drawn from the Dry Food People and serve a term of one year. Appointments within these roles are made by the Summer and Winter chiefs. (Ortiz, 1969; 62)
} 
interaction to ensure equitable water distribution and maintenance of irrigation systems

(Ortiz: 1969; 61-77).

\section{Mexican Independence}

Frequent changes in Mexican political offices, in addition to lax oversight

provoked considerable misappropriation of water rights on the northern frontier after Mexico won independence from Spain in 1821. The newly instituted Mexican government's ideology of equality for all paved the way for contemporary rights and sovereignty issues the Tewa and other Pueblos face presently. Equality of citizenship instilled during the Mexican era gave Puebloans citizenship status as opposed to their previous pseudo-ward status under Spanish rule. This change in status resulted in a catch-22 for Puebloans that fully manifested itself after the United States acquired ownership of the area in 1848 through the Treaty of Guadalupe Hidalgo ${ }^{114}$.

Dunbar-Ortiz (2007) develops this train of logic by specifying the details of

Article VIII of the Treaty of Guadalupe Hidalgo that verbatim states:

"Mexicans now established in territories previously belonging to Mexico, and which remain for the future within the limits of the United States, as defined by the present treaty, shall be free to continue where they now reside, or to remove at any time to the Mexican republic, retaining the property which they possess in the said territories, or disposing thereof, and removing the proceeds wherever they please, without their being subjected, on this account, to any contribution, tax, or charge whatever. "Those who shall prefer to remain in the said territories, may either retain the title and rights of Mexican citizens, or acquire those of citizens of the United States. But they shall be under the obligation to make their election within one year from the date of the exchange of ratifications of this treaty; and those who shall remain in the said territories after the expiration of that year,

\footnotetext{
${ }^{114}$ Signing of the treaty marked the end to the ongoing three year conquest $(1845-1848)$ of the United States within the territorial bounds of Mexico. The 1848 treaty succeeded 500,000 square miles of Mexico's northern territory to the United States, nearly half of Mexico's total land area (Dunbar-Ortiz, 2007).
} 
without having declared their intention to retain the character of Mexicans, shall be considered to have elected to become citizens of the United States.

"In the said territories, property of every kind, now belonging to Mexicans not established there, shall be inviolably respected. The present owners, the heirs of these, and all Mexicans who may hereafter acquire said property by contract, shall enjoy with respect to it guaranties equally ample as if the same belonged to citizens of the United States. ${ }^{115}$ ",

According to Article VIII, all Mexican citizens (Puebloans are now included in that category) are entitled to American citizenship and all liberties appropriated to individuals of the United States, including property rights. Contemporary debates ensue concerning the citizenship status of Puebloans ${ }^{116}$. Chapter nine examines those pertinent federal acts, legislation, and court rulings implicating alternative motives to the equal integration of Puebloans into American society as specified in Article VIII.

\section{Conclusion}

This section provides a holistic interpretation of the historic contexts contributing to modified conceptualizations of the Puebloan traditional lifeworld and lifeways prior to United States acquisition of the area. Following the steps in Ollman's Dance of the Dialectic, this section analyzed, historically contextualized, and placed in perspective the development of Puebloan culture as influenced by the colonial rule of the Spanish and early 'democratic' influence of Mexico. Historicizing is a key component to conducting this analysis as it lends credence to the next steps in the Ollman's 'dance', visionize and organize, undertaken in chapters nine and ten.

\footnotetext{
${ }^{115}$ Refer to the June 2004 United States General Accounting Office (GAO) Report GAO-04-59 Treaty of Guadalupe Hidalgo Findings and Possible Options Regarding Longstanding Community Land Grant Claims in New Mexico. http://www.gao.gov/new.items/d0459.pdf

${ }^{116}$ Refer to the June 2004 United States General Accounting Office (GAO) Report GAO-04-59 Treaty of Guadalupe Hidalgo Findings and Possible Options Regarding Longstanding Community Land Grant Claims in New Mexico. http://www.gao.gov/new.items/d0459.pdf
} 
Altogether, Ollman’s steps provide a conceptual process or blueprint to undertake and interpolate how events situated in the past contribute to, or provide logical connections to, conditions of the present that contribute to uneven development. For instance, conceptually this analysis looked into the past to search for the preconditions of uneven development, manifested through the process of accumulation by dispossession, establishing connections relevant in the present. Aided by the rigourous and comprehensive research of Simon Ortiz (1969), Elsie Clews Parsons (1939a and 1939b) and Joe Sando (1992 and 1998) this chapter dialectically analyzed the effects of accumulation by dispossession in relation to Tewan conceptualization of their lifeworld and lifeways. Chapter nine continues the 'dance' and futher develops linkages in the blueprint of uneven development, achieved through accumulation by dispossession, by analyzing the impact of specific federal legislation, acts, treaties, and court rulings specifically geared toward modifying and reducing Pueblo land holdings and water rights. 


\title{
Chapter 8: Tlingit of Southeastern Alaska
}

\author{
Haa Aaní: Our Land \\ Honoring and Utilizing Our Land \\ Our ancestors, who have lived in this land for more than 10,000 \\ years, taught us that everything has a Spirit. \\ When we utilize our resources, we must acknowledge the Spirits of \\ the Land, Sea and Air and tell them the benefits that their use will \\ bring to our People. \\ Our ancestors protected the ownership of our land for their \\ children and grandchildren just as we must do for future \\ generations. (In Sealaska Heritage Institute Core Cultural Values, \\ 2009; pg.1)
}

\section{Introduction}

Unlike chapters 6 and 7, a variance exists in the ideological structure of this chapter. Geographic placement and spatial organization of the Tlingit precedes the discussion of traditional social organization. The derivation for this ideological deviation stems from the constraints encountered within chapter 5, that of cosmology. Like chapters 6 and 7, the Tlingit cosmologies are utilized throughout this discussion to aid in providing the reader a conceptual roadmap dialectically linking the socio-spatial (Soja's third space) to Harvey's spatio-temporal vantage point of human experience.

Attempts to organize this chapter in accordance with the structures followed in 6 and 7 seemed successful in producing disjointed analyses of unrelated parts, in total opposition to a goal of this research to dialectically link the socio-spatial to Harvey's spatio-temporal vantage point of human experience. Limitations were encountered in relation to access to reliable historic resources, in conjunction with confusing and questionable interpretations of historic Native accounts. Anthropologist Thomas Thornton (2007; 41) states: 
'Strictly speaking there is no such thing as a pure aboriginal or "traditional" form of social structure or governance among the Tlingit. Their socio-political organization has been evolving continuously in response to the current environment.'

This statement clarifies why access to historic resources pertaining to traditional Tlingit social structure may present an issue. Further investigation into historic and contemporary literature revealed an underlying spatial intricacy informing Tlingit socioeconomic and political organization. This conceptual light bulb provided the ideological support and connections needed, discussed throughout this chapter, to initiate the discussion encompassing the reconciliation of the Tlingit perspective of experience.

While social structure, and its relative lack of inclusion within Tlingit cosmologies, may not be as integral to societal development as seen with the OglalaLakota or Tewa. The malleable nature of the Tlingit social structure lends credence to the underlying social connections and processes needed to maintain social cohesion. Acknowledging these outlined limitations, the following chapter utilizes the works of more contemporary researchers, such as Thomas Thornton and Kirk Dombrowski, studying the historic and contemporary impacts of uneven development by actively engaging members of Tlingit society.

Similar to the Oglala-Lakota, traditional Tlingit society is characterized as semisedentary and follows subsistence patterns based upon migratory game. As revealed in the cosmologies, Tlingit culture derived much of its identity, cultural norms, values and social organization from their relationship with the environment that sustain their lifeworld. The introduction of Western socio-economic and political ideologies into this culture has redefined and reorganized their traditional social organization, and it is a goal 
of this research to more thoroughly understand how these people have adapted and responded to these external influences into their lifeways.

The socio-economic and political history of the Tlingit is distinctive from either the Oglala-Lakota or the Eastern Tewa Pueblo societies included in this research. Within the context of Native American uneven development the Tlingit are often considered to be more economically affluent than those indigenous societies that were assigned to the reservation system, such as the Olgala-Lakota. This notion of affluencey derives from the spatio-temporal disconnect of the Tlingit, and other indigenous cultures within Alaska, during the eras of treaty organization, treaty dissolution, and assimilation. The Tlingit and other indigenous cultures of Alaska were able to avoid the many sociopolitical and economic intrusions of the United States government as much due to circumstance as anything substantive.

The circumstances differentiating the Tlingit from the Eastern Tewa Pueblos and the Oglala-Lakota experiences with federal policies aimed at assimilation and acculturation stem from spatio-temporal barriers. In brief, a spatio-temporal barrier isolated and excluded the Tlingit, and other indigenous Alaskans, from many of the United States's early federal policy initiatives aimed toward territorial dispossession of its indigenous peoples. Prior to the 1867 Treaty of Cession, ${ }^{117}$ in which the United States

\footnotetext{
${ }^{117}$ According to Andrews (1943; 109-131), at the foundation of the treaty was the fact that the Russians had been loosening their grasp on their possession in America for nearly thirty years. The first step was the lease of the lisiere of the coast from Portland Canal to Cape Spencer to the Hudson's Bay Company in 1840. Next was the sale of Ross, in California. Then followed the failure to expel the Hudson's Bay Company from Fort Yukon when they placed that post in the Russian territory and there maintained it. Russia was adverse to surrendering it to Great Britain, for she had been against them in the Crimean War, and had crowded them hard on their American borders. As a result of these influences the United States received the territory now known as Alaska.

The treaty was concluded by Wm.H.Seward, Secretary of State, on March 30, 1867, under which for the sum of $\$ 7,200,000$ the Russian 'purported' possessions in America were transferred to the United States.
} 
obtained 375,000,000 acres of land at the cost of roughly two cents per acre, Russia had been the dominant Western influence within the territorial bounds of the present state of Alaska. Within the context of the present day, the $\sim \$ 7,500,000$ spent to purchase the territory of Alaska may resemble a Black Friday door-buster, however, this monetary expenditure received mixed approval from Congress and the American people.

Examined from a historic perspective it is easier to discern why this purchase was received with some trepidation. The 1867 purchase of the territory occurred while the United States was still recovering from the social, political, and economic impacts induced during the era of Civil War, in addition to the effects from post war reconstruction. In addition, federally subsidized projects such as the transcontinental railroad, had yet to be completed and was experiencing considerable opposition from the Siouan peoples of the Powder River Basin whose traditional lands were being allocated to the Union Pacific in the form of land grants to be used as the railroad's right of way (Brown, 1977) ${ }^{118}$. In the end, the capitalist territorial logic of power prevailed and, in doing so, secured immeasurable amounts of natural resources and materials to expand commidification and escalate the profits of the timber, fur, fishing, and mineral industries.

October 18, 1867, three ships of the United States, the Ossipe, the Resaca, and the Jamestown, lay in the harbor of Sitka. At 3:30 p.m., to the accompaniment of a salute from the artillery of both nations, the Russian ensign was lowered and the Stars and Stripes raised.

${ }^{118}$ According to Asa Whitney, early proponent for the construction of the transcontinental railroad, who surveyed and foresaw the optimal route for the railroad's construction extending through Sioux lands as the main obstacle to impair completion. Whitney assured Congress that the native Americans were, "ready and willing to sell all that may be desirable for this object, and for a very small sum... and this road would produce a revolution in the situation of the red as well as the white man." Whitney shrewdly pointed out that the building of the railroad would drive the "savage" Sioux and their buffalo northward, "and we can then succeed in bringing the removed and small tribes to habits of industry and civilization, and their race may be preserved until mixed and blended with ours, and the Sioux must soon follow them." See Brown, 1977; pg. 28-31. 
From the perspective of historicizing these events and discourses within the framework of Ollman's (2007) Dance of the Dialectic it is easier to visualize the preconditions for the capitalist present as explainable within Harvey's (2006) unified field theory. Specifically, conditionality one, the material embedding of capital accumulation

processes in the web of socio-ecological life. In order to fully comprehend the impacts of capitalism through accumulation by dispossession it is necessary to examine the traditional Tlingit lifeworld and lifeways prior to the 1867 Treaty of Cession.

\section{Geographic Placement \& Spatial Organization}

Ecologically rich and diverse are perhaps the best descriptions for the environment of Southeast Alaska. Situated within resource rich Southeastern Alaska, traditional Tlingit territory extended from Yakutat to Ketchikan (Figure 30). In combination with the expansive costal environment, Southeast Alaska is home to a Sitka Spruce/Western Hemlock rainforest. The Tlingit people adapted their lifeways in relation with the natural resources provided by the surrounding environment. 


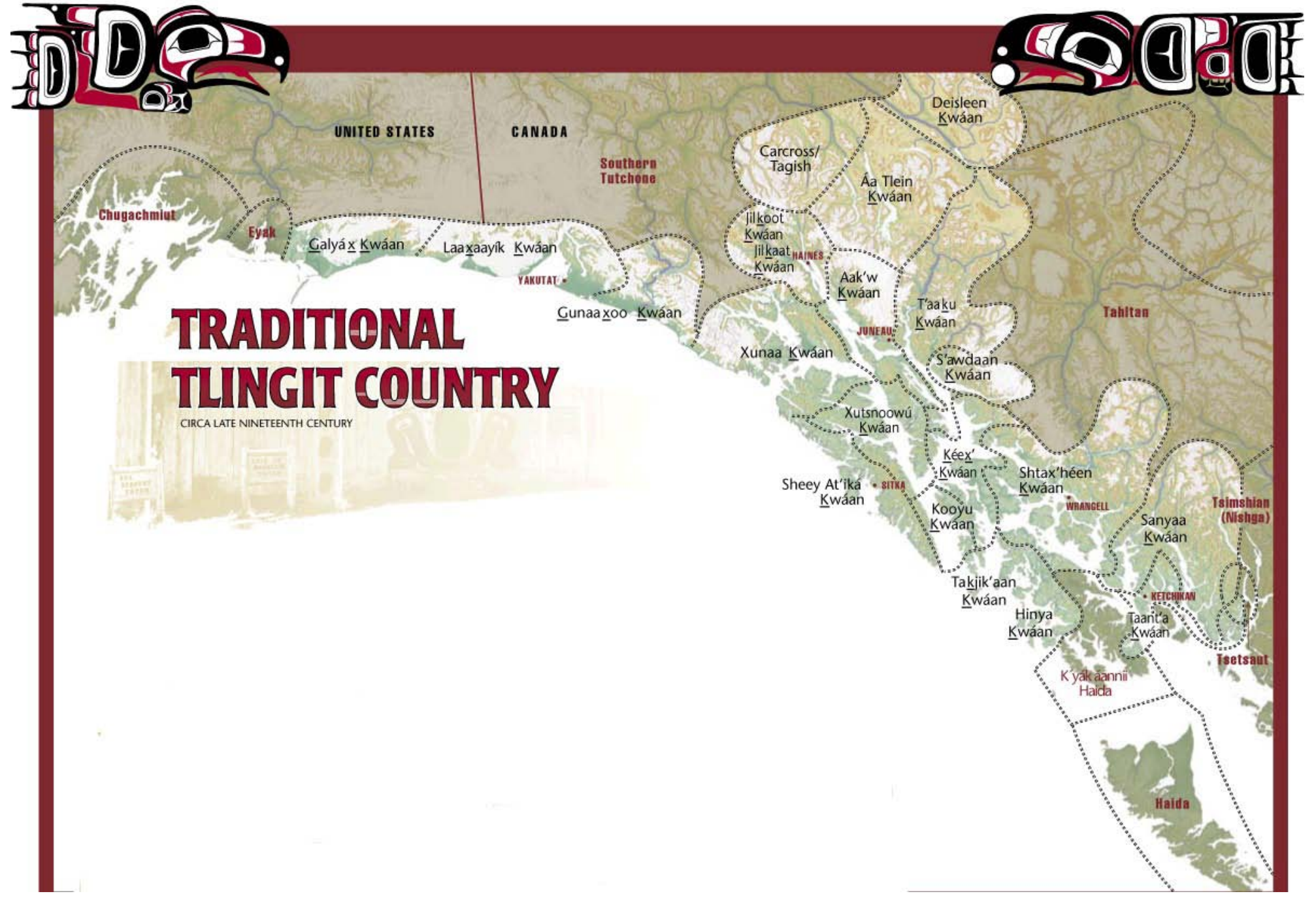

Figure 30: Map depicting traditional Tlingit Country. Source:

http://ankn.uaf.edu/Resources/mod/glossary/showentry.php?courseid=2\&eid=2436\&displ ayformat=dictionary

Much of the ecological abundance of this region is attributed to the diverse mainland and coastal ecosystems found in the area. For instance, topographically the coastal region consists of expansive areas of archipelagos, bays, and estuaries while, the mainland contains complex riverine systems and rugged coastal mountains. While the coastal ecosystem contained abundant forgeable marine flora and fauna such as mammals, seaweeds, seaberries, and fish. Whereas, the mainland ecosystem supported subsistence lifeways supported by the riverine salmon run and vast array of migratory game and seasonal flora.

Thornton (2008; 40-41) emphasizes the ecological diversity within the region that supported distinct microenvironments contributing to variances within Tlingit society 
such as, dialect. In addition, the variability in access to forageble foods within these microenvironments contributed to the development of socio-economic and political relations needed to support trade networks between Tlingit coastal and mainland villages and foreign settlements.

A part of the vast expanse of traditional Tlingit territory exist unique microenvironments supporting diverse species of flora and fauna. Depending upon location and history within these microenvironments certain at.óow are considered a specific clan's property. Food is a central aspect of Tlingit culture and therefore certain forms of at.óow are place specific and consist of clan rights over certain subsistence areas along rivers, coastline, berry patches, and etc. More abstract forms of at.óow encompass everything from stories, names, and designs to speeches. The knowledge of Elders or Cultural Bearers are significant to communicating the history of clan, their relationship within the environment, and the maintenance of at.óow. Utilizing the tradition of oral communication elders taught cultural values utilizing the surrounding environment as the classroom. For instance, many Tlingit lifeways are shared and taught to the youth by such as how to treat animals taken for survival, traditional methods for gathering and preparing plants, and reinforce the connections between sacred resources (such as salmon) and Tlingit people.

Tlingit production and subsistence patterns centers on resource availability and abundance. For instance, contemporary curriculums developed by the Sealaska Heritage Institute (2004) teach children traditional subsistence methods and production techniques and begin with those resources most abundant and species diverse such as trees, fish, sea mammals, berries, and indigenous plants as fiddlehead ferns. Reinforced through the use 
of oral communication, the knowledge of elders or cultural bearers, and immersion into the natural environment children are introduced to those resources their ancestors relied upon for centuries. For example, salmon Xáat is a vital, traditional subsistence source for the Tlingit therefore the curriculum is developed to inform children of the proper Lingít names of the five species of salmon found in this region, identify their habitats and life stages, in addition to, the correct Tlingit methods of showing respect to the salmon as well as traditional ways of catching, preserving and identifying salmon species. Throughout the instruction elders and cultural bearers provide the reinforcement of traditional cultural values, norms, and ethos utilizing sacred stories and cosmologies.

Numerous curricula utilizing similar instruction techniques exist for sea mammals, red cedar, yellow cedar, hemlock, spruce, hooligan, herring, and berries. Each provides the student with the traditional ecological knowledge of their culture in relation to the development of socio-economic and political organizations. The end goals of these programs are to educate the youth within the environment of their ancestors and to reinforce traditional lifeways through a shared lifeworld. The children are essentially learning who they are according to the spatio- historic relationship their ancestors shared and developed within the surrounding environment.

\section{'Traditional' Social Organization?}

The Tlingit were included within this research due to two predominate factors: the first being their uniqueness in relation to their socio-economic and political experiences within the constraints of federal Indian policy and in comparison to those of the OglalaLakota and Eastern Tewa Pueblos; second, reason derives from involvement and contact with other governments and economies, namely Russian and to a lesser extent Spanish, prior to contact with the United States and involvement within its capitalist economy. 
The Tlingit, along with the other indigenous cultures situated within the present bounds of the state of Alaska, were able to maintain a relatively independent existence from encroaching explorers and missionaries for centuries due to the harshness of the terrain and climate which were considered to be unsuitable for agricultural pursuits. Combined, these variables were in essence responsible for halting or limiting westward expansion and the introduction of the capitalist land tenure system within the territorial bounds of Alaska.

Figure 30 depicts traditional Tlinglit territorial extents from the scalar perspective of the tribe, moiety, clan, and clan house. From a western perspective, figure 31 may simply communicate spatial boundaries as defined by scales of ownership. This map, however, communicates more than ownership. As examined with the Oglala-Lakota, a sense of place and identity within indigenous cultures are often transferred through scalar socio-political levels of generality linked to ecological factors that communicate a sense of place. Therefore, the scale at which a person identifies themselves communicates a level of knowledge unique to specific shared socio-political and ecological history. For the purpose of this analysis, the next section briefly discusses the six traditional sociopolitical units comprising Tlingit social organization and the derivation of this social structure within the Tlingit cosmology. 


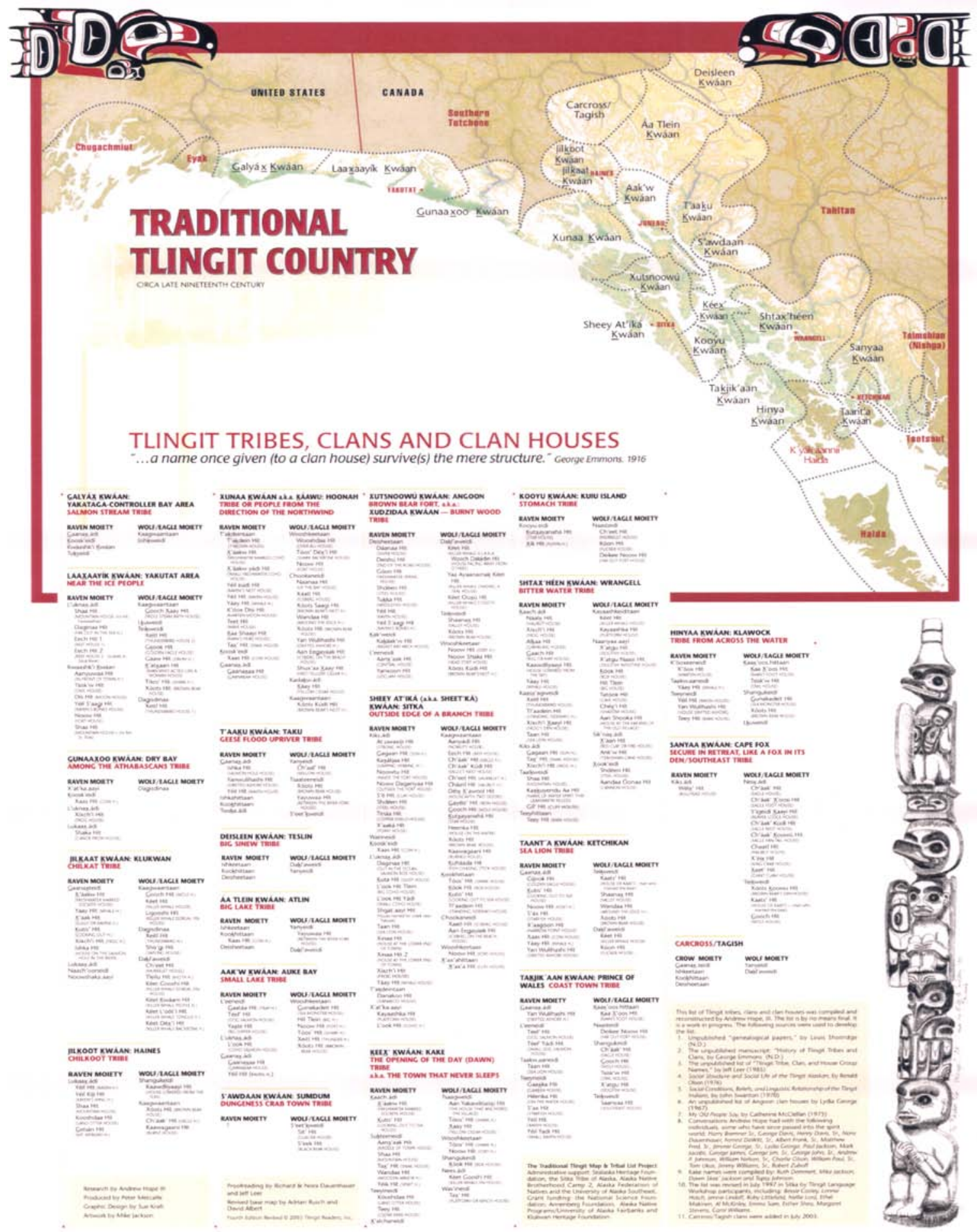

Figure 31: Map depicting Tlingit Tribes, Clans, and Clan Houses ${ }^{119}$. Source: http://ankn.uaf.edu/Resources/mod/glossary/showentry.php?courseid=2\&eid=2436\&displ ayformat=dictionary

${ }^{119}$ The Traditional Tlingit tribes, clans, and clan houses map is a project of the Sealaska Heritage Foundation, the Sitka Tribe of Alaska, and the Alaska Federation of Natives, with grant funding provided by the National Science Foundation. 


\section{Tlingit Socio-Political Units}

In order to more thoroughly examine the connections between place and identity construction in relation to the social and cosmologic elements two fundamental socioecological components of Tlingit culture must be incorporated within the analysis, at.óow and shagóon. Exhaustive research conducted by Thorton (2008) comprehensively examines the concepts of at.óow and shagóon as essential variables connecting the sacred to the profane, the material to ethereal, and the ideological to reality in relation to the Tlingit primordial union of the ancestral landscape or place, as translated within the context of the present, and transcends to the future. At.óow translates in Tlingit literally as "owned things" (Thorton, 2008; 29-30) and is described by the anthropologist and Tlingit Dr. Rosita Worl ${ }^{120}$ as:

At.óow are the most prized possessions of a clan. At.óow is literally translated as "an owned or purchased object" and can refer to land or sacred sites, celestial bodies such as the moon and sun, names, stories, songs, spirits and crests. The rights to these objects or a clan's at.óow were acquired through an ancestor. On occasion, the payment involved the death of an ancestor. The event in which this occurred may be recorded as a crest or spirit design on a physical object or through names, songs and stories. Clan crests and spirit designs are socially and spiritually important to the Tlingit. A crest depicted on an object identifies clan members and reinforces the kinship bonds among clan members. Crests are also considered to be sacred in that they embody the spirits of ancestors and unite them with their living clan members. (From http://www.pbs.org/harriman/explog/lectures/worl.html)

\footnotetext{
${ }^{120}$ Dr. Rosita Worl, whose Tlingít names are Yeidiklats'akw and Kaa haní, is an Eagle of the Shungukeidí (Thunderbird) Clan from the Kaawdliyaayi Hit (House Lowered from the Sun) of Klukwan and a Lukaax.ádi yadi (Child of the Sockeye Clan). She is the president of the Sealaska Heritage Institute, a member of the Alaska Federation of Natives board, and teaches at the University of Alaska-Southeast.
} 
While shagóon translates as "heritage or destiny" (Thorton, 2008; 37-39), Worl further describes this concept in the below excerpt:

The Tlingit have a concept known as "Haa Shagoon" that means "our ancestors" and simultaneously unites ancestors with the present and future generations. (From http://www.pbs.org/harriman/explog/lectures/worl.html)

Communicated by Thorton (2008), at.óow and shagóon are elemental components within the Tlingit social structure and organization because they reveal the socioecologic, socio-geographic, and socio-political factors informing a persons sense of place. Essentially, Thorton's (2008) research revealed that connections exist between Tlingit's perception of place and identity and are traceable through the sacred and profane relationships (at.óow and shagóon) binding social organization. Figure 32, identifies the six Tlingit socio-political units prior to the 1867 Treaty of Cession of Alaska between the United States and Russia. Within traditional Tlingit society, the coarsest level of generality, a person identifies themselves as belonging to a Nation or Lingit. 


\begin{tabular}{|c|c|c|c|}
\hline Socio-Political Units & Equivalent Example & No. of Units & Generality \\
\hline Nation or Lingít & $\begin{array}{l}\text { Weak political status based } \\
\text { primarily on common language } \\
\text { and culture. }\end{array}$ & 1 & \multirow[t]{5}{*}{ most general } \\
\hline Moiety & $\begin{array}{l}\text { Important for organizing } \\
\text { reciprocal exchange in ritual } \\
\text { politics. }\end{array}$ & 2 & \\
\hline Village or Kunáan & $\begin{array}{l}\text { Weak political status based on } \\
\text { common habitation, usually of } \\
\text { a single winter village. }\end{array}$ & $13-18$ & \\
\hline Clan or $\mathrm{Naa}$ & $\begin{array}{l}\text { Central sociopolitical unit } \\
\text { based on matrilineage. }\end{array}$ & $70+$ & \\
\hline House or Hít & $\begin{array}{l}\text { Based originally on the segment } \\
\text { of a matrilineage residing in } \\
\text { one house. }\end{array}$ & $200+$ & \\
\hline Person or Káa & $\begin{array}{l}\text { Sociopolitical status acquired } \\
\text { by birth, but big names/titles } \\
\text { also reserved for high born } \\
\text { Tlingits who distinguish } \\
\text { themselves }\end{array}$ & $10,000+$ & most specific \\
\hline
\end{tabular}

Figure 32: Illustration of the traditional socio-political units of the Tlingit (1750-1812) as classified according to generality. Modified from: Thornton, 2008; pg.43.

While this level of identification is considered from the perspective of a Tlingit, the most general, it serves as a means to communicate a ubiquitous sense of place and identity to those outside the Lingit. In addition, this more indigenous perspective provides the foundational basis for understanding the elements of at.óow and shagóon as communicated through a shared language, Lingit. Sharing a common Lingit is important because as seen in Figure 32, Tlingit society is highly stratified. Therefore, the ability to communicate who you are aids in establishing a shared or communal sense of place and identity from multiple socio-political scales.

For instance, Tlingit elder Dr. Walter Soboleff created and organized a document entitled, Tlingit Protocols: Forming a Tlingit World View (2000). Soboleff (2000) 
communicates that at the heart of Tlingit culture is respect. In order to perpetuate respect through generations requires an understanding of traditional Tlingit social and ceremonial protocols. Soboleff (2000; pg.1) explains:

Tlingit people are taught to speak with sensitivity, as thoughtless and careless use of words will harm the unity of the family, clan, and can harm other relationships. Words are powerful; they can cause trouble and unrest. The expression used to describe this concept is Shx'adaat hundat, which means "to weigh your words with care." A Tlingit clan is required to pay damages to others for verbal or other errors of its clan members.

As explained in the above passage, the weight of words within Tlingit society carries considerable social-political and economic consequences. Therefore, it should be of no surprise that Soboleff (2000; pg.3) details the proper protocol for inquiring and introducing yourself to a person of unknown identity. First, you are to ask the person's name, followed by asking their tribe and clan (Soboleff, 2000; pg.3).

Addressing these questions during an introduction reveals an individuals connection within three finer scales of socio-political affiliation: moiety, village/ Kwáan, and clan/Naa. In addition to addressing scales of socio-political affiliation, these questions also intentionally reveal spatial connections to clan at.óow and subsistence patterns. The process of naming within Tlingit culture, whether it be at the scale of the individual or clan house, communicates detailed social, political, and economic information connecting place and identity to a shared history/heritage (shagóon). Traditionally, Tlingit society is matrilineally ${ }^{121}$ structured with the clan functioning as the

\footnotetext{
${ }^{121}$ Within traditional Tlingit culture, when a woman marries the husband physically moves to the wife's clan but retains affiliation with his original birth clan. All offspring of the marriage, become members of and trace decent through the mother's clan. Clan affiliation or shagóon forms the basis for communicating
} 
basis for socio-political identification therefore, the process of naming typically establishes connections between these social identifiers.

To demonstrate the importance of the naming processes in conjunction with the effectiveness of Soboleff's (2000) protocol for introductions, each of the three questions will be addressed to explain the type of information revealed during this interaction. Question one, asking an individuals name may seem very general or broad, however, as aforementioned in Tlingit culture, names reveal considerable amounts of information concerning those elements of at.óow and shagóon that contribute to a shared sense of place and identity. Traditionally, names are considered a form or type of clan or house at.óow ${ }^{122}$. Within this highly stratified society, the process of naming a child provided a means to establish an individuals role within the collective identity of the greater Tlingit social structure. Therefore, a person's name in itself reveals considerable information concerning an individual's shared history/heritage (shagóon) in relation to other Tlingit houses and clans ${ }^{123}$.

The next question in Soboleff"s (2000) procedure for formal identification addresses the person's tribal affiliation. The proper uses of the term tribe has been discussed throughout this document. The term tribe, within the context of Soboleff's (2000) guide in addition to it's use in figure 31 were at first confusing and seemed to conflict with another socio-political unit, the Kwáan. After further research it was determined that in contemporary times the term tribe is often used interchangeably with

not only a shared sense of place and identity through a common history but, also represents the fundamental scale for property 'ownership' or at.óow.

${ }^{122}$ Inherited clan names may also be acquired through debt. If a clan is indebt to another clan they may offer at.óow, as a inherited clan name, until the debt is paid off. Once the debt is paid the at.óow is usually returned.

${ }^{123}$ Tlingit names are protected by cultural and intellectual property rights. 
the term Kwáan within Tlingit society. Identification at the tribe or Kwáan scale according to Thorton (2008; pg. 44-51) essentially denotes, an individual's social geography within a certain living space comprised of the total land and waters used and controlled by clans residing in a particular winter village. As seen in figures 30 and 31 Kwáans are used as a means to demarcate spatial boundaries namely for the purpose of subsistence. Traditionally, these social units did not comprise a political structure, formal political organization is held at the clan level. Identifying oneself at the Kwáan scale informs persons of a specific area of traditional ecological knowledge and shagóon in which you and other persons of the same K wáan share a common knowledge and history.

The third question outlined by Soboleff (2000) requests you introduce yourself according to clan affiliation. The clan structure provides the dominate social, political, and economic identifier for Tlingit culture. In conjunction with individual names, the names of clans specify a unique and shared history/heritage (shagóon) communicated and transferred through multiple generations and are oftentimes tied to topographic or natural places. In addition to sharing a common history/heritage (shagóon), members of clans share rights to physical (berry grounds, salmon streams, hunting grounds, and etc.) and intellectual property (songs, inherited names, crests, and etc.), i.e. at.óow.

\section{Conclusion}

Revealed throughout this discussion, the concepts of being and place are intertwined with the Tlingit concepts of shagóon and at.óow and intricately communicated through a highly refined process of naming. While exploring Soboleff's (2000) procedures for personal introduction was a valuable method to clarify connections 
between the hierarchical organization of Tlingit social structure in relation to the scalable concepts of shagóon and at.óow. Similar abstraction and translation issues encountered during the textual analysis of the Tlinglit cosmologies were also experienced in this analysis. As a result, the role of the moiety within the Tlingit social structure seemed to be muted within the literature compared to the information and research available for the clan and house. Within the Tlingit cosmologies, the roles of the Raven and Wolf moieties are integral to comprehending the spatio-temporal components informing place and identity development. However, as in the textual analysis, there appears to be a gap in the literature that connects the socio-spatial significance of moieties within the hierarchical Tlingit social structure.

For the purpose of this research it is important to acknowledge the significance of the socio-political scale of the moiety as a means to transfer a shared sense of place and identity (shagóon) throughout the spatial extent of the entire Tlingit territorial bounds. For instance as illustrated in figure 32, the Kwáan, clan, and house are spatially distributed socio-political organizations with scalable access to the shagóon and at.óow that inform a unified sense of place and identity. While the Kwáan, clan, and house seem to represent a more spatially refined means to communicate place and identity, the moiety unit establishes a common sense of place and identity over a large spatial extent and, more importantly, throughout the Kwáan, clan, and house socio-political units.

The remainder of this chapter briefly examines the socio-political and economics interactions that occurred between the Tlingit and Russians prior to the 1867 Treaty of Cession. Within this section specific attention is devoted to exploring the isolationist 
attitude of the Tlingit in respect to Russian occupation which, may identify one plausible factor contributing to the historic and cosmologic literature gap.

\section{Russia Involvement and Occupation}

Similar to the Tewa's long and turbulent socio-policial and economic interactions with the Spanish, the Tlingit had extensive contact with other Western colonial governments prior to interaction with the United States. Russia, was the predominate Western influence within the contemporary spatial bounds of the state of Alaska prior to the United States acquisition of the territory through the 1867 Treaty of Cession. Fur, was the natural resource sparking Russian interests in exploration beyond their most eastern boundary of Siberia ${ }^{124}$. Czar Peter the First, enticed by the prospect of discovering an untapped source for economic gain, prompted the first expeditions organized and led by Vitus Bering ${ }^{125}$. The primary objective of this early expedition was to map and determine if a landmass connected Russia's easternmost territory of Siberia to North America.

Czar Peter the First would not live to see Bering and his crew return to St. Petersburg. If he had, he would have learned that an overland passage connecting the two continents did not exist but, a sea route was a minimal fifty-five nautical miles. The information obtained from the early expeditions commanded by Bering provided the foundation directing Russia's socio-economic and political agenda within Alaska.

\footnotetext{
124 Andrews (1943) suggests, the interests of the Russian empire in those territories east were sparked by the amount and quality of furs brought back by Cossacks who had followed the Chukchee hunters to the Sea of Okhotsk.

${ }^{125}$ Vitus Bering, of Danish origin and captain in the Russian Navy, for whom the Bering Sea, Bering Straight, Bering Island, and etc... are contemporarily known was a prominent figure who contributed to the mapping of terra incognita, i.e. the Northern Pacific.
} 
According to the Western colonial ethos of ownership, Russia formally retained possession of the lands and natural resources within the territorial bounds of Alaska for well over one hundred years. Throughout their occupation the Russians, operating under the influence and control of the Russian-American Company ${ }^{126}$, were never fully able to conquer the natives inhabiting the area, including the Tlingit. Relations between the indigenous cultures and, first, the Russian military, followed by the traders, trappers, and settlers, were never completely harmonious. For the most part the Tlingit, in addition to other indigenous societies, were able to successfully stave off Russian settlement and limit it to predominantly Southeastern coastal areas, with little intrusion into the interior mainland.

However, gradually, the occupied areas of North America grew closer to Alaska's terra incognita. From the East, Britain's Hudson Bay Company began to encroach within the territory. In pursuit of westward expansion from the South, the United States was acquiring copious amounts of land at a very rapid rate previously held by the French and Spanish $^{127}$. Essentially closing the spatial gaps for settlement, trade, and development to occur between the booming industrial centers of the Eastern Atlantic and Western Pacific coasts.

By the 1867 Treaty of Cession, the United States was well entrenched in the policy and doctrine of accumulation of dispossession in relation to its indigenous

${ }^{126}$ Under state sponsorship, support, and protection of the Russian government the Russian-American Company played a dominate role in shaping the historic socio-economic and political landscape that is evident still to this day. For instance, the Russian-American Company was granted a monopoly on trade within the region, in addition to, the responsibility of establishing settlements, constructing works of defense, providing a rudimentary justice system, and maintaining churches and schools (Andrews, 1943). The Russian-Orthodox church became well established within settlement areas such as Sitka and to this day is an excellent source for historic socio-political and economic interactions between Alaska's indigenous cultures during Russian occupation.

${ }^{127}$ Louisiana Purchase of 1803 and Treaty of Guadalupe Hildago of 1848. 
cultures. As aforementioned, Russian interest in the territory of Alaska first stemmed from the economic gains to be made from the abundance of furs within the region. However, by 1867 the fur industry had fallen into decline due to overuse and mismanagement of resources. In addition, the military and economic effects from the strain of the Crimean War had deteriorated Russia's influence within the territory. Russia, faced with economic hardships induced by mismanagement of natural resources and a lengthy war, in addition to indigenous populations that remained hostile, continued to lose foothold in the territory and specifically as opposing nations (namely the United States and Britain) sought to interject their own political and economic influence.

Although the fur industry was in steady decline due to overuse, the prevailing theory ascertained this problem easily corrected with the application of appropriate resource management plans. Also, other maritime industries, such as whaling and fisheries, had yet to be fully developed within the territory. With these known resources still available for exploit, serious interest in regards to purchasing the territory was pursued by the United States and Britain. It is widely acknowledged that as a result of Britain's opposition role in the Crimean War, Russia chose to sell the territory to the United States.

Russia, operating under the guise of the Russian-American Company, did not fully conquer the indigenous cultures as was experienced in other areas of North America as in the desert Southwest. Considerable Western influences were visible within indigenous cultures in those areas where the Russia-American Company developed and established trade along the coast. For instance, according to Andrews (1943;110), the natives were divided into two classes: the settled natives, or those subject to Russian 
control....and the wild tribes, over whom the company exercised little control. In addition, large Creole ${ }^{128}$ populations were also seen in areas where the Russian-American Company had established trade, settlements, or military posts.

\section{Conclusion}

The indigenous cultures of Alaska never fully embraced the era of Russian occupation and settlement. This relationship of no love lost is best summarized in Article III of the 1867 Treaty of Cession which states:

The inhabitants of the ceded territory, according to their choice, reserving their natural allegiance, may return to Russia within three years; but if they should prefer to remain in the ceded territory, they, with the exception of uncivilized native tribes, shall be admitted to the enjoyment of all the rights, advantages, and immunities of citizens of the United States, and shall be maintained and protected in the free enjoyment of their liberty, property, and religion. The uncivilized tribes will be subject to such laws and regulations as the United States may, from time to time, adopt in regard to aboriginal tribes of that country. (Source: http://www.ourdocuments.gov/doc.php?doc $=41$ \&page $=$ transcript $)$

Essentially, this article in no way or form included the consultation or input of any indigenous person during the treaty's organization and development prior to formal execution. In short, it seems the Russians are simply stating to the United States, well they're not our problem anymore, let's see how you do. Chapter nine examines those pertinent laws, acts, and legislation influential in shaping the socio-political and economic interactions influencing the Tlingit lifeworld and lifeways.

Recognizing the unique spatio-historic juxtaposition of the Tlingit in comparison to the Oglala-Lakota and Tewa, chapter nine analyzes the socio-economic and political

\footnotetext{
${ }^{128}$ In this reference, individuals of Creole decent are persons who's mother is of indigenous decent and father of Russian heritage.
} 
interactions between the United States and the Tlingit as this society becomes integrated within the Western capitalist economy. Specific attention is directed toward the reorganization of the Tlingit traditional social structure as this society became federally recognized as 'corporations' through the passage of the Alaska Native American Claims Settlement Act (Figure 33). Dombrowski's (1995 and 2001) and Thornton's (2001 and 2008) research into the effects of federal Indian policy on the social restructuring of Tlingit society is integral to this research. Dombrowski and Thornton construct comprehensive analyses of the paramount differences which existed between traditional Tlingit perceptions of their lifeworld and lifeway as viewed prior to the introduction of capitalism and heavy industry in the state compared to the contemporary cultural systems now in place.

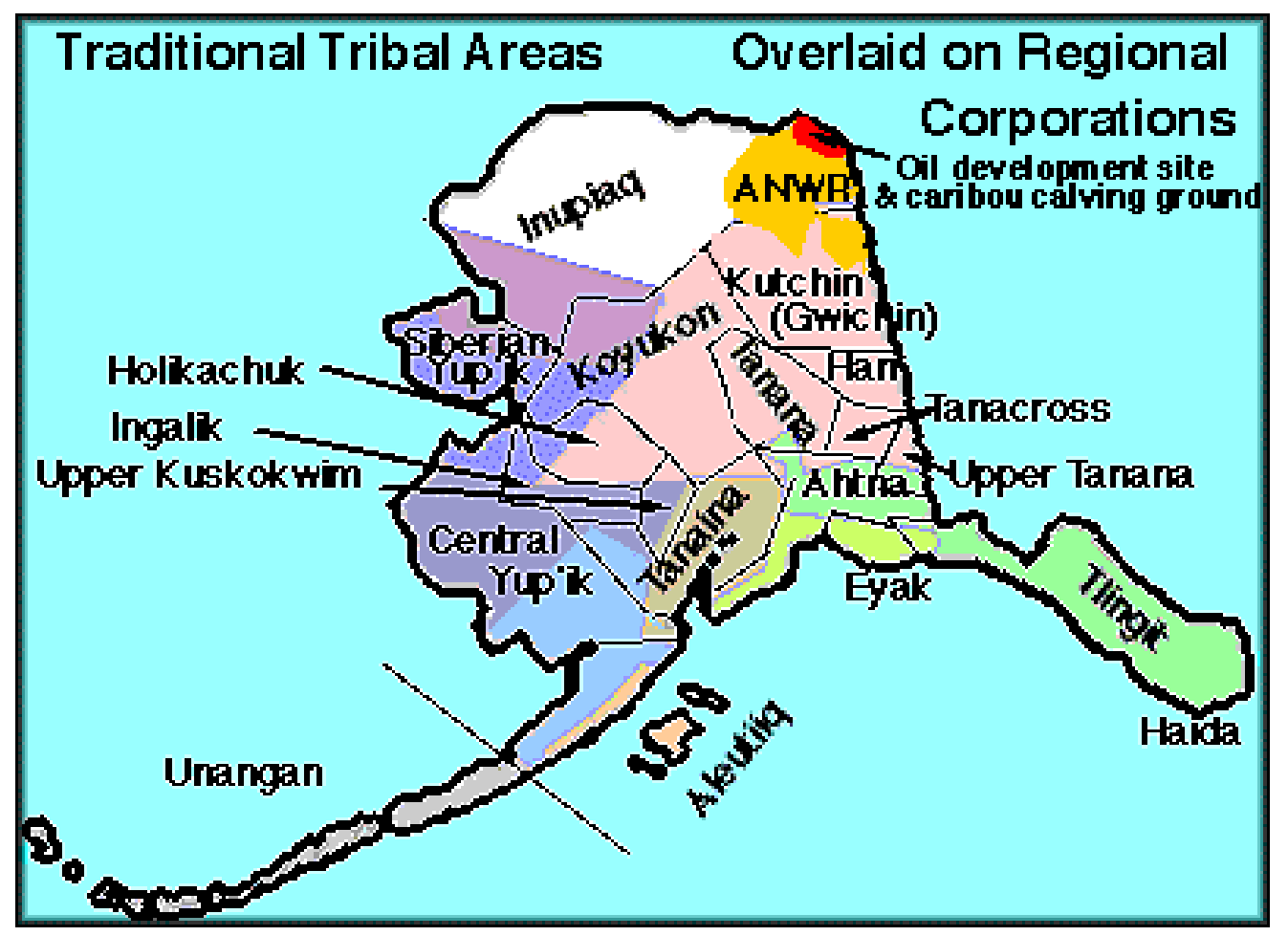

Figure 33: Traditional Tribal Areas of Alaska as Delineated by Corporation Boundaries. Source: $\underline{\text { http://www.kstrom.net/isk/maps/ak/aklinks.html }}$ 


\section{Chapter 9: Engaging Harvey's Conditionalities}

\section{Introduction}

Historically, Native American uneven development was and continues to be marred by the territorial logic of power that predominantly operates as accumulation by dispossession and continues to function within the neo-conservative imperialism movement prevalent in the United States socio-political economy. During this time the federal government pursued their policy of accumulation by dispossession through treaty organization aimed at reducing Native American territories. As stated by Thomas Jefferson to the Indian agent, William Henry Harrison, for the North and West tribes:

'...the decrease of game rendering their subsistence by hunting insufficient, we wish to draw them to agriculture, to spinning and weaving’ (In Prucha, 1994: 118).

When formal treaty organizations ceased in 1871, congress continued to direct the lifeworlds of Native Americans directly, with no voice from the people, through the establishment of Acts (Indian Removal Act, Homestead Act, Dawes Act, and etc.) specifically aimed to sell off lands, extract mineral resources and acculturate these peoples in Western 'civilization’. From this period to the era of Indian SelfDetermination, reservations political and economic systems were controlled by federally appointed agents from first the Bureau of the Interior and, later, the Bureau of Indian Affairs. This historical period proved detrimental to preserving Native American culture. Reservations became essentially characterized economically and politically as 'captive nations’ and 'internal colonies’ (Snipp, 1986). These pieces of legislation were very important in creating and establishing a pattern of uneven development throughout Indian country. 
The objective of this chapter is to better establish the preceding argument that uneven development in Native American cultures stems from two prominent conditionalities: (2) accumulation by dispossession and (3) the law-like character of capital accumulation through space and time. Understanding the impact of these two conditionalities on influencing Native American perceptions of place and identity, and in turn their lifeworlds and lifeways, are paramount to this research. To a lesser extent, conditionality one is examined in relation to the spatio-historic reaction of these Native American societies to the prevalence, or lack there of, of capitalist culture within the web of daily life. While chapters six, seven, and eight have discussed the actions of Native Americans in regard to conditionality four, chapter ten examines this conditionality from a more contemporary perspective. The following section discusses how conditionalities two and three were spatio-historically implemented and led to uneven development in Native American societies.

\section{Uneven Development and Accumulation by Dispossession: The Native American Experience}

As discussed in chapter two, accumulation by dispossession is a fundamental conditionality interwoven into both capital and territorial logics of power. Dispossession, perpetuated through these logic of power and enforced through socio-economic and political action has proven detrimental by displacing Native American populations from their traditional lifeworlds, livelihoods and territories.

As reiterated throughout this research, the development of Native American culture within the spatio-historic evolution of the United States is complex and unique. Much of this complexity stems from Native American's unique extra-constitutional 
status, best characterized by Prucha (1994) as a political anomaly. The role and responsibility of federal acts, treaties, and case law influenced Native American lifeworlds and lifeways through territorial eminent-domainesque initiatives sponsoring, encouraging, and perpetuating uneven development throughout 'Indian Country' (figure 34). Explored throughout this research are the intimate connections the Oglala-Lakota, Eastern Tewa, and Tlingit share with their surrounding environment. Traditionally, these connections were reinforced through shared cosmologic identities which, communicate a common sense of place experienced through shared lifeways. The practice and sharing of lifeways, as explored in chapters five through eight, provides a historic connection to the conceptual/lived spaces comprising societal lifeworld. Therefore, it cannot be overstated, when tribal land-bases or territories are altered, as through capitalist encroachment, there is an undeviating affect upon the evolution and sustainability of Native lifeworlds and lifeways.

\section{Datum}

The political quagmire encompassing the status of Native Americans as either independent sovereigns or wards under the guardianship of the United States has been debated since the founding of this nation. The sovereign versus ward debate is of particular concern because political status defines the freedom through which indigenous cultures have control over their own economic assets. Historically these assets are landbased. However, many assets now fall into the realm of intellectual property rights and are now subject to the laws, rules, and regulations supporting the capitalist logic of power. 
Discussed throughout chapters six to eight, no matter the occupying force or nation, Native Americans have overwhelmingly fought and voiced their opinion that all peoples native to the area comprising the territorial boundaries of the United States have and always will be free and independent sovereigns. Whereas, historically, the prevailing ideology informing the opinion of the United States federal government, in relation to Native Americans, favors economic benefits obtained first through sovereign relations and later forced acculturation sponsored through guardianship.

Figure 34, is a detailed timeline illustrating significant federal treaties, acts, laws and events affecting the sovereign status of indigenous cultures within the United States. Although, this research is especially concerned with legislation and events occurring 1871 to the present, important political happening occurring pre 1871 are included. In addition, this timeline graphs Harvey's four conditionalities and the predominate logic of power dictating the form of accumulation by dispossession occurring throughout the historic implementation of capitalist philosophies promoting uneven development within Native American communities. 


\section{Significant Events, Federal Treaties, Acts, \& Laws Affecting \\ Conditionalities \\ Native American Sovereignty}

\section{One Two Three Four}

|

United States Constitution: 1789

Trade and Intercourse Act: 1790

Mexican Independence from Spain: 1821

Johnson v. McIntosh 'John Marshall Ruling': 1823

Indian Removal Act: 1830

Cherokee Nation v. Georgia: 1831

Worcester v. Georgia: 1832

Creation of U.S. Department of Indian Affairs (War Department): 1834

First Russian-Greek Orthodox Church School established in 'Alaska': 1843

War between the U.S. and Mexico: 1845: 1848

Treaty of Guadalupe Hidalgo: 1848

U.S. Department of Indian Affairs (Department of the Interior): 1849

Treaty of Fort Laramie: 1851

Warren Commission (Paha Sapa): 1858

Bureau of Indian Affairs (Department of the Interior): 1861

Homestead Act: 1862

Lakota (Teton) Uprising: 1863-1864

Peace Commission Recommendation: 1867

U.S. Purchase of Alaska: 1867

Indians denied the right to vote: 1868

Second/Revised Fort Laramie Treaty: 1868

Southern Plains War: 1868-1869

Transcontinental Railroad Completed: 1869

Cherokee Tobacco Case: 1870

Gold discovered in the Black Hills: 1871

Treaty making formally ends: 1871

U.S. Mining Act: 1872

Allission Act: 1875

Custer in Black Hills: 1874

Battle of Little Big Horn: 1876

Black Hills Act: 1877

Active

$-\cdots-\cdots \rightarrow$ Passive

Territorial

$-\cdot-\cdots \cdot$ Intellectual
Sioux War for Black Hills: 1876-1877

Beginning of Salmon Industry: 1878

Reynolds v United States: 1879

First Important Gold Discovery in Alaska: 1880

United States v. McBratney: 1883

Ex parte Crow Dog: 1883

Organic Act Congress acknowledges right of Native Alaskans to territorial lands: 1884

Figure 34: Socio-political and economic timeline illustrating Harvey's (2006: 75) four conditionalities. 


\section{Conditionalities}

\section{One Two Three Four}

Seven Major Crimes Act: 1885

Dawes General Allotment Act: 1887

Oklahoma Land Run: 1889

Emergence of the Ghost Dance: 1890

Wounded Knee Massacre: 1891

Indian Leasing Act: 1891

First Oil Wells drilled in Alaska at Cook Inlets: 1898

Proclamation 37 Creating the Alexander Archipelago National Forest: 1902

Cherokee Nation v. Hitchcock: 1902

Lone Wolf v. Hitchcock: 1903

Antiquities Act: 1906

Winters Act (water rights): 1908

Alaska Native Brotherhood Formed: 1912

World War I: 1914-1918

Alaska Mineral Leasing Act: 1920

U.S. Indian Citizenship Act: 1924

Pueblo Land Act: 1924

Alaska Territory Game Law: 1924

The Meriam Report: 1928

Wheeler-Howard Indian Reorganization Act: 1934

Johnson-O'Malley Act: 1934

Omnibus Tribal Leasing Act:1938

World War II: 1939-1945

Hanna Opinion: 1944

National Congress of American Indians: 1944

U.S. Indian Claims Commission: 1946

Folta Decision: 1952

Relocation: 1949-1960

Public Law 280: 1953-1954

Termination Era: 1953-1954

Alaska Statehood Act: 1958

Court of Claims Rules Tlingits and Haidas land title not extinguished: 1959

National Indian Youth Council: 1961 American Indian Chicago Conference 'A Declaration of Purpose': 1961

Tlinglit and haida Indians v United States: 1968

Vietnam War: 1965-1973

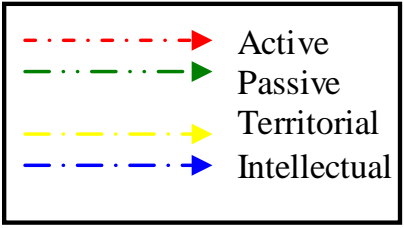

National Historic Preservation Act: 1966 American Indian Movement Founded (AIM): 1968 Indian Civil Rights Act: 1968

'Indians of All Tribes' Occupation of Alcatraz: 1969

National Environmental Protection Act: 1969

Figure 34: Socio-political and economic timeline illustrating Harvey's (2006: 75) four conditionalities. 


\section{Conditionalities}

One Two Three Four

Nixon's Special Message on Indian Affairs: 1970

Indian Termination Act: 1971-1973 Aamodt I (Pueblo Water Rights): 1971

Trail of Broken Treaties: 1972

Alaska Pipeline Authorization Act: 1973

Alaska Native Claims Settlement Act: 1974

Boldt Decision: 1974

Indian takeover at Wounded Knee, South Dakota: 1974

Trans-Alaska Oil Pipeline: 1974

Limited Entry License Fishing System Enacted in Alaska: 1974-1975

Pine Ridge Reservation Shootout: 1975

Indian Self-Determination and Education Assistance Act: 1975

Helsinki Accords: 1975

First Annual Un-Thanksgiving Day: 1976

Working Group on Indigenous Populations Draft Declarations of Principles (13) for the Defense of the Indigenous Nations and Peoples of the Western Hemisphere: 1977

Santa Clara Pueblo v Martinez: 1978 Indian Child Welfare Act: 1978

American Indian Freedom of Religion Act: 1978

Tribally Controlled Community College Assistance Act: 1978

Treaty Fishing Rights of the U.S. Supreme Court (Boldt decision): 1979

Alaska National Interest Lands Conservation Act: 1980

Alaska National Petroleum Reserve: 1980

Camp Yellow Thunder (Black Hills, South Dakota): 1981-1987

Indian Mineral Development Act: 1982

Voight Decision: 1983

Nuclear Waste Policy Act: 1983

Aamodt II (Pueblo Water Rights): 1985

-...... $\rightarrow$ Active

$\longrightarrow \cdots \rightarrow$ Passive Territorial Intellectual
Alaska Native Claims Settlement Act Amendments: 1987 Indian Gaming Regulatory Act: 1988 National Museum of the America Act: 1989 Native American Language Act: 1990 Indian Arts and Crafts Act: 1990 Native American Grave Protection and Repatriation Action: 1990 Tongass Timber Reform Act: 1990 Alaska Wilderness Recreation and Tourism Association v U.S. Forest Service: 1994

Native American Free Exercise of Religion Act: 1994
Executive Order, October 21 on Tribal Colleges and Universities: 1996
Executive Order on Native American Sacred Sites: 1996
Declaration on the Rights of Indigenous Peoples: September 15, 2007
Claims Resolution Act of 2010: December 8, 2010

Native American Free Exercise of Religion Act: 1994
Executive Order, October 21 on Tribal Colleges and Universities: 1996
Executive Order on Native American Sacred Sites: 1996
Claims Resolution Act of 2010: December 8, 2010

Native American Free Exercise of Religion Act: 1994
Executive Order, October 21 on Tribal Colleges and Universities: 1996
Executive Order on Native American Sacred Sites: 1996
Declaration on the Rights of Indigenous Peoples: September 15, 2007
Claims Resolution Act of 2010: December 8, 2010

Native American Free Exercise of Religion Act: 1994
Executive Order, October 21 on Tribal Colleges and Universities: 1996
Executive Order on Native American Sacred Sites: 1996
United Nations Declaration on the Rights of Indigenous Peoples: September 15, 2007
Claims Resolution Act of 2010: December 8, 2010

Native American Free Exercise of Religion Act: 1994
Executive Order, October 21 on Tribal Colleges and Universities: 1996
Executive Order on Native American Sacred Sites: 1996
Declaration on the Rights of Indigenous Peoples: September 15, 2007
Claims Resolution Act of 2010: December 8, 2010

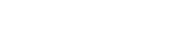

Figure 34: Socio-political and economic timeline illustrating Harvey's (2006: 75) four conditionalities. 
As seen in Figure 34, the political ideologies actively promoting Native

American accumulation by dispossession were prominent in the early 1800's with congressionally sponsored and approved Indian Removal Bills ${ }^{129}$. Within the established timeframe of this research, the policies dictating accumulation by dispossession were, perhaps, brought to the forefront of America’s mainstream social consciousness during the notorious Indian wars fought during the mid to late $19^{\text {th }}$ century. These wars, unfolding in such places as the Little Big Horn and Sand Creek, set forth the precedence for the dramatic deterioration of socio-political and economic relations between the United States and Native Americans. At the terminus of these wars Native Americans found their once acknowledged and recognized sovereign political status permanently modified to that of guardianship within the eyes of the United States. Essentially, the federal government declared plenary power over all Native Americans and, in fact, through the Supreme Court ruling concerning Lone Wolf vs. Hitchcock (1903) retroactively established the precedence for Congressional plenary power over Native Americans ${ }^{130}$ (Deloria, 1974 and Prucha, 1984 and 1994).

\footnotetext{
${ }^{129}$ Cherokee Nation vs. Georgia is of particular concern to this research. In brief, the Cherokee of Georgia proclaimed they were a sovereign nation and therefore not subject to the law of the state of Georgia. The case made it to docket of the Supreme Court where the ruling made by Chief Justice Marshall declared: they (the Cherokee) have been uniformly treated as a State from the settlement of our country. The numerous treaties made with them by the United States recognize them as a people capable of maintaining the relation of peace and war, of being responsible in their political character for any violation of their engagements, or for any aggressions committed on the citizens of the United States by any individual of their community. Although Marshall made this proclamation he threw the case out of court because he did not see the Cherokee as a foreign nation. He asserted that Indian tribes were, instead, "domestic dependent nations: and that their relation tot he United States "resembles that of a ward to this guardian." (See Prucha, 1994, 161-168)

${ }^{130}$ As usual, the political quagmire surrounding the political status of Native Americans is anything but clear-cut. While Lone Wolf vs. Hitchcock created a historic precedence for retroactively defining Congressional plenary power, at the same time Congress passed the Indian Depredations Act (1891-1919). The Indian Depredations Act was passed by Congress to assist Western settlers affected by the hostilities spurred by the Indian Wars of the $19^{\text {th }}$ century. This act made indigenous societies liable for damages incurred by settlers if the tribe had previously signed a treaty containing a clause to refrain from any type of
} 
Throughout this research process I have yet to identify a specific date in which Native Americans collectively agree their political status within the United States forever changed. Throughout an exhaustive literature review, it is assumed that the lack of recognition on the behalf of Native Americans at any social scale to recognize this change in political status derives from their inability to see themselves as anything but sovereign and independent.

For the purpose of establishing a temporal frame of reference, March 3, 1871, is identified as the specific date in United States history that initiated the formal introduction of capitalist uneven development perpetuated through the conditionalites of accumulation by dispossession and the law-like character of capital accumulation through space and time. This conditionality is of particular importance because, as explained in detail by Harvey (2006: 91), accumulation by dispossession is a necessary condition to ensure the survival of capitalism. Therefore, in order for capitalism to survive, it relies on the assumption that external coercion from a superior capitalist power will penetrate non-capitalistic society (indigenous) to, often forcibly, embed and replace the preexisting social system (Harvey, 2006).

March 3, 1871 on this date, Congress attached to an Indian appropriation bill a provision specifying: "hence forth no treaties would be made with Indian tribes, although

hostility toward settlers. This combination of the Lone Wolf vs. Hitchcock Supreme Court ruling and Indian Depredations Act illustrates the systemic problem plaguing the Constitutional status of Native Americans. While the Supreme Court ruling established Native American status as wards of the United States, the Indian Depredations Act required indigenous societies to pay reparations to settlers. These two items of legislations contradict one another in that if a tribe signed a treaty then they were at one time recognized by the United Stats as independent and sovereigns therefore, liable to pay reparations if they did indeed break agreements within a previously established treaty. However, Lone Wolf vs. Hitchcock should have overturned the act but instead tribes were required to pay reparations to settlers well into 1919, even though the ruling set the precedence for Native Americans to be considered wards, not independent sovereigns, of the United States. See Deloria (1974), Pruscha (1994), and, Deloria and Wilkins (1999) for further explanation of the historical derivation, context, and underlying purpose organizing these two forms of legislation. 
it reaffirmed the validity of those already ratified (Prucha, 1994; pgs.287-288).” It is important to note that while Prucha (1994: 287-288) notes that the original wording of the March 3, 1871 Indian appropriation bill reaffirms the validity of ratified treaties, i.e. the federal government must uphold promises specified in these historic documents, the future of the clause would eventually become modified beyond the recognition of its original intent through the clever use of ideological gerrymandering of the political system.

To reinforce, up until March 3, 1871, the United States actively organized treaties with Native peoples, typically for land cessions, right of ways for travel on native lands, or the right to carry out trading and build forts on native lands. Treaty organization on behalf of the federal government with native peoples implies that, at one time, the United States federal government viewed these nations as independent sovereigns and, therefore, only the federal government could/can regulate the socio-political and economic networking as specified in the Commerce Clause ${ }^{131}$ of the United States Constitution. Although tribal land may be spatially situated within the political boundaries of states or emerging territories, their unique federal status prohibited any other jurisdictional authority other than that of the federal government to participate in tribal socio-economic or political activities.

${ }^{131}$ Article I, Section VIII: The Congress shall have power to lay and collect taxes, duties, imposts and excises, to pay the debts and provide for the common defense and general welfare of the United States; but all duties, imposts and excises shall be uniform throughout the United States; To regulate commerce with foreign nations, and among the several states, and with the Indian tribes. (See Cornell University Law School Legal Information Institute, 2010) 
The 'extra-constitutional' position held by indigenous cultures can be viewed as both a blessing and a curse. While Native Americans became a political anomaly in the sense that they were situated within the territorial bounds of specific states, no nation, tribe, or indigenous society would ever become ward to any state, regulating any state's notion of entitlement to territorial or natural resources found on federally designated tribal lands. However, historically the entitlement to 'extra-constitutional' status has proven more detrimental than positive to Native American society.

In order to understand the fundamental detriment in falling under the title 'extraconstitutional' status simply think of the meaning behind the term. The United States Constitution, in its most fundamental interpretation, defines and outlines the basis of the laws informing and underlying the political system. When an entity is defined as 'extra' it then, by definition, falls beyond a defined boundary or scope. Assigning Native Americans the position of 'extra-constitutional' is an example of ideological gerrymandering of the political system in that this status allows the Federal government the privilege to govern without any of the hassles of rules and laws outlined in the very document they swore to uphold , the Constitution. ${ }^{132}$

The position of 'extra-constitutional' becomes even more of a detriment to Native Americans post-1871, and the end of formal treaty organization, in that, all forms of tribal representation were omitted. While, the federal government interacted with Native Americans in constructing treaties and other formal agreements, these associations followed the ceremonialesque fashion of western culture. Federal interactions with and

\footnotetext{
${ }^{132}$ In the context of the present era other entities allocated the position of 'extra-constitutional' are persons under suspicion of treason and terrorism as the prisoners in Guantanamo Bay, Cuba. Since these individuals hold the position of 'extra-constitutional' they are not entitled to certain constitutional rights as the right to a lawyer.
} 
between indigenous cultures were organized according to western codes of conduct and did not acknowledge the variation in Native American social organization. Unable to grasp this cultural difference, often times a Native American male was designated the authority to speak for the entire society. The Western political structure did not acknowledge or accommodate the socio-political organization of indigenous societies that did not place total discretionary authority in the hands of a male figurehead. While these negotiations were sufficient for government approval of treaties, these interactions did not speak for the collective majority of Native Americans during the construction and organization of these documents. During the era of treaty making, attempts were made on behalf of the United States to engage the Indian Nations in political negotiations. Post 1871 no longer was this attempt made.

In essence, this federal, state and tribal quandary has caused tremendous debate, since all three entities (federal, state, indigenous people) feel entitlement to the commodities found within territorial bounds of tribal lands. Snipp (1986) characterizes the Native American role in law and public policy from the period of reservation establishment up to the era of self-determination (1974) as one of a 'captive nation'. According to Snipp (1986:146), the term captive nation describes the limited political autonomy of tribal governments, and reflects the relative isolation and detachment of Indians from the mainstream of American society and economic life. As captive nations, tribes are subject to the highest political authority of the United States federal government, but in other respects their lands are closed enclaves outside of American society. 
The United States federal government used their status as guardians to take full advantage of dispossessing these peoples of their territorial holdings and natural resources (accumulation by dispossession), acting in the so-called best interest of indigenous cultures. The guardianship status the United States government exerted over tribes also extended to tribal capital, as specified in the General Allotment Act or Dawes Act $1887^{133}$ which allocated power over tribal monies and land to the United States Congress.

The economic status of Native American societies in this era is characterized as one of an internal colony where the underdevelopment and exploitation of one area or region is for the benefit of a core region (Snipp, 1986). Reinforced through legislation such as the Dawes Act, Indian Leasing Act, Relocation, and Public Law 280 the underdevelopment of Native American tribal economies in relation to the remainder of the United States was rooted in this era of assimilation. During this time, the federal government established guiding policies and acts to direct the exploitation of natural resources for the purpose of capital accumulation and, to even greater detriment, attempt to acculturate Native Americans into Western society and establish a 'dependency' relationship, conditionality one. In addition to land dispossession, assimilationist policies also addressed the 'Indian Problem' through the systematic implementation of programs aimed at extinguishing Native American identity. Many government officials felt the best method to address assimilation started with the children. Programs created by the BIA such as the suppression of native language and forced attendance of children to

\footnotetext{
133 This act, made law, gave the government authority to divide up reservations into allotments and dispose of the 'surplus' land without resorting to a new piece of legislation for each case (See Prucha, 1994; 327329).
} 
Indian Boarding Schools were means to erase the identity of Native American children and replace it with that of western culture.

Although congressional policies supporting campaigns of acculturation and the dispossession of Native Americans traditional subsistence grounds and lands remained status quo, these policies were relatively unsuccessful in fully engraining capitalist material culture (conditionality one) into Native American lifeways. The relative inability to successfully integrate Native Americans such as the Oglala-Lakota and Tewa into a western capitalist cash based economy is evidenced in these societies relative lack of contribution to western capitalism in the form of labor ${ }^{134}$. In the United States, corporations and industries benefiting from colonization did so for the most part, as with the exception of the Spanish, from the dispossession of Indian lands rather than through the exploitation of Indian labor (Deloria and Wilkins, 1999). This is not to suggest that the integration of Native Americans into the capitalist workforce was never attempted or achieved. Again, legislation supporting initiatives integrating Native Americans into the workforce while also dispossessing these peoples from their traditional land base and subsistence grounds were enforced. Assimilationist legislation and attitudes supporting conditionalities two and three at work are evidenced in the Indian Relocation ${ }^{135}$ and Termination ${ }^{136}$ policies

During the predominate reign of the territorial logic of power (Figure 34), the trend in legislation dictated accumulation through dispossession. The greatest change in

\footnotetext{
${ }^{134}$ The Tlingit were omitted from this statement due to their unique integration into the western capitalist market.

${ }^{135}$ Wilkinson (2005; 84-85), describes relocation as another major assimilation initiative encouraged by the BIA. This initiative encouraged Indians to leave their reservation for the cities

${ }^{136}$ Also known as House Concurrent Resolution 108, this legislation formally announced the policy of termination, directed the end of reservations and federal services and protections to be completed, "as rapidly as possible" (Wilkinson 2005; 57).
} 
the socio-economic status of Native Americans has occurred post the Self-Determination and Education Assistance Act of $1974^{137}$. This act allowed Native Americans further rights in managing and allocating tribal monies, lands and natural resources. In addition, indigenous societies were given more responsibilities in organizing and establishing their governments and in reconfiguring the role of the Bureau of Indian Affairs (BIA) in tribal government. Prior to the Self-Determination Act, the BIA was mainly another means for the United States Bureau of the Interior to regulate and keep in check tribal political and economic development. While this act represents a move in the right direction, many Native Americans criticize the legislation's bureaucratic red tape inhibiting the expedient execution of tribal authority over programs.

While many native peoples see these changes as a means for their culture to take control of their lifeworld and reclaim sovereignty, others have noted that in the modern neo-liberal and neo-conservative capitalist markets, most indigenous societies will continue to experience uneven development. Unlike previous eras when the uneven development of tribes was considered unilateral and contiguous across tribal country, there is an emergence of a more stratified trend in uneven development.

For instance, some indigenous societies have abundant access to natural resource commodities on their tribal land, such as the Tlingit and Eastern Tewa, and others, like the Oglala-Lakota, are relatively resource scarce. Furthermore, neo-conservative politicians have recently attempted to reinstate territorial control over Native American mineral resources, particularly energy resources such as coal, natural gas, oil and uranium, through the interpretation of antiquated rulings made at the turn of the century.

\footnotetext{
${ }^{137}$ According to Chaudhuri (1985; 28-29), this act in principle gives tribal government the "authority" to assume contractually the responsibility for various governmental services.
} 
Luckily, recent generations of Native Americans have been, and are being, educated in the convoluted American legal system and are effectively fighting back.

As noted by Anders (1980: 696), the Indian Self-Determination and Education Act became an integral and promising piece of legislation because it directs Indian participation as a step forward in establishing public policies toward improving Indians’ low levels of health, education, and employment by allowing Native Americans, not federally appointed employees or agents, the right to transform not only their economic structures, but also their political administration. This legislation is viewed as tremendously beneficial because it allows Native Americans to develop according to their own cultural dictates (Anders, 1980).

To this date, the modern development of Native American socio-political and economic systems is predominantly controlled by tribal governments. However, the tribal paths are merging toward in this capitalist era is diverging due to cultural concerns as to the proper 'place' and 'identity' Native American should carve out for themselves in the future. Inter-tribal debate centers on indigenous peoples, on the one hand, which feel traditional lifeways should be strictly adhered, as in the case of the Oglala-Lakota, and on the other hand, which aim to develop a more modern-capitalist economy, such as the Tlingit and certain Tewa Pueblo communities (Cornell and Gil-Swedberg, 1995).

Unfortunately, both paths are in conflict with the views of the neo-liberal and conservative political-economic movements currently embedded in the United States federal government. Although the federal government is no longer specifically organizing treaties and acts to acculturate Native Americans, legislation is being written attacking Native American attempts to establish both modern capitalist economies and 
preserve traditional lifeways. This is occurring through the anti-environmental policies, as embedded within ANCSA, aimed at extracting energy resources and other natural resources such as timber, fisheries and water from established indigenous lands, and awarding the contracts to private commercial corporations. Native American communities with abundant access to natural resources are being displaced from the profits they should be receiving and those indigenous peoples practicing traditional lifeways are loosing access to sacred places and spaces.

These, eminent domain-esque, policies are affecting Native American's ability to successfully regulate and develop either traditional or modern sustainable societies. These impacts upon Native American cultures are reinforced through Western (neoconservative and neo-liberal imperialist) ideologies that favor the uneven development of indigenous societies (territorially, politically and economically) in order to achieve elevated status in the global hegemony through capital accumulation.

\section{Linking Dispossession, Place, and Identity}

\section{Oglala-Lakota}

Of the three Native American societies included within this research, the OglalaLakota has the most extensive record of historical contact and negotiation with the United States. As a result, the Oglala-Lakota have collectively experienced all forms of assimilationist policies Congress enacted pre-treaty abrogation up to the present. In addition, members of this society are activists responsible for developing, organizing, and maintaining the power geometries needed to advance social and political awareness (conditionality four) within the sphere of Indian policy and the Indigenous Rights Movement as interjected within tribal, regional, and global scales of influence. 
Chapters five and six explored the dialectical connections comprising the social organization and construction Oglala-Lakota lifeworld and lifeways in relation to the emergence and creation cosmologies. Researchers such as Basso (anthropology), Gulliford (archaeology), Powers (ethnography), and Howitt (geography) characterize these cosmologies as key components to comprehending indigenous perceptions of place and identity in their world. The creation story highlights the importance of both the absolute and abstract components of the Oglala-Lakota lifeworld integral to comprehending the complexity of identity and place development. Powers (1986) reinforces that these cosmological histories expressed through oral tradition grounds identity within absolute and abstract perceptions of place or what this research has identified as perceived sacred space.

These cosmological components represent the foundation through which OglalaLakota social organization and identity was designed and perpetuated. The organization of societal structures within the Oglala-Lakota cultures reflects their absolute (physical) and abstract (cosmological) relationships with their surrounding environment as spatiotemporal beings. Therefore, this research assumes for the Oglala-Lakota to be devoid of a relationship with their environment adversely results or severs the society's continuance and development of their lifeworld and lifeway. This section explores how this symbiotic relationship and connection between cosmology, environment, and social organization has been tested, and perhaps compromised, through the introduction of capitalist assimilationist ideologies promoting western individualism, as the only option for social, economic and political development. 


\section{Abrogation and Assimilation}

The 1868 Treaty of Fort Laramie, also known as the Sioux Treaty of 1868, is of particular importance for prior to 1871 and the federal abrogation of Native American treaty organization, Congress organized the Indian Peace Commission to travel to areas where Indian hostilities were adversely affecting Expansionism and White settlement within the region. In the spring of 1868, the Peace Commission traveled to the Northern Great Plains to establish a treaty with leaders of the Siouan nation. Upon signing this treaty, the United States federal government promised to secure a parcel of territory (this parcel included the sacred cosmological center of the Oglala-Lakota the Black Hills), provide provisions, deter further reductions in land, remove all military posts on the Bozeman Trail ${ }^{138}$, and allow traditional hunting practices. In exchange, Siouan leaders ensured their people would remain within the boundaries of the lands allocated and attempt to live or acculturate themselves into agricultural livelihoods and, of course, discontinue all warring campaigns against the United States.

However, in response to the United States government's inability to successfully fulfill those promises outlined in the Fort Laramie Treaty of 1868, many indigenous peoples were never able to acculturate themselves into Western society and often left to join other tiyošpayes in the Plains Indian Wars. Considerable animosity toward the federal government continued within the Oglala-Lakota and other Siouan societies as the treaty promises were broken. This growing animosity reached a boiling point in 1874 when miners, under military escort of the Seventh Calvary, were allowed to make claims, mine, and settle within the Sacred Black Hills. This invasion into the sacred cosmologic

\footnotetext{
${ }^{138}$ Pointed out by Pruscha (1994; 283), Congress no longer felt the Bozeman Trail was needed as a western supply route since the Union Pacific railroad had expanded service to the region.
} 
epicenter of the Council of the Seven Fireplaces led to heightened warring campaigns from both sides. While the Oglala, members of the Council of the Seven Fireplaces, and other Plains societies made notable victories at places such as The Little Big Horn; the expansionist policies informed by the territorial logic of power prevailed, led to the eventual relocation and dispossession of the Oglala-Lakota.

The Oglala-Lakota were placed in federally organized reservations within their ancestral homelands, albeit this land base is much reduced and did not meet the land allotment allocated in the 1868 Fort Laramie Treaty (Figure 35). Included within this reduced land base was the 'taking' of the sacred Black Hills, which remains a source of considerable contention between the Oglala-Lakota and the Federal government as the former continue to fight to reclaim their 'stolen' lands. Contested land issues are common discourses occurring between tribal communities and state or federal agencies. 


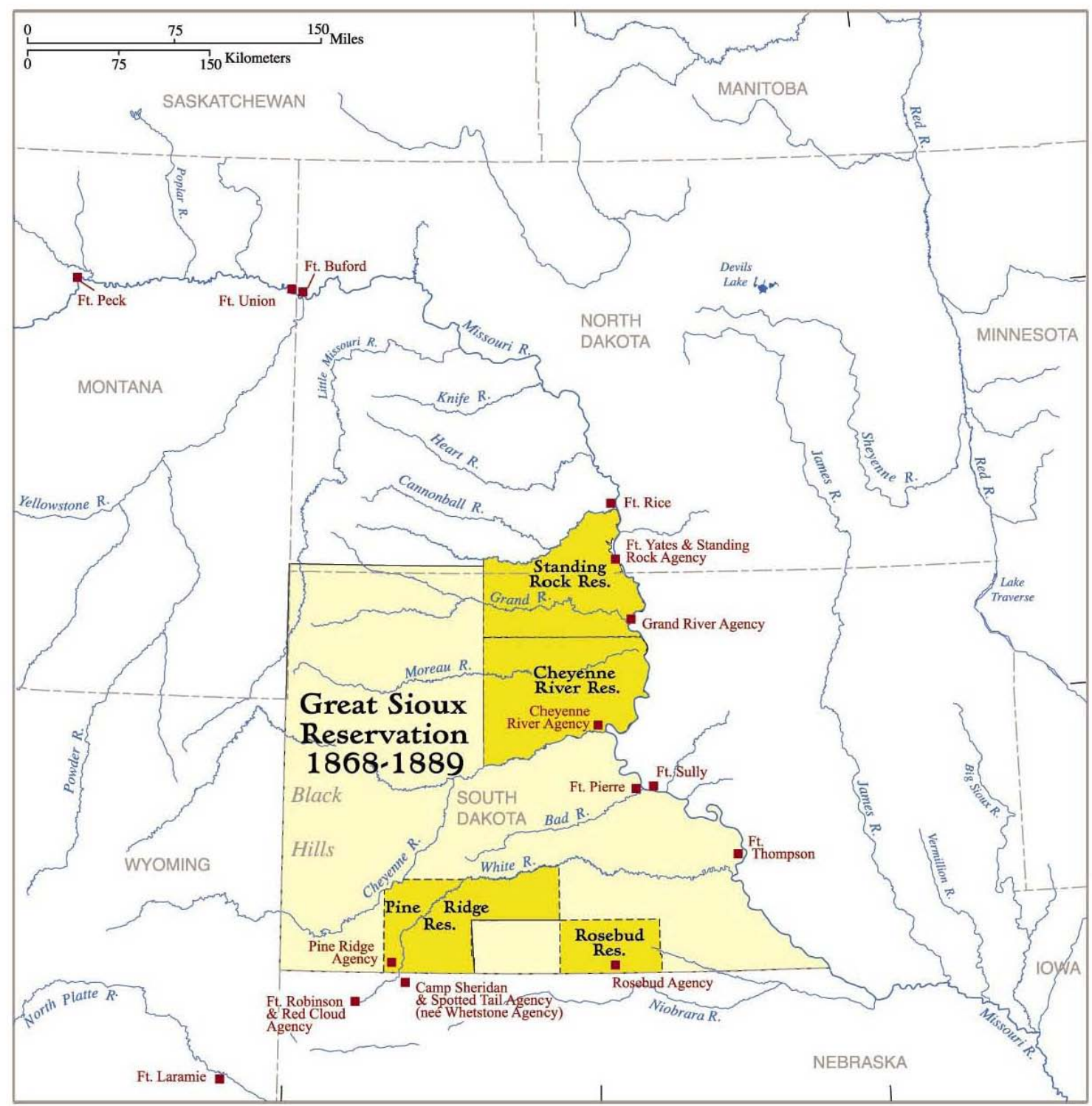

Figure 35: Map of the Great Sioux Reservation and Surrounding Areas (1868-1869). The term Sioux is a French term grouping the Lakota, Dakota, and Nakota Nations as one. The Pine Ridge and Rosebud Reservations are where the Oglala-Lakota were assigned land holdings and tenure.

Source: $\underline{\text { http://wintercounts.si.edu/html_version/pdfs/map.cmyk.pdf }}$

In combination with the reduction in promised land allocated in the 1868 Fort Laramie Treaty, the Oglala-Lakota were systematically indoctrinated into assimilationist policies targeting identity erasure of their traditional lifeworld and lifeways. Displaced from their cosmologic home, the Black Hills, other methods of acculturation were informally 
encouraged in order to settle these warring people and discourage their lifeways through the systematic annihilation of the buffalo herds. In 1874, the Secretary of the Interior ${ }^{139}$ stated:

"The buffalo are disappearing rapidly, but not faster than I desire. I regard the destruction of such game as Indians subsist upon as facilitating the policy of the government, of destroying their hunting habits, coercing them on reservations, and compelling them to begin to adopt the habits of civilization (In: W. T. Hornaday, 1889)."

Likewise Asa Whitney, an early proponent for the construction of the transcontinental railroad, surveyed and foresaw the optimal route for the railroad's construction extending through Sioux lands as the main obstacle to impair completion. Whitney assured

Congress that the native Americans were,

"ready and willing to sell all that may be desirable for this object, and for a very small sum... and this road would produce a revolution in the situation of the red as well as the white man." (See Brown, 1977; pg. 28-31)

Whitney shrewdly pointed out that the building of the railroad would,

drive the "savage" Sioux and their buffalo northward, "and we can then succeed in bringing the removed and small tribes to habits of industry and civilization, and their race may be preserved until mixed and blended with ours, and the Sioux must soon follow them." (See Brown, 1977; pg. 28-31).

Statements such as these demonstrate the malice aforethought instituted toward policies to dispossess Native Americans, such as the Oglala-Lakota, from their traditional lifeways informed through the cosmologic relationship with their lifeworld.

Attitudes such as this aided in legitimizing and turning a blind eye toward the rapid annihilation of the buffalo herds. Combined with these attitudes several factors

${ }^{139}$ The Secretary of the Interior oversees and directs all agencies under the Department of the Interior including the Bureau of Indian Affairs. Prior to being organized within the Department of the Interior the Bureau of Indian Affairs was first contained within the War Department. 
contributed to the nineteenth century near annihilation of the North American buffalo herds such as the intrusion of the railroads within the Great Plains that affected the migratory routines of the species and also passengers on trains were encourage to shoot for sport upon sight. In addition, the U.S. Army used the buffalo for subsistence but also were encouraged to kill without purpose. However, research conducted by Taylor (2008) addresses the impacts from the expansion of the hide trade suggests an international increase in demand for industrial leather, in combination with a foreign innovation in the tanning process, dramatically influenced the 'punctuated' decline of the North American bison herds to approximately ten years in the latter part of the nineteen century.

Taylor's (2008) conclusions are pertinent to this research in that the factors contributing to the decline of the bison are tied to the international (namely European) demand for industrial type leather, the innovation in processing technologies, the increasing ease in distribution, the fixed prices ensured the new supply of buffalo hides did not dampen the incentive to hunt, the abundant workforce, and the open access to an abundant unregulated resource. These conclusions aid in reaffirming the first three conditionalities of uneven development outlined by Harvey (2006) in addition to, laying the groundwork for the perpetuation of capitalism through the dilution of spatial boundaries supported by technologies increasing geographic expansionism and the increased accessibility to fresh labor and resource markets (Harvey, 2001;1-4).

For the latter part of the nineteenth century, the Oglala-Lakota were continually subjected to assimilationist policies that attacked the traditional ideologies that informed their lifeworld and lifeways. Unfortunately, for the remainder of the nineteenth century this cycle of broken promises became status quo. Once permanently situated on the Pine 
Ridge Reservation ${ }^{140}$, the next step in the Westernization of the Oglala-Lakota was to turn these skilled subsistence hunters and gathers into ranchers and farmers. Congress furthered this initiative through the passage of the 1887 General Allotment Act. In brief, underlying the act were two main goals. First, to encourage commodity ranching and agriculture each individual within the 'tribe' was assigned a parcel of land, typically 160 acres (Wilkinson,2005; 43). Second, once all individuals within the 'tribe' received their allotments the remainder of the lands could be either leased or sold to non-tribal members. At this point, the Office of Indian Affairs (OIA), operating under the authority of the BIA, retained primary control over the lease and selling of tribal lands ${ }^{141}$. Much of the monies and interest generated from the leasing and selling of these lands did not go toward improvements on the reservation and, instead, remained in accounts untouchable to tribal leaders. Investigation and resolution into misappropriation of reservations monies is currently being addressed at the executive level and is further addressed in chapter ten.

Bilosi (1985 and 1992) describes the federal governments attempts to acculturate these people into the Western methods of ranching and farming as largely unsuccessful. Bilosi (1992) attributes this lack of success in establishing commodity agricultures to the arid environmental conditions that were unable to sustain and support this type of production without a developed system of irrigation. On the other hand cattle ranching seemed a logical choice considering the region once supported tens of millions of buffalo. The introduction of cattle may have proven successful if proper land management

\footnotetext{
${ }^{140}$ The Pine Ridge Reservation was formally created in 1889 as a result of non-Indian pressure to break up the Great Sioux reservation in favor of forming six separate reservations (Powers, 1986; 108).

${ }^{141}$ The 1887 General Allotment Act did require tribal authorization to sell reservation land but the methods utilized to acquire individual signatures would today be considered unlawful.
} 
practices were enforced, because overgrazing became an issue especially after reservation lands were sold or leased to private cattle ranches. Bilosi (1992) also prescribes the failure of the ranching economy on the Pine Ridge Reservation to the enticement of rising beef prices during World War I which led many allotment owners to sell their herds to private ranchers. Once the price of beef plummeted many private ranchers left the area bankrupt and defaulted on their leases.

The policy of allotment carried on until 1934 and the passage of the Indian Reorganization Act. Spurred on by the controversial findings outlined in the 1928 Meriam Report describing the detrimental condition of reservations, the Indian Reorganization Act was enacted as a means to place more power into the hands of the Native American peoples and lessen the grasp of the OIA. Prior to 1934, reservations such as Pine Ridge operated under the political and economic control of the OIA agent placed in charge. These agents were responsible for enforcing those assimilationist policies handed down by Congress to the BIA. These agents were able to enforce policies in a more direct manner at the scale of the oyate which suppressed the use of native language, forced children to attend day schools ${ }^{142}$ or boarding schools, and removed forms of traditional native dress. Passage of the 1885 Seven Major Crimes Act added additional power to the role of OIA reservation superintendents and made Native Americans susceptible to federal prosecution. Labeled, along with intoxication, as a as major crime, the practice of traditional ceremonies (i.e. the Sun Dance) and religious activities were outlawed.

\footnotetext{
${ }^{142}$ Day schools encouraged Western forms of education, in addition to, including Christianization and oppression of native religious traditions.
} 
Facing tremendous cultural suppression the Oglala-Lakota and other reservation societies took their traditional ceremonies underground and practiced them in secrecy. This era of extreme cultural suppression laid the foundation for the next uprising known as the Ghost Dance Movement. Starita (1995; 97) describes the introduction of the Ghost Dance Movement from the perspective of a people who:

"In the early spring of 1890, after the long summers of drought and the winter of disease, after the land sale had been approved and the beef issue slashed, a small party of Oglala Sioux returned from a journey across the western mountains and deserts to the United States to their home on the Pine Ridge Reservation.

They brought with them a wondrous story, a story about an Indian messiah who foretold a promising new world, a world in which all the white people would soon disappear and the buffalo would return and all the dead Indian ancestors of long ago would rejoin the living in a new way of life. A way that was much like the old, a way that had been lost in the spiraling gloom and hopelessness of the last decade. This story quickly swept through all the Lakota tribes."

According to Starita (1995: 97-98) this story had been told to the returning Oglalas by the messiah himself. The messiah was Wovoka, a Paiute. Wovoka's revelation came in a vision during a dream in which he died and journeyed to heaven and spoke to God and the dead (Starita, 1995; 98). During this vision God spoke to him and provided a set of commandments to obey in order to bring salvation to Native Americans and the initiation of a new world order set aside solely for the Indigenous People where the great herds of buffalo, elk, and deer returned (Starita, 1995; 98).

Within the commandments handed down by God to Wovoka were the details of a dance that was to continue for five days and four nights, and where during the final night the dance was to continue to the morning of the fifth day and everyone was to bathe in the river and then return home (Starita, 1995; 98-99). Faced with deplorable conditions 
upon the reservations, Staritia (1995) discusses at depth the evolution of this vision, commandments, and dance into a religious movement. Empowered by the Seven Major Crimes Act and threatened by the development of this movement and the renewed empowerment of reservation Indians, agents began to employ the help of the U.S. Army to suppress any uprisings. The fear of the reservation superintendents, agents, and the U.S. Army about multiple Native American uprisings culminated December 29, 1890 with the massacre of approximately 151 Lakota men, women, and children at Wounded Knee Creek on the Pine Ridge Reservation (Starita, 1995; 100-103).

Clearly the reservation system was broken for Pine Ridge is just one example of the ineffective and ultimately destructive assimilationist agenda put forth by the federal government in an effort to incorporate these societies into the western capitalist economy. Although the post abrogation history between the United States and Oglala-Lakota is predominately filled with conflict, grassroots movements to improve reservation conditions exist and were spurred by individuals such as John Collier. Collier, once a New York social worker, became President Roosevelt's new Commissioner of Indian Affairs in 1932 and is most famously known as the initial proponent and organizer of the 1934 Indian Reorganization Act.

During Collier's tenure as Commissioner of Indian Affairs, he sought total reform and reversal of the assimilationist policies enacted by post treaty abrogation. Collier's plans entailed scrapping the allotment system altogether, returning all surplus land to the reservations, encouraging the development of Native American business, overhauling the education system to bring the children back home and include Native American traditional cultural values, removing the practice of traditional cultural ceremonies and 
rites as a major crime, and reducing the role of the BIA and OIA in favor of Native

American self-governance (Starita, 1995; 239-241). Unfortunately these lofty goals

became watered down after Congressional compromise gutted the final version of the

Indian Reorganization Act (Starita, 1995;240-241).

Devoid of his original intention, Collier's legacy within the context of the Indian

Reorganization Act is seen in Section 16:

" Any Indian tribe, or tribes, residing on the same reservation, shall have the right to organize for its common welfare, and may adopt an appropriate constitution and bylaws, which shall become effective when ratified by a majority vote of the adult members of the tribe, or of the adult Indians residing on such reservation, as the case may be, at a special election authorized and called by the Secretary of the Interior under such rules and regulations as he may prescribe. Such constitution and bylaws when ratified as aforesaid and approved by the Secretary of the Interior shall be revocable by an election open to the same voters and conducted in the same manner as hereinabove provided. In addition to all powers vested in any Indian tribe or tribal council by existing law, the constitution adopted by said tribe shall also vest in such tribe or its tribal council the following rights and powers: To employ legal counsel, the choice of counsel and fixing of fees to be subject to the approval of the Secretary of the Interior; to prevent the sale, disposition, lease, or encumbrance of tribal lands, interests in lands, or other tribal assets without the consent of the tribe; and to negotiate with the Federal, State, and local Governments. The Secretary of the Interior shall advise such tribe or its tribal council of all appropriation estimates or Federal projects for the benefit of the tribe prior to the submission of such estimates to the Bureau of the Budget and the Congress." Retrieved from: http://www.personal.utulsa.edu/ nathan-wilson/

Within Section 16 can be seen Collier's vision of Native American self governance and restrictions that limited the totalitarian governance of the BIA and OIA. Although, the Oglala-Lakota of the Pine Ridge formally organized a Constitution and government 
January $15^{\text {th }}$, 1936 many were skeptical of how this new power would evolve within the current socio-political and economic conditions upon the reservation.

As discussed in-depth by Biolsi (1985 and 1992), Starita (1995), and Reinhardt (2007), considerable wariness emanated throughout the reservation concerning this new legislation and stemmed from demographic inequalities associated with blood quantum. Division within the full blood and mixed blood populations concerning the most effectual means to officially reorganize and form a tribal government were complicated by historic reservation politics. This historic animosity between these groups is best described by Guy Dull Knife:

"For a hundred and twenty-five years, it was often the friendliesthose Lakota who acceded to the wishes of the military, the government, the police, the missionaries and the reservation agentwho survived and occasionally prospered and it was the traditionals who often died, who felt the brunt of sickness, alcoholism, corruption, isolation, and despair. (In Starita, 1995; 297).

These feelings dominated the socio-political and economic environment on the reservation as the traditionalists sought to reorganize and establish a government reflecting the traditional Oglala tiospayes social structure (Reinhardt, 2007; 89). Backed by the OIA the Euro-American model of organization according to geographic boundaries was adopted (Reinhardt, 2007; 89-90). In addition, the political structure of the Oglala Tribal Council also mirrored that of the Euro-American system where nineteen members from the geographic districts comprised the council. The executive council consisted of a president, vice president, secretary, treasurer, and chairman who served two year terms. 
The adoption of a western political structure disheartened many full bloods who felt they would once again become marginalized within their own land. Unlike the full bloods, a majority of the mixed bloods were English speaking and, depending on blood quantum, land poor. Many mixed bloods felt economic prosperity was attainable through the assimilation. Recognizing these differences, many reservation agents and superintendents used these social differences to generate tension and conflict between the groups in order to assure OIA and BIA control. Dunbar-Ortiz (1985; 183) characterizes this era as government controlled 'tribalism' responsible for further degrading internal reservation politics between the traditionalist and progressive factions.

To this day, the social climate on the Pine Ridge Reservation continues to reflect these tensions. As discussed in chapter ten is the evolution toward the beneficial use of these tensions which, generated a hyperaware society capable of articulating the social inequalities of uneven development perpetuated through the capitalist and territorial logics of power enabling accumulation by dispossession. The Oglala of Pine Ridge were ,and continue to be, active participants and organizers of peaceful protests against federal and state policies of intrusion inhibiting indigenous societies path to sovereignty.

\section{Eastern Tewa Pueblos}

The Pueblo peoples, along with other Southwestern indigenous cultures (Apache, Navaho, and Hopi), were able to successfully prevent Spanish occupation in the region until the late seventeenth century. Once settled within the region Spanish influence and occupation in northern New Mexico resulted in a complex history. During Spanish occupation of the Pueblo region, the Spanish forcibly extended considerable cultural influence and intermixing within the Puebloan communities resulting in modifications to 
the traditional Tewan social organization . In addition, the land tenure system imposed under Spanish rule is characterized as a feudal hierarchy with communal land shares, diverging from traditional Pueblo perceptions of land use and organization, but still retaining a somewhat communal aspect in comparison to the capitalist fee based land tenure system imposed after American occupation of northern New Mexico.

The expansionist agenda of the United States to remove control of foreign occupation of those lands situated between the Atlantic and Pacific Coastlines became a high priority at the start of the nineteen century. The Jefferson administration acquired a considerable portion of this foreign held land through the 1803 Louisiana Purchase from France. The significance of this purchase, in relation to lands still controlled to the west by Spain and later Mexico, firmly established trade routes and encouraged western settlement into the areas. As explained by Dunbar-Ortiz (2007) the impact of the establishment and development of trade and commerce on the Santa Fe Trail further enticed the United States to acquire the region. During the era of Mexican Independence, demand for goods brought along the Santa Fe Trail were being distributed via the ports acquired during the Louisiana Purchase. More merchants within the territories began relying upon trade centers to the East in the United States instead, of traditional trade routes and distributions to the West. Also it is important to note the increase in AngloAmerican settlement within Mexico Territory, especially the state of Texas. These settlements approved through land grant allocations by Mexico became strategic military posts during the Texas Revolution and later Mexican American War.

Puebloans, as the Tewa, and members of the Generizaro caste in the northern regions grew increasingly dissatisfied with the direction in which Mexico's politics 
seemed to be tilting toward those of the elite status. Support for a cash economy within a region where barter and mercantile trade had flourished, the Tewa and Generizaro began to see their interests dissolve as trade and land grants increased throughout the region. This dissatisfaction led to two Puebloan (namely Tewan) and Generizaro uprisings prior to the 1848 Treaty of Guadalupe Hidalgo. The first revolt was squelched by Mexican troops within the region but the second uprising, known as theTaos Revolt protested United States encroachment within the region, and supported to cause for formal declaration of war against Mexico by President Polk.

\section{Puebloans: Citizens or Wards in Trust?}

When the United States signed the 1848 Treaty of Guadalupe Hidalgo with Mexico it was not established as to whether Pueblo people were Mexican or indigenous, creating complex legalities surrounding Pueblo citizenship which, in turn, affects Pueblo control over land, water and mineral rights. The issue of Pueblo citizenship continues to be mired and impede progress in attempts to obtain sovereignty, because capitalist industry continually advocates for more lenient restrictions on the use of federal Indian lands 'held in trust', resulting in the dispossession and estrangement of the Pueblo from the source of their lifeworld and lifeway as directly expressed by James Paytiamo, a member of the Acoma Pueblo, in the below historical recount and declaration.

"I remember the old men of my village (Acoma). These old, old men used to prophesy about the coming of the white man. They would go about tapping their canes on the adobe floor of the house, and call to us children.

"Listen! Listen! The gray-eyed people are coming nearer and nearer. They are building an iron road (railroad). They are coming nearer every day. There will be a time when you will mix with these people. That is when the Gray Eyes are going to get you to drink hot, black water, which you will drink whenever you eat. Then you teeth will become soft. 
"They will get you to smoke at a young age, so that your eyes will run tears on windy days, and your eyesight will be poor. Your joints will crack when you want to move slowly and softly.

"You will sleep on soft beds and will not like to rise early. When you begin to wear heavy clothes and sleep under heavy covers, then you will grow lazy. Then there will be no more singing heard in the valleys as you walk.

"When you begin to eat with iron sticks, your tones will grow louder. You will speak louder and talk over your parents. You will grow disobedient. You will mix with those gray-eyed people, and you will learn their ways; you will break up your homes, and murder and steal."

Such things have come true, and I have to compare my generation with the old generation. We are not as good as they were; we are not as healthy as they were. How did these old men know what was coming? That is what I would like to know.

-James Paytiamo Acoma Pueblo (In Nerburn, K., 1999; pgs. 53-54)

This issue concerning citizenship status, especially after the 1848 treaty, created a quandary in land distribution and allocation once the United States took possession of the territory. According to the 1848 treaty, Mexicans and Puebloans within the territory retained possession and rights to their land including, grants. Included within these rights was the ability to sell. The former citizens of Mexico were well aware of these rights. A major issue emerged between the United States and Tewans as it became clear the new government only recognized individual allotment parcels and not community land grants as a part of those lands in which entitlement rights were guaranteed in the 1848 treaty. This issue became especially problematic as many of the lands held in community status were sold sometimes, unbeknownst to the individuals within the Pueblo. As a result, many Pueblos lost a considerable portion of their land base traditionally used for subsistence agriculture and ranching. 
Land barons utilized this technicality to build monopolies within the region. Dunbar-Ortiz (2007; 100), describes this early era of American occupation in the region as one of a military dictatorship where the territorial governor placed in charge ensured colonist policies were put in effect. During this era when the territorial logics of power dominated, four interest groups were represented: none of them included the Puebloans. The four groups consisted of wealthy ranchers of the Rio Abajo, land speculators, religious leaders, and merchants (Dunbar-Ortiz, 2007; 100-101). This assembly was formally recognized in 1861 and would direct the politician and economic interests in the area for nearly sixty years. Worth noting is the work of one territorial politician in this interest group, Thomas B. Catron. Catron, by the turn of the century, became the largest single landholder in the United States owning nearly three million acres at one time allocated through land grants (Dunbar-Ortiz, 2007; 100-104). Significant to Catron's land monopoly was his strategic acquisition of claims along natural water sources.

This monopolistic approach to land acquisition and water resources became problematic for Pueblos as the quality and quantity of water utilized from expanding ranching corporations became a growing concern, in combination with the reduction in their community land grants. Informed of the abysmal socio-economic and political state of many Native American societies, Puebloans began to wonder if their interests would be best served if they advocated in-trust status and become wards of the federal government. Directing this logic was the hope that the federal government might stave off any further sales of community held lands, especially along water courses.

An 1876 Supreme Court ruling in United States vs. Joseph declared the Puebloans citizens of the United States but denied them the right to vote. This ruling was based 
upon the Supreme Court definition of the Indian Intercourse Act that defines and regulates trade between Native Americans and non-natives. The 1876 court did not feel the Pueblos fell within the 1834 and 1851 definitions of this act. This decision proved beneficial to the land monopolies that continued to purchase land grants from squatters outside the Pueblos, in addition to, community land grants.

This 1876 decision was later overturned by the 1913 Unites States vs. Sandoval Supreme Court ruling declaring Pueblos wards of the federal government. Although this decision is what Puebloans sought as a desperate means to stave off any further reduction in land or water rights, the ruling brought with it a sense of humility when the presiding judge reinforced the popular assimilationist agenda by declaring: 'They (Puebloans) are essentially a simple, uninformed, inferior people (Dunbar-Ortiz, 2007; 115)." The Supreme Court's reversal of opinion threw the status of title to lands occupied by 12,000 non-Indians in New Mexico into serious doubt, along with the water rights exercised on those lands. Based upon this 1913 ruling Puebloan disputes concerning lands lost during the territorial era began to be formally addressed in 1924 with the passage of the Pueblo Lands Act in order to "settle the complicated questions of title and to secure for the Indians all of the lands which they are equitably entitled (United States Bureau of Reclamation, 2009):

However the 1924 act had several loopholes complicating Pueblo's ability to secure lands previously lost. For instance, according to the 1924 Act non-Indians could persuade a special lands board that they had used and occupied Pueblo land for a period of time, the non-Indians were awarded title, and the Pueblo was supposed to be compensated for the value. Unfortunately, this resulted in non-Indians successfully 
claiming some of the most valuable, irrigable Pueblo farmland. The Taos Pueblo lost

2,401.16 acres to claims by non-Indians under the 1924 Act and title to 926 acres in the

Town of Taos. Statements made by Michael L. Conner, the Commissioner of the Bureau

of Reclamation (2009), illustrate the inadequacies of 1924 act:

"The compensation awarded by the lands board to the Pueblos was lower than actual appraised values, and woefully inadequate. Congress followed up by enacting the 1933 Pueblo Lands Act, which provided additional compensation to the Pueblo and also expressly preserved the Pueblo prior water rights, but the compensation still did not adequately remedy the losses to the Pueblo. In passing the 1924 and 1933 Acts, Congress recognized the necessity of resolving the uncertainty of title to land and water and also restoring the severely eroded economic footing of the Pueblos caused in large part by the loss of land and interference with water rights. Cash awards made to the Pueblos under the Acts were expressly intended to compensate the Pueblos for their losses and to help fund the replacement of their lost economic base through the purchase of lands, construction of irrigation projects, and by financing various other permanent improvements for the benefit of Pueblo lands. Sadly, the Acts did not fully accomplish their purposes.

The following section discusses the complications surrounding the evolution of water rights within this region.

\section{Water Rights}

Critical omissions within the 1924 and 1933 Acts were water rights. Imperative to sustaining traditional Tewa lifeways is water. The development of commodity scale ranching operations within this semi-arid region relies on accessibility and abundance of two resources land and water. In the case of the Oglala, the intent was to reconstruct their perceptions of place and identity and replace it with that of the appropriate Western conceptualization. This entailed suppressing the Oglala lifeways and encouraging commodity ranching and farming. 
In addition to being skilled subsistence hunters and gathers, the Tewa people had been successful agriculturalists for centuries prior to intrusion from the Spanish or Americans. If the purpose of assimilation was to reform indigenous ideologies in favor of Western modes, the question must be raised why the government would allow the systematic reduction of land and water access to people, as the Tewa, with a highly organized socio-economic and political system centered upon agriculture? Logic directs the assumption, the Tewa conceptualization of the their lifeworld and lifeways did not fit within the capitalist and territorial logics of power driven by the continuous search for the expansion and accumulation of capital in order to generate profit.

Successful commodification of any resource (cattle, sheep, gold, silver, copper) within this region requires water. As discussed in chapters five and seven, the Tewa developed an intricate hierarchical social organization necessary in order to achieve subsistence agriculture within this region. The importance of water as a part of traditional Tewa lifeways and lifeworld are reaffirmed in the cosmologic connection communicated in rituals and ceremonies. Even during periods of Spanish occupation, adherence to the laws of prior appropriation and beneficial use were maintained in order to ensure successful crop yields needed for mandatory tithing.

Specifically, Vlasich (2005; 1-8) differentiates three types of irrigation agriculture that existed amongst New Mexico Pueblos : floodwater farming (not pure irrigation); hydraulic irrigation farming; combination of floodwater and canal farming. Vlasich notes that Pueblos within the Rio Grande River Valley typically employed a combination of floodwater and canal farming; spatial variance identifies one method being more dominant than the other according to placement on either the east or west side of the river 
valley. The eastern side of the river valley relied more upon irrigation through a system of canals whereas, the western side relied more upon floodwater farming dictated by the ambiguities in rainfall (Vlasich, 2005; 7-8).

Vlaisch (2005; 74) describes at length the evolution of the law of prior appropriation for beneficial use origin with the Spanish, to be later adopted by the Mexican government, dictated that agricultural settlements and pueblos retain the right to water needed to ensure their agriculture activities and possible expansion of economic development. This law pertains to the Pueblos by describing their superseding right over water distribution to lands held in common along unnavigable streams. In short, the law of prior appropriation ensured that Pueblos retained the ability to carry on, and in the hopes of the Spanish, expand farming agriculture by ensuring rights to water use over that of individual settlers (Vlaisch, 2005; 74).

Growing concerns over water availability and quality began to emerge during Mexican Independence and the expansion of trade with the east along developing routes such as the Santa Fe Trail. Once the United States gained possession of the region the territorial era predominated until the passage of the Pueblo Lands Acts of 1924 and 1933. During this time persons such as Catron had near unfettered access to the continuous accumulation of lands, development of resources, and expansion of capital. All of which relied upon water availability and access.

The issue of water rights is not geographically isolated to the region of the American Southwest. In a rare occasion, the Supreme Court ruled in 1908 case Winters vs. United States in favor of the Fort Belknap reservation stating:

"An Indian reservation may reserve water for future use in an amount necessary to fulfill the purpose of the reservation, with a 
priority dating from the treaty that established the reservation.

This doctrine establishes that when the federal government created

Indian reservations, water rights were reserved in sufficient

quantity to meet the purposes for which the reservation was

established (Bureau of Land Management Western States Water

Laws, 2011)."

However, recall Pueblos did not receive their in-trust ward status until 1924 and could not utilize the Supreme Court precedence in order to secure water rights as outlined in the 1908 Winters Doctrine ${ }^{143}$. While title to their lands were being appraised in the 1924 and 1934 Pueblo Land Acts, these acts did not resolve issues pertaining to water rights and the law of prior appropriation.

Further complicating this issue was the passage of the 1952 McCarren

Amendment by Congress. The backbone of the amendment returned substantial power to the states with respect to the management of water. The McCarren Amendment requires that the federal government waive its sovereign immunity in cases involving the general adjudication of water rights. This act was a blow to the Pueblo communities since New Mexico achieved statehood in 1912 and they had only recently gained footing on the reclaim of improperly and illegally sold lands during the territorial era.

Title to water rights continued to plague the Tewa Pueblos of the upper Rio Arriba as seen in the decision handed down in Reynolds vs. Aamodt 1973. The case derived from the Tesuque, Nambe, and Pojoaque, and San Illdefonso Pueblos (Tewa) that brought issue with the state and state engineer over the jurisdiction of Indian water rights

\footnotetext{
143 The Winters Doctrine outlined: (1) the reservation had been culled from a "much larger tract," which was necessary for a nomadic and uncivilized peoples"; (2) the government's policy and the "desire of the Indian" was to be transformed and to elevate tribal culture from a "nomadic" to an "agrarian" lifestyle; (3) this transformation could only occur if the tribal lands were severely reduced in size, making them more amenable to agricultural pursuits; and finally, the capstone argument completing the package, (4) since the lands were judged "arid," they would remain” practically valueless without an adequate supply of water for irrigation. (In Wilkins and Lomawaima, 2001; 130.)
} 
and usage (Dunbar-Ortiz, 2007; 131). The state had asked the court to limit Indian water rights and remove federal jurisdiction to the state engineer as defined in the McCarren Act. The ruling by U.S. District Court Judge H. Vearle Payne determined that the same water rights apply to Pueblos as to non-Indians and therefore did not fall under the umbrella of the Winters Doctrine. The judge declared a difference existed between reservations and Pueblos and therefore Winters did not apply. The conflict concerning state oversight of Pueblo water rights continued to play out in the judicial system. Vlasich (2005) explains, nineteen years after Reynolds vs. Aamodt, several Pueblos filed suit. The result of these suits established overwhelming precedence whereby the courts essentially determined the irrigation agriculture of the Pueblos no longer alive therefore, Pueblos were not in need of the waters rights specified in the Winters Doctrine.

Vlasich (2005) states some of the more detrimental impacts to Pueblo water rights occurred during the Regan Administration when many lost up to half their water rights once secured under the law of prior appropriation. The socio-economic impacts resulting from these court rulings and executive agendas are not quantifiable and have only contributed to the prevalence of uneven development within these communities.

\section{Conclusion}

As examined in chapter seven, Tewan society and land tenure organization, prior to colonial rule under the Spanish, was organized to support intensive hydraulic farming sustained through complex irrigation systems (Dunbar-Ortiz, 2007). In contrast to the Oglala-Lakota and Tlingit, the Pueblo social structure reflected the demands of intensive agriculture and the maintenance of irrigation works that intertwined religion and the agricultural seasons, intimately establishing and connecting lifeways to the surrounding 
lifeworld or perceived sacred space (Dunbar-Ortiz, 2007). Fundamentally, Pueblo ceremonies and land use were inseparable components of the perception of their lifeway.

After the Treaty of Guadalupe Hidalgo of 1848 and the United States’ occupation of the region, federal officials omitted any communal land sharing in favor of the fee base system. Numerous problems occur with the implementation of this type of economic system in this particular type of environment and region where water is scarce.

A key component of the organization of the Pueblo lifeworld is their relationship with water, and their ability to construct their lifeway upon this resource. The importance that water played in the Pueblo lifeworld and lifeway is visible in their highly developed and sophisticated system of agriculture, which is dependent on sustainable and communal water use. In addition to the introduction of an individualist land base system into a historically communal structure, water rights became and continue to be a source of contention with the introduction of capitalist development in the region, particularly in the form of large scale commodity ranching and agriculture.

The hierarchical power structure organizing the complex socio-political structure is rooted in the cosmologic arrangement outlined in the Eastern Tewa Emergence story. Lending credence to previous colonial power systems influencing traditional Eastern Tewa society prior to the United States formal acquisition of their traditional land-base, specific government acts and legislation were examined that directly influenced traditional lifeways, in turn reorganizing conceptualization of the Tewa lifeworld, through accumulation by dispossession. The process of organizing these contradictions made apparent the process responsible for the reformation of traditional 
conceptualizations of the Eastern Tewa lifeworld and lifeways (place and identity) to the preconditions linking uneven development sponsored by accumulation by dispossession.

\section{Tlingit: Alaska Native Claims Settlement Act (ANCSA)}

The integration of indigenous Alaskans into the socio-economic and political fabric of America is unique in relation to the experiences shared by other Native American societies who have struggled to regain their sovereignty for well over a century, as the Oglala-Lakota and the Tewa Pueblos. While the territory of Alaska has been in the possession of the United States since 1867, the influence of western capitalist economies within the region was slow to emerge. In the interest of this research, focus is directed toward southeast Alaska, the traditional land base of the Tlingit.

Enticed by the economic prosperity spurred by the fur industry, Russia was responsible for the initial military settlement of southeastern Alaska. While the Russian era of occupation can not be characterized as totally successful, as the Tlingit were able to successfully limit Russian settlement into the interior, Russia was able to plant the seed for the organization and development of trade relations with western based capitalist economies. The economic benefits available from the markets of fur industry were in decline after United States acquisition of the territory, the next market to soon emerge was fisheries based.

Similar to Russian military backing of the fur economy, the United States in the 1870's began to establish fishery and cannery industries supported through military protection. The workforce within the fisheries industry was dominated by three groups: 
Asian, American, and indigenous labors ${ }^{144}$. After all, the traditional socio-economic and political structure of the Tlingit was largely based upon traditional ecological knowledge surrounding fisheries. Through the successful introduction of a fisheries based economy within the region another integral component to integrating indigenous societies in capitalism was incorporated, a cash economy (Dombrowski, 2001).

Thorough research conducted by Dombrowski (2001), discusses the integration of the capitalist economic structure within southeast Alaska. Within this research, the foundation for the socio-economic and political integration of the capitalist market within the indigenous social structure of the Tlingit is developed to suggest the prevalence of the capitalist logic of power versus the territorial logic of power that dominated the early histories of the Oglala-Lakota and Eastern Tewa Pueblos. For instance, Dombrowski (2001) provides an example in which canneries, with the backing of military support, were able to locate closer to more abundant traditional subsistence grounds, in turn, enticing Tlingits to work in the canneries during the summer months when traditional subsistence activates were occurring in the area.

During the summer months the Tlingit worked in the canneries, men fished, and women worked inside on the lines. Together men and women earned enough cash to purchase goods needed to return to their traditional villages and still continue their traditional subsistence activities the remainder of the year. As Dombrowski (2001) alludes, the introduction of this cash economy created tension within the Tlingit highly developed social structure. In essence, money was becoming an indicator of social ranking.

\footnotetext{
${ }^{144}$ The passing of the Chinese Exclusion Act 1882 affected the overall cultural distribution in the fisheries labor force.
} 
The incorporation of a cash economy was further intertwined into the Tlingit social structure as the canneries, with the backing of the United States military, were attempting to transform the traditional Tlingit subsistence base socio-economic and political structure by simply building canneries in the Tlingit subsistence areas. Cognizant of the growing tensions between clans resulting from the impacts of capitalist economy, Tlingits began to reformulate their social structure to mitigate the impacts. The first mitigation was the organization of a labor union, the Alaska Native Brotherhood $(\mathrm{ANB})^{145}$.

During the peak of Alaska's fishing industry, the union organization was successful in addressing many native rights issues such as the outlawing of fish traps owned and operated by canneries, in addition to, bringing the right to vote to native Alaskans before the passing of the 1924 Indian Citizenship Act that allowed natives in the lower 48 states the same right (Dombrowski, 2001; 29-32). Although the ANB would gradually loose its political influence during the decline of the fisheries industry, the organization exist's today and continues to support and ensure the continuation of native rights. The early successes of the ANB in ensuring the security of the right of native Alaskans was significant not only in the achievement of these goals but, more importantly, laid the foundation for guiding native Alaskans through the socio-political and economic processes underlying a western capitalist based political economy.

The next major event culminating in the indoctrination of native Alaskans into the socio-economic and publication processes of the capitalist driven political economy was the drop in fish prices, leading to the closing of canneries, and the passing of the

\footnotetext{
${ }^{145}$ The Alaska Native Brotherhood was founded in Sitka by several missionary educated Tlingit and Tsimshian natives and led by William Paul a native lawyer from Wrangell (Dombrowski, 2001; 29).
} 
1934 Indian Reorganization Act. At the heart of the Indian Reorganization Act was the strengthening of the tribal government through the development of a more corporate economic based organization (Prucha, 1994; 375). Pressured by the Bureau of Indian Affairs, many native villages supported by the once booming fisheries and canneries industries were encouraged to develop corporate political structures in order to secure loans to fully integrate a wage economy centered on fisheries (Dombrowski, 2001: 2932). However, as the price of fish continued to drop, the developing wage economies of many native villages were in threat of default.

Although these village economies were in threat of decline, most native Alaskans still relied upon traditional subsistence strategies to sustain daily needs. It is important to note that while wage based capitalist markets were able to penetrate the traditional Tlingit tribal area, for the most part, the Tlingit did not fall victim to the affects of primitive accumulation described by Smith (1990) where as the increasing scale of commodities becomes ingrained in daily life (conditionality one), the producer becomes divorced from the land. Instead, educated by the political processes and successes of the ANB, Tlingit and native Alaskans were prepared to act when the threat of primitive accumulation or accumulation by dispossession were spurred by talks of statehood.

The full economic potential of Alaska's vast natural resources (timber, minerals, natural gas, and oil) were finally becoming visualized. Unlike, the Oglala-Lakota, the Eastern Tewa Pueblos, or for the most part any native society in the lower 48 states, the vast majority of Tlingit and other Alaskan natives had not participated in any form of formal land claim organization, dispute, or treaty with United States federal government. Therefore, when surveyors began showing up in the rural backcountry of Alaska on or 
near traditional subsistence grounds Tlingits and other native Alaskans began to take notice and interject themselves in the land claims process ${ }^{146}$ (Wilkinson, 2005; 230-233). Alaska achieved statehood January $3^{\text {rd }}$, 1959. Prior to statehood, native southeastern Alaskans began to reorganize their social structure to compensate for this new political and economic shift through the creation of the Tlingit and Haida Central Council $^{147}$. Alaskan natives sharing the same concerns convened in 1966 to form the Alaskan Federation of Natives whose main objective was to create a freeze on any type of federal or state land transfer (Wilkinson, 2005; 233-235). For nearly eleven years, Tlingits and natives throughout Alaska fought lobbyists on capital hill to ensure the rights to their traditional subsistence grounds. December 18, 1971 the Alaska Native Claims Settlement Act (ANCSA) was signed into law by President Nixon.

ANCSA forever changed the traditional socio-economic and political structure of the Tlingit (Figure 36). This act set aside 45 million of Alaska's combined 425 million acres, paid one billion dollars to Alaska Natives, and led to a study to set aside an additional 100 million acres to national parks, forests, and other preservations and conservation agencies (Wilkinson, 2005; 235-236). In comparison to the wars, tribulations, and eventual dismissive attitude toward the Oglala-Lakota, Eastern Tewa Pueblos, and natives of the lower 48, this act seemed to project justice and equality had finally arrived to Native Country.

As seen in Figure 36, this act added levels within the traditional Tlingit sociopolitical organization. The positive and negative aspects of expanding the traditional

\footnotetext{
${ }^{146}$ Wilkinson (2005) also mentions that during Russian occupation no formal land treaties were developed with the Alaskan natives.

${ }^{147}$ Dombrowski (2001; 32-33) comments that the Tlingit and Haida Central Council was created as an offshoot of the ANB, although in later years the two organizations would grow to seeperate.
} 
Tlingit socio-political organization is not the primary concern of this research. Instead, emphasis within this research is directed toward understanding the processes contributing to these modifications and the possible outcomes of these changes as they are projected into the future. The most fundamental modification occurring to the Tlingit traditional social structure was the reorganization of native communities into regional and village corporations (Figures 33 and 36). The formation of these socio-economic and political organizations were in line with the popular Western ideology carried forth from the Indian Reorganization Act, supporting the introduction of corporate/capitalist structures into indigenous societies as a means to further acculturation. 


\begin{tabular}{|c|c|c|c|}
\hline Socio-Political Units & Equivalent Example & No. of Units & Generality \\
\hline $\begin{array}{l}\text { Alaska Federation of Natives } \\
\text { (AFN) }\end{array}$ & $\begin{array}{l}\text { Statewide advocacy } \\
\text { organization, composed of } \\
\text { representatives } \\
\text { from ANCSA and other entities }\end{array}$ & 1 & most general \\
\hline $\begin{array}{l}\text { Alaska Native Brotherhood } \\
\text { (ANB)/ Sisterhood (ANS) }\end{array}$ & $\begin{array}{l}\text { Grand camp organized at the } \\
\text { regional level (although some } \\
\text { Sisterhood (ANS) camps exist } \\
\text { outside of Southeast) and } \\
\text { composed of communities at the } \\
\text { kwáan level }\end{array}$ & $\begin{array}{l}1 \text { Grand Camp } \\
\text { and dozens of } \\
\text { local camps }\end{array}$ & \\
\hline $\begin{array}{l}\text { ANCSA Regional } \\
\text { Corporation (Sealaska) }\end{array}$ & $\begin{array}{l}\text { For-profit corporations control } \\
\text { land and other economic } \\
\text { resources and wield considerable } \\
\text { political clout }\end{array}$ & $\begin{array}{l}1 \text { Southeast } \\
13 \text { Statewide }\end{array}$ & \\
\hline $\begin{array}{c}\text { Central Council of Tlingit } \\
\text { and Haida Indian Tribes of } \\
\text { Alaska (CCTHITA) }\end{array}$ & $\begin{array}{l}\text { Regional organization; has } \\
\text { annual meeting and local } \\
\text { community delegate structure, } \\
\text { but no local camps like ANB; } \\
\text { maintains large day-to-day } \\
\text { presence, providing a variety of } \\
\text { services }\end{array}$ & 1 & \\
\hline Nation or Lingít & $\begin{array}{l}\text { Weak political status based } \\
\text { primarily on common language } \\
\text { and culture. }\end{array}$ & 1 & \\
\hline Moiety & $\begin{array}{l}\text { Important for organizing } \\
\text { reciprocal exchange in ritual } \\
\text { politics. }\end{array}$ & 2 & \\
\hline Village or Kwáan & $\begin{array}{l}\text { Weak political status based on } \\
\text { common habitation, usually of a } \\
\text { single winter village. }\end{array}$ & $13-18$ & \\
\hline IRA/tribal governments & $\begin{array}{l}\text { Kwáan-level unit created by } \\
\text { federal government in } 1935 \text { with } \\
\text { most becoming federally } \\
\text { recognized tribes in 1993; have } \\
\text { sovereign powers and access to } \\
\text { federal resources }\end{array}$ & 13 & \\
\hline ANCSA village corporation & $\begin{array}{l}\text { Not as wealthy or powerful as } \\
\text { regional corporations, although } \\
\text { some have done well; may vie } \\
\text { with tribal government and other } \\
\text { kwáan-level entities }\end{array}$ & $\begin{array}{l}12 \text { Southeast } \\
171 \text { Statewide }\end{array}$ & \\
\hline & & & \\
\hline
\end{tabular}




\begin{tabular}{|c|c|c|c|}
\hline Clan or Naa & $\begin{array}{l}\text { Central sociopolitical unit based } \\
\text { on matrilineage. }\end{array}$ & $70+$ & \\
\hline House or Hít & $\begin{array}{l}\text { Based originally on the segment } \\
\text { of a matrilineage residing in one } \\
\text { house. }\end{array}$ & $200+$ & \\
\hline Person or Káa & $\begin{array}{l}\text { Sociopolitical status acquired by } \\
\text { birth, but big names/titles also } \\
\text { reserved for high born Tlingits } \\
\text { who distinguish themselves }\end{array}$ & $15,000+$ & $\downarrow$ \\
\hline
\end{tabular}

Figure 36: Restructuring of the Tlingit socio-political units 1971-Present. Yellow cells identify modifications from the traditional Tlingit socio-political organization listed in Figure 15. The green cell identifies a population increase in comparison to the data found in Figure 15. Modified from: Thornton, 2002; pg.189-190.

Essentially, while the United States government would continue to recognize Alaskan 'tribes,' when ANCSA was signed, no land was actually transferred to the 'tribes.' Instead, all lands claimed under ANCSA were transferred to village and regional corporations ${ }^{148}$ where each Alaskan Native received shares of stock in the local village and associated regional corporation (Wilkinson, 2005; 36-39). Prucha (1994), Dombrowski (2001), and Wilkinson (2005) discuss the similarities which existed between ANASCA and the Indian Termination Policy 1953 or Public Law 280 which sought to eliminate the 'special relationship' that existed between Native Americans and the federal government.

The prevailing ideology behind Public Law 280 assumed that the most effective method to incorporate indigenous societies within Western culture was to remove the pseudo-sovereign in-trust/ward status and require Native Americans to become susceptible to federal and state jurisdictional powers. The attitude taken by Congress

\footnotetext{
${ }^{148}$ Unlike tribes, these corporations were regulated Alaskan state corporate law (Wilkinson, 2005; 37).
} 
during this time reflected a complete misunderstanding as to why Native American communities and reservations throughout the United States continued to statistically sustain the highest rates of poverty, infancy death, alcoholism, suicide, and unemployment in comparison to surrounding communities of similar demographics.

When the Era of Termination and Public Law 280 was enacted most indigenous peoples, other than those in Alaska and Hawaii, had been exposed to multiple eras of Federal Indian policy agendas aimed at varying forms of accumulation by dispossession with the added objective of acculturation. Congress seemed to assume by enacting Public Law 280, that the stunted economies of Native American societies and reservations was the result of federal policies enabling these communities to remain off the grid. In order to rectify this perceived conundrum, Congress's rationale assumed they need only to remove all federal oversight previously guaranteed through the in-trust status assigned after the era of treaty making in 1871 . No more federal programs, no more rights to traditional subsistence grounds guaranteed through treaty making and vehemently fought to protect for decades, no more protection from state government oversight. This is perhaps the most dramatic form of acculturation and accumulation by dispossession to occur since the terminus of the nineteenth century Indian Wars.

By the end of the Era of Termination 109 'tribes' throughout the United States had been affected. Through lengthy court proceedings many of Native American peoples were able to regain lands lost during this policy initiative. After this failed policy the Era of Termination switched to that of Self Determination. ANCSA is a product of these chains of events. The federal government recognized the errors and no longer wanted to expand the reservation system but still sought a means to acquire resource rich lands from 
the Alaskan Natives. While ANCSA did provide Alaskan Natives rights to a traditional land base, albeit much reduced, and stock options they were giving up their pseudosovereign status and would now be: affected by state and federal laws; extinguish rights to traditional subsistence areas; children born after ANCSA would not be entitled to shares in either corporation; and after twenty years shares in the village and regional corporations could be sold to non-natives in the open market (Figure 37) (Wilkinson, 2005; 236-239).

Again, as seen during the eras of statehood and the rise and fall of the cannery and fishery industries, Alaskan Natives were able to cooperatively restore many of the rights lost in ANCSA. Aided by recent court precedence such as the Boldt Decision $1974^{149}$ which, upheld the rights of Native Americans to traditional subsistence grounds as originally defined in historic treaties. According to Prucha (1994; 404-405) Boldt's decision was groundbreaking for Native American communities because: 'after thoroughly analyzing treaties, the migratory patterns of fish, Indian fishing patterns, and the history of state regulation, Boldt's findings showed a reduction of Indian rights over the years by state regulation and non-Indian encroachment. He enunciated a set of principles to govern Indian fishing: the treaties reserved fishing rights for Indians that differed from those of other citizens; off-reservation fishing rights extended to all places that a tribe had customarily fished; and the state could regulate Indian fishing only to the extent needed to conserved fish resources; plus, Indian's right to take fish, in common with the citizens of the territory, meant not only fishing sites but a share of the fish, 50 percent of the harvestable number (i.e. their limit would exceed those of the normal citizen).'

By 1987, Alaskan Natives were able to amend ANCSA and restore three significant socio-economic and political losses negated in the law: children born after 1971 would be

${ }^{149}$ The Boldt Decision was later accepted and enforced by the United States Supreme Court in their July 2, 1979 ruling Washington v. Washington State Commercial Passenger Fishing Vessel Association. 
able to become shareholders in both village and regional corporations, if the corporation agreed to dilute their interests in order to make room for the new members, blocking the ability for non-Native takeovers; preferential rights to traditional subsistence ground, Alaska National Interest Land Conservation Act (ANILCA), were established; and the village tribal governments reestablished many rights to govern according to traditional edict (Dombrowski, 2001 and Wilinson, 2005; 238-240).

Figure 37: Sealaska Native Corporation boundary with inset map of all ANCSA Native Corporation Boundaries. 


\section{Conclusion}

The many successes of the Tlingit and Alaskan Natives, in comparison to the Eastern Tewa and Oglala-Lakota, seem to be derived from the communities' ability to work the system when the system was not working in their best interest, such as through the organization of unions that lobbied in Washington for their interests. These successes may not have occurred outside of the unique spatio-historic perspective in which they were situated. That being said, the Tlingit and Alaskan Natives are still actively pursuing many of the sovereignty rights lost during the enactment of ANCSA directly affecting their ability to ensure the continuance of traditional lifeways organizing the conceptual underpinnings to their lifeworld. For instance, Dombrowski (2001) discusses the intricacies/fine print associated with enrollment for Tlingit and Alaskan Natives into regional and village corporations. An individual's enrollment into a village corporation was based on a loose set of rules that did not require the individual to actually live in the village. The outcome of these loose rules led to many non-resident shareholders in village corporations. The division in resident versus non-resident shareholders has fed the fire in the traditionalist versus modernist debates spreading throughout Indian Country.

In brief, although non-residents do not live in the village their vote can carry considerable sway, especially since more and more children are moving away from their original village communities or the economies of the villages fail and require families to relocate. Therefore, as increasing numbers of individuals left, their votes often went toward short-term monetary ventures instead of looking toward future long term 
investments. Many village corporations tried to offset these exoduses by distributing monies allocated through ANCSA as dividends to the village shareholders. Distributing these monies were meant to offset the economic lull villages were experiencing prior to the establishment of their ANCSA land allotments (Dombrowski, 2001). These monies, distributed as dividends, were originally earmarked to be used in order to start timber harvesting companies. However, the land allotments were not distributed concordant with the money, leaving village corporations desperate to turn a profit.

Subsequently, when the lands did become available, the villages did not have the revenue to start up harvesting companies. Many villages resigned to selling the timber on the stump to outside private corporations for harvest, these companies did not concern themselves with hiring the native labor ${ }^{150}$. Dombrowski (2001), emphatically discusses the trials and tribulations these villages experienced during the first two years postANCSA. The most poignant effects felt by the Tlingits who chose to remain in their traditional villages came from the impacts placed upon the ecosystem and especially from the clear cutting that would later be encouraged by cleverly amending the tax code in line with the 1987 ANCSA amendments. Please keep in mind, for those individuals who chose to remain in the village, where the wage economy was virtually nonexistent, traditional subsistence patterns and practices remained an integral component to daily life.

The conflicts and animosity between resident and non-resident shareholders continued to grow as the interests of the non-residents gained majority in the village populations. By the late 1980 's, this unbalanced majority aided in the eventual revision

\footnotetext{
${ }^{150}$ Dombrowski (2001; 75-76) mentions that those villages who chose to go into debt in order to purchase the necessary timber harvesting equipment often borrowed money from Asian corporations who would then have considerable control over the sale of the timber.
} 
of the 1986 United States Tax Code and the 1987 amendment to ANCSA to include the Net Operating Loss (NOL). The inclusion of the NOL supported practice that led to severe environmental degradation throughout traditional Tlingit subsistence areas and, in general, Southeast Alaska. Essentially, the factors that contributed to the decline of many ecosystems within Southeaster Alaska boils down to one prominent factor encouraged through the NOL. First, in order to claim a NOL the timber industry tax loophole was extended to ANCSA village corporations. According to Dombrowski (2001;76-80) this loophole essentially allowed corporations to claim decreases in the value of standing timber between purchase and harvest as operating losses but, this provision meant little to the village corporations because few had ever returned a profit large enough to be concerned with a tax advantage.

The second provision to the tax code including the NOL represents, from the perspective of this researcher, the epitome of contemporary methods through which accumulation by dispossession occurs under the current dominance of the capitalist logic of power. Many of the village corporations who had held onto their timber harvests until the mid-late 1980's had generated NOLs exceeding several millions to tens of millions of dollars. These NOLs were bad for the shareholders until the 1986 tax amendment that allowed the village corporations to sell these losses to high profit corporate American companies who were in dire need of finding a tax shelter, in order to lower their taxable rate $^{151}$. The result led to several village corporations, where the majority of voters were non-resident, to sell their accumulated NOLs to the highest bidder. The caveat to this amendment resulted in considerable environmental degradation where the requirement

\footnotetext{
${ }^{151}$ According to Dombrowski $(2001 ; 212)$ the regional corporation Sealaska also purchased NORs from debt ridden village corporations.
} 
stated the loss be either sold on the stump or harvested in order to be actualized (Dombrowski, 2001; 78). Also, please note, the environmental losses endured by the clear cutting have been exacerbated by the status of the land as private instead of public. Land classified as private are not subject to the same environmental regulations as public lands ${ }^{152}$.

Researchers such as Vine Deloria Jr., Kirk Dombrowski, and Thomas F. Thorton have raised the question whether ANCSA was really termination in disguise? Great question, up to this juncture this researcher found it difficult to concretely place conditionalties one through three within Tlingit socio-political or economic structures. However, since the original enactment of ANCSA, followed by the 1987 amendments, I have placed three of Harvey's conditionalities: the material embedding of capital accumulation processes in the web of socio-ecological life (i.e. the increase in the number of individuals who moved from their village due to deficient wage economies); accumulation by dispossession (removing sovereign status to favor a corporate based socio-economic and political structure); the law-like character of capital accumulation in space and time (ANCSA).

Is ANCSA termination? Characteristics of the law certainly seem to correspond to this hypothesis. While this may be the case, from the perspective of this researcher Harvey's conditionality four (political, social, and “class” struggles at a variety of geographical scales) has always coexisted throughout the historic socio-economic and political struggles between the Tlingit and the federal and state governments or private industry. While a struggle, the intimate connections shared between the conceptual

\footnotetext{
${ }^{152}$ From a Federal Regulatory perspective the laws, rules, and regulations governing public and private land development are subject to change according to Congressional or Judicial mandates.
} 
understanding of the Tlingit lifeworld and lifeways continues to surpass temporal barriers and has, as seen in the past, reconceptualized in order to react to contemporary changes in the socio-economic and political capitalist climate. These struggles and reactions parallel those of the Oglala-Lakota and Eastern Tewa Pueblos as they fought/fight to retain their lifeways as territorial and capitalist logics of power continued to intruded into their traditional lifeworld.

\section{Conclusion: Conditionality Four \& The Cycle of Enforcement and Resistance}

Many of the white man's ways are past our understanding... They put a great store upon writing; there is always paper.

The white people must think that paper has some mysterious power to help them in the world. The Indian needs no writing; worlds that are true sink deep into his heart, where they remain. He never forgets them. On the other hand, if the white man loses his papers he is helpless.

I once heard one of their preachers say that no white man was admitted to heaven unless there were writings about him in a great book!

-Four Guns

Oglala Sioux

(In Nerburn, K., 1999: pg. 57)

The more recent neo-liberal trend in utilizing native intellectual property for capitalist profit has generated new avenues to explore in the theory of uneven development. Western practice uses the authority of copyright to protect intellectual property from being used or infringed upon by outside interests. However, what actions should secure the rights of native knowledge that thrives on oral tradition as opposed to written? As expressed in the above statement by a member of the Oglala-Lakota. Researchers such as Cornell, Howitt, Rowlands, Brown, Humphrey and Verdery address this question and seek a solution that will generate a unified concept for the protection of 
all forms of 'cultural property' that will fall within the discourses surrounding intellectual property rights.

Most Native American societies, as the Oglala-Lakota, Tlingit, Eastern Tewa Pueblos contemporary responses and actions toward the historic precedence of United States occupation perpetuated through capitalist accumulation by dispossession now occurs in the courts. Efforts to reclaim and maintain original land bases, mineral rights, water rights and intellectual rights are a primary means through which the Pueblo, Tlingit and Oglala-Lakota people are attempting to reestablish socio-economic and political sovereignty. The process of culturing that has and is occurring in Oglala-Lakota, Tlingit and Tewa societies has culminated into a multi-scaled network of socio-political and economic space aimed at communicating and preserving the sovereign lifeworld and lifeways of native peoples.

Aided by technology, the social impact and influence of grassroots power geometries extend beyond the local and are now engaged at the glocal scale. Specific to Native American societies as the Oglala, Tewa, and Tlingit is their continuous engagement of social activism as defined by Harvey's conditionality four. Supporting the discussions outlined in chapter nine, figure 34 illustrates the historic scale of activism on behalf of these societies in response to legislative attempts to forcefully acculturate and ensure the material embedding of capital accumulation processes in the web of socioecological life, i.e. conditionality one. While Native Americans, especially traditionalists, vociferously reject attempts to embed and replace Native American ideologies whether it be through war or protest there is no doubt the assimilationist policies have affected the cultural continuance of these people. Bombarded by policies of 
suppression and illegalization of indigenous language, ritual, ceremonies, dress, and lifeways adversely impacted the traditional methods through which the transfer of knowledge ensures cultural development and continuance.

So, although policies geared toward physical and intellectual acculturation have occurred for decades, figure 34 illustrates that Native American peoples have been thoroughly engaged in some form or act of defiance in order to ensure cultural continuance. On the rise since the 1960's, issues pertaining to uneven development and the social ramifications produced through centuries of political agendas aimed at economic superiority through motives of accumulation by dispossession are being publically addressed at multiple scales. For instance, in the early sixties an increase is seen in formal protests led by Native American activist groups such as the American Indian Movement (AIM) and National Indian Youth Council. In particular, AIM is responsible for organizing famous protests such as the: 1969 Indians of All Tribes Occupation of Alcatraz; the 1970 takeover of the Bureau of Indian Affairs' main office in Washington D.C. to show improper BIA policies; the 1972 Trails of Broken Treaties march on Washington D.C.; and aided in organizing the Wounded Knee Standoff ${ }^{153}$ on the Pine Ridge Reservation.

The dialectical tensions encompassing the cycle of forceful embedding of material capital accumulation processes in the web of socio-ecological life (i.e. conditionality one) and the responses of Native American societies political, social, and “class" struggles at a variety of geographical scales (i.e. conditionality two) are constantly evolving. Seen throughout this research, the context in which these dialogues interact are dependent

\footnotetext{
${ }^{153}$ The Wounded Knee Standoff occurred as a result of increased frustration by Lakota elders concerning corruption on behalf of the BIA on the Pine Ridge Reservation.
} 
upon historic socio-economic and political interconnections at multiple scales. For instance, early interactions between these conditionalities resulted in the formation of the 1885 Seven Major Crimes Act and the emergence of the Ghost Dance that culminated in the tragic Wounded Knee massacre. Violent responses to these conditionalites plagued Native American societies post-treaty abrogation. The evolution of the interactions between these dialogues or conditionalites now occur at various socio-political and economic scales.

Interactions between Native Americans and individuals at the legislative and executive scales of government dictated the signing of the December 8, 2010 Claims Resolution Act ( also known as bill H.R. 4783). This act specifically addresses two settlements related to two court cases, Cobell v. Salazar (2009) and Pigford v. Glickman (1999). The Pigford settlement pertains to the waste, fraud, and abuse carried forth by the U.S. Department of Agriculture in the knowing discrimination of Black Farmers. While this specific portion of the act does not address this researcher's focus upon Native Americans, this settlement is congruent to the overall objective of identifying the many socio-economic and political affects of accumulation by dispossession on cultural continuity, cohesiveness, and sustainability. The Cobell settlement addresses two claims: first, the historic precedence of waste, fraud, and abuse perpetuated by the U.S. Department of Interior and second its policies aimed at dispossessing Native Americans of territorial land rights and monies held in-trust and second, settling historic water rights abuses negating the doctrine of prior appropriation and beneficial use when pertaining to Native American claims. 
In brief, the Cobell settlement has publically acknowledged the historic and contemporary precedence of waste, fraud, and abuse carried forth through federal legislation directed toward the dispossession of the rights of Native Americans in relation to the rights afforded to all United States citizens. The Cobell settlement recognizes that the dispossession of these rights have occurred through physical territorial injustices and monetary/capital abuses. In restitution for these actions funds were created to compensate individuals for these historic 'accounting errors ${ }^{154}$, and also to aid in the purchase back of fractionalized land interests. This bill also settles four Native American water rights cases ensuring the adequate supply, security, and allocation of this natural resource to their communities. To further emphasize the importance of water rights to the cultural continuity of specific Native American societies, of the four cases, the Aamodt suit filed by the Tewa Pueblos Tesuque, Nambe, Pojoaque, and San Ildefonso, was the longest running water rights case in the federal court system. While the socio-political activism of indigenous societies has proven integral to the Native Voice now being heard at the state, federal, and international scales. Considerable work still remains in order to undo many of the policies that contributed to overall uneven development within Native American societies. While determined to move their people forward into the future, this research has shown the multiple paths that exist for societies such as the Oglala-Lakota, Tewa, and Tlingit but, now issues pertaining to traditional versus modernist approaches are challenging these people to determine the best method to project their cultures forward and still retain the foundational ideological

\footnotetext{
${ }^{154}$ These historic accounting errors exceed 1.4 billion dollars. http://www.doi.gov/news/pressreleases/Secretary-Salazar-Lauds-Senate-Passage-of-Five-Historic-IndianCountry-Settlements-to-Resolve-Cobell-Litigation-and-to-Deliver-Clean-Water-to-IndianCommunities.cfm
} 
components of their lifeworld and lifeways responsible for constructing and developing place and identity for centuries.

This movement forward is no small feat, 2003 statistics generated by the U.S. Census Bureau and Bureau of Indian Affairs speak volumes for the current socioeconomic status of Native Americans in the United States in comparison to white population: $49 \%$ unemployment for those individuals able to work (5.1\% white population) and $23 \%$ of the total population lives under the established poverty line ( $8 \%$ white population). In addition, the real median income for Native American households is $\$ 32,866$ versus $\$ 48,000$ for white households. In addition, the most recent analysis of statistics generated from the 2010 census by Austin (2011) indicates:

1. From the first half of 2007 to the first half of 2010, the American Indian unemployment rate nationally increased 7.7 percentage points to $15.2 \%$. This increase was 1.6 times the size of the white increase.

2. By the first half of 2010, the unemployment rate for Alaska Natives jumped 6.3 percentage points to $21.3 \%$ - the highest regional unemployment rate for American Indians.

3. Since the start of the recession, American Indians in the Midwest experienced the greatest increase in unemployment, growing by 10.3 percentage points to $19.3 \%$.

4. By the first half of this year, slightly more than half$51.5 \%$ - of American Indians nationally were working, down from 58.3\% in the first half of 2007.

5. In the first half of this year, only $44 \%$ of American Indians in the Northern Plains were working, the worst employment rate for Native Americans regionally.

6. The employment situation is the worst for American Indians in some of the same regions where it is best for whites:

Alaska and the Northern Plains.

These numbers clearly illustrate the prevalence and imbalance of uneven development within Native American communities. What effect does this inequality in economic status carry over into shaping social development, including cultural sustainability? This 
research has focused upon dialectics to comprehend how dispossession and its affect upon shaping Native American lifeworlds and lifeways. This research has shown that utilizing a dialectical method contributes to a more holistic understanding of the dynamic web of relations contributing to uneven development within Native American cultures. Future projections of Native American cultural continuance are varied as the current world capitalist marketplace has generated socio-economic and political uncertainty for all participants at the global scale. The territorial and capitalist logics of power have generated an economic global interdependence no longer explainable or sustainable utilizing Keynesian, Neo-Keynesian, Friedman, or Mundell-Fleming models of macroeconomics.

The ability of Native American communities to gain a positive foothold within this uncertain and tumultuous economic climate is questionable. Many communities, especially traditional communities, rely on income generated from the production of Native American arts and crafts. Passage of the 1990 Indian Arts and Crafts Act enabled many Native American communities and individuals the opportunity to sell traditional handmade works by eliminating competition of mass produced items sold under the guise of Native American made. These mass produced fakes sold and made cheaply often limited sales of traditional made item and caused many Native American arts and craftsmen to reduce prices in order to compete with the knockoffs. Perhaps one of the best examples of the protection created under the Indian Arts and Crafts Act is at the annual Santa Fe Indian Market. The Santa Fe market has become the preeminent event where Native Americans throughout the country present their trades, art, and crafts. A 
niche market now exists at the fair where some well established artisans fetch thousands of dollars for their wares.

Enabled by the perpetuation of Native American activism throughout history, many achievements reversing the affects of assimilationist policies have become actualized through the passage of: the 1978 Indian Child Welfare Act, 1978 American Indian Freedom of Religion Act, 1990 Native American Language Act, 1990 Native American Grave Protection and Repatriation Act, 1994 Native American Free Exercise of Religion Act, 1996 Executive Order on Native American Sacred Sites, and etc...

However passage of the 1988 Native American Gaming and Regulatory Act has ignited additional controversy within traditional and progressive factions of Native American communities throughout the nation. In an effort to stimulate reservation and Pueblo economies many communities are utilizing this legislation to create an additional revenue stream. This act allows Native American communities to open casino operations but, depending on the establishment's gaming class (I, II, or III) the tribe or community would now be subject to certain federal and state oversight. Class I and II facilities were solely subject to tribal oversight however, class III establishments require the organization of state-tribal compacts. Without state approval class III gaming facilities are not allowed on reservations or other tribal lands. While this act is seen by some as a means to empower Native American communities with the ability to strengthen tribal economies, others see this act as another means to interject additional regulatory oversight at the state level and contribute to the historic goal of assimilation.

The Oglala-Lakota, who are relatively resource deficient, have introduced gaming as an additional source of revenue by opening the Prairie Wind Casino on the Pine Ridge 
Reservation. In addition to the Prairie Wind, six of the eight Tewa Pueblos have opened casinos: Tesuque has opened the Camel Rock Casino, the Pojoaque Pueblo opened the Cities of Gold, the Santa Clara Pueblo opened the Big Rock Casino, San Juan Pueblo opened the Ohkay Casino, the Taos Pueblo opened the Taos Mountain Casino, and the Nambe Pueblo is developing plans to open a casino. Currently, the Tlingit and Haidia Central Council has opened a Bingo establishment.

The introduction of gaming is further igniting the traditional versus modernist debate within Native American communities. Individuals within these communities view the revenue generated from these operations as helping support tribal programs and provide economic assistance to its members. However, many traditionalist Native Americans are voicing concerns over the introduction of this new type of revenue stream and the possible effects that may contribute to the further deterioration of their lifeways. Nonetheless, Class III casinos are popping up within states containing Native American reservations and Pueblos such as: Oklahoma, New Mexico, South Dakota, California, and Connecticut. While the social impacts obtained through the economic benefits of these facilities have yet to be fully actualized. The concerns of traditionalists are valid, in that this economic benefit conflicts with the historic struggle of Native Americans to suppress the material embedding of capitalist culture within their societies, i.e. conditionality one. 


\section{Chapter 10: Assessment, Reflection, \& Look Ahead}

\section{Assessment}

Throughout this dissertation the objective to better articulate and comprehend the processes influencing place and identity development has been approached utilizing the dialectical method. Influenced by the historical works of Henri Lefebvre and the more contemporary research of Bertell Ollman, dialectics provided the conceptual framework to postulate and critically examine the dominate geographic theoretical constructs influencing the perspectives and methods in which the concepts of place, identity, uneven development, and accumulation by dispossession are perpetuated within the discipline. The desire of this research was to explore and analyze how dialectics informs the perspective(s) in which research is undertaken; this being a key component to overcoming the prominent hurdle of incorporating the Native American 'missing voice' or vantage point as a conscious perspective within the research. Underutilized in most research, specific cosmologies and creation stories of the Oglala-Lakota, Eastern Tewa Pueblos, and Tlingit were textually analyzed and specific themes identified that were woven throughout this research in order to illustrate to the reader the holistic spatio-social and temporal interrelationships communicated through these stories in relation to the development of these indigenous societies’ lifeworlds and lifeways.

Admittedly, throughout the research process preserving an unbiased level of cultural neutrality was difficult given the extensive history of Western subjugation and repression of indigenous peoples in the United States. However, deconstructionist theories perpetuating the popular Western perspective of the 'victim,' 'noble savage,' or 
'vanishing Indian' paradigms dismiss the complex cultural traditions (lifeways) composing of indigenous peoples lifeworlds. Retaining cultural neutrality to ensure rigourous research was achieved by adhering to the philosophy of internal relations that predicates that the totality of society is spatio-temporally emergent, this ideology sparked the notion for the inclusion of cosmologies. Interpreted within the theoretical construct of the philosophy of internal relations cosmologies provided the spatio-social and temporal interconnections for these indigenous societies translating the development of their lifeworld and lifeways in conjunction with the intrusion of Western society and culture.

This specific component to the philosophy of internal relations assumes that the totality of society is best examined from the spatio-social relations examinable through multiple perspectives or vantage points. Western cultures rely predominantly on the written record as a tool to assemble and construct historic perspectives or vantage points. Complications arise when applying this method to indigenous cultures that rely on oral communication to preserve their traditions especially as policies aimed at cultural assimilation dominated the political landscape and significantly reduced the number of native speakers. More recently, in response to these assimilationist policies, certain limitations exist on the access and use of indigenous cultures cosmologies and creation stories. In addition to physical property rights, many indigenous cultures have successfully defended and established legal precedence concerning intellectual property rights under which cosmologies are typically classified. The cosmologies of the indigenous cultures included in this research were publically accessible. Every attempt was made by this research to ensure cultural sensitivity toward sacred cultural rights were 
maintained and the stories included were accurately and properly represented in their appropriate context.

While specific challenges and limitations were encountered in locating and accurately representing the cosmologic literature, as the 'missing voice', included in this research. The crux of this research sought to develop a means to holistically analyze the spatio-social and temporal interrelationships occurring between indigenous cultures and Western societies as they evolved in historic and contemporary contexts. Informed by dialectics, Harvey’s (2006) general matrix of spatialities (figure 3) provided the initial theoretical structure to explore Merrifield's (1993) ontological space-place dilemma. Harvey acknowledges the limitations of viewing the general matrix of spatialities in a two dimensional linear type of diagram and only cautions the user to think abstractly to comprehend the complexity of spatio-temporal and social interconnections that contribute to an understanding of the totality or whole. Beyond the visual limitations of the graphic additional constraints were encountered in the matrix's ability to fully engage and capture non-Western forms of socio-spatial and temporal interactions. Attempts were made to accommodate for these constraints by modifying the two dimensional $3 \times 3$ (Figure 3) matrix to first, a 3 x 4 (Figure 4) and then, a 4 x 4 (Figure 5).

The intent of the $4 \times 4$ matrix was to incorporate the concept of spatial practice (perceived space), as understood by Lefebvre, that appears to be latent within Harvey's original 3 x 3 matrix. Perceived space is understood within this research to act as the mental binding agent informing the connections shared between the experienced, conceptualized, and lived spaces. Visually the same graphical representation was used to 
depict the inclusion of this temporal socio-spatial interactions and, upon further reflection, was determined inadequate.

Figure 38 was constructed to try to visually illuminate and describe a metatheory that seeks to comprehend how the dialectical process functions within indigenous cultures as understood through spatio-social and temporal relationships. Moving beyond

\section{Thought Concrete}

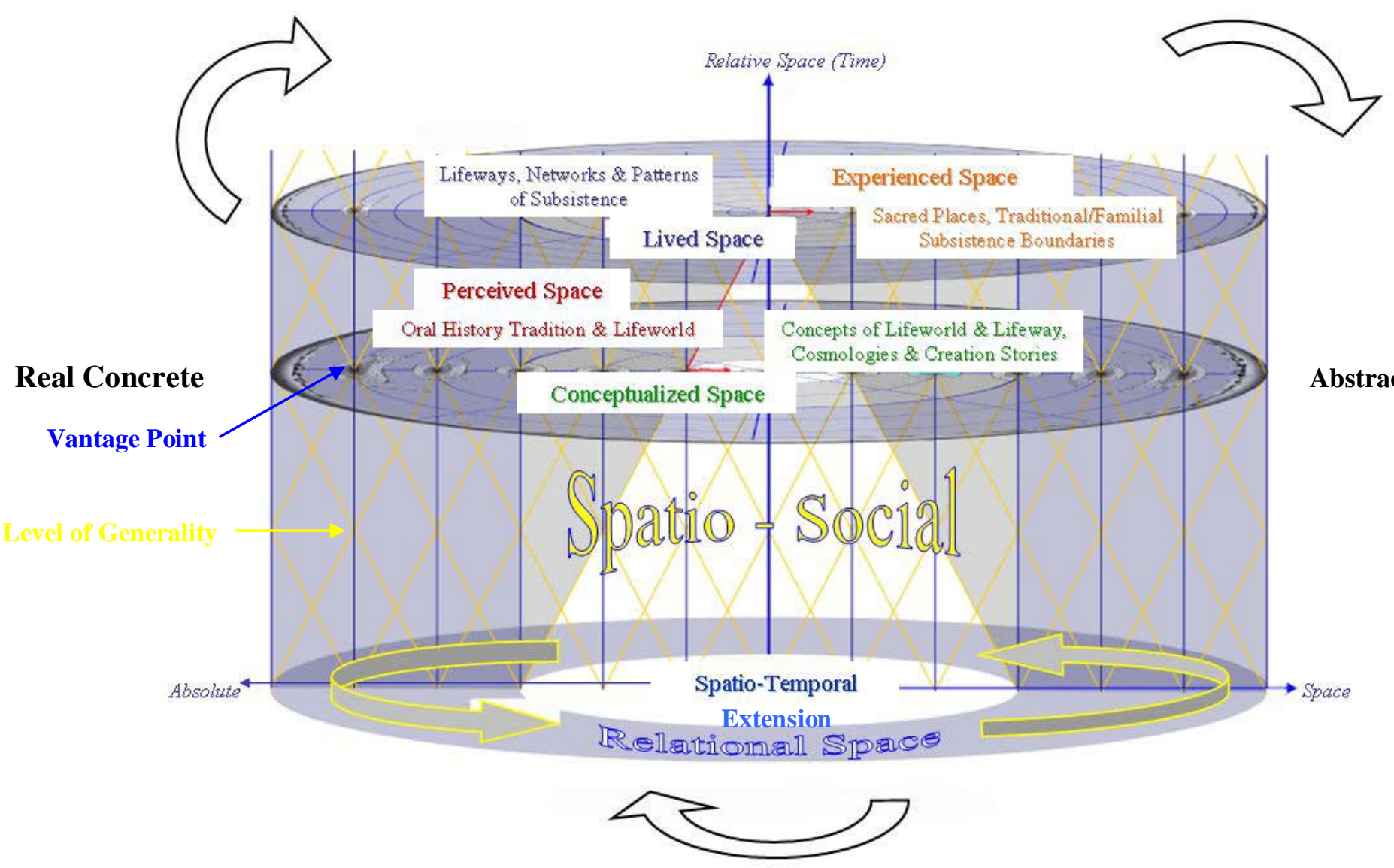

Figure 38: Reconfigured depiction of Harvey's general matrix of spatialites to accommodate non-Western conceptualizations and interrelations of the spatio-temporal and social as informed by the philosophy of internal relations. Modeled after Minkowski's relational quantum gravity diagram for a spherical universe.

Harvey's depiction, figure 38 attempts to visually address the rectification between the material and abstract as informed by the dynamic interrelationships between the spatio- 
temporal and social realities. In comparison to Harvey (2006) this model (Figure 38) brings to the forefront the processes operating in a dynamic mutual interrelationship as informed by the philosophy of internal relations, specifically the process of abstraction.

Focusing upon the three modes of abstraction extension, level of generality, and vantage point, this model illustrates to the reader the 'processes' and 'relations' that communicate the dynamic interrelationships of social history and futures as part of what the object of inquiry is, that ties 'it', with other relations. Decrypted, the reader or researcher is asked to view the model as a means to conceptually construct and consider the spatio-temporal (extension) and social interrelations that transpired within lived, experienced, perceived, and conceptual spaces that contribute to the conditions of the present, as understood from the specific perspectives (vantage points) that inform indigenous cultures lifeworld and lifeways (level of generality).

The application of this model outside the context of the metatheory explored in this research is plausible. Recontextualizing how experienced, lived, perceived, and conceptual ideas of space are transferred in the production or cycle of knowledge may require adjustment. The model is not meant to be viewed as static, instead the user is required to engage the model to determine the optimum spatio-social configuration to explore their 'object' of study. This model is not a prescription to be used to define the goals of the research process. Ideally, the model should be utilized as a conceptual tool to more holistically organize and define the boundaries of your object of inquiry as the dynamic spatio-temporal and social interrelationships are explored.

The manner in which this research, metatheory, and model are received within varying audiences, especially indigenous cultures and academia, is uncertain. That is to 
assume that individuals other than those who sat on this committee read this dissertation. Unwavering cultural neutrality was a requirement throughout this process but, the ability to please all audiences is an illusion that can detract, obscure, and bias the goal of the research. This dissertation is conceptual and sought to assemble a holistic means to explore the impact of capitalist uneven development and accumulation by dispossession within the indigenous societies explored in this research. In order to refine this conceptual metatheory, future field research is necessary that engages and establishes a trust based communicative relationship with the Oglala-Lakota, Tewa, and Tlingit communities.

\section{Reflection}

As commonly encountered with most dissertation research, the process to formally announce the intent and purpose guiding how you will structure the next several years of your life begins after completing comprehensive exams but, realistically the idea or interest that brought me, and I venture to say most individuals in this ship, to this juncture was planted several years ago. Personally, the cumulative ideological impacts responsible for the firing those nerves in the frontal lobe, influencing the collective unconscious, which led me to embark upon this fulfilling yet somewhat masochistic endeavor occurred in six years ago in 601.

Completing previous graduate degrees, underwater archaeology and geomorphology, following technical and applied research processes the decision to undertake a conceptual dissertation presented unique challenges. Formally trained as an archaeologist, and spending several years working in the field, the tangibility of the methods or work itself such as unearthing artifacts represented an integral component of 
the research process. While the tangibility of the science is grounded in highly technical and technologically developed methods often times the inability to properly structure and logically plan hypotheses has perpetuated lazy and loosely developed conclusions.

Frustrated with these inaccuracies and, then newly acquainted, with terminology such as ontology and epistemology I was quickly propelled out of my technical comfort zone and into the conceptual.

The ability to articulate the conceptual is difficult. Combined, the five human sensory mechanisms vision, hearing, smell, taste, and touch contextualize experience. While sensory mechanics provides the means to absorb the elements within the surrounding environment the path to making those experiences meaningful and useful are guided by societal ethos, norms, and behaviors. The term ethnopsychology, used by Thornton (2008), was utilized within this research as a means to describe the processes involved in conceptualizing the ethos, norms, and behaviors, structuring the OglalaLakota, Eastern Tewa, and Tlingit social organizations which contribute to the development of a collective sense of place and identity. In brief, the ability to contextualize concepts such as place and identity requires the application of all sensory mechanisms in addition to the means to comprehend and articulate how we come to know, understand, and develop these concepts. The latter being the focus of this research.

Paragraph one of this document outlined the focus and goals of this research. To refresh the readers memory:

the goal of this research was to dialectically conceptualize how capitalist uneven development has and continues to shape Native American perceptions of place and identity. Specifically, this research focuses on accumulation by dispossession, a key 
component of uneven development, and the spatio-historic effects this form of dispossession has had on Native American lifeworlds. This research focuses primarily upon federal legislation in the form of treaties and acts as the predominant component sustaining accumulation by dispossession and, in turn, perpetuating uneven development within Native American communities.

Focusing upon three Native American societies the Oglala Lakota, Eastern Tewa, and Tlingit these goals were accomplished by dialectically conceptualizing spatio-historic the ideological connections informing these societies lifeworlds and lifeways to geographic ontologies which, address and challenge ideological discourses surrounding how we come to know. Following Merrifield's (1993: 516) argument that the fundamental flaw embedded within theoretical constructs concerning the place is the failure of most researchers to establish the basic ontological nature of place itself or the manner in which they construct their specific 'object' of inquiry. In response, this research utilized Ollman's (2003) Dane of the Dialectic as the conduit to advocate for Merrifield's (1993) reconciliation of the way in which experience is lived and acted out in place, and how this relates to and is embedded in political and economic practices that are operative over broader spatial scales. Harvey's (2006) general matrix of spatialities has provided a means to better ground the complex scenarios of combination that exist to comprise multiple spatio-temporal contexts. However, in respect to 'fitting' Native American the matrix was also found to be conceptually limiting when attempting to interrelate temporal conceptualizations of human experience through Harvey's conceptualization of perspective or vantage point. The solution required modifying the matrix to accommodate using the role Native American spatial practices (perceived space) play in structuring daily life and a broader social reality. 
These conceptual underpinnings provided the structure to explore the impact of capitalist uneven development in chapters six through nine. I found the use of dialectics beneficial in allowing connections to be established outside of a linear historical framework and instead allowed me to explore the concept of Native American identity from a multi- scalar, temporal, and spatial perspective. This was helpful in that I was able to situate myself within a more fluid framework to investigate these societies concepts of place and identity from traditional social, economic and political processes functioning at multiple scales of interactions. A weakness of the analysis was encountered in chapter nine when attempts to include more contemporary discourses concerning the impact and role of Native Americans living outside the reservation or federal lands. The weakness centered on the lack of available literature ${ }^{155}$. While the responsibility of the research is to locate reliable data sources, I found sparse literature available for the Tlingit or Tewa. As the dissolution of blood quantum within Native American societies continues, the impact and discourses from these individuals whose offspring may loose access to certain entitlements will likely spark rancorous debate from multiple socio-spatial scales.

\section{Look Ahead}

In addition to the above setback, attempts were made to try and include a statistical component within this research that would supplement my argument that uneven development sponsored by accumulation by dispossession impacted Native American perception of place and identity, time constraints did not make this objective possible. As discussed throughout this research, the Oglala-Lakota, Eastern Tewa, and

\footnotetext{
${ }^{155}$ However, ample publications were found available for the Tlingit due to their unique socio-economic status after the enactment of ANASCA.
} 
Tlingit have experienced physical and intellectual forms of dispossession. To support this research I envisioned exploring the relationship between dispossession and Native American community health. For instance, historic and contemporary statistical data collected through empirical health surveys provide an excellent source to track Native American societal health as capitalist and territorial logics of power imbedded specific legislation targeting dispossession. One means of testing this relationship entails performing a regression analysis to test the relationship between economic dispossession or uneven development, such as unemployment, of these Native American societies in relation to the physical and mental health status of surrounding non-Native communities. It would be interesting to further clarify or draw a relationship between impacts associated with economic dispossession to the health of communities once they become removed from traditional lifeways.

This research interest is supported by data from the U.S. Center for Disease Control (CDC) that has seen dramatic increases in chronic cardiovascular and pulmonary diseases, infant mortality, and suicide within Native American communities. This regression analysis would explore the connections between variables associated with economic uneven development, such as unemployment, to health data, such as diabetes. Connections drawn from this analysis may provide a conceptual relationship to the effects of dispossession upon Native American communities as traditional lifeways governing daily routine, such as traditional food patterns and culture, become obsolete. The primary deterrent for not conducting this analysis was data availability. Although statistical data does exist for many Native American communities, prominent data gaps 
do exist. No quick solution presented itself to fill these gaps. Conducting community surveys were not within the scope of this research and, therefore, not an option.

Dialectics is a method centered on transcending the spatio-temporal barriers constructed by other philosophical constructs, and searches to develop connections to construct holistic representations of social processes. Native Americans, unlike Westerns, traditionally did not rely on written word as their medium to communicate history. I suggest that material, typically utilitarian, items are probable sources of objective and subjective knowledge that communicate the physical, mental and social dialectical processes occurring spatio-historically.

As discussed by Tuan (2004), geographers are concerned with place, artists and art historians with art, psychologists and philosophers with self. But what commonalties are shared between place, art, and self and to what extent do place and art define who we are? Typically, place is thought of being a material tangible environment, but art transcends the materiality of place and allows viewers to place themselves in a virtual or abstract representation of place as perceived from the artist's perspective.

Tuan (2004) discusses the interpretation of place through the artistic mediums of paintings, photographs, poems, novels, music and motion pictures. However, thus far no researcher has attempted to interpret place through the artistic medium of indigenous utilitarian items such as ceremonial items, basketry, pottery or clothing. Native American and other indigenous peoples are unique in that they are typically thought of as cultures based on oral tradition, instead of written. Therefore, I find it reasonable to suggest that the culture of indigenous peoples is visibly (abstractly/subjective and 
absolutely/objective) communicated, in pseudo textual representation, within the materials and processes that produce utilitarian/everyday objects.

Art in this sense becomes simply an additional source of subjective and objective knowledge that may aid in understanding and interpreting the Native American evolving concept of place as indigenous lifeworlds as it becomes affected by federal policymaking and Western capitalism. Sparse research is available on the interpretation of native/indigenous visual materials.

The misconception that indigenous societies lack visual materials or do not place emphasis on visual material within their society is inaccurate. I suggest that while modern models of visual analysis represent an important stepping stone in the methodological development of analyzing visual materials these models are still unable to adequately address the questions surrounding the meaning of place in native or indigenous populations because these models assume art is a mode or form of expression without utilitarian value. These methods do not address the question of how visual material or objects can be both functional and meant to convey meaning. There is further meaning that is conveyed in their use that is not addressed by modern methods of visual analysis. Additional research is needed to develop an alternative method of visual analysis that more accurately addresses the holistic balance between art and utility in a dialectic fashion, in an effort to more clearly reveal the socio-historic interactions and relationships affecting Native American lifeworlds and lifeways in response to uneven development introduced through capitalism. 


\section{Works Cited}

Agnew, J. (1987). A theory of place and politics. Place and Politics The Geographical Mediation of State and Society Boston, Allen \& Unwin: 2543.

Alaska Dispatch. (2011)." Native American Unemployment Rate Worst in Alaska." Retrieved from: http://alaskadispatch.com/dispatches/alaskabeat/88-alaska-beat/8163-native-american-unemployment-rate-worst-inalaska

Alaska Native Knowledge Network. (2006) Stories Recorded in English at Sitka, Retrieved from: http://www.ankn.uaf.edu/IKS/Subsistence/Tlingit/myths.html

Alaska Native Knowledge Network. (2011) Traditional Tlingit Map and Tribal List. Retrieved from: http://ankn.uaf.edu/ANCR/Southeast/TlingitMap/

Ambrose, S.E. (1996a). Crazy Horse and Custer: The parallel lives of two American warriors. New York, Anchor Books.

Ambrose, S.E. (1996b). Undaunted Courage: Meriwether Lewis, Thomas Jefferson, and the opening of the American West. Touchstone, New York.

Anders, G. (1980). "Theories of Underdevelopment and the American Indian." Journal of Economic Issues 13(3): 681-701.

Andrews, C.L. (1943). The Story of Alaska. Caldwell, The Caxton Printers, Ltd.

Austin, A. (2010). "Different Race, Different Recession: Native American Unemployment." Economic Policy Institute. 289:1-7. Retrieved from: http://alaskadispatch.com/images/media/files/news/nativejoblessstudy_epi .pdf

Barnhardt, R., and Kawagley, A.O. (2005). "Indigenous knowledge systems and Alaska Native ways of knowing." Anthropology and Education Quarterly: 36(1): 8-23.

Basso, K. (1988). "Speaking with Names: Language and Landscape among the Western Apache." Cultural Anthropology 3(2): 99-130.

Basso, K. (1996). In Wisdom Sits In Places: Landscapes and Language Among The Western Apache. Albuquerque, University of New Mexico Press. 
Biolsi, T. (1985). "The IRA and the Politics of Acculturation: The Sioux Case." American Anthropologist 87(3): 656-659.

Biolsi, T. (1992). Organizing the Lakota: The Political Economy of the New Deal on the Pine Ridge and Rosebud Reservations. Tuscon: University of Arizona Press.

Bird, S.E. (2002). "It makes sense to us: Cultural identity in local legends of place." Journal of Contemporary Ethnography. 31(5): 519-547.

Blaut, J. (1999). "Environmentalism and Eurocentrism." The Geographical Review 89(3): 391-408.

Boggs, J. P. (1992). "Implicit Models of Social Knowledge Use." Knowledge: Creation, Diffusion, Utilization 14(1): 29-62.

Bradshaw, M. and Stratford, E. (2005). "Qualitative Research Design and Rigour." In Hay, I. (2005) Qualitative Research Methods in Human Geography. (pp. 67-76). Oxford, Oxford University Press.

Brenner, N. (2001). "Henri Lefebvre in Contexts: An Introduction." Antipode: 763768.

Brenner, N. (2001). "The limits to scale? Methodological reflections on scalar structuration." Progress in Human Geography 25(4): 591-614.

Brown, D. (1970). Bury my Heart at Wounded Knee: An Indian History of the American West. New York, Holt, Rinehart, and Winston.

Brown, D. (1977). Hear that Lonesome Whistle Blow, Railroads in the West. New York, Holt, Rinehart, and Winston.

Brown, J. E. (1970). The Sacred Pipe: Black Elk's Account of the Seven Rites of the Oglala Sioux. Norman, The University of Oklahoma Press.

Cajete, G. (2000). "Indigenous Knowledge: The Pueblo Metaphor for Indigenous Education." In Battiste, M. (2000). Reclaiming Indigenous Voice and Vision. (pp. 181-191) Vancouver, University of British Columbia Press.

Chaudhuri, J. (1985). American Indian Policy: An Overview. In Deloria, V. American Indian Policy in the Twentieth Century. Norman, University of Oklahoma: 15-34.

Cornell, S. and Gil-Swedberg, M. (1995). "Sociohistorical Factors in Institutional Efficacy: Economic Development in Three American Indian Cases." Economic Development and Cultural Change: 239-268. 
Cornell University Law School Legal Information Institute. (2010). United States Constitution. Retrieved from:

http://topics.law.cornell.edu/constitution/articlei

Crang, M. (2004). "Qualitative Methods (part 3): There is nothing outside text?" Professional Geographer.

Crang, M. (2005). "Qualitative Methods: there is nothing outside the text?" Progress in Human Geography 29(2): 225-233.

Dana, L. and Anderson, B. (2007) "Taos Pueblo: an indigenous community holding on to Promethean values." Journal of Enterprising Communities: People and Places in the Global Economy. 1(4):321 - 336.

Deloria, E. (1988). Waterlily. Lincoln, University of Nebraska Press.

Deloria, E. (1993). Iron Hawk. University of New Mexico Press: Albuquerque.

Deloria, V. (1974). Behind the Trail of Broken Treaties: An Indian Declaration of Independence. Vine Deloria, Jr.

Deloira, V. (1985). The Evolution of Federal Indian Policy Making. American Indian Policy in the Twentieth Century. V. D. Jr. Norman, University of Oklahoma: 239-256.

Deloria, V. (1988). Custer Died for Your Sins. Norman, University of Oklahoma.

Deloria, V. and Wilkins, D. (1999). Tribes, Treaties, and Constitutional Tribulations. Austin, University of Texas.

Dombrowski, K. (1995). "Totem poles and tricycle races: the certainties and uncertainties of Native village life, Coastal Alaska 1878-1930." Journal of Historical Sociology 8(2): 136-157.

Dombrowski, K. (2001). Against Culture: Developoment, Politics, and Religion in Indian Alaska. Lincol, University of Nebraska Press.

Dozier, E.P. (1970). Pueblo Indians of North America. New York, Holt Reinhart, and Winston Inc.

Dunbar-Ortiz, R. (1984). Indians of the Americas: Human Rights and SelfDetermination. New York, Pragear Publishers. 
Dunbar-Ortiz, R. (2007). Roots of Resistance: A History of Land Tenure in New Mexico. Norman, University of Oklahoma Press.

Entrikin, J. (1991). The Characterization of Place, Worecester, Clark University.

Entrikin, J. (1999). The Betweeness of Place Towards a Geography of Modernity. Baltimore, The John Hopkins University Press.

Fairclough, N. (2003). Analyzing Discourse Textual analysis for social research. London, Routledge.

Feld, S. and Basso, K. (1996). Senses of Place. Santa Fe, School of American Research Press.

Gonzales, T. and Nelson, M. (2001). "Contemporary Native American Responses to Environmental Threats in Indian Country." In Grin, J. (2001). Indigenous Traditions and Ecology: The Interbeing of Cosmology and Community (Religions of the World and Ecology). Cambridge, Harvard University Center for the Study of World Religions.

Gulliford, A. (2000). Sacred Objects and Sacred Places Preserving Tribal Traditions. Boulder, University of Colorado.

Harvey, D. (2001). "Globalization and the 'Spatial Fix'." Geographische Revue. 2.

Harvey, D. (2003). The New Imperialism. Oxford, Oxford University Press.

Harvey, D. (2004). "Retrospect on The Limits of Capital." Antipode Part 3: The Limits of Capital Afterword.

Harvey, D. (2004). Neo-liberalism and the restoration of class power. Spaces of neoliberalization: towards a theory of uneven geographical development, Heidelberg, Franz Steiner Verlag.

Harvey, D. (2004). Notes towards a theory of uneven geographical development. Spaces of neoliberalization: towards a theory of uneven geographical development, Heidelberg, Franz Steiner Verlag.

Harvey, D. (2004). Space as a key word. Spaces of neoliberalization: towards a theory of uneven geographical development, Heidelberg, Franz Steiner Verlag.

Harvey, D. (2006). Spaces of Global Capitalism: Towards a Theory of Uneven Geographical Development. London, Verso. 
Hornaday, W.T. (1889). Saving the American Bison. Smithsonian Scrapbook: Letters, Diaries, and Photographs from The Smithsonian Achieves. Retrieved from: http://siarchives.si.edu/history/exhibits/documents/index.htm

Hosmer, B. A. O. N. C. (2003). Native Pathways: American Indian Culture and Economic Development int he Twentieth Century. Boulder, University Press of Colorado.

Howitt, R. (1993). "A world in a grain of sand: Towards a reconceptualization of geographical scale." Australian Geographer 24(10): 33-44.

Howitt, R. (2002). "Scale and the other: Levinas and geography." Geoforum 33: 299-313.

Indian Reorganization Act (Wheeler-Howard Act) 1934. Retrieved from: http://www.personal.utulsa. edu/ nathan-wilson/

Jessop, B. (1999). Narrating the Future of the National Economy and the National State: Remarks on Remapping Regulation and Reinventing Governance. State/Culture: State Formation after the Cultural Turn. G. Steinmetz. Ithaca, Cornell University.

Krause, A. (1956) Tlingit Indians: Results of a Trip to the Northwest Coast of America and the Bering Straits. Seattle, University of Washington Press.

Mansvelt, J. R., Berg, L. (2005). Writing qualitative geographies, constructing geographical knowledges. In I. Hay (Eds.). Qualitative Research Methods in Human Geography (2nd ed.). (pp. 248-265). Melbourne, VIC: Oxford University Press.

Massey, D. (1993). Power-Geometry and a progressive sense of place. Mapping the Futures: Local cultures, global change. J. Bird. London, Routledge: 59-69.

Massey, D. (1995). The conceptualization of place. A Place in the World. D. M. a. P. Jess. Oxford, Oxford University Press: 45-86.

Massey, D. (1998). Imagining globalization: power-geometries of time-space. Power-Geometries and the Politics of Space-Time, Heidelberg, University of Heidelberg.

Melody, M.E. (1977). "Maka's Story: A Study of Lakota's Cosmology." The Journal of American Folklore 90 (356): 149-167. 
Merrifield, A. (1993). "Place and space: a Lefebvrian reconciliation." British Institute of Geography 18: 516-531.

National Park Service. (2011) Detailed Map of Wind Cave National Park Map. Retrieved from http://www.nps.gov/carto/PDF/WICAmap3.pdf

National Park Service. (2011) Wind Cave National Park Map. Retrieved from http://www.nps.gov/pwr/customcf/apps/maps/showmap.cfm?alphacode=wi ca\&parkname=Wind\%20Cave\%20National\%20Park

Native GIS. (1997) Map of Traditional Tribal Areas Overlain on Alaska Native Regional Corporations. Retrieved from http://www.kstrom.net/isk/maps/ak/aklinks.html

Naylor, S. (2005). "Historical Geography: knowledge in place and on the move." Progress in Human Geography 29(5): 626-634.

Nerbern, K. (1994). Neither Wolf nor Dog: On Forgotten Roads with a Indian Elder. Novato, New World Library.

Nerbern, K. and Mengalkoch, L. (1991). Native American Wisdom. Novato, New World Library.

Nerbern, K. (1999). The Wisdom of the Native Americans: Including the soul of the Indian and other writings of Ohiyesa and the Great Speeches of Chief Red Jacket, Chief Joseph, and Chief Seattle. Novato, New World Library

Ollman, B. (1990). "Putting Dialectics to Work: The Process of Abstraction in Marx's Method." Rethinking Marxism (Spring, 1990).

Ollman, B. (2003). Dance of the Dialectic: Steps in Marx's Method. Urbana: University of Illinois.

Ollman, B. (2008). "Why Dialectics? Why Now?" In B. Ollman and T. Smith (2008). Dialectics for the New Century. (pp. 8-26). New York: Palgrave Macmillan.

Ortiz, A. (1969). Tewa World Space, Time, Being, and Becoming in a Pueblo Society. Chicago: The University of Chicago Press.

Parsons, E.C. (1926). Tewa Tales. Tucson: University of Arizona Press.

Parsons, E.C. (1939a). Pueblo Indian Religion (Volume I). Chicago, University of Chicago Press. 
Parsons, E.C. (1939b). Pueblo Indian Religion (Volume II). Chicago, University of Chicago Press.

Powers, M., 1986, Oglala Women. The University of Chicago Press: Chicago.

Powers, W., 1975, Oglala Religion. University of Nebraska Press: Lincoln.

Prucha, F. (1984). The Great Father: The United States Government and the American Indians. Lincoln, The University of Nebraska Press.

Prucha, F. (1994). American Indian Treaties The History of a Political Anomaly. Berkeley, University of California Press.

Public Broadcasting Station. (2002) The 1899 and 2001 Harriman Expedition A Century of Change; Rosita Worl: Introduction to Tlingit Culture and Repatriation. Retrieved from http://www.pbs.org/harriman/explog/lectures/worl.html

Reinhardt, A. (2007). Ruling Pine Ridge: Oglala-Lakota Politics from the IRA to Wounded Knee. Lubbock, Texas Tech University Press.

Rose, G. (1995). Place and identity: a sense of place. A Place in the World. Oxford, Oxford University Press: 87-132.

Rose, G. (2001). Visual Methodologies An Introduction to the Interpretation of Visual Materials. London, Sage Publications.

Sando, J.S. (1992) Pueblo nations: Eight centuries of Pueblo Indian history Santa Fe, Clear Light Pub.

Sando, J.S. (1998). Pueblo Profiles: cultural identity centuries of change. Santa $\mathrm{Fe}$, Clear Light Publishers.

Sava, I. and Nuutinen, K. (2003). "At the meting place of Word and Picture: Between Art and Inquiry." Qualitative Inquiry 9(4): 515 - 534.

Sealaska Heritage Institute Core Cultural Values (2009). "Tlingit Kusteeyí: The Real Peoples Way of Being." Juneau, Sealaksa Heritage Institute. Retrieved from http://www.sealaskaheritage.org/core cultural values.pdf

Sealaska Heritage Institute. (2004). "Language Immersion Program." Juneau, Sealaksa Heritage Institute. Retrieved from http://www.sealaskaheritage.org/programs/language_and_culture_curricul um_tlingit.htm 
Shields, R. (1999). The production of space. Lefebvre, love, and struggle. New York, Routledge: 141-186.

Smith, N. (1990). Uneven Development: Nature, Capital and the Production of Space. Oxford, Basil Blackwell.

Smithsonian National Museum of Natural History National Anthropological Archives (2010). Lakota Winter Counts Online Exhibit Maps. Retrieved from http://wintercounts.si.edu/html_version/pdfs/map.cmyk.pdf

Snipp, M. (1986). "The Changing Political and Economic Status of the American Indians: From Captive Nations to Internal Colonies." American Journal of Economics and Sociology 45(2).

Soboleff, W. 'Kaajaakwtí.' (2000). Tlingit Protocols: Forming a Tlingit World View. Juneau, Sealaska Heritage Institute. Retrieved from http://www.sealaskaheritage.org/programs/tlingit_protocols_soboleff.pdf

Soja, E. (1980). "The Socio-Spatial Dialectic." Annals of the Association of Amreican Geographers 70(2): 207-225.

Soja, E. (1999). "In Different Spaces: The Cultural Turn in Urban and Regional Political Economy." European Planning Studies 7(1): 65-75.

Starita, J. (2002). The Dull Knifes of Pine Ridge: A Lakota Odyssey. Lincoln, Bison Books.

Taylor, M.S. (2008). " Buffalo Hunt: International Trade and the Virtual Extinction of the North American Bison." Revised Thesis: Department of Economics University of Calgary. Retrieved from:

http://www.watsoninstitute.org/rhodes/conference/papers/taylor.pdf

Thornton, T.F. (2001). "From Clan to Kwáan to Corporation: The continuing complex evolution of Tlingit political organization." Wicazo Sa Review 17(2): 167-194.

Thornton, T.F. (2008). Being and Place among the Tlingit. University of Washington Press.

Tiller, V.E. Velarde (2005). Tiller's Guide to Indian Country: Economic Profiles of American Indian Reservations. Albuquerque, BowArrow Pub. Co.

The State of New Mexico Tourism Department. (2011) Native America in New Mexico. Retrieved from http://www.newmexico.org/nativeamerica/ 
The United States Censes Bureau. (2001) American Indian Population be Selected Tribes. Retrieved from http://www.census.gov/population/socdemo/race/indian/cp-3-7/tab01.pdf

The United States Bureau of Land Management. (2011). Western States Water LawsFederal Reserved Water Rights. Retrieved from: http://www.blm.gov/nstc/WaterLaws/fedreservedwater.html

The United States Bureau of Reclamation. (2009). Statement of Michael L. Connor, Commissioner Bureau of Reclamation U.S. Department of the Interior Before the Natural Resources Committee Subcommittee on Water and Power U.S. House of Representatives on H.R. 3254 Taos Pueblo Indian Water Rights Settlement Act September 09, 2009. Retrieved from: http://www.usbr.gov/newsroom/testimony/detail.cfm?RecordID=1461

The United States Department of the Interior. (2010) Press Releas: Secretary Salazar Lauds Senate Passage of Five Historic Indian Country Settlements to Resolve Cobell Litigation and to Deliver Clean Water to Indian Communities. Retrieved from http://www.doi.gov/news/pressreleases/Secretary-Salazar-Lauds-SenatePassage-of-Five-Historic-Indian-Country-Settlements-to-Resolve-CobellLitigation-and-to-Deliver-Clean-Water-to-Indian-Communities.cfm

The United States General Accounting Office. (2010) Report to Congressional Requesters, Treaty of Guadalupe Hidalgo Finding and Possible Options Regarding Longstanding Community Land Grant Claims in New Mexico. Retrieved from http://www.gao.gov/new.items/d0459.pdf

The United States National Archives. (2011) Transcript of Check for the Purchase of Alaska (1868). Retrieved from http://www.ourdocuments.gov/doc. php?flash=true\&doc=41\&page=transcri pt

Tuan, Y.-F. (1974). Topophilia A Study of Environmental Perception, Attitudes, and Values. New York, Columbia University Press.

Tuan, Y.-F. (1977). Space and Place the Perspective of Experience. Minneapolis, University of Minnesota Press.

Tuan, Y.-F. (1984). "In Place, Out of Place." Geoscience \& Man 24: 3-10.

Tuan, Y.-F. (1991). "Language and the Making of Place: A Narrative-Descriptive Approach." Annals of the Association of American Geographers 81(4): 684-696. 
Tuan, Y.-F. (2002). "Community, Society, and the Individual." Geographical Review 92(3): 1-12.

Tuan, Y.-F. (2004). Place, Art, and Self. Reykjavik, Center for American Places.

Tuan, Y. F. (2007). "Power, Modernity and Traditional Cultures." New Global Studies 1(1): 1-9.

University of New Mexico School of Law. (2007) Tribal Law Journal Archives. Retrieved from http://tlj.unm.edu/archives/vol2/index.php

Vlasich, J.A. (2005). Pueblo Indian Agriculture. Albuquerque, University of New Mexico Press.

White, R. (1978). "The Winning of the West: The Expansion of the Western Sioux in the Eighteenth and Nineteenth Centuries." Journal of American History 65: 319-343.

Wilkins, D. and Lomawaima K. T. (2001). Uneven Ground American Indian Sovereignty and Federal Law. Norman, University of Oklahoma.

Wilkinson, C. (2005). Blood Struggle The Rise of Modern Indian Nations. New York, Norton and Company. 
Appendix 


\section{The Lakota Cosmology}

\section{In the Beginning: (Powers, 1986)}

"Inyan (Rock) had no beginning for he was when there was no other." Soft and shapeless, he was everywhere. Inyan's spirit was Wakan Tanka (The Great Mystery). Han (Black of Darkness) also existed then.

Inyan desired to exercise his powers, but there was no one for him to exercise them upon. To create another, he would have to give a spirit and part of his blood. Yet, since his power was in his blood "he decided to create another as part of himself so that he might keep control of all the powers." "He took from himself that which he spread around about himself in the shape of a great disk whose edge is where there can be no beyond." In this way Maka (Earth) was created. Inyan gave her a spirit which is Makaakan (Earth-goddess). Being created out of Inyan's blood, she was part of him. In fact Inyan lost so much blood that he became hard and powerless. As his blood flowed it became the blue waters, but since power cannot remain in water it took another shape. It became a large blue dome whose edge is at Maka's boundary. Thus was created Tanka (Sky).

Inyan, Maka, and the waters are the world; they are material. Tanka, however, is spirit. Nagi Tanka (Sky God) is "the great Spirit who is all powerful and the source of all power, and his name is Skan" (Almighty, Most High). When the powers assumed shape, a voice spoke: "I am the source of energy, I am Skan."

In creating Maka, Inyan gave her that part of his spirit which is discontent, and accordingly, she was not happy. Maka was disgruntled because she was not a separate being. She also could not see Skan, Inyan or even herself. In addition, Maka could not control the waters. "How can I see whether I am ugly or beautiful if Han remains forever upon the world? Send him away that I may look upon you, Inyan, and upon Skan, and that I may behold myself." Yet, Inyan's powers were depleted; he could do nothing to aid Maka. After being nagged, Inyan suggested that they bring the matter before Skan because the Sky God possessed all the power that had departed from him. "O Skan, I pray to you, answer the demands of this creature that I may again have the peace that was mine before I so rashly took a part of myself that I might give her being." Skan said that Maka would remain part of Inyan, but that she could control the waters and see herself. "Thus Skan was established as a judge and he is the final arbiter of all things."

Skan divided Han in half. One part was darkness, and it was sent under the world. From the remaining half, Skan created light (Anp). Anp was "the red that shines." Skan then commanded Anp to light the world.

Maka saw herself: "Alas! How bare I am, and how cold and ugly!" She noticed that the waters were beautiful so she divided them into seas, lakes and streams to serve as her adornment. But she complained again. The light was glaring and she was cold. Skan then created Wi (Sun) from Inyan, Maka, the waters and himself. He gave Wi a spirit, Wi-akan (Sun-God). As such, these are the four superior Gods.

Skan commanded Wi to shine and give heat. Wi obeyed and the world became hot. To please herself Maka ordered Wi to make shadows, but Wi refused to do this because he obeyed only Skan. Maka told Wi that he ought to obey her since she was the first created and that he, in effect, was a younger brother. Skan, hearing all of this and 
still wishing to placate Maka, commanded Wi to give a shadow to everything except spirits. Skan then announced that the shadow of each thing would be its spirit, remaining with it always.

Maka, however, still was not content. She was maddened by the shadows and scorched by the heat. Wi, though he was material, had no shadow, and he also was tired. Thus he joined Maka in her complaining. Skan, in response, decreed that time would henceforth be divided into two equal parts. Daytime belonged to Anp, and nighttime to Han. Anp and Han were to follow one another, one coming onto the world as the other went to the regions under it. Anp's time was to be marked by activity and Han's by rest. Every day Wi appeared over the edge of Maka, moved across the sky and then went to the regions under the world where he rested. Skan also made Anp Wi's herald. Thus, Anp precedes Wi onto the world and follows him over the edge. Now Maka was more comfortable.

Maka, though, was still argumentative. She nagged Inyan and she was also jealous of Wi. Skan, knowing this, assembled the gods.

I, Skan, and you, the other gods, Inyan, Maka, and Wi, are from one and the same source. Although we are four, we are only one; and that one is Wakan Tanka, which no one, not even the gods themselves, can understand. Each of us is only a part of Wakan Tanka, and he is the God of Gods. What is more, I, Skan, am all powerful and the source of all power of any kind. I, Skan, can give and take at will.

Then he gave each god a rank. Since Skan placed Wi above all, even the blue dome of himself, he was given the highest rank. Thus Wi was first in precedence, and he was to govern the two times, Anp and Han. Maka was placed third and Inyan, the source of all, was fourth. Skan, while retaining authority over all, placed himself second. Each of the gods was also given a domain. Wi's domain included everything above the world while Maka's comprised all lands except mountains and high hills which, along with rocks, belonged to Inyan. Skan retained supreme authority everywhere.

Yet Maka complained once again. She asked for a color so that she would be beautiful. Each god was then given a color as an emblem. Wi was assigned red which is a symbol for all that is sacred. Maka's color is green, Skan's is blue, and Inyan's is yellow. Thus, the gods can be recognized.

Lacking companions, Skan, Maka, and Inyan were lonely. Accordingly, Skan assembled the gods. He gave each of them the power to create a companion. Wi made Wi-win (Feminine Sun or Moon), a disk like himself but more beautiful. Wishing to gaze upon her, he did not make Wi-win as bright as himself. Together they governed Han and Anp. Maka created Unk (Passion). Unk was beautiful, alluring. Maka, giving Unk her own ill nature, soon quarrelled with her. As a result, Unk was thrown into the waters, and Maka did without a companion. Skan fashioned Tate (Wind), a spirit like himself. Tate was created to be Skan's messenger and could come and go as he pleased. Inyan, remembering Maka, decided to create a companion unlike any of the others. He made Wakinyan (Winged-one or Thunderstorm). Thunderstorm had two wings with many joints, sharp teeth, a huge beak and large talons. He was terrifying; his voice was thunder 
and his one eye lightning. Wakinyan was given a dual nature. He holds the responsibility for the growth and increase of creatures, and he also destroys evil ones. Wakinyan also "delights in opposition and contrariness." When he is pleased, he seems angry. Similarly, he appears pleased when he is angry. Inyan gave Wakinyan the level top of a high mountain at the edge of the world. His lodge is found there. Since Inyan cannot move, Wakinyan acts as "his other self and carries out his wishes." In cleansing the world of evil, Wakinyan is associated with Tate. These companions are the associate Gods.

Inyan, pleased with Wakinyan, "desired offspring by him." Thunderstorm made a large egg and Rock fertilized it. Ksa (Wisdom) resulted from this. He took characteristics of both parents, thus, he was both god-like and formless. Skan gave Ksa a spirit and Tate supplied a ghost. Ksa was "very wise and very amiable, and sought always to benefit and please others." He invented language, pleasant sounds, told stories as well as gave puzzles and games. Ksa also named the creatures and things. Everyone liked him except Unk and her offspring who sought to harm him. Skan did not give Ksa the rank of a god; he was, however, a counselor to the gods.

Skan, however, was still lonely. Since Tate was gone all the time, he decided to create another offspring. He made a daughter, Wohpe (Peace or Mediator). Skan made her the "medium among gods and between gods and things." She is the most beautifuland pleasing of all beings. Wohpe was given the powers of a goddess, and she became the patron of amity, compassion, beauty, and happiness. In all that makes for harmony the gods receive her as their equal. Maka, still lacking a companion, pleaded with Skan to make Wohpe her consort. Skan decided that Wohpe, while appearing as the associate of Maka, would never do her will. Wohpe and Ksa were companions. Their good deeds delighted Skan, and they were liked by everyone except Unk.

Being vicious, Unk desired to shame Maka for casting her into the waters. Unk asked Skan to pity her. Skan then gave her the waters as her domain, and he allowed her to associate with the gods. Now she told Inyan of her loneliness. Unk was so clever and beautiful that Inyan forgot Wakinyan. Unk and Inyan had a son whose evil disposition led Skan to name him Iya (Evil-one). Unk, however, called him Takapa (First-born) since he was the first being to come into the world by birth. Due to his destructiveness Iya is also known as Ibom (Windstorm). Unk sent Ibom into the world to plague Maka. Being jealous of Wohpe and Ksa, Iya also sought to harm them.

Now, Unk became "infatuated" with Iya, and they had a son whom Skan named Gnas (Demon). He shamed his mother, tormented his father and ridiculed Inyan, his grandfather. Gnas tried to associate with Wohpe and Ksa, but Ksa, while admitting kinship, would not permit it. Wohpe pitied Gnas and tried to turn him from deceit and cunning. With his mother's encouragement, Gnas badgered Maka until she permitted him to live in her domain. Now, Iya and Gnas made their mother miserable. Gnas incited Iya to mischief while he himself escaped blame.

Meanwhile, Wakinyan, knowing of the love between Inyan and Unk, declared himself an enemy of Unk and Iya. He attacked them whenever he found them. As a result of this, Unk complained to Skan who then decided that Wakinyan should not enter Unk's domain, harm a Cedar tree or anyone under the branches of this tree. Gnas now persuaded Iya to defy Wakinyan and to trouble Maka. Iya went upon Earth and, as Ibom, fought Wakinyan. Being unable to destroy Iya, Wakinyan drove him back into the waters. Wakinyan now turned against Gnas who escaped punishment by claiming that it was he 
who lured Iya onto Maka where Wakinyan could attack him. Thunderstorm believed the cunning Gnas. Demon now persuaded Iya that he could defeat Wakinyan. As a result they fought again. "Thus began a never-ending strife which is waged between Wakinyan and Iya as Ibom."

Skan, in the interim, asked Ksa why all were in awe of him in light of the fact that there was no "friendly communion" between them. Ksa told him that all, excepting Tate, were material while he, Skan, was spirit. Wisdom suggested to Skan that he create a people with whom he could be familiar and who would also be his servants. Meanwhile, Tate complained that when Han was on the world he could see nothing. So Skan took part of the Nagila (Spirit or Steam) .and made Star People called Wican (Sunlets). He put them above his dome and gave them the power to give a pale light. So that Tate could see, they were to travel across the dome of the sky at night. They were to observe all that occurred and then report to Skan. The Wican who did not do this would be cast into the world where they would become evil spirits. One of the Wican, the North Star, was made chief of all the others.

Now, Wohpe and Ksa were visiting Wi and Wi-win when Wi-win suggested to Ksa that he invent pleasures that could be tasted and smelled. Ksa wondered how this could be done without making the other gods jealous. Wohpe suggested that such things be put under the world, a place of happiness, peace, and plenty. Wakinyan, whose aid was sought, gave Wohpe a "fine dust." He told her to blow on it and then plant it under the earth. This grew into a delicious white fruit that smelled like perfume. Ksa then made a lodge and Wohpe created utensils. Ksa also made ten tokens and Wohpe ornamented them. They gave each god a token and invited them to a feast. Iya and Gnas were also invited. Each token would be redeemed at the feast.

Gnas asked Iya to shake the lodge down so as to make Ksalook ridiculous. But he could not destroy it and all the gods laughed at him with Gnas laughing the loudest of all. Then Skan seated the gods, retaining the seat of honor for himself. All the gods said "Nunwe" (So be it).

During all of this Gnas suggested to Iya that he "defile" the fruits to make Ksa and Wohpe look ridiculous. Iya, however, was the one who ate the defiled fruit. He then complained and made accusations. Skan, knowing all, decided to punish Iya.

Because Iya has defiled food intended for the gods, because he is a glutton, and because he has berated the daughter of the gods, he is unfit to sit with the gods. He shall go from them and sit no more with them. lya shall forever hunger with a hunger that food will not satisfy so that he shall devour filth and his breath shall stink. Because of his rage he shall destroy without satisfaction.

After feasting, Ksa and Wohpe sang and all the gods except Iya and Gnas danced. Following this, Wohpe asked Skan to grant each god a wish when they presented a token. Skan agreed.

Wi asked to be the patron of bravery, endurance, fortitude, contests, honesty, and reliance. Wi-win wanted to be the patron of constancy and feminine things. She also wanted such beauty that Wi would long for her so much that she would be always at his side. Maka, in presenting her token, asked to be the patron of sustenance, shelter, 
protection, contentment, comfort, and happiness. Inyan, granted his request, exercised dominion over construction and destruction, offense and defense, permanence and change. As Heyoka, Wakinyan assumed the role of a destroyer of evil. His province also included increase and growth. Tate wished to remain the companion of Skan and an aid in his work. Unk, the patron of waters, desired offspring and the freedom to do as she wished in her domain, but she did not return the token. "I will not give my token to be held as a pledge to compel me to exercise my powers in any manner save as I please." Gnas, the patron of plots and schemes, asked for pleasing features and a persuasive tongue. "Skan granted to each, even to Unk, that for which they expressed desire, and he held his own token as a memento binding him to listen to the prayers of his daughter." When the tokens had been redeemed, Skan said: "So it shall be always, whenever one gives a token it shall be redeemed by granting the desire of the one receiving it."

Although Wohpe had no token, Skan said that she could have what she most desired. He did this because Wohpe served "so that all have had much pleasure." Wohpe desired to do the will of her father so that "harmony" could prevail; she wished to give pleasure to others. Skan replied: "Wohpe, your wish is granted. Peace shall follow upon your footsteps, and the gods shall enjoy many feasts." Skan also granted Ksa a request. Ksa, pointing out that Wohpe was exhausted and that it was inappropriate for the daughter of the Great Spirit to be a servant, asked that Skan make a creature to serve the gods. All the gods shouted "Nunwe" (So be it).

Skan then created the Oyata Pte (Buffalo People). Their bones were made from Inyan, their flesh came from Maka and their entrails were fashioned from the white fruit. Skan gave each of the first two buffalo a spirit that was a little lower than that of the gods. The Nagi (Spirit) of the Buffalo People he took from himself. (As such, the Nagi "advises the conduct of each being.") Skan commanded Wi to give them warmth and Tate breathed into them a Niya, a ghost. (The Niya is the breath of life, and a witness to the advice which the Nagi gives.) Ksa gave them intelligence while Wakinyan, as Heyoka, offered growth and increase. Wi-win made them affectionate, and Wohpe bestowed upon them a longing and a love for offspring. Skan then instructed the Pte People. Anp and Han governed them, and they were obeyed in all things. [The text adds "this was the beginning of mankind." Yet in context it is clear that the term mankind refers to the Buffalo People and not man per se.

Meanwhile, Gnas, scheming to cause strife, used Maka's jealousy of Wi-win's servants to embarrass her. Unk also conspired with her sons, Iya and Gnas, to make Maka appear ridiculous. Gnas, pretending to feel sorry for Maka, offered more advice. He suggested that she demand adornment. So Maka asked Skan for people of her color (green) that would do her will. Skan then appointed Ksa, Wohpe, Tate, and Wakinyan to work for the pleasure of Maka and "to create such creatures as they would." After consulting Maka and each other they created vegetation. All the while, Skan knew of Gnas's scheming. Skan granted Maka's request in such a way as to thwart Gnas. Realizing this Gnas asked to help with the planting. He spat on the plants before he put them into the ground and they became thorny and poisonous.

In the meantime, Gnas schemed with his mother. He suggested that she also require a favor from Skan. In response to the demand, Tate, Wakinyan, Wohpe, and Ksa designed plants that grow in the waters. Since Unk was obliged to nourish the plants, Gnas laughed at her. "For every pleasure there is an added care and labor." 
Unk, intending to annoy Maka, boasted that her plants grew and multiplied while Maka's did not. Ksa, Wakinyan, Wohpe, and Tate considered this. If water was given to the plants, perhaps Skan would make it into blood. Tate said that "Skan is just and will approve if you [Wakinyan] by your might take from Unk that which is needed for the growth of the plants." Thus Ibom and Wakinyan fought. Wakinyan was victorious so he drew water into his robes and flew over the land squeezing them. Skan, being pleased, made the water into sap. In this way Wakinyan invented rain.

Gnas, in the interim, played upon Unk's jealousy of Maka's plants so as to torment her. With Unk's permission, Gnas breathed on the ground around the plants. As a result they withered and died. The gods noticed this and Skan said, "Plants should have offspring that they may not utterly perish." Then Skan in conjunction with Wakinyan and Wohpe created flowers, seeds, and fruits.

Unk, once again inflamed by Gnas, now complained that the waters which nourished Maka's adornment were stolen from her. She was jealous and wanted adornment for herself. Skan, knowing of Gnas's involvement, commanded Ksa, Wohpe, Tate, and Wakinyan to appease Unk. They created plants that grow in all the waters.

Gnas, once again, incited Maka to jealousy. While she nourished her plants, they grew into the domain of Wi and Wi-win who both enjoyed them. At the next feast Maka and Wi-win argued. Gnas, intervening, reminded Maka about an edict of Skan. "He put a curse on any who create discord at a feast. Much better appear pleased with your adornment, but tell of the added care and beg Skan for assistance to relieve you of that care." When Maka and Wi-win stopped arguing Skan said:

All exists for the world, and but for it none would be except Inyan alone. All that makes the world more pleasing shall be for the pleasure of all, both gods and creatures. Maka shall support and nourish all creatures on the world, Wi shall warm them, and Wakinyan shall give them growth and increase. All the gods and all their creatures shall take pleasure, each according to his ability.

The gods cried "Waste-e-e" (beautiful).

Ksa went to the lodge of Wakinyan and told him that Skan intended to make many creatures. Yet there was nothing to feed them. Ksa suggested that Wakinyan make much that was "fit for food." Accordingly, edible things were created.

Urged on by Gnas, Maka once again complained that she was weary of caring for her ornaments. This time Wohpe intervened and reminded Skan of the reason he created the Buffalo People. Since Wohpe's suggestion "was in keeping with his plans," Skan ordered Tate, Wakinyan, Wohpe, and Ksa to do as Maka wished. Ksa said that creatures were needed that would break the silence and consume the food prepared by Wakinyan. Ksa, Wohpe, Wakinyan, and Tate, thus, joined together in making creatures that have no blood. In this way insects were created. Gnas once-again intervened in the process and biting and stinging insects resulted.

Maka, being bit and stung, worried that the insects would eat all of her adornment. Unk and Gnas laughed at her misfortune. Maka now demanded flesh and blood servants. As a result Wohpe, Ksa, Wakinyan, and Tate made three kinds of reptiles. 
Gnas's participation resulted in the creation of poisonous ones. The reptiles, moreover, were ugly and they frightened Maka. Unk, however, liked them so Maka gave them to her. Maka wanted flesh and blood creatures that were beautifully clothed and could both walk and fly. She also wanted them to make sounds. Ksa, Wohpe, Wakinyan, and Wi joined together to make such creatures-birds. The newly hatched birds, however, were hungry and helpless. Unk, Iya, and Gnas laughed and Wohpe prayed to Skan. He came and condemned Gnas, Iya, and Unk.

Because you, Gnas, have schemed to make Maka ridiculous, you must feed these creatures so that they will grow and become strong. You, Iya, because you would have destroyed these creatures, must gather food for Gnas to feed to them. You, Unk, because you encouraged your sons to do evil, must prepare food for these new creatures.

Due to Skan's help the new creatures were fed, and they thrived. Wohpe gave them colored feathers, and Ksa taught them how to make nests and care for their young. Birds who sing harsh songs were hatched in nests made by Gnas.

Finally, Maka was delighted, and she invited the gods to come to see the birds. The gods were pleased and pronounced the creation good. Since Wohpe made and cared for them, Maka gave her the birds as her subjects.

Unk grew jealous again. As an associate of Maka she should share in this creation. Wohpe allowed Unk to choose some of the birds to serve as her subjects. Unk chose the cranes, swans, geese, ducks, and snipes. They would serve Unk but revere Wohpe as their patron.

Meanwhile, Maka discovered that whenever she talked of service the birds flew away. Gnas laughed and suggested that she appeal to Skan at a feast. "Skan smiled, for this was in accord with his purpose." Inyan then made a speech.

I was before there was any other. Long alone in the darkness, my soft mass, though shapeless, was all powerful. Then I thought only to gratify myself with the first of creation. So I became the source of all. I gave of my substance and all my blood and all my powers so that there might be others, and in so doing I shriveled and became hard so that I shall endure forever. She, Maka, the cause of my impotency, being young was big with purposes whose benefits I did not foresee. She lashed me with taunts until I consented to be the beginning of all other creations. Her aggravating ambition provoked only that which was for the best and was its own cure. Because of her all creatures exist, but none are subject to her. The ancestress of all, none look to her as their patron goddess. I am contented because I am the ancestor of all, and I am disturbed only because of the strife of my grandchildren. It has pleased you, Great Spirit, to create the Pte People [Buffalo People] to be servants of the gods. Now I pray you, Skan, to make 
creatures little inferior to the Pte People to be subjects of Maka, but to be for the benefit and pleasure of all alike.

In response, Skan, in the presence of the other gods, created animals. He mixed clay from the ground and substance from the creatures. He gave some of this mixture to each god and told them to mold shapes. Wakinyan clothed each of the forms. When he came to the shapes molded by Unk, she glared at him. Thus, Wakinyan clothed them with slime and scales. Wi then warmed the forms, but Unk also glared at him, so he turned away from the forms that she made. Wakinyan and Wi told Skan about Unk's forms. Skan decided that Unk's forms would, though living, remain cold. These forms were fish. Skan gave each shape a nagila (little spirit) and commanded Ksa to instruct them. "You are the animals, created to abide in the world and serve Maka." Ksa taught each type a language. He did this in such a way that all of them could understand each other. Ksa also taught them games, amusements and how to live together. "There was harmony on all the world, and Wahan [sic] Tanka was pleased."

Now, Skan addressed Maka. Since she listened to Gnas and always insisted upon more, she would forever nurture all that exists. Though all created things would know her as grandmother, they would exist for the benefit and pleasure of all the gods and each other. Maka now experienced a change of heart.

I am unworthy of a seat in the circle of the gods. I have wrought only for my own pleasure. On all my domain are symbols, the gravel and stones beside the waters, reminding me of my folly. The gods have justly humiliated me. My grievous punishment is just.

Wohpe, standing beside Maka, said, "The tokens placed to annoy you shall ever remind you that the greatest pleasure is in pleasing others. Be comforted, for none sit more securely in the circle of the gods than the humble.... I love and respect you now more than ever before." Maka asked Skan if Wohpe could be her advisor and counselor. Skan replied that Wohpe was subordinate to no one except himself. Wohpe then asked if she and Ksa could stay with Maka while they were needed. "The gods all cried, 'Nunwe' (So be it). 'Nunwe,' said Skan."

Skan then declared creation completed. The gods said "Waste-e-e" (beautiful). "Thus was created all that exists." 


\section{The Emergence of the Pte Oyate (Deloria, 1993)}

Alone on the newly formed Earth, some of the gods become bored, and Ite prevails upon Inktomi to find her people, the Buffalo Nation. In the form of a wolf, Inktomi travels beneath the earth and discovers a village of humans. Inktomi tells them about the wonders of the Earth and convinces one man, Tokahe ("the first"), to accompany him to the surface.

Tokahe does so and upon reaching the surface through a cave (Wind Cave in the Black Hills), marvels at the green grass and blue sky. Inktomi and Ite introduces Tokahe to buffalo meat and soup and shows him tipis, clothing, and hunting utensils.

Tokahe returns to the subterranean village and appeals to six other men and their families to travel with him to the Earth's surface.

When they arrive, they discover that Inktomi has deceived them: buffalo are scarce, the weather has turned bad, and they find themselves starving. Unable to return to their home, but armed with a new knowledge about the world, they survive to become the founders of the Seven Fireplaces." 


\section{The Coming of the Pipe- The Story of White Buffalo Calf Woman (Powers, 1986)}

Many winters ago the Lakota people were starving. The chief of the Itazipco 'No Bows,' also called Sans Arcs, sent two hunters out to see if they could find buffalo to help them lie over for the winter. They left early in the morning and headed west out onto the prairie. They decided to separate for a while and to meet at an appointed place. They searched all day, but when they met neither had found game.

As they began to plan what to do the next day, one of the hunters noticed a solitary creature advancing from the west. At first they thought it was a buffalo, but as it got closer it appeared to be human. It moved rapidly toward them. They in urn advanced toward it, hiding behind a hill in case it turned out to be an enemy. But as the human approached they saw it was a woman. As she got nearer, they saw that she was beautiful and wore no clothing; her long hair hung down and covered her like a robe except on the left side, where it was tied with a tuft of buffalo hair. She carried a flat fan made of sage in her left hand, and there was a bundle strapped to her back. Her face was painted with vertical red stripes. She spoke: " I am sent by the Buffalo Nation to visit your people. It is right that you are trying hard to fulfill the wishes of your people and find buffalo even through it is a difficult task. Go home to your people and tell them to erect a large lodge in the middle of the camp circle with the doorway facing west. Tell them to spread sage at the place of honor in the rear of the lodge, and let them prepare a small space of mellowed earth. Directly behind the altar tell them to build a small rack, and in front of the rack let them place a buffalo skull. I have something important to present to the tribe that will help them in the future. I shall be in camp at sunrise.

As she was speaking one of the men lusted for her. "Let us leap upon her," he said to his companion. "If she is good, I will take her to my tipi."

"No!" said the other. "She is one of the mysterious people. It is not well that you should do anything of that sort."

The first insisted, "I will attack her, for no one is around."

The other answered, "You may, but I will stand aside."

The woman hearing them, said: "I do not come here to cause strife. I come from Wakantanaka." With these words she took a filled pipe from her bundle and laid it on a buffalo chip with the stem pointed toward the east. Then she laughed and sat down.

The first attacked her and threw her to the ground. And as he began to ravage her, suddenly there was a rumbling in the heavens, and something like a snake flew down from above. A great mist descended upon them where they lay and lingered awhile. When the mist lifted the woman rose. Beside her was only the skeleton of the man who had attacked her.

Seeing what happened to his companion, the other hunter became frightened, but the woman consoled him. She took up the pipe from the ground and approached him, saying: " I bring you this pipe. It is a calf pipe. I bring it to you because your people are starving. This pipe will bring you many buffalo."

She then told him to hurry back to his village and follow the instructions she had

given. " A sacred pipe is coming to you, she said, "that will furnish you with abundance in the Spirit Land." She also told him that this people would know when she was about to arrive because they would see four puffs of smoke under the sun at midday. They 
must then prepare food and seat themselves in a circle for a feast. She instructed that all the men should bow their heads and look at the ground until she was in their midst. Only after she had served everyone the food could they look at her. Anyone who tried to harm her would meet the fate of the first hunter, but if the people obeyed her their prayers would be answered by Wakantanka and they would prosper.

Then she disappeared in a mist.

The hunter ran back to the camp in a zigzag course, as hunters do when they have found game. When he arrived he eagerly told the chief about he woman and gave the people her instructions. Quickly they began to construct a large lodge as she had ordered, and a camp crier circled the village telling the people to assemble on the next day and to ready themselves for this important occasion.

On the following day she could be seen standing on a hill, and lightning flashed around her. She came into the camp, and even the dogs were afraid to bark as she entered. The people were assembled, dressed their finest clothing, the men with their heads bowed to the earth. She was now dressed in a beautiful fringed buckskin dress, leggings, and moccasins. She no longer carried the sage fan, bur rather she held a large pipe, the bowl resting in her left hand and the stem in her right. As she entered the lodge she began to sing the following song:

Niya taninyan mawani ye

Oyate le inawani

Na hotaninyan mawani ye

Niya taninyan mawani ye

Waluta le imawani ye.

With a visible breath I am walking;

I am walking toward a Buffalo Nation,

And my voice is loud.

With a visible breath I am walking;

I am walking toward this sacred object.

She walked in a circle clockwise, as the sun travels in the sky. The women seeing her beauty began to exclaim in admiration. One man curiously raised his head to behold her, and immediately a puff of black smoke blew into his eyes and a voice said, "You have disobeyed me, and there will be smoke in your eyes as long as you live." She then sat at the place of honor and laid the pipe against the specially made rack.

The chief then rose and addressed the woman as sister and welcomed her to the camp. He acknowledged that Wankantanka had sent her to the people and that she had come to their rescue just when they were in great need. "Sister, we are glad you have come to us and trust that whatever message you have brought we may be able to abide by it. We are poor, but we have a great respect for visitors, especially relatives. Although it is our custom to serve our guests special foods, all we have is this water that falls from the clouds. Drink it and remember that we are poor."

The chief then dipped some sweet grass into a buffalo horn filled with water and gave it to the woman to drink. After she drank the chief said, "Sister, we are now ready to hear the good message you have brought." 
"My relatives, brothers and sisters: Wakantanka has looked down and smiles upon us this day because we have met as belonging to one family. The best thing in a family is good felling toward every member. I am proud to become part of your family-a sister to you all. The sun is your grandfather, and he is the same to me. Your tribe has the distinction of always being very faithful to promises, and of possessing great respect and reverence toward sacred things. It is known also that nothing but good feeling prevails and that whenever someone has been found guilty of ay wrong, that member has been cast out and not allowed to mingle with the others in the tribe. For all these good qualities you have been chosen as worthy and deserving of all good gifts. I represent the Buffalo nation, who have sent you this pipe. You are to receive it in the name of all common people. Take it, and use it according to my directions."

Holding up the sacred pipe she said: "With this sacred pipe you will walk upon the Earth: for the Earth is your Grandmother and Mother, and She is sacred. Every step that is taken upon her should be as a prayer. The bowl of this pipe is of red stone; it is the Earth. Carved in the stone and facing the center is this buffalo calf who represents the four-leggeds who live upon your mother. The stem of the pipe is of wood, and this represents all that grows upon the Earth. And these twelve feathers that hang here where the stem fits into the bowl are from Wanbli Gleška, the Spotted Eagle, and they represent the eagle and all the wingeds of the air. All these peoples, and all the things of the universe, are joined to you who smoke the pipe-all send their voices to Wakantanka."

"This pipe shall be used as a peacemaker. The time will come when you shall cease hostilities against other nations. Whenever peace is agreed upon between two tribes or parties this pipe shall be binding instrument. By this pipe the medicine men shall be called to administer help to the sick."

Turning to the women, she said: "My dear sisters, the women: You have a hard life ito live in this world, yet without you this life would not be what it is. Wakantanka intends that you shall bear much sorrow - comfort others in time of sorrow. By your hands the family moves. You have been given the knowledge of making clothing and of feeding the family. Wakantanka is with you in your sorrows and joins you in your griefs. He has given you the great gift of kindness toward every living creature on earth. You he has chosen to have a feeling for the dead who are gone. Eh knows that you remember the dead longer than do the men. He knows that you love your children dearly."

Then turning to the children: "My little brothers and sisters: Your parents were once little children like you, but in the course of time they became men and women. All living creatures were once small, but if no one took care of them they would never grow up. Your parents love you and have made many sacrifices for your sake in order that Wakantanka may listen to them, and that nothing but good may come to you as you grow up. I have brought this pipe for them, and you shall reap some benefit from it. Learn to respect and reverence this pipe, and above all, lead pure lives. Wakantanka is your greatgrandfather."

Turning toward the men: "Now my dear brothers: in giving you this pipe you are expected to use it for nothing but good purposes. The tribe as a whole shall depend upon it for their necessary needs. You realize that all your necessities of life come from the earth below, the sky above, and the four winds. Whenever you do anything wrong against these elements they will always take some revenge upon you. You should reverence them. Offer sacrifices through this pipe and ask for what you need and it shall 
be granted you. On you it depends to be a strong help to the women in raising children. Share the women's sorrow. Wakantanka smiles on the man who has a kind feeling for a woman, because the woman is weak. Take this pipe and offer it to Wakantanka daily. Be good and kind to the little children."

Turning to the chief: "My older brother: You have been chosen by these people to receive this pipe in the name of the whole Sioux tribe. Wakantanka is pleased and glad this day because you have done what it is required and expected that every good leader should do. By this pipe the tribe shall live. It is your duty to see that this pipe is respected and reverenced. I am proud to be called a sister. May Wakantanka look down on us and take pity on us and provide us with what we need. Now we shall smoke the pipe.”

Lighting the pipe with a glowing buffalo chip, she raised its stem to the sky and prayed to Wakantanka and all the good things that come from above. She then pointed the stem toward the earth and prayed to the place from which come all god's gifts. Then, systematically, she pointed the stem of the pipe toward the Four Directions, beginning with the West Wind and turning slowly clockwise until all the directions had been prayed to, and then she passed the pipe to the chief and instructed him. And after he smoked, all the people assembled to smoke the pipe and pray accordingly, the pipe being passed clockwise from left to right around the seated assembly.

She then took a sacred stone from her bundle, inscribed with seven circles. These seven circles stood for seven very important rituals that would eventually be revealed to the people. She stayed with them four days, and during this time she taught them the first ritual, wanagi wicagluha 'spirit-keeping ritual.' The other six that she would teach then were wiwanyang wacipi 'sun lodge' - old ceremonies to which the ceremony of the pipe would be added; išnati awicalowanpi 'female puberty ceremony'; hunka 'the making of relatives'; and tapa wankaiyeya 'the sacred ball game.'

When she had finished instructing the people about the pipe and the seven sacred rituals, she told the chief to send two good runners to the top of the nearest hill to look for buffalo. She told the people to construct a buffalo drive. And she told them not to dill any buffalo before they entered the drive, because the buffalo might be followed by enemies.

The chief sent out the two runners, and presently the people saw a herd of buffalo running toward the drive following them. When the herd entered the drive the people fell upon them, slaughtering them. Just as the woman had predicted, the enemies also entered the drive after the buffalo, and they too were killed.

After the slaughter, the woman instructed the people to decorate the pipe with the scalps of their enemies and to feast on the buffalo meat. They were to end the feast with a victory dance.

At the end of the feast and the dance, she told the people to take a good look at her, because she was going to leave. As they bade her farewell she left the lodge, still walking clockwise. As she reached the edge of the camp the people were amazed to see her turn into first a red buffalo (north, where woman comes from), then brown (actually yellowish brown, representing the east - sunrise), then white (south - at the center), and finally a black buffalo as she passed over the hill (west - sunset). This represented the path of the sun. Symbolically her place was in the center, as a symbol of fecundity and of the birth of the Oglalas who emerged from the center of the earth just as the white buffalo 
is found at the center of the herd (universe). Then, as mysteriously as she had come, she disappeared. 


\section{Tewa of Eastern New Mexcio Cosmologies The Emergence (Parsons, 1926)}

There was a big lake, Ohange pokwinge, Sand Lake ${ }^{2}$. There were lots of people in there. They stayed underneath the water. Then they were talking about it, how to go up from the water, how to get ready to group. And so our mother was born, Kutsaebukwi payokaga, ${ }^{3}$ corn white our summer mother. In four days after our mother was born, our ice mother, Kutsaebukwi oyikaga, was born. Where she was born there was a little green grass (tatsauwe behge ${ }^{4}$, ta, grass, tsauwe, green-blue). And so they said, those people, "This is our mother, summer one," said the people. When our corn white mother, ice mother, was born there was just the same round place. So the people said, "This is our mother, winter mother."

Then those people said they would get a man. They said, "You are a man and a woman." 5 Then the man said, "I am not a man, I am not a woman." And he repeated he was not a man and a woman. They asked him three times. "You ought to be a man and a woman.” He said he was not. The fourth time they spoke, they said, "You have to be a man and a woman." So he said, " All right. Yes, I am a man and a woman for all the people who are in here." "At that time while they were under the water they did not know where was nother (pimpiye), west (tsampiye), south (akompiye), east (tampiye), zenith (opamakore), nadir (nasogenoye). ${ }^{7}$ So they told this man he was to go up. They did not know where north was. They let him go up. Then he went up northwards. "Wonder if you are going to have good fortune," they said. "If you find anything good, you must come and let us know it." Then he came back all ragged and brown. They said, "What did you see where you were?" He said he did not see anything except the ground, near the big hills. They said to him, "You must think like a man and a woman. Now you must go westward." Then he came back. So again when he came they asked what he had seen. He had seen everything all dry, nothing but ground. Now he was to go southward. He went, he came back. They asked him again. In just the same words he answered. Then they said to go out eastwards. When he came back, they asked him again, and in the same words he answered. They said, "You have to be a man and a woman, now you are going up above." He went up. So they said to him, "YOU did not see anything when you went, now you belong to Kanyotsanyotse. You have to go out from here. Wonder if anybody will love you." So he went out and to a big court. And then he came to a certain place. They opened to go down. He was in the upper story with a man. And under then were different kinds of animals (tsiwi), mountain lion (kae), bear (ke), koho (kuyo, wolf) ${ }^{8}$, fox (de), sosa, different kinds of cat, tamagiin (dragon flies), also bees (worobe), the big and the little ones. Then they told the man to go in. Then he saw those things and when he saw those things, he got scared. They said, "We are your friend.” He was afraid and pushed the other one. Those animals jumped up on him and scratched him all over. They were supernatural (pinan). They gave him arrow points and buckskin to hang over the right shoulder, red feathers for his hair, moccasins, leggings and shirt of buckskin. They told him, “These are what you are to use.” They put $(\text { poshu) })^{8}$ all over his face. They put downy feathers all over his hair. They told him to take his bow and arrows. "Now you are ready. We love you." So he went out from there. He went back to the lake. He came near the lake and he began to dance and to sing and to call, U...u.! They heard it, they said, “That's good! That's good!” They said, 
"Maybe somebody loves us." He came in and they saw him. He was Kanyotsanyotse. ${ }^{9}$ That was the first one (i.e, he was the original Kanyotsanyotse) ${ }^{10}$.

And those na imbi kwiyo kotsaebukwi payokaga oyikaga (Corn Mothers), they statyed in the same place where they were born. Then he (Kanyotsanyotse) said, "I need a woman.” There were lots of men. He was walking around where they were sitting and he caught hold of one and stood him up and he got kotsaebukwi and gave it to the man he caught. So he took the Mother and gave it to him. "You are Poaetoyo; ${ }^{11}$ you have to care for all these people in the summer time. You are their father and mother." Then he said, "Yes." "You are the father and you are the mother," they said to him. So Kanyotsanyotse said to the man, "You are the father and you are the mother. If any little boy or any man or woman talks about you, do not get mad with your children. You have to treat them well, even if they speak against you. " Then he was looking for another mother. He was looking and looking around when he saw anther man. He caught him. He gave na imbi kwiyo kotsae bukwi oyikaga to the man and said, "You are the father and you are the mother. If any man or woman speaks against you, do not get mad. You have to treat you children well (as Winter Chief). So those were the old ones, pat' owa sendo ${ }^{12}$. Then they said, "Yes; now we have found a mother and a father,: they said. "So we have to walk up from here," they said. So they stood up in the north. They said, "Here is not the place." They stood up in the west. They said, "Here is not the place." They stood up in the south. They said, "Here is not the place." They stood up in the east. They said, "Here is not the place." Then they were singing poaka ${ }^{13}$. Then they went northwards and they came out from there.

While they were under the lake they had made two T'owa' $\mathrm{e}^{14}$. So they said, "Those two little boys have to think like a man and a woman." From the Lake they went up and said, "Whatever you see you must come and let us know." So the came in and let them know. So they questioned them. They said, "Yes, we went up and we did not see any hills." Then they told them again and so they said to them, "You belong to our father and mother," said they to them. Then they were getting ready what they would need when they went up from the Lake. They were thinking about how they could live in this world. They went out again. As they were walking they saw wake. The younger one was ahead of the elder. ${ }^{15}$ The elder said, "Wait for me, tiupare." ${ }^{16}$ He waited, they changed places. The younger said, "Wait for me, tiupare." Then they came to the Lake. They said, "We are tiunpare." So they went on. Then they told them, "You have to go out from here and go to the north, the west, the south, the east, and bring back a true account of what you see.: So they went out. They stood up. Then they said to them, "Try it, tiupare." So he took out his arrows. Then he said, "If I shoot it this way, if the arrow does not come back, that way is the north." Then it went and did not come back. They said, "Now we know where the north is." They gave the name "north.” Now, tiupare, try with the arrow again. "He shot and the arrow did not come back. They named it "west." "Try with the arrow again, tiupare. If the arrow does not come back, that is south." He shot again and the arrow did not come back. That was south. He shot again and the arrow did not come back. That was east. "Shoot the arrow up and if it does not come back that will be opamakore (sky)." ${ }^{17}$ He shot it, it did not come back. So he said, "Try, tiupare. Shoot up the arrow and if it comes down on the ground and into the ground that will belong to the nadir." He shot up the arrow. It came down and went into the ground. That was the nadir (nansogenoge). ${ }^{18}$ Then they went in. Then they asked 
them, "How did you fare?" They said, "We fared well. We know where north is, and west, south, east, above and below." So they said, "That is all right. Thank you. Now we know you have placed the steps (directions)." Then they said, "You have left out one word yet (you have omitted one thing). You have to get them all together, two by two, blue, yellow, red, white and nokunwi and tsaege (all colored) (six T'owa'e).” Those are Indians, what they need they are to mind them (guards for them). ${ }^{19}$ They still use them. They belong to the akonotuyu ${ }^{20}$ of Taos, Picuris, San Juan, Santa Clara, San Ildefonso, Nambe, Cochiti. So they were all two by two. They said, "Now you have to think like a woman. You have to put up the big hills now to the north." So they took a little mud and they threw it this way (indicating the directions) and there were the hills. Then they said, "When we work pinan, the sky will get dark, there will be white ones, like a flower, (clouds), ${ }^{21}$ there will be a rainbow and lightning (tsiguwenu) and the sound of rain falling, and fog."

They came out from that Lake. They could not walk. Poaetoyo kicked a ball ${ }^{22}$ and it could not go. So he said, "Oyike, now you try, tiupare. I wonder could you do it?" He threw it. It ran and it made a noise. Where it stopped was hoarfrost (oyegebeye). It made the ground hard. ${ }^{23}$

Then they were going along walking and walking. And some got head-ache and some, stomach-ache. And they said they needed something again. "That is why we have head-ache and stomach-ache." And sot hey said, "Maybe those mothers we are carring are not god mothers." So they went back again. Then Kanyotsanyotse said, "Whatever does she (payokaga) need?" He opened her stomach and she had pointed things and stones in her stomach. ${ }^{24} \mathrm{He}$ took all these bad things out and put in good things. ${ }^{25}$ Then they moved on again. They still had head-ache and stomach-ache. They still needed something. Sot they came back again. They needed $\mathrm{Pu}$ 'fona. ${ }^{26}$ The made four $\mathrm{Pu}$ 'fona, and went out again. The $\mathrm{Pu}$ 'fona gave them medicine.

They came to a big river. There was Magpie (kwaeae). He put his tail across the river an don it the To' owa'e passed over. The two old ones, the caciques (Summer Chief and Winter Chief), came on the other side. Then Magpie's tail turned over in the middle of the river and the people down into the water. ${ }^{27}$ Those old mothers (caciques) said, "You have to turn into fish." Some were left on one side, some on the other side. They were calling to one another. They threw stones and sticks at one another. Ten those who stayed on the other side said, "That is what you need. You are Navaho, Ute, Apache, Kaiowa, Comanche.” So when they called their names, they said, "You belong to them." They have their own languages. They could not talk to each other. S the caciques told them, "You do not need to build houses. You can build houses of deer hide and buffalo hide. When you have babies you have to use deer meat. That is what you will use," they said to them. "If you come and try and fight with our people, it will run blood." That is why when the Comanche and Kaiowa fought with our people only one or two of our men were killed. Our father and our mother said, "You are my own fighting people. Our houses are adobe houses." Thus they said to them, "Sometimes you will come to our places, when you need meal and corn." 28 So they went out waling to the north, west, south, east. "There you are going to be with all your children."29

Those Akogee ${ }^{30}$ were walking along, they were very sorrowful. "We need something," they said, so they went back again, those older ones, into the Lake. Then 
they brought those Kossa. ${ }^{31}$ They were making fun, those Kossa. And the people began to laugh and grow glad again.

The Summer Mother got the western hills and the Winter Mother got the eastern hills. So the Winter Mother comes up in the east and the Summer Mother in the west with their Oxuwah. ${ }^{32}$ Those people, their children, were coming along the hills. The Winter Man was coming with his children on the hills. The last ones were coming on, back on the hills. "When they were going to have oxuwabi ${ }^{33}$ Posew ' $\mathrm{a}^{34}$ would call from one side to the other side. So they came together in Tekeowinge. ${ }^{35}$ That is the way it happened, how they came up from the Lake. Hu '!

\section{Migration $^{1}$}

Oweweham'baiyo lived at Uwipinge ${ }^{2}$ all the people (t'aekitwa.) ${ }^{3}$ The people had moved along Pingkwaiye ${ }^{4}$ (Sangre de Cristo Mountains) and along Tsampiripingkwaiye, the west side range (Jemez Mountains). The eastern mountains belonged to the Winter People and the western Mountains belonged to the Summer People. Those on the Eastern Mountains, The Winter People, were eating deer, elk (the meat of wild animals); and the Summer People were eating jucca fruit (pahhe), mantsanitabe (?apples), berries (puhpahbe), okumbe, ${ }^{5}$ prickly pear (saebe $)^{6}$ - all different kinds of fruit. The Winter People's leader was Oyi'ke, the Summer People's leader was Poaetoyo. As they were walking divided, ${ }^{7}$ some on the west side liked the east side and walked over, some on the east side liked the west side and walked over. All came down together to Uwippinge. So when they were all down together, they talked about where they were going to make a place to live. So they said, "From here we ought to find a place to live, wherever we like.” Some said, "We loike Oke'anyebu '.” So they said, “Then you will be Oke' (San Jean)". Others said, "We like to be on the other side of the river." So they gave them a name, Kahpo, Leaf water (Santa Clara). So others said, "We like that place on the other side of the river. "So the gave them the name Pow'oge (San Ildefonso. Others said, "We like the same river, clear up there, Kibu' (gopher place). - "Well, you have the name Nambe'." 8 Other said, "We like way up there, Tatunge, dry ones," 9 _ "You have the name T'et'suge.: The people from down there, they always like to drink water. "So you have the name Posuwege ${ }^{10}$ (Pojoaquue)." These six have just one language.

We used to live at Okeowingeanyebu '. ${ }^{11}$ So they said, "Here we do not have a good life. Let us go over to Okeowinge powongwi koochute'. At Okeowinge powongwi koochute' at that time it was new.

(Follows the story why they moved.) At that time they would keep the boys ${ }^{12}$ pinangkwa ${ }^{13}$ and those T'owa'e they would take care of the boys. They kept them in the house for twelve days. They kept them in there for rain, to have good rains. And one of those boys, he was waiting until those who were taking care of them fell asleep. It was the business of the guards to give them rainwater. ${ }^{14}$ The guards say a boy going up, and they went after him, they ran after him. He ran over to a lake, and they ran after him, but they did not catch him; and he jumped into the water and he drank all he needed, and he got full of water; and they brought him back and took him back to Sibo 'pene ${ }^{15}$ (where they were in). And all the water he drank came up from his mouth and all those in there turned into frogs (pembowin). Then they said, "We do not have good times here.” So 
then they went to where we live now. They all moved. Only Tesque did not move. Haeheinamu (thus it happened). Hu '!

\section{Emergence Myth (Ortiz, S., 1969)}

The Tewa were living in Sipofene beneath Sandy Place Lake far to the north. The world under the lake was like this one, but it was dark. Supernaturals, men, and animals lived together at this time, and death was unknown. Among the supernaturals were the first mothers of all the Tewa, known as "Blue Corn Woman, near to summer," or the Summer mother, and "White Corn Maiden, near to ice," the Winter mother.

These mothers asked on of the men present to go forth and explore the way by which the people might leave the lake. Three times the man refused, but on the fourth request he agreed. He went out first to the north, but saw only mist and haze; then he went successively o the west, south, and east, but again saw only mist and haze. After each of these four ventures he reported to the corn mothers and the people that he had seen nothing, that the world above was still ochu, "green” or "unripe."

Next the mothers told him to go to the above. On his way he came upon an open place and saw all the tsiwi (predatory mammals and carrion-eating birds) gathered there. There were mountain lions and other species of cat; wolves, coyotes, and foxes; and vultures and crows. On seeing the man these animals rushed him, knocked him down, and scratched him badly. Then they spoke, telling him: "Get up! We are your friends." His wounds vanished immediately. The animals gave him a bow and arrows and a quiver, dressed him in buckskin, painted his face black, and tied the feathers of the carrion-eaters on his hair. Finally they told him: "You have been accepted. These things we have given you are what you shall use henceforth. Now you are ready to go."

When he returned to the people he came as Mountain Lion, or the Hunt Chief. This is how the first Made person came into being. On approaching the place where the people awaited, he announced his arrival by calling out like a fox (de). This is his call. The people rejoiced, saying, "We have been accepted."

The Hunt chief then took an ear of white corn, handed it to one of the other men, and said, "You are to lead and care for all of the people during the summer." To another man he handed another ear of white corn and told him, "You shall lead and care for the people during the winter." This is how, according to the myth, the Summer and Winter chiefs were instituted. They jointed the Hunt chief as Made People.

Among the people were also six pairs of brothers called Towa é, literally "persons." TO the first pair, who were blue, the newly appointed chiefs said: "Now you shall go forth to the north and tell us what you see." They went with the older one in the lead, but could not walk very far because the earth was soft. All they saw was a mountain to the north. They returned and reported their observations to the people. Next the tallow pair were sent out to the west, followed by the red ones who went south, the white ones who went east, and the dark (nuxu in) ones who went to the zenith. Each successive pair returned and rported that the earth was still soft. The yellow, red and white brothers reported seeing mountains in each direction, while the dark pair who went above reported seeing agoyo nuхu, a large star in the eastern sky. The first four pairs each picked each picked up some mud and sling it toward each of the cardinal directions, thereby creating four tsin, or flat-topped hills. 
Finally, the last pair of Towa é, the all-colored (tsege in) ones of the nadir, were sent out. They found that the ground had hardened somewhat, and they saw a rainbow in the distance. When they returned and reported this, the people made preparations to leave the lake. The summer chief led the way, but as he stepped on the earth it was still soft and he sank to this ankles in the mud. Then the Winter chief came forth, and as he stepped on the ground there was hoarfrost. The ground became hard, and the rest of the people followed. The original corn mothers and other supernaturals, the predatory mammals, and the carrion-eaters remained beneath the lake. The Towa é, or brothers, went to the mountains of the directions to stand watch over the people.

As the people started southward many began to fall ill. The Winter and Summer chiefs decided that they were not yet complete; something else was needed. All returned once again to the home under the lake, and there the Hunt chief opened up Summer chief's corn mother. He discovered that the hollow core was filled with pebbles, ashes, and cactus spines. The Hunt chief replaced these with seeds and declared that one among the people was "of a different breath," or a witch, for the items discovered in the corn mother were recognized as items of witchcraft. This, then, marked the beginning of witchcraft and other forms of evil. In order to combat these and to make the people well, the $K e$ (medicine man) was created as the fourth Made person. The people then started out once again.

Before they proceeded very far south, they all had to return to the lake three times more, because the chiefs felt they were still not complete. At each subsequent return the Kossa and Kwirana (clowns), the Scalp chief, and the Kwiyoh (Women's society) were instituted, in that order. The Kossa and Kwirana were created to entertain the people when they grew tired and unhappy, the Scalp chief to insure success in warfare, and the Women's society to care for the scalps and to assist the Scalp chief. The people at last felt they were complete, and prepared to proceed southward once again.

Before doing so, the Hunt chief divided the people between the Summer chief and the Winter chief. Those who were to follow the Summer chief would proceed south along the mountains on the west side of the Rio Grade. The Winter chief and his group would proceed along the mountains on the east side of the river. The Summer People, as the former group came to be called, subsisted by agriculture and by gathering wild plant foods, while the Winter People subsisted by hunting. Each group "took twelve steps” (make twelve stops) on this journey, and after each step they built a village and stayed for a day. "In that time one day was one year." Those who died along the way - for death was now known - were buried near the village and stones piled over the graves.

At the twelfth step the two groups rejoined and founded a village called Posi, near present day Ojo Caliente. The village grew and prospered and the people remained there for a long while. In time, however, and epidemic struck and the elders decided to abandon the village. Six different groups left and founded the six Tewa villages we know today. San Jan was founded first, so it became the "mother pueblo" for the other five. Each of the six departing grouped included both Winter and Summer people, so the chiefs and other Made People were replicated in each village. The origin and migration myth ends with an informant's observation:

In the very beginning we were one people. Then we divided into Summer people and Winter people; in the end we came together again as we are today. But you can see we are still Summer people and Winter people. 


\section{Tlingit Cosmologies}

\section{The Story of El \\ MYTHS RECORDED IN ENGLISH AT SITKA (Alaska Native Knowledge Network, 2006)}

There was a time, say the followers of El, when there was no light, and all the people lived and moved in the darkness. At that time lived a certain man who had a wife and a sister. He loved his wife to such an extent that he would not allow her to do any kind of work; and she spent the day either sitting in the house, or sunning herself on the hillock outside. She had eight little red birds, four on each side of her, who were always near her, and who would instantly leave her if there was any familiarity between her and any man except her husband. Of such a jealous disposition was her husband, that, whenever he went away, he locked her in a chest. Every day he went to the forest, where he made boats and canoes, being very proficient in such work.

His sister, who was called Kitchuginsi (daughter of a sea-swallow), had several sons (it is not known by whom); but the jealous uncle, so soon as they reached manhood, destroyed them. Some say that he took them out to sea and drowned them; but others say that he sealed them up in a hollow log. The helpless mother could only weep for her children. One day when she was sitting on the beach, mourning over a son, who disappeared in the usual way, she saw a school of small whales pass- ing by, and one of them coming in closer, stopped and started a con- versation with her. When he had learned the cause of her grief, he told her to throw herself into the sea and from the bottom bring up a pebble, swallow it, and wash it down with a little sea-water. So soon as the whale departed, Kitchuginsi went down to the bottom of the sea, fetched up a small pebble, swallowed it, and drank some sea-water. The effect of this extraordinary dose was that she conceived, and in eight months gave birth to a son, whom she considered an ordinary mortal, but he was El. Kitchuginsi, before giving birth to El, hid herself away from her brother in a secret place.

When El began to grow up, his mother made him a bow and arrows and instructed him in the use of them. El liked this kind of exercise, and soon became such an excellent shot that not a bird could fly by him; and from the hummingbirds alone that he killed his mother made herself a parka; and to fully indulge his passion for the chase he made a hunting-barrabara. Sitting there one morning in the early dawn, he saw that directly in front of his door sat a large bird resembling a mag- pie, with a long tail and a long and thin bill, bright and strong as iron. El killed her instantly and carefully skinned her, as is usually done for stuffing, and put the skin on himself. He had no sooner done this when he felt the desire and ability to fly, and immediately flew up, and soared so high and with such a force that his bill pierced into the clouds, and he was held there so strongly that with difficulty he extricated him- self. After that he flew back to his barrabara, took off his skin and hid it. At another time and in the same manner he killed a duck, and, tak- ing off her skin, put it on his mother, who instantly received the ability to swim. 
When El reached full growth, his mother told him of all his uncle's doings. El, so soon as he heard about them, went to his uncle's, and at the time when he is usually at his work. Going into the barrabara, he opened the chest in which his uncle's wife was kept, and debauched her; the birds instantly deserted her. The uncle, returning from his work and seeing all that happened, became extremely angry; but El sat very quietly and did not even move from his place. Then the uncle, calling him outside, seated himself with him in a canoe, and went with him to a place where many sea-monsters gathered; there he threw him into the sea, and thought that he had again got rid of a rival. But El walked on the bottom of the sea till he came to the shore, and reappeared before his uncle.

The uncle, seeing that he could not destroy his nephew in the usual way, said, in his anger: "Let there be a flood." The sea began to over- flow its banks and rose higher and higher. El put on his magpie skin and flew up into the clouds, and, as before, pierced them with his bill, and hung there suspended until the water, which had covered all the mountains, even reaching so high that his tail and wings were wet, subsided entirely. $\mathrm{He}$ then began to descend as lightly as a feather, and thinking, "Ah, if I could only drop on some good place," and he dropped there where the sun goes down. But he fell not on land, but into the sea, on the kelp; from there a sea-otter brought him safely away. Others say that he fell on the Queen Charlotte Islands, and, taking in his bill chips of the fir-tree, flew away to other islands, and where he dropped the chips there trees grow; and where he did not there they are not.

On coming to land again after the flood, El went towards the east, and in one place finding some dead boys, brought them to life by tickling them in the nose with hair which he had pulled out from a certain woman; in another place he set the sea-gull and heron to quar- rel, and in this manner obtained a smelt fish which he afterwards exchanged for a canoe and other things. But of all his adventures and doings, which are so numerous that it is impossible for one man to know them all, the most remarkable is the way he obtained the light.

At the time when the above-mentioned wonders were worked there was no light on the earth; it was in the possession of a rich and power- ful chief, being kept in three small boxes, which he guarded jealously and did not permit any one even to touch them. El, learning this, wished above all things to obtain the light, and he obtained it.

That chief had an only daughter, a virgin, whom he loved dearly, indulged, and tended, even to the extent of carefully examining her food and drink before she used it. There was no other way to obtain the light from the chief except by becoming his grandson, and El concluded to be born of his daughter. To accomplish his end was not difficult for him; since he could assume the shape of any object that he desired, -birds, fish, grass, etc., appearing as crow the oftenest, however. In this case he changed himself into a tiny piece of grass, and stuck to the side of the cup out of which the chief's daughter drank, and when she, after the usual examination, began drinking, it slid down her throat. Small though it was, she felt that she had swallowed something, and she tried hard but unsuccessfully to bring it up. The result, of all this was that she conceived; and, when the time came around for her to give birth, the chief ordered to be placed under her 
sea-otter skins and other valuable things. But the woman could not give birth, although her father and others assisted her in every known way. Finally a very old woman took her into the forest, where she made a bed of moss for her under a tree and laid her on it; and just as soon as she lay on it she gave birth to a son.

No one even suspected that the new-born child was El; the grand- father was delighted with his grandson, and loved him even more than his daughter. One day, after El commenced to understand a little, he set up a loud bawl and no one nor anything could quiet him. No matter what was given him, he threw it away and cried louder than before, and kept reaching out and pointing to the three little boxes which contained the heavenly lights. They could not be given to him without the permission of the chief, and he would not for a long time consent; at last he was obliged to give the boy one of the boxes. He immediately became quiet and happy, and began playing with it. A little later he took it out-of-doors, and, when unobserved, opened it and instantly stars appeared in the sky. Seeing this, the chief regretted the loss of his treasure, but he did not reprove the boy. In the same cunning manner El obtained the second box, in which the moon was Kept, and opened it; he even cried for the last and most precious box, containing the sun. The chief would not indulge him any longer; El did not leave off crying and bawling, refused to eat and drink, and consequently became ill. To humor him, the tender grandfather gave him the last box too, and ordered that he be watched and prevented from opening it; but El, so soon as he came outside, changed himself into a crow, flew away with the box, and appeared on the earth.

In passing over one place, El heard human voices, but could see no one; for the sun was not yet. El asked them: "Who are you; and would you like to have light ?" "You are deceiving us," they said; "you are not El, who is the only one that can make light." To convince the un- believers, El opened the box, and at once the sun in all his splendor appeared in the sky. At this sight the people scattered themselves in all directions, some to the forests and became beasts, others to the trees and became birds, still others to the waters and became fishes.

There was no fire on the earth, but on an island in the mid-sea. Thither El, dressed in his magpie skin, flew, and snatching a live brand, he hastened back. But the distance was so great that by the time the mainland was reached the brand and half of his bill were nearly con- sumed. Near the shore he dropped the brand, and the sparks were blown on to the rocks and trees. This explains why fire is found in these substances.

Until El's time there was no fresh water on the mainland and islands, with one exception. On this island, situated not far from Cape Om- maney, was a small well of fresh water guarded by Kanuk, the hero and ancestor of the Wolf tribe of the Tlingit. El (the details will be told later in connection with Kanuk) went over there, and taking in his bill as much water as it would hold, and after suffering racking tortures, flew back to the mainland of America. While flying over the earth, the water dripped on the land; where small drops fell springs and creeks appeared, and the larger drops formed lakes and rivers. 
At last El, providing the people with all the necessaries, went to his home, Nasshakiel, which is inaccessible both to men and spirits, as is shown from the following. One daring spirit undertook to go there, and as a punishment had his left side turned to stone; for in flying forward he looked on the left side where El's palace was. The left side of the spirit's mask, which was at the time in possession of the shaman at Chilkat, also became stone. 


\section{Raven MYTHS RECORDED IN ENGLISH AT SITKA (Alaska Native Knowledge Network, 2006)}

No one knows just how the story of Raven really begins, so each starts from the point where he does know it. Here it was always begun in this way. Raven was first called Kitka'ositiyi-qâ-yît ("Son of Kit-ka'ositiyi-qâ"). When his son was born, Kit-ka'ositiyi-qâ tried to instruct him and train him in every way and, after he grew up, told him he would give him strength to make a world. After trying in all sorts of ways Raven finally succeeded. Then there was no light in this world, but it was told him that far up the Nass was a large house in which some one kept light just for himself.

Raven thought over all kinds of plans for getting this light into the world and finally he hit on a good one. The rich man living there had a daughter, and he thought, "I will make myself very small and drop into the water in the form of a small piece of dirt." The girl swallowed this dirt and became pregnant. When her time was completed, they made a hole for her, as was customary, in which she was to bring forth, and lined it with rich furs of all sorts. But the child did not wish to be born on those fine things. Then its grandfather felt sad and said, "What do you think it would be best to put into that hole? Shall we put in moss?" So they put moss inside and the baby was born on it. Its eyes were very bright and moved around rapidly.

Round bundles of varying shapes and sizes hung about on the walls of the house. When the child became a little larger it crawled around back of the people weeping continually, and as it cried it pointed to the bundles. This lasted many days. Then its grandfather said, "Give my grandchild what he is crying for. Give him that one hanging on the end. That is the bag of stars." So the child played with this, rolling it about on the floor back of the people, until suddenly he let it go up through the smoke hole. It went straight up into the sky and the stars scattered out of it, arranging themselves as you now see them. That was what he went there for.

Some time after this he began crying again, and he cried so much that it was thought he would die. Then his grandfather said, "Untie the next one and give it to him." He played and played with it around behind his mother. After a while he let that go up through the smoke hole also, and there was the big moon.

Now just one thing more remained, the box that held the daylight, and he cried for that. His eyes turned around and showed different colors, and the people began thinking that he must be something other than an ordinary baby. But it always happens that a grandfather loves his grandchild just as he does his own daughter, so the grandfather said, "Untie the last thing and give it to him." His grandfather felt very sad when he gave this to him. When the child had this in his hands, he uttered the raven cry, "Gâa," and flew out with it through the smoke hole. Then the person from whom he had stolen it said, "That old manuring raven has gotten all of my things. 
Journeying on, Raven was told of another place, where a man had an everlasting spring of water. This man was named Petrel (GAnû'k). Raven wanted this water because there was none to drink in this world, but Petrel always slept by his spring, and he had a cover over it so as to keep it all to himself. Then Raven came in and said to him, "My brotherin-law, I have just come to see you. How are you?" He told Petrel of all kinds of things that were happening outside, trying to induce him to go out to look at them, but Petrel was too smart for him and refused.

When night came, Raven said, "I am going to sleep with you, brother-in-law." So they went to bed, and toward morning Raven heard Petrel sleeping very soundly. Then he went outside, took some dog manure and put it around Petrel's buttocks. When it was beginning to grow light, he said, "Wake up, wake up, wake up, brother-in-law, you have defecated all over your clothes." Petrel got up, looked at himself, and thought it was true, so he took his blankets and went outside. Then Raven went over to Petrel's spring, took off the cover and began drinking. After he had drunk up almost all of the water, Petrel came in and saw him. Then Raven flew straight up, crying "Gâ."

Before he got through the smoke hole, however, Petrel said, "My spirits up the smoke hole, catch him." So Raven stuck there, and Petrel put pitchwood on the fire under him so as to make a quantity of smoke. Raven was white before that time, but the smoke made him of the color you find him to-day. Still he did not drop the water. When the smokehole spirits let him go, he flew around the nearest point and rubbed himself all over so as to clear off as much of the soot as possible.

This happened somewhere about the Nass, and afterwards he started up this way. First he let some water fall from his mouth and made the Nass. By and by he s Pit more out and made the Stikine. Next he spit out Taku river, then Chilkat, then Alsek, and all the other large rivers. The small drops that came out of his mouth made the small salmon creeks.

After this Raven went on again and came to a large town where were people who had never seen daylight. They were out catching eulachon in the darkness when he came to the bank opposite, and he asked them to take him across but they would not. Then he said to them, "If you don't come over I will have daylight break on you." But they answered, "Where are you from? Do you come from far up the Nass where lives the man who has daylight?" At this Raven opened his box just a little and shed so great a light on them that they were nearly thrown down. He shut it quickly, but they quarreled with him so much across the creek that he became angry and opened the box completely, when the sun flew up into the sky. Then those people who had sea-otter or fur-seal skins, or the skins of any other sea animals, went into the ocean, while those who had land-otter, bear, or marten skins, or the skins of any other land -animals, went into the woods [becoming the animals whose skins they wore].

Raven came to another place where a crowd of boys were throwing fat at one another. When they hit him with a piece he swallowed it. After a while he took dog's manure and threw at the boys who became scared, ran away, and threw more fat at him. He consumed all in this way, and started on again. 
After a while he came to an abandoned camp where lay a piece of jade (s!̂̂) half buried in the ground, on which some design had been pecked. This he dug up. Far out in the bay he saw a large spring salmon jumping about and wanted to get it but did not know how. Then he stuck his stone into the ground and put eagle down upon the head designed thereon. The next time the salmon jumped, he said, "See here, spring salmon jumping out there, do you know what this green stone is saying to you? It is saying, 'You thing with dirty, filthy back, you thing with dirty, filthy gills, come ashore here."'

Raven suddenly wanted to defecate and started off. Just then the big spring salmon also started to come ashore, so Raven said, "Just wait, my friend, don't come ashore yet for I have some business to attend to." So the salmon went out again. Afterward Raven took a piece of wild celery (yâ'naet), and, when the salmon did come ashore, he struck it with this and killed it. Because Raven made this jade talk to the salmon, people have since made stone axes, picks, and spears out of it.

Then, Raven, carrying along the spring salmon, got all kinds of birds, little and big, as his servants. When he came to a good place to cook his fish he said to all of them, "Here, you young fellows, go after skunk cabbage. We will bury this in the ground and roast it." After they had brought it down, however, he said, "I don't want any of that, My wife has defecated all over that, and I will not use it. Go back and pass over two mountains." While they were gone, Raven put all of the salmon except one fat piece cut from around the "navel" which is usually cooked separately, into the skunk cabbage and buried it in the fire. Before they returned, he dug this up and ate it, after which he put the bones back into the fire and covered them up.

When the birds at last came back he said to them, "I have been across two mountains myself. Now it is time to dig it up. Dig it out." Then all crowded around the fire and dug, but, when they got it up, there was nothing there but bones.

By and by the birds dressed one another in different ways so that they might be named from their dress. They tied the hair of the blue jay up high with a string, and they added a long tail to the ts! êgênî́', another crested bird. Then they named one another. Raven let out the ts!êgênî' and told him that when the salmon comes he must call its slime unclean and stay high up until the salmon are a all gone.

Now Raven started off with the piece of salmon belly and came to a place where Bear and his wife lived. He entered and said, "My aunt's son, is this you? The piece of salmon he had buried behind a little point. Then Bear told him to sit down and said, "I will roast some dry salmon for you." So he began to roast it. After it was done, he set a dish close to the fire and slit the back of his hands with a knife so as to let grease run out for Raven to eat on his salmon. After he had fixed the salmon, he cut a piece of flesh out from in front of his thighs and put it into the dish. That is why bears are not fat in that place.

Now Raven wanted to give a dinner to Bear in return, so he, too, took out a piece of fish, roasted it, set out the dish Bear had used, close to the fire and slit up the back of his hand, 
thinking that grease would run out of it. But instead nothing but white bubbles came forth. Although he knew he could not do it, he tried in every way.

Then Raven asked Bear, "Do you know of any halibut fishing ground out here?" He said "No."' Raven said, "Why! what is the use of staying here by this salt water, if you do not know of any fishing ground? I know a good fishing ground right out here called Just-onthe-edge-of-kelp (Gî'ck! îcuwAnyîn'). There are always halibut swimming there, mouth up, ready for the hook."

By and by Raven got the piece of fish he had hidden behind the point and went out to the bank in company with Bear and Cormorant. Cormorant sat in the bow, Bear in the middle, and, because he knew where the fishing ground was, Raven steered. When they arrived Raven stopped the canoe all at once. He said to them, "Do you see that mountain, Was!ê'tî-câ? When you sight that mountain, that is where you want to fish." After this Raven began to fill the canoe with halibut. So Bear asked him, "What do you use for bait anyhow, my friend?" [Corvus respondit, "Testium cute ad escam præparandam utor." Ursus aiebat corvo, "Licetne uti meis quoque?" Sed corvus dixit, "Noli id facere, ne forte sint graviter attriti." Paulo post ursus aegre ferens aiebat, "Abscide eos." Tum corvus cultellum acuens aiebat, "Pone eos extrema in sede." Postea corvus eos praecidit, at Ursus gemens proripuit circum scapham et moriens incidit in undas extremo cum gemitu.]

After a while Raven said to Cormorant; "There is a louse coming down on the side of your head. Come here. Let me take it off." When he came close to him, he picked it off. Then he said, "Open your mouth so that I can put it on your tongue." When he did open his mouth, however, Raven reached far back and pulled his tongue out. He did this because he did not want Cormorant to tell about what he had done. He told Cormorant to speak, but Cormorant made only a gabbling noise. "That is how young fellows ought to speak," said Raven. Then Raven towed the dead body of the bear behind the point and carried it ashore there. Afterwards he went to Bear's wife and began to take out his halibut. He said to the female bear, "My father's sister, cut out all the stomachs of the halibut and roast them." So she went down on the beach to cut them out. While she was working on the rest of the halibut, he cooked the stomachs and filled them with hot rocks. Then he went down and said to her, "You better come up. I have cooked all those stomachs for you. You better wash your hands, come up, and eat." After that Cormorant came in and tried to tell what had happened but made only a gabbling sound. Raven said to the bear, "Do you know what that fellow is talking about? He is saying that there were lots of halibut out where we fished. Every time we tried to get a canoe load they almost turned us over." When she was about to eat he said, "People never chew what I get. They always swallow it whole." Before she began she asked Raven where her husband was, and Raven said, "Somehow or other he caught nothing, so we landed him behind the point. He is cutting alders to make alder hooks. He is sitting there yet."

After the bear had swallowed all of the food she began to feel uneasy in her stomach, and Raven said to Cormorant, "Run outside quickly and get her some water." Then she drank a great quantity of water, and the things in her stomach began to boil harder and harder. Said Raven, "Run out Cormorant." He did so, and Raven ran after him. Then the female 
bear ran about inside the house grabbing at everything and finally fell dead. Then Raven skinned the female bear, after which he went around the point and did the same thing to the male. While he was busy there Cormorant came near him, but he said, "Keep away, you small Cormorant," and struck him on the buttocks with his hand saying, "Go out and stay on those rocks." Ever since then the cormorants have been there. Raven stayed in that Place until he had consumed both of the bears.

Starting on again, Raven came to a place where many people were encamped fishing. They used nothing but fat for bait. He entered a house and asked whit they used for bait. They said "Fat." Then he said, "Let me see you put enough on your hooks for bait," and he noticed carefully how they baited and handled their hooks. The next time they went out, he walked off behind a point and went under water to get this bait. Now they got bites and pulled up quickly, but there was nothing on their hooks. This continued for a long time. The next time they went out they felt the thing again, but one man among them who knew just how fish bite, jerked at the right moment and felt that he had caught something. The line went around in the water very fast. They pulled away, however, until they got Raven under the canoe, and he kicked against it very hard. All at once his nose came off, and they pulled it up. When they landed, they took it to the chief's house and said, "We have caught a wonderful thing. It must be the nose of the GonaqAdê't." So they took it, put eagle down on it, and hung it up on the wall.

After that, Raven came ashore at the place where he had been in the habit of going down, got a lot of spruce gum and made a new nose out of it. Then he drew a root hat down over his face and went to the town. Beginning at the nearer end he went through the houses saying "I wonder in what house are the people who caught that GonaqAdê't's nose." After he had gone halfway, he entered the chief's house and inquired, "Do you know where are the people who caught that GonaqAdê't's nose?" They answered, "There it is on the wall." Then he said, "Bring it here. Let me examine it." So they gave it to him. "This is great," he said, and he put up his hat to examine it. "Why," said he, "this house is dark. You ought to take off the smoke-hole cover. Let some one run up and take it off so that I can see." But, as soon as they removed it, he put the nose in its place, cried "Gâa," and flew away. They did not find out who he was.

Going thence, Raven saw a number of deer walking around on the beach, with a great deal of fat hanging out through their noses. As he passed one of these, he said, "Brother, you better blow your nose. Lots of dirt is hanging out of it." When the deer would not do this, Raven came close to him, wiped his nose and threw the fat by his own side. Calling out, "Just for the Raven," he swallowed it.

Now Raven formed a certain plan. He got a small canoe and began paddling along the beach saying, "I wonder who is able to go along with me." Mink came down and said, "How am I?" and Raven said, "What with?" (i. e., What can you do?). Said Mink, "When I go to camp with my friends, I make a bad smell in their noses. With that." But Raven said, "I guess not. You might make a hole in my canoe," so he went along farther. The various animals and birds would come down and say, "How am I?" but he did not even listen. After some time Deer ran down to him, saying, "How am I?" Then he answered, 


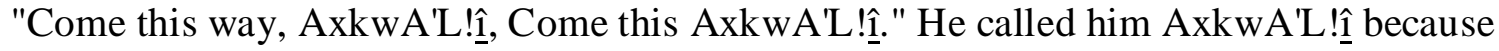
he never got angry. Finally Raven came ashore and said to Deer, "Don't hurt yourself, AxkwA'L!̣̂." By and by Raven said" Not very far from here my father has been making a canoe. Let us go there and look at it."

Then Raven brought him to a large valley. He took very many pieces of dried wild celery and laid them across the valley, covering them with moss. Said Raven, "AxkwA'L! 1 , watch me, AxkwA'L! î, watch me." Repeating this over and over he went straight across on it, for he is light. Afterwards he said to Deer, "AxkwA'L! 1̂, now you come and try it. It will not break," and he crossed once more. "You better try it now," he said. "Come on over." Deer did so, but, as he was on the way, he broke through the bridge and smashed his head to pieces at the bottom. Then Raven went down, walked all over him, and said to himself, "I wonder where I better start, at the root of his tail, at the eyes, or at the heart." Finally he began at his anus, skinning as he went along. He ate very fast.

When he started on from this place, he began crying, "AxkwA'L!1̂-1̂-1̂l, AxkwA'L!1̂-1̂-1̂!," and the fowls asked him, "What has become of your friend, AxkwA'L! 1⁇" "Some one has taken him and pounded him on the rocks, and I have been walking around and hopping around since he died."

By and by he came to a certain cliff and saw a door in it swing, open. He got behind a point quickly, for he knew that here lived the woman who has charge of the falling and rising of the tide. Far out Raven saw some kelp, and, going out to this, he climbed down on it to the bottom of the sea and gathered up a number of small sea urchins, (nîs!) which were lying about there. He brought these ashore and began eating, making a great gulping noise as he did so. Meanwhile the woman inside of the cliff kept mocking him saying, "During what tide did he get those things?"

While Raven was eating Mink came along, and Raven said, "Come here. Come here." Then he went on eating. And the woman again said, "On what tide did you get those sea urchins you are making so much noise about?" "That is not your business," answered Raven. "Keep quiet or I will stick them all over your buttocks." Finally Raven became angry, seized the knife he was cutting up the sea urchins with and slit up the front of the cliff out of which she spoke. Then he ran in, knocked her down and began sticking the spines into her buttocks. "Stop, Raven, stop," she cried, "the tide will begin to go down." So he said to his servant, Mink, "Run outside and see how far down the tide has gone." Mink ran out and said, "It is just beginning to go down." The next time he came in he said, "The tide is still farther down." The third time he said, "The tide is lower yet. It has uncovered everything on the beach." Then Raven said to the old woman, "Are you going to let the tide rise and fall again regularly through the months and years?" She answered "Yes." Because Raven did this while he was making the world, nowadays, when a woman gets old and can not do much more work, there are spots all over her buttocks.

After the tide had gone down very far he and his servant went out. He said to Mink, "The thing that will be your food from now on is the sea urchin (nîs!). You will live on it." The tide now goes up and down because he treated this woman so. 
Now Raven started on from this place crying, "My wife, my wife!" Coming to some trees, he saw a lot of g um on one of them and said to it, "Why! you are just like me. You are in the same state." For he thought the tree was crying.

After this he got a canoe and began paddling along. By and by Petrel met him in another canoe. So he brought his canoe alongside and said, "Is this you, my brother-in-law? Where are you from?" He answered, "I am from over there." Then Raven began to question him about the events in this world, asking him how long ago they happened, etc. He said, "When were you born? How long have you been living?" And Petrel answered, "I have been living ever since the great liver came up from under the earth. I have been living that long." So said Petrel. "Why! that is but a few minutes ago," said Raven. Then Petrel began to get angry and said to Raven, "When were you born?" "I was born before this world was known." "That is just a little while back."

They talked back and forth until they became very angry. Then Petrel pushed Raven's canoe away from him and put on his hat called fog-hat (qogâ's! s!âx ${ }^{\mathrm{u}}$ ) so that Raven could not see where he was. The world was round for him [in the fog]. At last he shouted, "My brother-in-law, Petrel, you are older than I am. You have lived longer than I." Petrel also took water from the sea and sprinkled it in the air so that it fell through the fog as very fine rain. Said Raven, "Î, î." He did not like it at all. After Petrel had fooled him for some time, he took off Fog-hat and found Raven close beside him, pulling about in all directions. Then Raven said to Petrel, "Brother-in-law, you better let that hat go into this world." So he let it go. That is why we always know, when we see fog coming out of an open space in the woods and going right back again, that there will be good weather.

Leaving this place, Raven came to another where he saw something floating not far from shore, though it never came any nearer. He assembled all kinds of fowl. Toward evening he looked at the object and saw that it resembled fire. So he told a chicken hawk $\left(\mathrm{kA} ! \mathrm{k}^{\mathrm{u}}\right)$ which had a very long bill to fly out to it, saying, "Be very brave. If you get some of that fire, do not let go of it." The chicken hawk reached the place, seized some fire and started back as fast as it could fly, but by the time it got the fire to Raven its bill was burned off. That is why its bill is short. Then Raven took some red cedar, and some white stones called nêq! which are found on the beach, and he put fire into them so that it could be found ever afterward all over the world.

After he had finished distributing the fire he started on again and came to a town where there were many people. He saw what looked like a large animal far off on the ocean with fowl all over the top of it. He wondered very much what it was and at last thought of a way of finding out. He said to one of his friends, "Go up and cut a cane for me." Then he carved this cane so as to resemble two tentacles of a devil fish. He said, "No matter how far off a thing is, this cane will always reach it."

Afterward he went to the middle of the town and said, "I am going to give a feast. My mother is dead, and I am going to beat the drums this evening. I want all of the people to come in and see me." In the evening he assembled all of the people, and they began to beat drums. Then he held the cane in his hands and moved it around horizontally, testing 
it. He kept saying "Up, up, up." a a He said, "I have never given any feast for my mother, and it is time I did it, but I have nothing with which to give a feast. Therefore I made this cane, and I am going to give a feast for my mother with this wonderful thing."

Then he got the people all down on the beach and extended his cane toward the mysterious object until it reached it. And he began to draw it in little by little, saying to the people, "Sing stronger all the time." When it struck land, a wave burst it open. It was an everlasting house, containing everything that was to be in the waters of the world. He told the people to carry up fish and they did so. If one had a canoe, he filled it; if he had a box, he filled that; and those that had canoes also boiled eulachon in them. Since then they have known how to boil them. With all of these things Raven gave the feast for his mother. After this was over he thought up a plot against the killer whales and sent an invitation to them. Then he told each of his people to make a cane that would reach very much above his head. So, when the killer whales came in and inquired, "What do the people use those canes for that extend up over their heads?", he replied, "They stick them down into their heads." They asked him several times, and he replied each time in the same way. After a while one of the whales said, "Suppose we try it." Raven was glad to hear that and said, "All right, we will try it with you people, but the people I have invited must not look when I put a cane into anyone's head." Then he went away and whittled a number of sticks until they were very sharp. After that he laid all of the killer whales on the beach at short distances apart, and again he told them not to look up while he was showing one how it was done. Then he took a hammer or maul and drove his sticks into the necks of these whales one after the other so that they died. But the last one happened to look up, saw what was being done, and jumped into the ocean.

[Now Raven and another person started to boil out the killer-whales' grease, and the other man had more than he. So Raven dreamed a dream which informed him that a lot of people were coming to fight with him, and, when such people really did make their appearance, he told his companion to run out. After he had done so, Raven quickly drank all the latter's grease. By and by, however, the man returned, threw Raven into a grease box, and shut him in, and started to tic it up with a strong rope. Then Raven called out, "My brother, do not tie the box up very strongly. Tie it with a piece of straw such as our forefathers used to use." The man did so, after which he took the box up on a high cliff and kicked it over. Then Raven, breaking the straw, flew out, crying "Gâ." When he got to the other side of the point, he alighted and began wiping himself.]

Next he came to a large whale blowing along out at sea, and noticed that every time it came up, its mouth was wide open. Then Raven took a knife and something with which to make fire. When the whale came up again he flew into its mouth and sat down at the farther end of its stomach. Near the place where he had entered he saw something that looked like an old woman. It was the whale's uvula (Anût!ayî). When the whale came up, it made a big noise, the uvula went to one side and the herring and other fish it lived on poured right in. Then Raven began eating all these things that the whale had swallowed, and, presently, he made a fire to cook the fat of the whale itself that hung inside. Last of all he ate the heart. As soon as he cut out this, the whale threw itself about in the water and soon floated up dead. Raven felt this and said, "I wish it would float up on a good 
sandy beach." After he had wished this many times, the whale began to drift along, and it finally floated ashore on a long sandy beach.

After a while some young fellows who were always shooting about in this neighborhood with their bows and arrows, heard a voice on the beach say, "I wonder who will make a hole on the top so that he can be my friend." The boys ran home to the town and reported, "We heard a queer noise. Something floated ashore not far from this place, and a person inside said, 'I wish that somebody would make a hole above me so that he can be my friend."' Then the people assembled around the whale and heard Raven's words very clearly. They began to cut a hole just over the place these came from and presently they heard some one inside say, "Xônê'-ê." When the hole was large enough, Raven flew straight up out of it until he was lost to sight. And they said to him, "Fly to any place where you would like to go." After that they cut the whale up and in course of time came to the spot where Raven had lighted his fire to make oil.

Meanwhile Raven flew back of their camp to a large dead tree that had crumbled into fine pieces and began rubbing on it to dry himself. When he thought that the people were through making oil, he dressed himself up well and repaired to the town. There he said to the people, "Was anything heard in that tc!ân (his word for whale)?" and one answered, "Yes, a queer noise was heard inside of the whale." "I wonder what it was," said Raven.

After their food was all prepared Raven said to the people, "Long ago, when a sound was heard inside of a tc!ân, all the people moved out of their town so as not to be killed. All who remained were destroyed. So you better move from this town." Then all of the people said, "All of us better move from this town rather than be destroyed." So they went off leaving all of their things, and Raven promptly took possession of them.

Raven once went to a certain place outside of here (Sitka) in his canoe. It was calm there, but he began rocking the canoe up and down with his feet until he had made a great many waves. Therefore there are many waves there now even when it is calm outside, and a canoe going in thither always gets lost.

By and by Raven came to a sea gull standing at the mouth of a creek and said to it, "What are you sitting in this way for? How do you call your new month?", "Y Adâq!o't," a replied the sea gull. Raven was questioning him in this way because he saw many herring out at sea. So he said, "I don't believe at all what you say. Fly out and see if you can bring in a herring." This is why, until the present time, people have differed in their opinions concerning the months and have disputed with one another.

After they had quarreled over it for a long time, the gull became angry, flew out to sea, and brought back a big herring. He lighted near Raven and laid the herring beside him, but, when Raven tried to get it, he gulped it down. In another direction from the sea gull Raven saw a large heron and went over to it. He said to the heron, "Sea gull is calling you Big-long-legs-always-walking-upon-the beach." Then, although the heron did not reply, he went back to the sea gull and said, "Do you know what that heron is saying about you? He says that you have a big stomach and get your red eyes by sitting on the beach always 
looking out on the ocean for something to eat." Then he went back to the heron and said to it, "When I meet a man of my own size, I always kick him just below the stomach. That fellow is talking too much about you. Go over, and I will help you thrash him." So the heron went over toward the sea gull, and, when he came close to it, Raven said, "Kick him just under his stomach." He did so, and the big herring came out. Then Raven swallowed it quickly saying, "Just for the Raven."

Going on again, Raven came to a canoe in which were some people lying asleep along with a big salmon which he took away. When the people awoke, they saw the trail where he had dragged it off, and they followed him. They found him lying asleep by the fire after having eaten the salmon. Seeing his gizzard hanging out at his buttocks, they twisted it off, ran home with it and used it as a shinny ball; this is why no human being now has a gizzard.

The People knew it was Raven's gizzard, so they liked to show it about, and they knocked it around so much that it grow large by the accumulation of sand. But Raven did not like losing his gizzard. He was cold without it and had to get close to the fire. When he came to the place where they were playing with it, he said, "Let it come this way." No sooner had they gotten it near him, however, than they knocked it away again. After a while it reached him, and he seized it and ran off, with all the boys after him. As he ran he washed it in water and tried to fit it back in place. It was too hot from much knocking about, and he had to remove it again. He washed it again but did not get all of the, sand off. That is why the raven's gizzard is big and looks as if it had not been washed.

Next Raven came to a town where lived a man called Fog (or Cloud)-on-the-Salmon (Xâ'tkA-kogâ's! î). He wanted to marry this man's daughter because he always had plenty of salmon. He had, charge of that place. So he married her, and they dried quantities of salmon, after which they filled many animal stomachs with salmon eggs. Then he loaded his canoe and started home. He put all of the fish eggs into the bow. On the way it became stormy, and they could not make much headway, so he became tired and threw his paddles into the bow, exclaiming to his wife, "Now you paddle!" Then the salmon eggs shouted out, "It is very hard to be in stomachs. Hand the paddles here and let me pull." So the salmon eggs did, and, when they reached home, Raven took all of them and dumped them overboard. But the dried salmon he carried up. That is why people now use dried salmon and do not care much for salmon eggs.

Journeying on, Raven came to a seal sitting on the edge of a rock, and he wanted to get it, but the seal jumped into the ocean. Then he said, "Yâak!ôct!A'L!," because he was so sorry about it. Farther on he came to a town and went behind it to watch. After a while a man came out, took a little club from a certain place where he kept it in concealment, and said to it, "My little club, do you see, that seal out there? Go and get it." So it went out and brought the little seal ashore. The club was hanging to its neck. Then the man took it up and said, "My little club, you have done well," after which he put it back in its place and returned to the town. Raven saw where it was kept, but first he went to the town and spoke kindly to the owner of it. In the night, however, when every one was asleep, he went back to the club, carried it behind a point and said to it, "See here, my little club, 
you see that seal out in the water. Go and get it." But the club would not go because it did not know him. .After he had tried to get it to go for some time, he became angry and said to it, "Little club, don't you see that seal out there?" He kept striking it against a rock until he broke it in pieces.

Coming to a large bay, Raven talked to it in order to make it into Nass (i. e., he wanted to make it just like the Nass), but, when the tide was out great numbers of clams on the flats made so much noise shooting up at him that his voice was drowned, and he could not succeed. He tried to put all kinds of berries there but in vain. After many attempts, he gave it up and went away saying, "I tried to make you into Nass, but you would not let me. So you can be called SkAnA'x" (the name of a place to the southward of Sitka).

Two brothers started to cross the Stikine river, but Raven saw them and said, "Be stones there." So they became stones. a

Starting on, he came to the ground-hog people on the mainland. His mother had died some time before this, and, as he had no provisions with which to give a feast, he came to the ground hogs to get some. The ground-hog people know when slides descend from the mountains, and they know that spring is then near at hand, so they throw all of their winter food out of their burrows. Raven wanted them to do this, so he said, "There is going to be a world snow slide." But the ground-hog chief answered, "Well! nobody in this town knows about it." Toward spring, however, the slide really took place, and the ground hogs then threw all of their green herbs, roots, etc., outside to him.

[Postea corvus in litus descendit cum quidam eum certiorem faceret de quattuor mulieribus, quae essent in insula, maturitatem adipiscentes. Deinde conatus est muliebria genitalia conficere e cortice lini arboris, et cum adveniret mediam in viam, quae in insulam perducebat, simile nomine eam nuncupavit; sed res male processerunt. Cortex edidit vocem argutam at ille, ira incensus, in undas eum proiecit. Eodem modo tentavit tabaci folia et alias res, sed inutile erat. Postremo processit in insulam, cui nomen erat mulieribus genitalibus (Gânq!â'tê̂). Eius comes vir quidem nomine Ignavus (Q!Atxâ'n) erat. Corvus autem aiebat ignavo, "Etiam si aliquid minime pavorem tibi iniicit, percute scapham." Mox ignavus scapham quassabat atque exclamavit, "Iam luna adest." Paene corvum in undas proiecit, qui, etsi ipse hortatus cum erat ut id faceret, aegre tulit. Corvus omnia genitalia, quae in insula erant, colligens, complevit scapham. Disponens ea locis in aequis, praeparvit dare propter ea convivium escis porci.]

After this he said to the people, "Make ear pendants because I am going to invite the whole world." He was going to invite everyone because he had heard that the GonaqAdê't had a Chilkat blanket and a hat, and he wanted to see them. First he invited the GonaqAdê't and afterwards the other chiefs of all the tribes in the world. At the appointed time they began to come in. When the GonaqAdê't came in he had on his hat with many crowns and his blanket but was surrounded by a fog. Inside of the house, however, he appeared in his true form. It is from this feast of Raven's that people now like to attend feasts. It is also from this that, when a man is going to have a feast, he has a manycrowned hat carved on top of the dead man's grave post (kûtî' yA). 
Raven made a woman under the earth to have charge of the rise and fall of the tides. a One time he wanted to learn about everything under the ocean and had this woman raise the water so that he could go there. He had it rise very, slowly so that the people had time to load their canoes and get into them. When the tide had lifted them up between the mountains they could see bears and other wild animals walking around on the still unsubmerged tops. Many of the bears swam out to them, and at that time those who had their dogs had good protection. Some people walled the tops of the mountains about and tied their canoes inside. They could not take much wood up with them. Sometimes hunters see the rocks they piled up there, and at such times it begins to grow foggy. That was a very, dangerous time. The people who survived could see trees swept up roots and all by the rush of waters, and large devilfish and other creatures were carried up by it.

When the tide began to fall, all the people followed it down, but the trees were gone and they had nothing to use as firewood, so they were destroyed by the cold. When Raven came back from under the earth, if he saw a fish left on top of a mountain or in a creek, he said, "Stay right there and become a stone." So it became a stone. If he saw any person coming down, he would say, "Turn to a stone just where you are," and it did so.

After that the sea went down so far that it was dry everywhere. Then Raven went about picking up the smallest fish, as bull heads and tom cod, which he strung on a stick, while a friend who was with him at this time, named CAk! ${ }^{\prime} \mathrm{k}^{\mathrm{u}}$, a took large creatures like whales. With the grease he boiled out,. CAk! ${ }^{\prime} k^{u}$ filled an entire house, while Raven filled only a small bladder.

Raven stayed with CAk! $\mathrm{A}^{\mathrm{u}}$ and one night had a dream. He said to his friend, "I dreamed that a great enemy came and attacked us." Then he had all the fowls assemble and come to fight, so that his dream might be fulfilled. As soon as Raven had told his dream, CAk! A' ${ }^{\mathrm{u}}$ went down and saw the birds. Then Raven went into the house and began drinking up his grease. But the man came back, saw what Raven was doing, and threw him into a grease box, which he started to tie up with a strong rope. Raven, however, called out, "My brother, do not tie me up with a strong rope, but take A straw such as our forefathers used to employ." He did so. Then Raven drank up all the grease in the box, and, when the man took him up on a high cliff and kicked him off, he came out easily and flew away crying, "Gâ."

One time Raven assembled all the birds in preparation for a feast and had the bears in the rear of his house as guests. All the birds had canes and helped him sing. As he sang along Raven would say quietly, "Do you think one of you could fly into the anus of a bear?" Then he would start another song and end it by saying in much the same language, "One of you ought to fly up into that hole" (i. e., anus). He kept taunting the birds with their inability to do this, so, when the bears started out, the wren (wu'łnAxwû'ckAq, "bird-thatcan-go-through-a-hole") flew up into the anus of one of them and came out with his intestines. Before it had pulled them far out the bear fell dead. Then Raven chased all of the small birds away, sat down, and began eating. 
Raven never got full because he had eaten the black spots off of his own toes. He learned about this after having inquired everywhere for some way of bringing such a state about. Then he wandered through all the world in search of things to eat.

After all the human beings had been destroyed Raven made new ones out of leaves. Because he made this new generation, people know that he must have changed all of the first people who had survived the flood, into stones. Since human beings were made from leaves people always die off rapidly in the fall of the year when flowers and leaves are falling.

At the time when he made this world, Raven made a devilfish digging-stick and went around to all created things (shellfish apparently) saying, "Are you going to hurt human beings? Say now either yes or no." Those that said "No" he passed by; those that said "Yes" he rooted up. He said to the people, "When the tide goes out, your food will be there. When the tide comes in, your food will be in the woods," indicating bear and other forest animals.

In Raven's time the butts of ferns (k!wAłx) were already cooked, but, after some women had brought several of these in, Raven broke a stick over the fern roots. Therefore they became green like this stick. He also broke the roots up into many layers one above another.

Devilfish were very fat then, and the people used to make grease out of them, but, when Raven came to a place where they were making he said, "Give me a piece of that hard thing." That is why its fatness left it.

[Corvus appellavit saxum, quod erat tectum algis, "Pudenda, ubi crescunt crines." Nepotes patris eius rogaverunt, "Esne capillatus?" Et ille respondit, "Sane, pudenda mea pilis vestita sunt." At modo habebat in mente copias algarum, quae protegebant saxum in quo sedebat.]

One time Raven invited all the tribes of little people and laid down bear skins for them to sit on. After they had come in and reached the bear skins, they shouted to one another, "Here is a swampy, open space." That was the name they gave to those places on the skins from which the hair had fallen out. By and by Raven seized the bear skins and shook them over the fire, when all the little people flew into the eyes of the human beings. He said, "You shall be pupils in people's eyes," and ever since human beings have had them.

Now he went on from this place and camped by himself. There he saw a large sculpin trying to get ashore below him, and he said to it, "My uncle's son, come ashore here. Come way up. One time, when you and I were going along in our uncle's canoe we fell into the water. So come up a little farther." Raven was very hungry, and, when the sculpin came ashore, he seized it by its big, broad tail intending to eat it. But it slipped through his fingers. This happened many times, and each time the sculpin's tail became smaller. That is why it is so slender to-day. Then Raven said to it, "From now on you 
shall be named sculpin (wêq!)."Raven had a blanket which kept blowing out from him, so he threw it into the water and let it float away. Then he obtained a wife, and, as he was traveling along with her, he said, "There is going to be a great southwest wind. We better stop here for a little while. I expect my blanket ashore here." After a while it came in. Then his wife said to him, "Take your blanket ashore and throw it on some branches." $\mathrm{He}$ did so and it became Rebis bracteosum (Tlingit, câx). When they went on farther the sea became so rough that his wife was frightened, and told him to put ashore some of the fat with which his canoe was loaded. He did this, but was so angry with his wife for having asked him, that he said to her, "You better put ashore you sewing basket," and so she did.

Then he left his wife and went along by himself. He assembled very many young birds, and, when he camped told them to go after cât!k!, the term he at that time applied to drinking water.

Afterwards he came to a certain place and started to make a salmon creek. He said, "This woman shall be at the head of this creek." The woman he spoke of had long teats, so he called her Woman-with-long-teats-floating-around (Hîn-cAkxê'nayî), saying, "When the salmon come to the creeks, they shall all go up to see her." That is why salmon run up the creeks.

After this he went into the woods and set out to make the porcupine. For quills he took pieces of yellow cedar bark, which he set all the way up and down its back so that bears would be afraid of it. This is why bears never eat porcupines. He said to the porcupine, "Whenever anyone comes near you, throw your tail about." This is why people are afraid of it when it does so.

Now Raven went off to a certain place and made the west wind, naming it Q!âxô'. He said to it, "You shall be my son's daughter. No matter how hard you blow you shall hurt nobody.

He took up a piece of red salmon and said to it, "If anyone is not strong enough to paddle home he shall take up this fish and blow behind him."

Raven is a grandchild of the mouse (kutê'łtA!nî). That is why a mouse can never get enough to eat.

Raven also made the south wind (sâ'naxet). When the south wind climbs on top of a rock it never ceases to blow.

He made the north wind (xûn) and on top of a mountain he made a house for it with something like ice hanging down on the sides. Then he went in and said to it, "Your buttocks are white." This is why the mountains are white with snow.

He made all the different races, as the Haida and the Tsimshian. They are human beings like the Tlingit, but he made their languages different. He also made the dog. It was at first a human being and did everything Raven wanted done, but he was too quick with 
everything, so Raven took him by the neck and pushed him down, saying, "You are nothing but a dog. You shall have four legs."

One time Raven came to a certain thing called fat-on-the-sea (ŷikAtâyî'), which stuck out of the ocean. He kept saying to it, "Get down a little," so it kept going under the surface. But every time it came up he took his paddle and cut part off. It did this seven times, but, when he spoke to it the eighth time, it went down out of sight, and he never saw it again.

As he was traveling along in another place, a wild celery came out, became angry with Raven, and said, "You are always wandering around for things to eat." Then he named it wild celery (yâ'naet) and said to it, "You shall stay there, and people shall eat you."

Once he passed a large tree and saw something up in it called cAxdA'q. Raven called out "CAxdA'q," and it shouted back, "You Raven." They called back and forth to each other for some time.

[Advenit in alium locum et alligavit aliquid circum caput ostrei, quod protrudebat ex arena. Appellavit idem Ldas-qê't (viri pudenda).]

\section{SUPPLEMENTARY TO STORY 1}

Near a bay not far from Kôts!ê'L! there used to be a sea-water pond in which lived a beaver. Raven very much wanted to get at this beaver and kill it, so he dug two trenches in order to drain the lake at low tide. After the water had run out through them, and the beaver had become visible at the bottom, he let down a kind of hook and pulled it up.

Raven had tried every sort of thing as a post under this earth. Last of all he caught this beaver and made the post out of the bone of its foreleg [which is very solid]. That is why the world is now standing. Old-woman-underneath (Hayicâ'nak! $!^{\mathrm{u}}$ ) attends to this post, but, when she is hungry, the earth shakes. Then people put grease into the fire and it goes to her.

After he had killed the beaver Raven killed also a big whale and got his people to tow it to the place where the beaver, had formerly lived. He got four large canoes full of people to tow it up the rapids in one of the canals he had then made. After they had labored for many days, they became tired, and he said to them, "Take it easy." Finally he himself became tired and said, "Turn into stone." All did so, and to this day you can see a large island there shaped like a whale and a string of four smaller islands extending out from one end of it.

Raven named several places in this neighborhood. One was Qâg ${ }^{\mathrm{u}}$ Antoqa', (A-hiddenperson); another Tsêtk! (Little Ladder). He named an island outside, Lat!An. Still another was called $¥ A q$ ' $^{\mathrm{x}} \mathrm{As}$ !, after the name of a small canoe, because one of these was passing at the time. 
Between two mountain peaks just eastward of Sitka is a hollow filled with trees supposed to resemble boys, so the place is called K! êsâ'nî-â'yaodihayiya, Where-is-a-big-crowd-ofboys. Raven appointed this as the place from which the sun would turn back north. A point on the coast just north of Sitka was called by him K!ołacAtq!a', Point-holdingthings-back, because when a canoe passes it coming toward Sitka it can not go fast (i. e., it does not seem to get by this rapidly). Just north of this is a kind of bay which Raven called KA'dAłAtc- $\underline{x} A k^{u}$, Noisy-beach. 


\section{Kanuk- The Wolf MYTHS RECORDED IN ENGLISH AT SITKA (Alaska Native Knowledge Network, 2006)}

Kanuk, the hero and ancestor of the Wolf tribe of the Tlingit, is represented as a mysterious and eternal being, older and more power- ful than El. Once upon a time Kanuk lived on a treeless island, Tikenum, - sea-fortress, - not far from Cape Ommaney. On that island is a small, square, stone well of fresh water, covered with a stone. Inside the well, on the stone, is a narrow horizontal line of a different color than the rest. This mark dates from the time, and indicates the quan- tity of water El drank and stole out of the well. The well is known as Kanuk's Well, because formerly, when there was no fresh water else- where on the earth, Kanuk kept it in the well and guarded it jealously; he even built a barrabara over it and slept on the cover of the well.

One time Kanuk, while out at sea in his canoe, met El there in his canoe and asked him, "Have you been living long in this world ?"

"I was born," said El, "before the earth was in its present place; and have you been living here long?"

"Since the time when the liver came out from below," answered Kanuk.

"Yes," said El, "you are older than I."

While continuing their conversation, they went farther and farther from the shore, and Kanuk, thinking it a good time to demonstrate his strength and superiority, took off his hat and put it behind himself; instantly such a thick fog appeared that one, sitting in one end of a canoe, could not see the other end. During that time Kanuk paddled away from his companion. El, unable to see Kanuk, and not knowing which way to go, began to cry to him, "Achkani, Achkani," but Kanuk made no answer; he called many times with the same result; finally, El, weeping, implored Kanuk to come to him. Kanuk then coming up to him, said, "What are you crying about?" Saying this, he put on his hat and the fog raised.

El.

"Nu Achkani (my father-in-law and brother-in-law), you are stronger than I," said

After this Kanuk invited El to go home with him to his island; there they refreshed themselves, and fresh water was one of the many things that El had. It tasted so sweet and good that he could not get enough to satisfy him, and he was too bashful to ask for more. When dinner was over, El commenced to tell about his origin and the history of the world. At first Kanuk listened attentively, then drowsily, and at last fell into a sound sleep in his usual place on the cover of the well. While he was sleeping El quietly placed 
some dung under and around Kanuk, and then going outside, called, "Achkani, wake up, look around you; you are, it seems, not well."

Kanuk woke up and felt around, and believing what El said, ran to the beach to wash himself. In the mean time El pushed the cover off the well, and drank all the water he could, and, changing to a crow, filled his bill with water and started to fly out by way of the chimney, but was mysteriously held back when almost at the top. Kanuk, returning from his wash, made a fire, and began smoking his guest until he turned black. This explains why the crow, who was formerly white, is now black. Finally Kanuk, pitying $\mathrm{El}$, let him go, and he (El) flew away to his earth, and dripped the water on it, as was mentioned be- fore. 